\title{
Material Cultures of Childhood in Second World War Britain
}

How do children cope when their world is transformed by war? This book draws on memory narratives to construct an historical anthropology of childhood in Second World Britain, focusing on objects and spaces such as gas masks, air raid shelters and bombed-out buildings. In their struggles to cope with the fears and upheavals of wartime, with families divided and familiar landscapes lost or transformed, children reimagined and reshaped these material traces of conflict into toys, treasures and playgrounds. This study of the material worlds of wartime childhood offers a unique viewpoint into an extraordinary period in history with powerful resonances across global conflicts into the present day.

Gabriel Moshenska is Associate Professor in Public Archaeology at University College London, UK. 


\section{Material Culture and Modern Conflict}

\section{Series editors: Nicholas J. Saunders, University of Bristol, Paul Cornish, Imperial War Museum, London}

Modern warfare is a unique cultural phenomenon. While many conflicts in history have produced dramatic shifts in human behaviour, the industrialized nature of modern war possesses a material and psychological intensity that embodies the extremes of our behaviours, from the total economic mobilization of a nation state to the unbearable pain of individual loss. Fundamentally, war is the transformation of matter through the agency of destruction, and the character of modern technological warfare is such that it simultaneously creates and destroys more than any previous kind of conflict.

The material culture of modern wars can be small (a bullet, machine-gun or gas mask), intermediate (a tank, aeroplane, or war memorial), and large (a battleship, a museum, or an entire contested landscape). All share one defining feature - they are artefacts, the product of human activity rather than natural processes. In this sense, for example, the First World War's Western Front is as much a cultural artefact as a Second World War V2 rocket, a cold war early-warning radar station, wartime factories and bombed buildings, as are photographs, diaries, films, war souvenirs, and a host of conflict-related art forms. Similarly artefactual, though not always understood as such, are people - the war-maimed (sometimes fitted with prostheses), war refugees and their camps, collectors of memorabilia, and the post-conflict 'presence of absence' in towns and cities of large numbers of missing men, women and children. Each in their own way - through objects, memories, attitudes and actions - perpetuate different engagements with conflict and its painful and enduring aftermath.

The material culture of conflict offers a field of study which is both rich and fiercely relevant to the world which we inhabit. Wars and other forms of conflict have formed that world. Today we still live in the shadow of two world wars which set new standards for extremes of violence, and violent conflicts remain in progress across the globe as this series of books is inaugurated. These events have created a truly massive volume of material culture. The ways in which people engage with it is conditioned by society's equivocal attitude to violent conflict itself. As John Keegan wrote, 'We are cultural animals and it is the richness of our culture which allows us to accept our undoubted potentiality for violence but to believe nevertheless that its expression is a cultural aberration' (Keegan, A History of Warfare 1994). Keegan himself knew that the reality was not so clear cut as this reassuring vision. The relationships which people have with the material culture created in a context of violence add weight to this assessment, for they are simultaneously capable of supporting or undermining the perception of warfare as an aberration or exception. 
Now as never before, we perceive unfamiliar but underlying truths in the way in which these artefacts reveal infinitely varied interactions with people: a 'social life' created by human engagement with objects. Although overwhelmingly inanimate, they are not merely passive signifiers, reifications or receptors of 'meaning', but can exercise positive agency in forming and embodying human thoughts and emotions. In short, objects make people as much as people make objects. The behaviours provoked by conflict illustrate how an individual's social being is determined by their relationship to the objects that represent them - how objects are a way of knowing oneself through things both present and absent. This is as true for First World War battlefield pilgrims (often widows), survivors of the Holocaust, and Second World War civilian internees and prisoners of war, as it is for uniformed service personnel who took part in both world wars, the Vietnam War, the Sarajevo militia of the Bosnian Conflict, and the war-maimed from Afghanistan and Iraq to name just a few.

A further incentive to focus on this subject lies in developments in the academic world. For decades, anthropologists and historians have devoted increasing amounts of effort to the study of conflict. Until recently their studies have followed discrete paths, but change has been afoot since the closing years of the last century. A slow-burning revolution in academic engagement with warfare (not to say a 'rebranding') relocated historians of conflict from the unfashionable suburb of 'military history' to uptown locales like 'war studies' and 'First World War studies'. Everyone now accepts that what we call 'peace' cannot be understood without knowing what happens in wars, any more than wars can be comprehended in isolation. Furthermore, ground-breaking work began to appear in which historians addressed wars from the perspective of their material and cultural milieus or manifestations.

Parallel advances have been occurring in the disciplines of archaeology and anthropology. The re-appraisal of materiality has been at the forefront of these developments. The ways in which we view and think about the things we make, their complex volatility, and their elusive meanings have been brought under academic scrutiny. The transformative quality of the material culture of modern conflict, and its ability to move across disciplinary boundaries, demands a robust interdisciplinary response. Focused on material culture, such an approach offers to revitalize investigations into the physical and symbolic worlds that conflict creates, and that defines us as subjects through memory, imagination, and technology.

Since the turn of the millennium the editors of this series have taken a lead in focusing the gaze of both disciplines on the material culture of conflict. Moreover, they have opened the discussion out to practitioners of the widest possible range of disciplines and vocations, including historians, anthropologists, archaeologists, museum curators and artists. For this growing international group of collaborators, the material culture of conflict represents the nodal point at which their disciplines can meet and cross over. This series of books seeks to build on this foundation and to offer a platform for those wishing to publish new research on the subject. 
The series adopts a genuinely interdisciplinary approach to re-appraise the material legacy of twentieth and twenty-first century conflict around the world. By conceiving and studying the material culture of conflict, it helps to construct biographies of objects, and explore their 'social lives' through the changing values and attitudes attached to them over time. The series aims to show how objects can survive as expressions of 'war beyond conflict', revitalizing meanings and creating new engagements between and understandings of people and 'war things'. It offers new perspectives on the intricate web of connections that bind and separate people and places in times of conflict and beyond.

In so doing, the series offers a radical departure in the study of modern conflict - proving a truly interdisciplinary forum that draws upon, but does not privilege archaeology, anthropology, military and cultural history, art history, cultural geography, and museum and heritage studies. The complexity of modern conflict demands a coherent, integrated, and sensitized hybrid approach which calls on different disciplines where they overlap in a shared common terrain - that of the materiality of conflict and its aftermath. This approach has extraordinary potential to bring together the diverse interests and expertise of a host of disciplines to create a new intellectual engagement with the understanding of conflict. 


\section{Material Cultures of Childhood in Second World War Britain}

Gabriel Moshenska

Routledge
(1) 总
LONIor \& Francis Group
LONDON AND NEW YORK 
First published 2019

by Routledge

2 Park Square, Milton Park, Abingdon, Oxon OX14 4RN

and by Routledge

52 Vanderbilt Avenue, New York, NY 10017

Routledge is an imprint of the Taylor \& Francis Group, an informa business

(c) 2019 Gabriel Moshenska

The right of Gabriel Moshenska to be identified as author of this work has been asserted by him in accordance with sections 77 and 78 of the Copyright, Designs and Patents Act 1988.

Trademark notice: Product or corporate names may be trademarks or registered trademarks, and are used only for identification and explanation without intent to infringe.

The Open Access version of this book, available at www.taylorfrancis.com, has been made available under a Creative Commons Attribution 4.0 license.

British Library Cataloguing-in-Publication Data

A catalogue record for this book is available from the British Library

Library of Congress Cataloging-in-Publication Data

Names: Moshenska, Gabriel, author.

Title: Material cultures of childhood in Second World War Britain / Gabriel Moshenska.

Description: Abingdon, Oxon ; New York, NY : Routledge, 2019. |

Series: Material culture and modern conflict | Includes bibliographical references and index.

Identifiers: LCCN 2018055160 (print) | LCCN 2018059186 (ebook) |

ISBN 9781351345514 (adobe) | ISBN 9781351345491 (mobi) |

ISBN 9781351345507 (epub) | ISBN 9781138565265 (hardback) |

ISBN 9781315122946 (ebook)

Subjects: LCSH: World War, 1939-1945-Children-Great Britain. | World

War, 1939-1945-Personal narratives, British. | World War, 1939-1945-Social aspects-Great Britain. | Material culture-Great Britain-History-20th century. | Children-Great Britain-Social life and customs-20th century. | Great Britain-Social life and customs-20th century. | War and society-Great Britain-History-20th century.

Classification: LCC D810.C4 (ebook) | LCC D810.C4 M67 2019 (print) |

DDC 940.53/41083--dc23

LC record available at https://lccn.loc.gov/2018055160

ISBN: 978-1-138-56526-5 (hbk)

ISBN: 978-1-315-12294-6 (ebk)

Typeset in Times New Roman

by Taylor \& Francis Books 


\section{Contents}

List of figures viii

Preface and acknowledgments $\quad \mathrm{x}$

Introduction 1

1 Gas masks 21

2 Collecting shrapnel 46

3 Air raid shelters $\quad 75$

4 Bombsites 110

5 Aircraft down to earth 130

$\begin{array}{ll}\text { Conclusion } & 153\end{array}$

$\begin{array}{lr}\text { Bibliography } & 159\end{array}$

$\begin{array}{lr}\text { Index } & 179\end{array}$ 


\section{Figures}

0.1 Gas mask boxes and cases hang outside the entrance to the basement air raid shelter in a Hampstead nursery. (C) Imperial War Museum, D 6129.

1.1 Child modelling the brightly coloured 'Mickey Mouse' gas mask. (C) Imperial War Museum, D 5894.

1.2 A group of young evacuees in Reading carrying their gas masks. A variety of cases, boxes and covers can be seen. (C) Imperial War Museum, D 824.

2.1 Pupils at Calvert Road School, South East London, admiring a fragment of metal collected after an air raid. Note gas mask cases. (C) Imperial War Museum, D 3160.

2.2 Children in Burton Bradstock, Dorset show American servicemen a machine gun belt that they had found on the local beach. It appears to be $.50 \mathrm{BMG}$ cases with M2 links. (C) Imperial War Museum, D 20122.

2.3 Pupils at Ancona Road School in South East London sort salvaged metal for recycling. Alongside milk bottle tops and sash window weights there is a heap of shrapnel fragments and a cluster of incendiary bomb tail fins. (C) Imperial War Museum, D 3166.

3.1 Two children sleeping on a bench inside an air raid shelter. Their mother tied ropes around them to prevent them falling onto the damp floor while they slept. (C) Imperial War Museum, D 1550 .

3.2 Lessons continue in the basement air raid shelter at Greek Road School, South East London. Several of the children are carrying their gas mask cases. (C) Imperial War Museum, D 3161.

3.3 Children being put to bed in the air raid shelter of John Keble Church, Mill Hill. (c) Imperial War Museum, D 1439.

4.1 Children working on a makeshift allotment on a London bomb site. (C) Imperial War Museum, D 8957. 
4.2 A child plants a Union Flag in the wreckage of his home, destroyed in an air raid on London. (C) Imperial War Museum, D 1303.

4.3 Children playing next to a bomb crater full of rubble in the playground of Lombard Wall School, South East London. (C) Imperial War Museum, D 3170.

5.1 Children playing in a layer of sand on the roof of their air raid shelter stop to watch aircraft pass overhead. (C) Imperial War Museum, D 20623.

5.2 In this photograph, originally intended to advertise the shirt and shorts, a 12-year-old boy stands next to his Morrison air raid shelter and plays with a $1 / 72$ scale model of a Westland Lysander aircraft. Behind him on top of the shelter sit models of an anti-aircraft gun and a searchlight, while a gas mask hangs to the right. (C) Imperial War Museum, D 13081. 


\section{Preface and acknowledgments}

It would be pointless to pretend that this book is anything other than an extended fan letter to the children's author Robert Westall and his award-winning fictional depictions of childhood in Second World War Britain. Westall's books drew on his own wartime childhood in the North East of England and their recurring cast of children, cats and ghosts were a formative and much loved part of my childhood reading. But it was Westall's non-fiction book, Children of the Blitz, that introduced me to the first-hand voices of wartime childhood. These sad, funny and astonishing stories, studded with rich descriptive accounts of the material relics of war, shaped my understanding of what a historical anthropology of childhood in the Second World War could achieve.

This book is the result of more than a decade of work, most of it carried out in the brief lulls of academic life and the gaps between other projects, but with a coherence and consistency of intent that betrays my enduring love of the subject matter. What began as a minor offshoot of my $\mathrm{PhD}$ research became an article on shrapnel collecting in the Journal of Material Culture, which in turn provided the framework and foundation for Chapter 2 in this book and established the method and approach for the rest of the project. In the months between the submission of my $\mathrm{PhD}$ thesis and my viva, I researched and wrote two papers on gas masks, which form the basis of Chapter 1. The first examined the relationship between children and their gas masks and was published in the Journal of the Royal Anthropological Institute; the second, published in Medicine, Conflict and Survival focused on the training regimes in which children were systematically (and controversially) exposed to tear gas, and drew on sources in the National Archives alongside the memory narratives that formed the basis of the other sections. The work that formed the basis for Chapter 4 was carried out in New Haven, Connecticut during an extended trip to the Beinecke Library at Yale University. After days spent reading the correspondence of nineteenth-century antiquarians, I spent my evenings sat up in my bed in a very lovely guest house where I researched and wrote the chapter, which was first published in the book Ruin Memories: Materialities, Aesthetics and the Archaeology of the Recent Past. I am grateful to the editors Bjørnar Olsen and bóra Pétursdóttir for permission to reproduce it here. Alongside these precursors I would like to draw attention to a later paper, Moaning Minnie and 
the Doodlebugs: Soundscapes of Air Warfare in Second World War Britain (Moshenska 2017), which can be considered a companion piece to this book.

Over many years this work has benefitted enormously from the wisdom, generosity, and painstaking edits of friends, family and colleagues, particularly from within the fields of contemporary archaeology and the interdisciplinary study of the material cultures of modern conflict. For their conversations, comments and criticisms I would like to warmly thank Iain Banks, Esther Breithoff, Victor Buchli, Gilly Carr, Wayne Cocroft, Simon Coleman, Don Cooper, James Dixon, Emma Dwyer, Neil Faulkner, Jesús Fernández Fernández, Charlotte Frearson, Jonathan Gardner, John Giblin, Emily Glass, Alfredo González-Ruibal, Vesa-Pekka Herva, Dan Hicks, Cornelius Holtorf, Matthew Johnson, Hilda Kean, Eerika KoskinenKoivisto, Matt Leonard, Mona Macksoud, Laura McAtackney, Leo Mellor, Chana Moshenska, Joe Moshenska, Tim Murray, Adrian Myers, Sarah De Nardi, Cassie Newland, Luisa Nienhaus, Hilary Orange, Sefryn Penrose, Dan Phillips, Angela Piccini, Tony Pollard, Louise Purbrick, Layla Renshaw, Raf Salkie, Tim Schadla-Hall, Nathan Schlanger, John Schofield, Oula Seitsonen, John Sharrock, James Symonds, Jaisson Teixeira Lino, Suzie Thomas and Robin Woolven. Apologies to anybody I have missed from this far from comprehensive list.

Since 2010 I have taught an MA module in the archaeology of modern conflict at UCL Institute of Archaeology, and I have benefitted enormously from the opportunity to discuss this work with students from around the world, and to hear stories of their own or their families' material cultures and memories of conflicts. The completion of this book was made possible by a sabbatical from UCL in 2018-19, for which I am extremely grateful. During this time I was a visiting researcher at the Amsterdam School for Heritage, Memory and Material Culture at the University of Amsterdam.

I would like to thank Maria Phelan who has shared my time and attention with this work for the past decade. Thanks to her I had the opportunity to complete much of the research and the bulk of the writing and editing of this book in the Openbare Bibliotheek Amsterdam, looking out over the Oosterdok. I am grateful to my parents for their comments on a draft of the manuscript, and for the input of the series editors on an earlier version. My thanks to the Imperial War Museum who allowed me to use photographs of Home Front Britain to illustrate this text, and to UCL Institute of Archaeology for a publication grant for licensing the images.

Since my first tentative steps into this field of research I have benefited from Nicholas Saunders' extraordinary kindness, generosity and support. He has been a fantastic mentor encouraging me in my work, reading and commenting on draft papers, providing opportunities to present and publish, and offering sound and supportive advice. This is the book that Nick has been telling me to write for years, and it only exists now because of him. 



\section{Introduction}

\section{A cardboard box}

I want to start with a cardboard box and a story. At the outbreak of the Second World War, Arnold Long and the other children in his class were issued gas masks in brown cardboard boxes, shown how to fit and wear them and instructed to carry them at all times. Long was born in 1931 and grew up north of Manchester, although he spent some of the war evacuated to rural North Wales. Like most British children in the Second World War his encounters with Civil Defence and the quasi-military discipline of gas mask tests and air raid drills came from teachers at school and was enforced with the same discipline. Writing for the BBC People's War project website in 2005, Long recalled a gas mask test carried out by his teacher Mr Bullock:

We carried our gas masks everywhere we went. Or, we were supposed to. I had discovered that my gas mask case was useful for all sorts of things. One day, to my absolute horror, Mr Bullock gathered us all together in the school hall and announced that we were going to have gas mask practice! 'Put on your gas masks', he said, smiling.

(Long 2005 [NB People's War sources are listed in a separate bibliography])

The girls in Long's class put on their masks and blew air out of the sides, making the farting noises that entertained virtually all gas-mask-wearing British children during this period. A few of the boys joined in, and of those who hesitated, Long was singled out and summoned to the front of the classroom, where he was ordered to open his gas mask case:

I had drawn Spitfires all over the outside of the box. Mr Bullock proceeded to gently open the grubby box ... He put his hand inside and drew out a screwed up Beano, bits of half carved planes, some string, several lumps of rusty shrapnel and an old tennis ball. Last of all, a dried up bit of bread.

(Long 2005) 


\section{Introduction}

Long received a blow with a cane across his fingertips, and the class was exhorted: 'We must ALWAYS carry our gas masks'. His treasured shrapnel, comics and model planes were confiscated, and he speculated that 'Maybe $\mathrm{Mr}$ Bullock read the Beano, or swapped shrapnel?' His classmates were more sympathetic, and at playtime they helped to make good his losses: 'Douglas Allen gave me a few lumps of his shrapnel and Edith Strickland gave me one of her immaculate Beanos. It was called "the wartime spirit!" (Long 2005).

Arnold Long's cardboard gas mask case is a microcosm of this book: together with its contents it embodies some of the most significant and affective material manifestations of the Second World War in the everyday lives of British children. The box itself, decorated with drawings of fighter aircraft, along with the pieces of carved wooden toy planes, speaks to the widespread 'air-mindedness' and fascination with military aviation amongst children and many adults, particularly in the early stages of the war. Through aero-modelling, aircraft recognition courses and the Air Training Corps many young people found the means to bring the high-flying aircraft down to earth. The shrapnel in the gas mask box, taken by the teacher and replaced by a friend, was part of an extraordinary and largely spontaneous market of trade and collecting, based largely around the fragments of anti-aircraft shell that fell on British streets and rooftops during air raids and was picked up often still warm and smelling of explosives. For many children, these twisted lumps of metal were the most tangible materialisation of the power, violence and threat of war, and their 'domestication' into established patterns of children's play can be seen in that light: Long recalled that good pieces of shrapnel could be swapped for comics, and that he had built up a good collection on that basis.

Finally, the cardboard box itself and the absence of a gas mask. The gas mask case dangling on a string or a strap was the single most ubiquitous material reminder of the war for most British children. While adults were encouraged to carry their masks, children were usually compelled to bring theirs to school, under pain of punishment as Long discovered. Some replaced the cardboard box with harder-wearing metal versions or sewed cloth covers for the original case, but the constant presence of the case is attested to in photographs, contemporary accounts and more recent recollections of the war years (Figure 0.1). The mask itself was a remarkable thing: a mass-produced object, a military technology, a reminder of the horrors of poison gas in the First World War, a mask, a uniform and a multi-sensory artificial environment. In some cases, training children in gas mask use and testing the efficacy of their masks involved exposing them to tear gas in dedicated gas chambers, one of the more brutal and lesser-known aspects of Home Front history.

\section{Aims of this book}

My aims in this book are threefold. First and foremost, I want to examine some of the principal material manifestations of the Second World War as experienced by young people in Britain. In particular, I want to consider the 


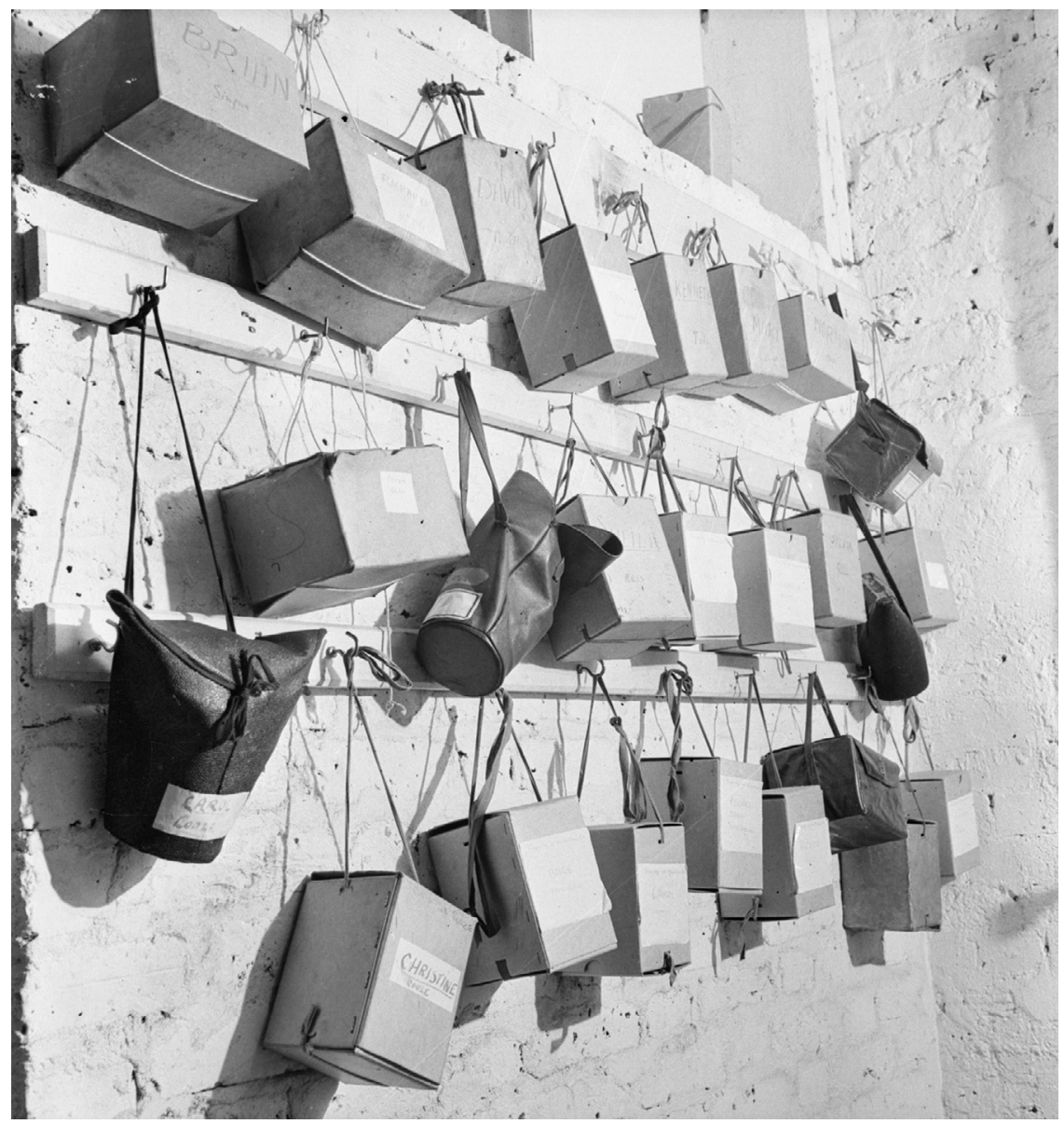

Figure 0.1 Gas mask boxes and cases hang outside the entrance to the basement air raid shelter in a Hampstead nursery. (C) Imperial War Museum, D 6129.

ways in which young people sought to master this material culture, individually and collectively, through various forms of creative, social and destructive play. By studying the material worlds of wartime childhood through the medium of memory narratives recorded more than half a century later, I am also interested in unravelling the relationships between material culture, memory and the senses.

My secondary aim relates to the disciplinary context of this work: I want to bolster the study of children and young people as a distinct strand within the wider interdisciplinary study of the material culture of modern conflict, represented by the work of the editors of the series in which this book appears (e.g. Saunders 2003, 2004; Saunders and Cornish 2009). While many of these earlier studies have included young people in their scope, there is a need for 


\section{Introduction}

research that emphasizes their unique relationship with the material world, while also recognising the diversity of age, gender, nationality, social class and other markers of identity and life experience within the category of 'children'.

The third aim of this book is to begin to generate a framework for studying the material cultures of wartime childhood beyond Britain and the Second World War. All conflicts impact upon children's lives, and the future of today's war-ravaged nations will be in the hands of the young people wounded, traumatized and displaced by violence. To assist or to treat these young people requires an understanding of their lived experience, their agency and the social and material worlds that they inhabit and construct for themselves in the ruins. The children of the Blitz who recorded their memories have a great deal in common, as many of them acknowledge, with the children in contemporary conflicts listening to bombers and missiles from the depths of their air raid shelters, sweating behind the stifling rubber of their gas masks, grabbing still-warm shrapnel and cartridge-cases from the pavement to show their friends and playing war-games in the tangled wreckage of bombed buildings.

\section{Origins of this research}

The research presented in this book was conducted over more than ten years, during which it evolved and shifted direction several times, but the core themes, methods and sources remained consistent. There are several points that could be considered the root or impetus for this research, and I want to consider each in turn to outline the project's long and strange genealogy. The first is the most direct point of origin: the woman in the air raid shelter. In 2006 I led the excavation of a Second World War air raid shelter beneath a school playing field in Edgware, north London (Moshenska 2007a). The edge of a concrete stairwell had been unearthed on the edge of the field by students at the school, and we were invited to investigate and secure the site. Having removed the earth and concrete fill from the stairwell, we found ourselves inside a large, 50-person shelter with intact fittings, artefacts, graffiti and even a maths lesson chalked on the end wall, traces of the last lesson taught inside the shelter before the 'all clear' sounded for the final time. We made contact with several former students at the school who remembered using the shelters, and invited them to visit the excavation. Inside the shelter the damp, musty smell and the oppressively dark underground space sparked extraordinary memories of the school in wartime, of the terrors and boredoms of air raids and of the experience of wartime childhood in general. Tessa Smith, eight years old when the war broke out, recalled her time in the shelters singing patriotic songs, but she also described the joys and complexities of collecting and trading 'shrapnel' (Moshenska 2007a). From her detailed description and the vividness with which she could recollect the allure of the hot, shining, pungent sherds of shell, I began to collect accounts of shrapnel collecting and pieced together a historical anthropology of the practice drawing on material culture theory and a variety of theories of childhood collecting. 
My interest in these connections between childhood memory and the material culture of the Second World War has an earlier root. Two years before the project in Edgware, I took a peripheral part in the televised excavation of a crashed Hawker Hurricane fighter aircraft from beneath a road close to London's Victoria Station (Moshenska 2007b). The central location and the presence of television crews caused considerable public interest and a crowd of onlookers watched the excavators at work, some of them standing for hours behind the barriers. Amongst these visitors were many who had first-hand memories of the area during the war that they were keen to share with us and with others in the crowd: some clearly relished their moment in the spotlight and the chance to tell and retell stories of their childhoods. One of the older men in the crowd claimed to have witnessed the crash in question, and to have watched the dogfight that preceded it. He presented as proof of his claims a fragment of the aircraft that he picked up from the wreckage in the street, and kept as a souvenir for more than 60 years. The green-painted scrap of crumpled aluminium was smaller than a credit card and included part of a painted serial number. For the man who presented it, it had been a childhood souvenir of an extraordinary event, an object of status amongst his peers and proof of his close encounter with danger and violence. Over time it had become a souvenir of his wartime childhood, and a conversation piece. Finally, at the excavation site it became a prop and a material symbol of his right to speak with authority and from experience to the crowd and to the media (Moshenska 2007b). This dig with its scrum of stories and things, and the performance of an excavation that gave it its stage, formed the foundations for my interdisciplinary study of the Second World War (see Moshenska 2009, 2010). It gave substance to the nexus of childhood memory, material culture and the public spheres of remembering and commemorating that has remained central to my work.

The earliest, and perhaps the most fundamental origin point for this study lies in the writings of the children's author Robert Westall, and in particular his award-winning book The Machine Gunners (Westall 2001). This Carnegie Medal-winning novel, aimed at older children, is a bright spot in the vast glum heap of representations of the Second World War in British popular culture. Westall portrays a group of schoolchildren in the town of Garmouth, a fictionalized area of Tyneside, in 1941. Following an air raid, the gang - all avid militaria collectors - find the wreckage of a crashed Heinkel 111 bomber, including a dead crew member and his machine gun, which they steal. With an imminent Nazi invasion in their minds the children build a substantial fortress in an overgrown back garden to house their gun. Even more fantastically they capture a downed German airman, Rudi, who repairs their gun before escaping. After a gunfight with Polish troops mistaken for invading Nazis, Rudi is wounded, the children surrender their fortress and several of them are sent to a residential children's home.

Westall's book is not so far from reality: as he discovered in the responses to his novel, collected and published as Children of the Blitz, during the war years plenty of British children armed themselves with stolen or abandoned 


\section{Introduction}

deadly weaponry and caused chaos across the country (Westall 1995). The novel and the main characters drew on Westall's own experience as a child in northeast England during the war, and this experience is reflected in the children's activities. The main protagonist, Chas McGill, collects shrapnel competitively and with some success, forming the focus for the novel: his aim in acquiring the machine gun is in part to gain an unassailable lead in the competition amongst his peers to collect the greatest quantity and quality of war souvenirs. In addition to this collector mania, Chas's experiences and his engagements with the material world are mirrored in the chapters of this book. Under sufferance he carries his gas mask, employing the metal case as a weapon in an after-school fight. He builds models, and obsesses over the identification of aircraft by sight and sound. Together with his family he endures air raids from the damp depths of the air raid shelter, made marginally more tolerable by the comforts introduced to make it seem more homely. I read The Machine Gunners at about the age of eight, adored it, and it has powerfully shaped my conceptions of wartime childhood and its material cultures ever since: this present volume could be considered an extended critical commentary on the book.

\section{Histories of wartime childhood}

There is a wealth of writing on childhood in wartime Britain: the books and articles that loom over and surround me in tall, unstable piles as I write are only a small sample of the ever-growing whole. A significant proportion of these are attractive, well-illustrated trade books that gallop swiftly through the iconic themes and moments of wartime childhood: from the outbreak of war in 1939 to the evacuation of children from danger areas, rationing, the Blitz, the arrival of American troops, 'doing one's bit' and end neatly with the street parties that greeted victory and the homecoming of fathers (e.g. Brown 2009; Gardiner 2005). Many (but by no means all) of these books embody and reinforce many of the national narratives and myths of the Home Front that have been variously skewered, defended and debated by historians from Angus Calder's Myth of the Blitz into the present (Calder 1991).

Another category of popular books following many of the same themes are those such as the Forgotten Voices series that are largely formed of extracts from oral histories collected into thematic chapters and introduced and linked with historical commentaries (e.g. Smith 2007). Some more scholarly works follow a similar pattern (e.g. Bell 2008), and this book can be considered a variation on this type. In this latter type of writing, those who were children during the Second World War can speak for themselves and describe their experiences, thoughts, feelings and actions. It is precisely this theme of children's agency that I find most troublingly lacking in many popular and scholarly accounts of the Second World War. The idea that war was something unfortunate, unpleasant and dangerous like measles that happened to children is a crude simplification that conceals the complexities 
of this experience, with war shaping every aspect of children's lives in often unexpected ways, as well as the ways in which children responded. One of the most important aims of this book is to acknowledge, examine and celebrate the agency of children in Second World War Britain.

Some of the most relevant, and for my purposes valuable, research is that which takes a gendered view of life in wartime Britain such as the work of Penny Summerfield (1997; 1998) and Susan Grayzel. For example, Grayzel's At Home and Under Fire (Grayzel 2012) examines the history of the idea of the 'Home Front' in Britain. She argues convincingly that there is a continual development of this idea from the earliest air raids of the First World War through the interwar period and into the Second World War, reflected in a variety of forms from government policy to popular culture. The primary focus of the book is the war as experienced by 'civilians': a term, Grayzel observes 'which contemporaries usually signified as women and children' (2012: 2). This sets the tone for the book, which provides a subtle and effective critique of Home Fronts as gendered spaces, but one where children are generally subsumed into this broader category of 'women and children'. This echoes Sonya Rose's 2003 Which People's War?, which examines the creation of identities in wartime Britain. Rose examines how ideals of womanhood became divided by the demands of the wartime society and economy between responsible motherhood (often in the absence of fathers) and the need for war workers. Here again children appear not so much as a distinct demographic within a divided society (the subject of Rose's study), but mostly in so far as they impacted upon women's lives.

One of the common themes in historical writing on this topic is the general concern for children's health and welfare across different areas of British state policy and wartime activity (e.g. Longden 2012). Grayzel highlights the concern for civilian victims of bombing in interwar and wartime Civil Defence policy as 'one of the Great War's most enduring legacies' (2012: 318), and notes the efforts made to provide adequate gas protection for children of all ages. Many of these accounts of official concern for children's wellbeing focus on the policy of evacuating children, their teachers and the mothers of babies and toddlers away from target areas: a practice that does not feature very much in this book due to its focus on first-hand memories of, primarily, the air war. Welshman's 2010 study of evacuation based on hundreds of first-hand memory narratives is one of the few histories of the subject that centres children's perspectives on their experiences. Many contemporary accounts of evacuation, and a considerable amount of historical scholarship, have noted the concern voiced in reception areas at the parlous condition of many poor children from slum areas who arrived with their growth stunted by malnourishment, ill, poorly dressed and generally suffering the effects of extreme poverty. Middle-class horror at poverty made material in the bodies of working class children has been credited as one force amongst several that drove the introduction of welfare policies throughout the war years and afterwards: Michael Shapira notes that 'evacuation focused a national spotlight on the lives of city children' (Shapira 2013: 70-71, and see also Mackay 2002: 241-2; Mayall and Morrow 2011: 88). 


\section{Introduction}

While the child's-eye-view of the war is commonly ignored or pushed to the margins, relatively few scholars are openly dismissive of it. Helen Jones' study of civilian war work amid air raids discusses John Boorman's 1987 film Hope and Glory, which gives a child's perspectives on air raids as (at least in part) exciting events presenting freedoms and opportunities. Jones notes that 'While the behaviour of a child in Hope and Glory resonates with much wartime evidence about children's behaviour, children and adults did not necessarily react in the same way, and the experience seen through the eyes of a child can, therefore, only be a partial one.' (Jones 2006: 8). Despite this, Jones is one of the few historians to examine the distinctive experience of children's contributions to civil defence, highlighting their employment as 'roof spotters', stationed on rooftops during air raids to warn of approaching bombers so that factories, businesses and schools could continue to operate for as long as possible after the air raid sirens sounded. Jones describes this as an ambiguity in policies and social attitudes towards children and a challenge to previous historical studies that focused on the protection of children and ignored their being placed in harm's way. However, the children mentioned as rooftop spotters in Jones' study were mostly aged 14 and over, an age when many children in Britain at this time would have left school and begun work. This illustrates amongst other things, the slipperiness of the category of 'child' and 'young person' in this period and the peculiar place in wartime society of children old enough to leave school but still too young for military service (Jones 2006: 195).

Children's contributions to war work and the wartime economy, both formally and informally, are the subject of Mayall and Morrow's remarkable You Can Help Your Country (Mayall and Morrow 2011). This engrossing historical sociology examines the often-contradictory attitudes towards children in wartime: as Jones noted in her earlier study, children as a demographic were simultaneously vulnerable civilians to be protected, a potential source of disorder and a valuable workforce (Jones 2006: 136). Mayall and Morrow's analysis covers a range of forms of war work undertaken by children, ranging from agricultural labour and factory work to service in Civil Defence organisations, fundraising and collecting recyclable materials. One of the main arguments for children contributing to the war effort was to keep them out of the trouble that it was widely assumed would result from absent fathers and male teachers, schools closed or at least disrupted and mothers out to work. As Mayall and Morrow note: 'Whether children should work was a debating point throughout the war. Some thought that if parents gave their children less attention this was bad for morale - neglected children ran wild' (Mayall and Morrow 2011: 89). As the Times Education Supplement stated at the time, 'A child brought into the war effort is better than a child brought into the juvenile court' (1942, quoted in Mayall and Morrow 2011: 168). Fear of juvenile delinquency was one of the most powerful driving forces in policies towards children in wartime Britain, with a heavily gendered emphasis on the perceived violence of young men and promiscuity of young women. 
As specialists in childhood studies, it is perhaps unsurprising that one of the most distinctive aspect of Mayall and Morrow's study is their emphasis on children as active participants in wartime society with their own distinctive interests and concerns. They recognize that war presented children with 'new opportunities to exercise their agency', and that 'adults who observed them had new opportunities to recognize children as agents, who dealt with the exigencies of wartime as best they could.' (2011: 91). One of the themes that they highlight is children's enthusiasm and desire for meaningful service in support of the war effort: they note the unexpectedly high uptake of schemes such as the Air Training Corps and other organisations dedicated to preparing young people for military service. Central to this analysis is an appreciation that children saw themselves as active participants in wartime society: 'What did become clear during the war was that children in England, whether evacuated or not, of whatever class, participated in the war effort, in a wide range of ways ... In these ways they promoted their own welfare, as well as that of the communities in which they lived.' (Mayall and Morrow 2011: 88). If we want to understand childhood and its material worlds in Second World War Britain, or indeed anywhere, we need to start from this understanding of children as people, keenly observant and aware of their environments even as they are shaped by them, and reshape them for their own purposes.

\section{What is this book?}

The simplest summary of this book is that it presents a historical anthropology of childhood in Second World War Britain. I use the term 'historical anthropology' in a similar way to that set out by the cultural historian Peter Burke, who outlined its disciplinary and methodological terms in the opening paper of his 1987 essay collection, in part by contrasting it with social history. Burke describes historical anthropology as a form of historical research grounded in the specific or microscopic and focused on thick description, the everyday and the material and embodied aspects of human existence rather than seeking trends or 'big picture' narratives: a thoroughly qualitative field of scholarship. While the historical anthropologist might draw back somewhat from discussions of causality, quantification and longer-term trends while delighting in the micro-scale, it would be unfair to suggest that they merely cherry-pick anecdotes without regard for their socio-political contexts and broader intellectual themes. Burke locates the intellectual genealogy of historical anthropology in the anthropologically informed (and sometimes misinformed) historical work of Marx and Weber, and sees its later developments influenced by Durkheim, Mauss and later Geertz and Bourdieu (Burke 1987). Burke's historical anthropology is thus grounded in the social or cultural strand of anthropology, while for my purposes the anthropology part, and the subject of my attempts at a Geertzian thick description, is more specifically the field of material culture studies (e.g. Saunders 2003). 


\section{Introduction}

What does this mean in practice? First and foremost that this is a profoundly humanistic study. My units of analysis, my data points, my sources are people: individuals telling the stories of their lives, and specifically the stories of their childhoods during the Second World War. For the most part, these stories are not focused on material culture, nor were they based on interviews or responses to specific questions: I will discuss my sources in more depth below. But despite this, the stories are stuffed with references to material culture, as virtually any human story must be: the food that is eaten; the homes that are inhabited; the clothes that are worn; the treasures hunted and the landscapes traversed. To discover the stories of children's gas masks for example, I could simply interview people about their childhood gas masks, but I can obtain a better assessment of their power and significance by seeking out stories of wartime childhoods where gas masks are mentioned. Reading these stories in their hundreds has given me a far richer and more rounded view, as these objects of significance bob to the surface time and again of their own accord, beyond the scope of coincidence, gradually become connected by slim threads of sense memory, emotion, fascination and trauma.

What are the limits of a historical anthropology of this kind, focusing on the stories of and in the material cultures of childhood in Second World War Britain? What is it capable of, and which of these potential achievements is unique and worthy enough of our effort and consideration? Contemporary archaeologist Alfredo González-Ruibal offers a generous but ruthless critique of 'story-telling' as an aim of historical archaeological studies of the material remains of painful and controversial histories, highlighting the unique modes of narration that material culture presents but also the limits of narrative itself:

do we really need more narratives about World War II, probably the bestresearched period in history? Do we need more fine-grained information about each and every event of the conflict? These are questions that are pertinent not only for that historical episode but for the recent past as a whole. Do we always need more stories and more voices?

(González-Ruibal 2008: 250)

González-Ruibal argues instead for an engagement with material culture based not on storytelling but on making things manifest: drawing from the shattered remains of violent conflict 'a rough material image of the daily banality of war'; recognizing the limitations of deriving linear narrative from material things and instead exploring new ways of seeing (González-Ruibal 2008: 250). He highlights the power of material things to haunt and affect us, summoning up the past: drawing on archaeological models of materiality he discusses how narratives based on fragments of the material world will themselves be, by necessity, partial and fragmentary. The approach that González-Ruibal proposes - his 'archaeology of the supermodern' - is of considerable relevance for this study. He locates it in the 'background noise' of ruins, rubbish and detritus such as 'an empty shell casing', and in abject places including bunkers and bomb-craters. 
The vision of 'supermodernity' at the heart of his critique stares directly at the horrors of recent history, and González-Ruibal charges archaeologists with the task of maintaining the uncanny 'aura' that gives the material remains of these events their power and salience, preserving their power to evoke emotion and memories.

In a direct challenge to the conception of historical anthropology that I have outlined above and practiced in my research, González-Ruibal asks 'Do we need 500 micro-histories about as many micro-events?' (González-Ruibal 2008: 259). I am still wrestling with these ideas, but my approach of illuminating categories of material culture through the accumulation and analysis of narrative fragments is a form of manifestation that in its form and outcomes at least partially responds to González-Ruibal's provocation.

\section{Material culture and war}

The primary intellectual context for this book is the rich body of interdisciplinary work focusing on the material culture of modern conflict, produced over the past 20 years or so. This field has many roots, but the single most significant point of origin is the body of work on the material culture of the First World War produced by Nicholas Saunders, his colleagues, collaborators and students (see Saunders 2004; Saunders and Cornish 2009; 2017; Cornish and Saunders 2014). This movement can best be described as taking the material culture of war in all its forms from artefacts, artworks and bodies to structures and landscapes, as the starting points for richly humanistic studies of conflict. Based around a series of conferences and published proceedings since 2001, this movement has been characterized by internationalism, a boldness in the selection of subjects and a generative approach to interdisciplinarity. The justification for organizing historians, museum curators, anthropologists, art historians, archaeologists and geographers around the theme of conflict material culture is best stated by Saunders, who argued that 'War is the transformation of matter through the agency of destruction, and industrialized conflict creates and destroys on a larger scale than at any time in human history' (Saunders 2002: 175), and that

The eclectic nature of that part of anthropology known as 'material culture studies' ... would seem perfectly matched to seeking knowledge and understanding of a war that itself is highly fragmented, divided up between a multiplicity of academic disciplines.

(Saunders 2004: 1)

For subject matter, there is the mind-boggling amount of stuff left over from the last century of total war. To exacerbate this embarrassment of riches, research in this tradition works across a range of scales that encompasses everything from portable material culture - the buttons and bullets so beloved of battlefield archaeologists - to battleships, battlefields and the vast (often global) landscapes of mechanized land, sea and air warfare. 


\section{Introduction}

Conflict material culture is good to think with, and the scholars working in this field have spun off in a number of different directions, while largely maintaining a disciplinary coherence. Some of these approaches have resembled a social archaeological approach to conflict sites and landscapes, such as the work of Breithoff $(2012 ; 2015)$ and Gonzalez-Ruibal (2008). Others have taken an object-focused approach, drawing on museum collections and personal or family archives, such as Joy (2002) and Phillips (2009). More recently there have been studies looking at the human body as a material thing that can be transformed, broken, annihilated and remade in warfare, and a growing focus on ways in which the bodily senses mediate individuals' experiences of the material worlds of conflict (Cornish and Saunders 2014; Saunders and Cornish 2017).

Saunders' foundational work in this field looked at 'trench art': conflict material culture transformed into new and often decorative forms (Saunders 2000; 2003). The largest body of this material dates to the First World War and its aftermath, and is formed from the brass shell cases that could be found in abundance around the battle lines. Shaped into vases and ashtrays, letter openers and matchbox holders, and decorated with stamped and incised markings, this vast and neglected corpus of material that formed the basis for Saunders' work highlights many of the key themes that have since taken root in the field of conflict material culture more widely (Saunders 2003). Trench art is a rich resource for a historical anthropology of war: the transformation of one shell-case amongst identical hundreds of millions into a unique artwork speaks to a humanscale specificity, while the life histories of individual pieces can illuminate the lives and experiences of other things and other people. At points in their material lives and afterlives trench art, like other souvenirs and artefacts of conflict, can be laden with burdens of collective commemoration and individual or family remembrance, as well as unspoken individual burdens of trauma, loss and grief.

How have Home Front historians approached the material traces of the conflict? In popular histories of the Second World War the same objects and sites recur: the ration book, the gas mask, the Anderson shelter. Helen Jones draws attention to these stereotypical artefacts, their inherent problems and what they can elide:

Local museums hold and display the material culture of air raids - sirens, gas masks and shelters - that have become the symbols of the civilian experience of war. These materials are about the system in place for protecting the population, and the population protecting itself. The other side of the coin, that of people eschewing protection, ignoring the siren and not taking cover, has not left material evidence, and cannot therefore be displayed.

(Jones 2006: 9) 
Jones makes the valid point that these objects are commonly treated as familiar illustrations to well-known and widely understood narratives. This echoes archaeologist Matthew Johnson's warning that an uncritical approach to the archaeology of the modern world risks becoming merely 'social-history-plus-artefacts' (Johnson 1999: 20). However, Jones' claim that 'Historians have to analyse a range of sources, not only the visually ubiquitous and iconic, which they then interpret as evidence in order to contextualize remaining material culture' betrays a historian's chauvinism towards the interpretive, communicative, symbolic and mnemonic values of the material traces of the past (Jones 2006: 9).

Some of the most stimulating historical approaches to conflict material culture draw on traditions in the history of science and in science and technology studies, such as David Edgerton's study of the British aircraft industry and John Law's study of the TSR2 aircraft development project (Edgerton 1991; Law 2002). Leo McKinstry's more superficial studies of the Spitfire, Hurricane and Lancaster aircraft echo the breathless excitement of wartime publications aimed at air-minded boys, but they embody a material-focused approach to history that has unexplored potential (McKinstry 2007; 2009; 2010). This potential is better explored by Susan Grayzel, who devotes a chapter to the origins and development of one of the most affecting artefacts of the Second World War era: the infant gas mask. Placing the development in the context of evolving civil defence policy and infrastructure in the inter-war period, she highlights the gender and class-based chauvinism of the planners, who questioned whether women living in slums would be able to operate even the simplest device to protect their young children (Grayzel 2012: 233). This account of the development of anti-gas protection for babies, which resulted in a space-helmet-like bag with a large clear window and a hand-operated air pump, illustrates for Grayzel the domestication of civil defence or the militarisation of the domestic sphere. Not unreasonably, given this viewpoint, the perspective of children on their own masks either at the time or later is not explored, although Grayzel notes the frequent outrage and fear of test subject babies at being laced into their gas masks (Grayzel 2012: 243).

For my purposes, one of the greatest values of Saunders' approach to the material culture of conflict is its focus on people's history from the ground up as makers, modifiers and users of tools, weapons, artworks and places. This emphasis on the interplay of human and material echoes (even unconsciously) the radical traditions of the history workshop and oral history movements, while recognizing the unique nature of violent conflict as a form of human experience:

Perhaps as never before, we perceive during war an unfamiliar but underlying truth - that objects make people as much as people make objects ... The extreme behaviours provoked by war illustrate how an individual's social being is determined by their relationship to the objects that represent them - how objects become metaphors for the self, a way of knowing oneself through things both present and absent

(Saunders 2004: 6) 


\section{Introduction}

My work on children and the material culture of conflict is distinctive from the vast majority of scholarship by Saunders and others working in his tradition in that I am not starting from the material. In fact, I first encountered pieces of anti-aircraft shell shrapnel in real (material) life years after I began to study and write about it. Building on the foundations of earlier work, I have been able to confidently assert the significance of material cultures in individuals' experiences and memories of conflict. Based on this assertion I set out my theory - well tested in this book - that the sensory and affective impacts of these material cultures were so powerful, and the resulting memories so detailed and enduring, that the objects, sites and landscapes of wartime childhoods could be traced and substantially reconstructed from memory narratives recorded decades later. Archaeologists, material culture anthropologists, social historians and others are accustomed to looking for stories in things: in this book, in contrast, I have looked for the things in the stories.

\section{Things in stories}

In the rich anthropological literature on material culture and the life histories, agencies and trajectories of objects, most studies that examine memory have considered it from the perspective of the material, where artefacts serve as bearers or symbols of memory, or as more elaborate mnemonic devices, for example in societies with strong and elaborate oral traditions (e.g. Küchler 2002). In my work I have taken inspiration from anthropologist Janet Hoskins' work in Indonesia, where she attempted to collect individual life histories in a society that she described as lacking a confessional tradition. In her ethnographic work, Hoskins found it most effective to avoid asking people to speak about their lives directly, but rather to talk about the stories associated with specific objects, whether ritual or mundane.

What I discovered, quite to my surprise, was that I could not collect the histories of objects and the life histories of persons separately. People and the things they valued were so complexly intertwined they could not be disentangled ... I obtained more introspective, intimate, and 'personal' accounts of many peoples' lives when I asked them about objects, and traced the paths of many objects in interviews supposedly focused on persons.

(Hoskins 1998: 2)

This latter point is of particular interest, as it ties in directly with my findings from reading memory narratives of childhood in the Second World War: the recurrence of often mundane objects and material aspects of space and place as reference points in life writing. Hoskins' view of life story telling is informed by Frank Kermode's theory of autobiographical narrative as a process of editing and selective erasure with the aim of creating a coherent and usable narrative. In this model: 
... narrators used the objects autobiographically, as a cornerstone of a story about themselves; a vehicle to define personal identity and sexual identity. In a way, the object becomes a prop, a storytelling device, and also a mnemonic for certain experiences. However, such devices are never innocent.

(Hoskins 1998: 4)

Amongst the most effective employments of this approach to conflict, materiality and also, crucially, corporeality is the work of Sarah De Nardi on landscapes and material memories of the Italian Resistance in the Second World War (De Nardi 2017). De Nardi explored the use of artefacts in reminiscence work and the ability of these relations to illuminate the embodiment of memories and the impacts of what she called 'worlds of feeling' on her informants' memories of war and conflict (De Nardi 2014).

Another interesting aspect of Hoskins' work is her suggestion that amongst the most common of these objects were various forms of container such as bottles, bags and shrouds: she suggests that things which contain other things are a metaphor, whether consciously or not, for the individual who holds the memories within themselves. This chimes with Arnold Long's account of the teacher's unpacking of his gas mask case, object by object, and his detailed memory of the box itself. As Hoskins' work demonstrates, the majority of work at the object/memory nexus treats the former as a route to the latter, even though she highlights the possibility and efficacy of the alternative. To treat memory narratives as sources for a historical anthropology of material culture, as I have done in this volume, remains a notably uncommon approach. These memories, the primary sources for this study, are drawn from the extraordinary online archive of the BBC People's War project, originally part of the BBC's website and now maintained by the British Library.

\section{The BBC People's War project}

The BBC People's War project ran from 2003 to 2006, and was primarily aimed at collecting first-hand accounts of the wartime experiences of ex-service men and women into a huge and publicly accessible online archive. However, of the more than 47,000 stories collected by the project, the largest single category was by those who had been children during the Second World War. The BBC People's War project was unusual in its time: a pioneering effort of user- or audience-generated online content in the early period of the so-called 'Web 2.0', at a time when only 12 percent of the over-65 population of the UK had access to the internet (Housden and Zmroczek 2007; Noakes 2009). The project recruited a network of several thousand volunteers who assisted users of the website in recording, transcribing and uploading their stories, often based in libraries and museums across the UK. I was a volunteer for the project in the latter stages of its operation in late 2005 and early 2006. 


\section{Introduction}

The BBC People's War project and its legacy represent a very particular approach to the commemoration and representation of the Second World War in the UK. Historian Lucy Noakes has identified it as part of a 'memory boom' around the period of the 60th anniversaries of the war from 1999 onwards, characterized by a Europe-wide rise in official commemorations of the conflict and the Holocaust, a growing number of associated heritage and museum resources and by a growth in popular culture representations in film and television. In the UK specifically she notes a focus on the Second World War in formal education and in children's literature and a widespread view of the war as a period of national unity and identity formation.

Looking at the People's War archive in detail, Noakes has observed three distinct themes emerging from the stories on the website (Noakes 2009: 147). The first is the enduring power and significance of Second World War memory in both private and collective acts of remembrance and in national processes of commemoration. The second, closely connected to this, is the connections that individuals draw between their own memories and the national historical narratives of the war, and the desire to elevate private remembrance to the levels of esteem and visibility enjoyed by national-scale acts of commemoration and heritage representation. This theme sheds important light on the motivations for individuals to record their stories for the project. The third theme that Noakes identifies is a hierarchy within the site, largely based on gender, with men's experience of combat, and particularly their participation in historically well-attested events, being presented more confidently and with more assumed authority than women's accounts of life and work in wartime.

This gendering of the archive is significant, and ties in to wider questions about national commemoration and heritage representation of women in wartime. It is also important for the sake of my work to consider its resonances and connections with issues of age. The immediate and enduring effects of the Second World War on gender roles in British society were significant, including the absence of large numbers of men serving abroad, changes to women's work cultures and consequent economic power, and the breaking of family and community ties due to evacuation and displacement. All of these processes had significant effects on children and young people, and many of these impacts were themselves gendered.

Noakes sees the BBC People's War archive as not merely a significant historical resource, but one that sheds light on the attitudes to the heritage of the Second World War and its representations in the period 2003 to 2006, offering insights into the digital transformation of the public sphere. She notes that while the site is dominated by conventional narratives that affirm popular perceptions of the conflict, it also creates space for minority viewpoints such as those of conscientious objectors to be heard and to find affirmation through similar stories. As Noakes observes, the site provides insights into: 
the processes by which the personal, private memories of individuals become part of a more widely shared popular memory. The stories entered here can be seen as part of the process of refining and shaping memory until it fits with one's sense of self

(Noakes 2009: 145)

These themes of public-private narrative formation and self-fashioning in individual life stories bring us back to the idea of a historical anthropology of wartime childhood. Housden and Zmroczek's study of the project examines the experience of recording reminiscences on the project website, and they too consider the process to be one of identity formation and affirmation, particularly considering the older age of most of the contributors. Noakes' focus is gender, and like other writers who have considered the BBC People's War project she does not look in any depth at the body of stories relating to childhood on the Home Front, but she does highlight the distinctive diversity of the site, its value as an archive of relatively unmediated primary sources and its potential to destabilize and challenge dominant memory narratives.

It is important to note that the sources used in this book are not stories told in wartime, but stories told often more than sixty years later, by older people, in specific personal and cultural contexts, and subject to a myriad of forms of distortion, as Housden and Zmroczek (2007) note. But to say that the meat of my research is doubtfully remembered stories told in 2003 to 2006 is not to negate their value as sources of information about the war years: rather, the passage of time can be understood to serve as a form of filtering or selection, and one that can be at least partially understood. This chimes with Hoskins' claim that the creation of an autobiographical narrative is at least in part a purposeful process of editing and excising to construct a clearer, more comfortable and artificially linear life story (Hoskins 1998). In this process material things - objects, spaces and places - serve as waypoints or markers that anchor the narrative, and in the process become illuminated in richer and more complicated detail.

\section{The structure of this book}

Each of the chapters in this book examines a different aspect of the material culture of childhood in Second World War Britain. In considering the specific characteristics of these materials, the chapters shed light on different dimensions of wartime childhood such as play, discipline, destruction and escapism, and also examine themes such as trauma, memory and the senses that cut across chapters and forge links between them.

The first chapter looks at gas masks, the mass-produced general civilian respirators that virtually every adult and child in Britain received and carried before and during the Second World War. The ubiquity and uniformity of these objects and their brown cardboard cases makes them a good subject to 
start with, drawing out themes such as the power and endurance of sense memory. The relationships between young children and the quasi-military technology of their gas masks were often fractious, and from a historical anthropological perspective they shed interesting light on the divergence between the intended functions of an object and the wider set of uses spawned by children's fear, frustration, playfulness and imagination. As Arnold Long's story at the beginning of this introduction highlights, gas masks were also the focus of an often brutal regime of training and discipline, including the use of gas chambers to expose children to tear gas. The fear of gas, which was never used against British civilians, is an interesting cultural phenomenon that ties in to legacies of the First World War in British military, political and popular cultures. The powerful symbolism of gas masks and the horror-image of the child in the gas mask have endured into the present in art, media and popular culture more generally: like several of the chapters in this book the study of gas masks is worthy of a book of its own.

The second chapter examines the practices and rituals around the collection of shrapnel and other military souvenirs, and the extraordinarily intricate systems of value and exchange that emerged seemingly organically amongst the children of wartime Britain. Most shrapnel was fragments of anti-aircraft shells, detonated at high altitudes with the intention of damaging, destroying or at least deterring enemy aircraft. The fragments of steel that fell to earth with lethal energy carried a glossy sheen, a whiff of explosive, and the heat from the explosion - all of which gave 'fresh' shrapnel a fleeting and anthropologically curious higher value. Like the gas masks, the vividness with which individual pieces of shrapnel were recalled in the BBC People's War accounts more than 60 years on speaks to their affective impacts: handling shrapnel provided a sensory experience and a mastery of the deadly energy of war, and integrating it into existing networks of trade, exchange, status and play rendered it 'safe' and familiar. More than any other chapter, the study of shrapnel mirrors Saunders' study of trench art discussed earlier: unique and treasured objects primarily derived from starkly mass-produced artillery shells, and entered into fascinatingly elaborate social relations very far from what their manufacturers intended.

From objects to spaces and places, the third chapter examines childhood memories of air raid shelters as material and sensory spaces and as the settings for the majority of experiences of bombing. The experiences of shelter users varied considerably, from the claustrophobic steel box Morrison table shelters and back-garden Anderson shelters, set up as family homes in miniature, to the larger public or municipal shelters, and in some places caves or underground stations. Pre-war planners imagined air raids to be short in duration, and it came as a surprise when families began to spend nights in shelters, presenting challenges of comfort, sanitation and public health. Many families worked to domesticate their air raid shelter with familiar comforts and decorations such as radios, heaters and wallpaper, aiming to transform the often dark, damp and cold spaces into at least tolerable simulacra of the home. For children shelters were marginal spaces for play, privacy, intimacy and vandalism. They were 
where air combat and bombing were experienced as soundtracks without pictures, the explosions and vibrations the most powerfully intense sense memories of the conflict. Yet for most children of the war it was the smell of shelters that recurred in memory narratives, the sense that has been shown to most powerfully stimulate recollections: the musty smell of damp concrete and unwashed bodies, of improvised toilets and sweat and fear. The air raid shelter, whether in the home, the school, the street or a public place was the nexus for British children's experiences of the Second World War.

Chapter 4 examines another powerful part of the geography of the Home Front: the bombed houses and buildings that became unofficial adventure playgrounds for many children in urban Britain during wartime. Viewing the ruins of newly destroyed buildings was a popular pastime for all ages, but for children in particular the ruins - officially off limits - became immensely popular places to explore, to vandalize, to build and to hide. As marginal, 'disordered spaces' they offered a freedom hard to find elsewhere, particularly in the heavily regulated and policed world of wartime urban Britain. In many cases the charred ruins of bombed houses quickly began to be reclaimed by nature: weeds including rosebay willowherb flourished along with wild flowers, birds, insects, stray animals, and stray children who became part of their ecologies. The attraction of bombsites to war-traumatized children did not go unnoticed by therapists, radical educationalists and others interested in the wellbeing of children during and after the war. The idea of adventure playgrounds with materials to build and create was rooted in this work and became the basis for studies in therapeutic play. But beyond the war games, den building and merry destruction, bombsites were also highly dangerous environments with falls and collapsing walls killing and injuring a number of children, and water tanks and gas pipes presenting further hazards. With their thrills, dangers, smells, freedoms, chaos of materials and strange ecology, bombsites were a remarkable and important part of young people's urban landscapes and feature strongly in their memories of wartime childhood.

Chapter 5 examines children's fascination with aircraft and aviation, part of a wider culture of 'air-mindedness', looking at the means by which young people materialized and mastered these generally distant and unobtainable objects of interest. Training and practice in aircraft recognition became a feature of Civil Defence as well as military training, with popular books, collectable cards, posters and other printed ephemera providing the means for young people to develop their skills, although the ability to recognize aircraft by sound was a skill developed through experience rather than training. One popular tool in aircraft recognition training was aero-modelling, and the already popular hobby took on a military-industrial aspect, with mass-produced models distributed to training units in their thousands. Aero-modelling and the display of models, together with aircraft recognition classes with certificates and other awards were features of the Air Training Corps, which from 1941 provided airminded young people with training and skills intended to inspire the next generation of airmen. 


\section{Introduction}

Beyond these officially sanctioned lines of activity there remained the illicit: the collection of fragments of airframe from crash sites, and in particular the clear Perspex popular with modellers. Access to actual aircraft was one of the attractions of Air Training Corps membership, but like the protagonists of Westall's The Machine Gunners cited earlier, some children did manage to get their hands on crashed aircraft and take souvenirs from them - although few as lethal as a machine gun. Children living near airfields were also more likely to be able to see, touch and even explore inside combat aircraft, sometimes illicitly but more often with the indulgent consent of the aircrews. The desire to master the iconic and threatening aircraft was a powerful force that transformed the material worlds of children in wartime: Arnold Long's gas mask case, cited at the beginning of this chapter, was decorated with images of Spitfires and contained pieces of wooden aircraft that he had been carving.

Taken together these chapters sketch out a handful of the most powerful and iconic dimensions of wartime children's material cultures. There are many other aspects that I could have considered alongside them as further chapter-length studies including war themed toys and games, landscapes of evacuation, food and drink, the collecting and trading of military cap badges, and the transformation of children's bodies in wartime through the violence of bombing, changes in diet and public health interventions. Another possible approach would be an international comparison with children in Germany, the Soviet Union, Japan and other Second World War-affected countries, including those who experienced occupation, ethnic cleansing and genocide and much closer encounters with combat. For now, these are some slivers of insight into children in Second World War Britain and their memories - sixty or more years later - of the material cultures of war that shaped their lives, hobbies, education, games, annoyances, delinquency, friendships, fears, and for some the traumas that would shape the rest of their lives. 


\section{Gas masks}

\section{Introduction}

The Civilian respirator protects the wearer against breathing any of the known war gases and is to be used on occasions where gas is present and a gas-protected room or refuge is not available.

(Home Office 1938: 25)

A Gas Procession passed through Plymouth, which many people watched. Men wearing Gas Masks wheeled handcarts, and tied on to each of them was a Winchester Quart glass bottle. Each bottle contained a different coloured liquid, and each was labelled with the name of a different poison gas.

(Dart 2005)

War meant gas masks.

(Monteith 2005)

The horrors of poison gas on the battlefields of the First World War lingered in European consciousnesses throughout the 1920s and 30s, both in literary and artistic representations of the conflict and in the wheezing broken bodies of gas casualties. The popular perception, reinforced by novels such as Valiant Clay and by the Italian use of gas in the invasion of Abyssinia, was that the next European war would be a gas bombing war with few if any survivors (Lindqvist 2002). The fear of gas warfare informed the military, political, scientific and social discourses of defence policy to an extent arguably analogous to the nuclear threat in the Cold War. The British government's decision in 1935 to create and store enough gas masks for the entire population should be understood in this light: during the 1938 Munich Crisis more than 35 million of these masks were distributed. At the outbreak of war, as Terrence O'Brien noted, 'every British adult citizen, for the first time in history, entered war with an article of personal defensive equipment' (O’Brien 1955: 330). However, O'Brien's perceptive observation elides an even more remarkable phenomenon: children, with the initial exception of babies, were also issued with their own version of the General Civilian Respirator. The 


\section{Gas masks}

principal focus of this chapter is the extraordinary process whereby young children were trained in the importance, carriage, care and use of a piece of technologically advanced military equipment. By examining these processes through memory narratives, I have focused in particular on the children's powerful aesthetic responses to their gas masks.

In the first part of this chapter I examine the history and development of gas protection, as well as the wider social and cultural significances of gas masks. The main section of the chapter examines the relationship between British children and their gas masks in the Second World War. This includes their modifications and subversive uses of both the masks and their cases, and the often brutal programmes of gas mask training.

The aesthetics of the gas mask form a central theme in this chapter, in which I conceptualize aesthetics in two distinct but related ways: firstly in their more common form as the basis for critical perception and response; and secondly in their more literal form as the experiential world of the senses. As I will demonstrate, the peculiarity of the gas mask is its ability to evoke powerful aesthetic responses of both types: from the outsider's view as an artefact, art object or thing observed, and from the insider's perspective as a near-complete synaesthetic environment. In this chapter I focus mainly on the second category: the inside-out sensory experience of gas masks.

Bridging these two strands is the concept of the gas mask as a mediator: both in a socio-cultural sense between the owner, the world around them and ourselves as observers; and in the physical sense between the wearer and the outside world. Like all forms of material culture gas masks can form and mediate social relationships, including that between a scholar and their (human or non-human) subject. As a physical mediator between the seats of the senses and a potentially harmful atmosphere, a gas mask restricts and distorts its wearer's perceptions and responses. This powerful affective impact is repeatedly attested to in memory narratives of wartime childhood recorded decades afterwards, in which gas masks play the part of Proust's madeleine: 'Recently, I used a dust filter mask while rubbing down paint, and its rubber smell evoked a long forgotten memory - that of my wartime gas mask' (Newman 2003).

\section{Material cultures of gas masks}

Today the child's gas mask is an iconic artefact, an instantly recognisable aspect of the material and visual culture of the British Home Front in the Second World War. The sinister image of young children clad in black rubber masks or the more pathetic figure of the evacuee with a cardboard gas mask case slung across his or her shoulder is familiar to us from history books, museums, documentaries and popular culture representations (Figure 1.1). The uncanny image of the child in a gas mask formed the basis of the Doctor Who episode The Empty Child (2005), while the gas mask equipped evacuee is a mainstay of children's literature and film from The Chronicles of Narnia to Bed-knobs and Broomsticks. Children in gas masks are also a recurring theme in the works of the graffiti artist Banksy as a 


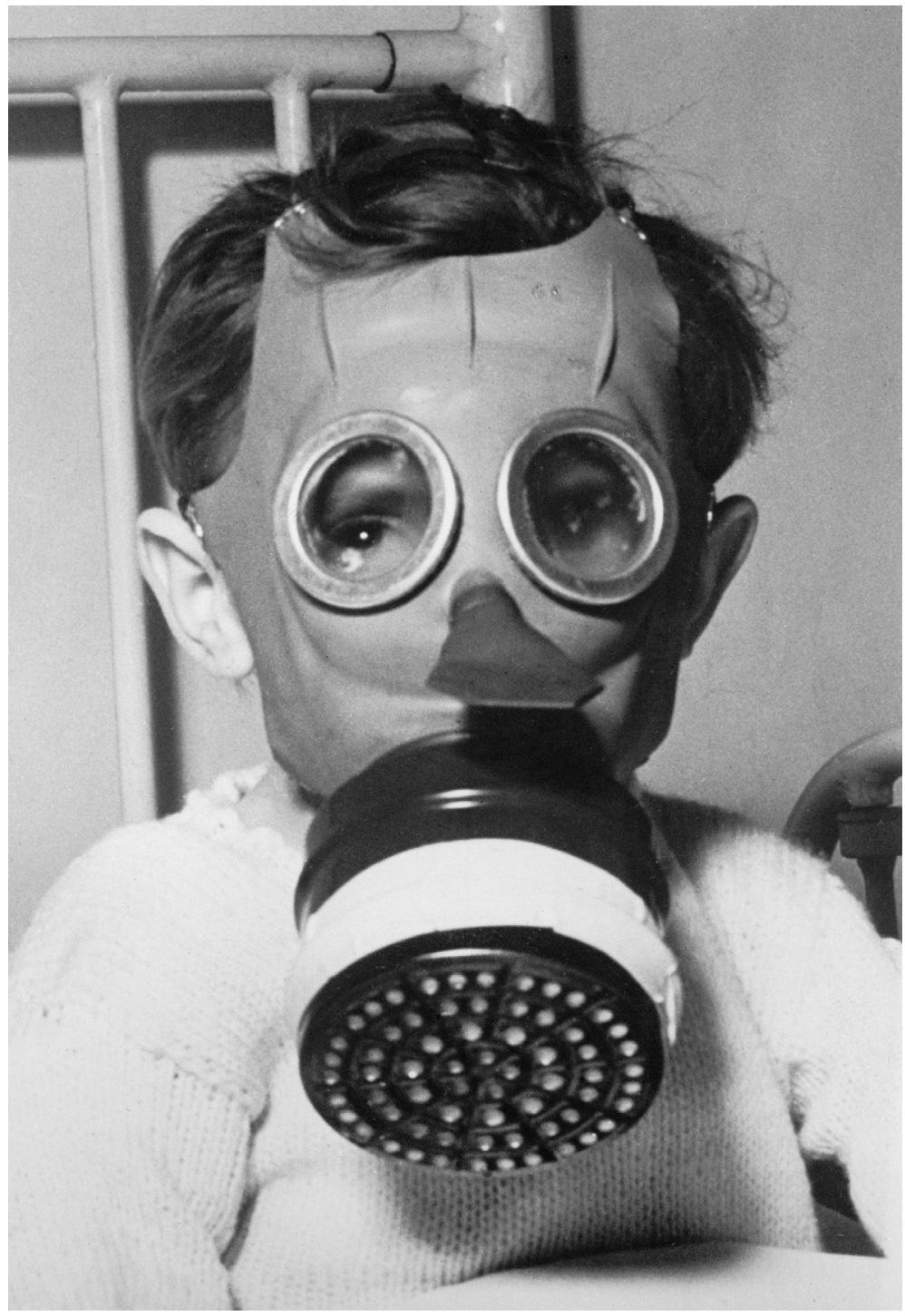

Figure 1.1 Child modelling the brightly coloured 'Mickey Mouse' gas mask. C Imperial War Museum, D 5894.

symbol of air pollution, urban decay and innocence (Banksy 2006). What makes the image of the gas mask so popular and widespread?

A respirator or gas mask is a peculiar type of object that defies categorization, bridging several classes of material culture. Originally devised to protect soldiers, gas masks are now used in industry, the service sector, erotic and autoerotic activities, civil disobedience, historical re-enactment and policing. They are also collected, curated and studied. In these very different contexts they can be defined 


\section{Gas masks}

as clothing, art objects, costumes, disguises, medical aids, historical artefacts, protective equipment and sexual fetish objects. Given the military-industrial origins of gas masks, it is perhaps useful to regard them as uniforms; as Craik (2003: 128) has observed, 'uniforms have overt and covert lives': on the one hand they encode strict hierarchies and patterns of behaviour and on the other they feature prominently in pornography, vaudeville, Mardi Gras and assorted subcultures. It is also possible to consider the gas mask as a mask, analogous to those studied by anthropologists as aspects of religious or secular ritual (Pollock 1995). The mask can be regarded, variously, as a means of disguising, transforming or displaying identity; the variety of gas masks forms, together with the rigid standardization within these forms, allow them to play all of these roles. Emigh (1996: xviii) unpicks this process further, highlighting the conflicts of identity and processes of negotiation between the mask and the wearer which he argues are analogous to the relationships between the performer and the audience, the self and the other.

For British children in the Second World War however, I will argue that the gas mask as symbol of identity was in practice often eclipsed by the more diverse, customizable and immediately visible containers in which the masks were transported. The unboxed mask-that-is-worn can almost be considered as a distinct object from the boxed gas mask that is ready-to-hand. As some of these memory narratives will demonstrate, children's resistance to the rules demanding that they carry their masks meant that in many cases the gas mask case concealed - alongside a myriad of objects - an absence of the gas mask itself. In this and in a number of other respects the life histories of these nested artefacts are as inseparable as they are eventful.

\section{Chemical warfare and the emergence of gas protection}

Under the terms of the 1899 Hague Convention, the signatories agreed 'to abstain from the use of projectiles the object of which is the diffusion of asphyxiating or deleterious gases' (Rosenne 2001). With typical regard for international law, the British, French and German armies immediately began experimenting with tear gases, which they regarded as outside the terms of the relevant declaration (Jones and Hook 2007). In the opening months of the First World War these were deployed in combat as grenades and shells, with little effect. In 1914 the German chemist Fritz Haber, later awarded a Nobel prize for his work on synthesising ammonia, suggested the use of chlorine as a war gas. This was judged to be legal provided the gas was released from static cylinders rather than fired in shells, thus obeying the letter rather than the spirit of the Hague Convention. On 22 April 1915, German Pionierkommando released the chlorine gas close to the French front line to the north of Ypres; combat troops wearing primitive respirators followed, and broke through the French defences (Jones and Hook 2007).

Chlorine caused severe irritation to the nose, mouth and lungs, with subsequent pulmonary edema resulting in death by drowning. Following the success of chlorine, the French developed a more potent phosgene gas, and the Germans then devised a highly effective combination of chlorine and 
phosgene nicknamed 'white star'. In 1917 the Germans developed mustard gas, a corrosive liquid that caused blistering, chemical burns and lung damage. By the end of the war total gas casualties were estimated at 88,000 dead and 1,200,000 wounded, the majority of these Russian. A new arms race had begun in which the most important defensive weapon was the gas mask.

Unlike bullets, shrapnel and explosives that destroy the vital organs, poison gases incapacitate and kill their victims by attacking the seats of the senses: the eyes, nose, mouth and skin. The aesthetic impact of gas is vividly evoked in representations of the First World War including the war art of Otto Dix and Wilfred Owen's poem Dulce et Decorum Est, in which he describes the bitter, choking, blinding effects of chlorine (Stallworthy 1996; Winter 1998). Gas masks, conversely, are designed to shield the sensorium, the seats of the senses, from the effects of poison gases. In the process they create a restrictive, minimal sensory environment: an anaesthetic shield against an anti-aesthetic weapon.

While a number of relatively advanced respirators had been developed for industrial purposes in America throughout the nineteenth century, the earliest military gas masks were primitive filters based on cotton soaked in water or various chemicals, designed to cover the mouth and nose only. These were soon superseded by the hypo helmet or 'smoke helmet' developed by a British army medic: this was a cloth bag impregnated with chemicals, with a mica window to see through. In 1915 the Royal Army Medical College in London developed the 'P-helmet' based on a sodium phenate filter, which set the pattern for the modern gas mask: a face-piece with eye holes, a chemical filter and a container (Barker 1926: 11). Further rapid developments of the gas mask by all sides in the conflict reflected the growing variety and brutality of the gasses employed on the battlefields, and by the close of the conflict in 1918 the respirators in use more closely resembled those issued to civilian populations 20 years later, than those simple improvised models of just two or three years before.

\section{Interwar paranoia, air raid precautions and the gas threat}

In 1932 Stanley Baldwin made his now often-quoted speech on air warfare to the British parliament in which he warned that:

I think it is well also for the man in the street to realize that there is no power on earth that can protect him from being bombed, whatever people may tell him. The bomber will always get through ... The only defence is in offence, which means that you have got to kill more women and children more quickly than the enemy if you want to save yourselves.

(Baldwin 1932)

In more recent discussions of this speech, it is generally not noted that the bombing Baldwin anticipated was as likely to be with gas as explosives or incendiaries (cf. Calder 1992; Smith 2000). In the speech he also criticized Britain's lack of preparedness for gas attack: 'on the Continent people are 


\section{Gas masks}

being taught the necessary precautions to take against the use of gas dropped from the air' (Baldwin 1932). With the Italian invasion of Abyssinia in 1935 the public became aware of the actual impact of poison gas dropped from above, further reviving the spectre that had haunted Europe since the First World War (Lindqvist 2002). In 1936 the Spanish Civil War reintroduced another widespread fear of the deliberate, systematic destruction of towns by waves of bombers: that the bombings of Guernica and Barcelona used conventional munitions did little to diminish this. J.B.S. Haldane, who had worked on the development of British respirators since the First World War, was more sanguine about the threat of gas, as he told subscribers to the Left Book Club: 'the high explosive bomb is very considerably (perhaps fifty times) more deadly than the gas bomb' (Haldane 1938: 23). Based on his studies of phosgene in air, and drawing on the outcome of a massive phosgene leak in Hamburg in 1928, Haldane concluded that gas was very unlikely to prove an effective weapon against urban targets in the European theatre, particularly 'after the promised supply of respirators becomes available for British civilians' (1938: 25).

\section{The General Civilian Respirator}

The civil defence of Britain in the interwar period, including air raid precautions (ARP) fell within the remit of the Home Office. As early as 1924 the ARP committee considered the threat of gas bombing in a future war and decided it was unlikely; they did, however, discuss the costs of gas proofing for vital infrastructure including government buildings and gas decontamination facilities for key workers (O'Brien 1955: 15, 26). By 1934 it had become clear that in the event of war the populace would demand access to low cost gas protection: the Home Office minister authorized the Chemical Research Committee to begin work on a suitable design, but it was still unclear who would pay for their manufacture, storage and distribution. However, in the aftermath of the Italian gas bombing in Abyssinia in 1935, the Cabinet approved funding for the manufacture and stockpiling of civilian respirators; a remarkably large commitment of resources. As O'Brien observed, 'The obligation was novel, since in no previous war had the Government had to contemplate the possible death or injury of so large a proportion of the civil population, and damage to so much civilian property, by one weapon' (O'Brien 1955: 77). By November 1936 a disused cotton mill in Blackburn had been transformed into a gas mask assembly plant, with the aim of producing 40 million of the newly designed 'General Civilian Respirators' by the summer of 1938. This new mask, while cheap to produce and easy to store, was far from simple:

The new mask consisted of a facepiece, a container which held the two filtering media, an india rubber band to connect these two parts, and an india rubber non-return valve for the inner end of container. The variety of components involved was considerable, and the total numbers of some items 
required were astronomical. The facepiece, for example, included vulcanised sheet rubber, cellulose acetate eyepieces, cotton webbing, slides, buckles, safety pins and other materials. Ninety million safety pins and the same number of slides were needed and thirty million of the other items. The complete container included canister bodies and ends, wire diaphragms, cotton pads, muslin diaphragms, filter pads, springs and activated charcoal.

(O’Brien 1955: 78)

The completed masks were packed into sealed cans filled with nitrogen, and stockpiled at strategic locations, in preparation for dispersal to the more numerous distribution depots.

One major flaw in the government gas protection programme was the lack of protection for children under five, including babies. As late as 1938, when gas masks began to be distributed to the general public, the so-called 'baby bag' and the colourful 'Mickey Mouse' respirator for young children were only at the design stage. Incredibly, by August 1939 these had still not been distributed, and some local authorities were reluctant to distribute any gas masks whatsoever until protection for the whole family could be guaranteed, for fear of public outrage (O'Brien 1955: 233; 289). Despite these planning errors and logistical setbacks, by the start of the war the vast majority of the population, including children, were beginning to familiarize themselves with their gas masks.

\section{The General Civilian Respirator at the outbreak of war}

At the outbreak of war there was a widespread assumption that the nation would come under immediate and potentially catastrophic attack from the air. Gas masks, issued more than a year earlier, began to be carried by a large proportion of the population, although this was never a legal requirement (Calder 1992). For many British children the second day of the war would have been the first day of the new school year, but most schools remained closed for some time. The testimony below describes the sense of dread in these early hours and days of the war, and the pervasive fear of gas attack:

Everyone anticipated invasion, imminent air raid and gas attacks. I discovered that gas masks had already been issued, horrible, smelly, rubber contraptions that we thankfully never had to use ... I can still recall the sense of doom and anxiety that was apparent on every face - my Father, my Auntie and Uncle Connell, the neighbours who had joined the group, and the elderly friends who had all lived through the First World War. One had been in the trenches and had been gassed; he had a bad chest and breathing difficulties, a quiet voice, and seemed weak physically ... My Uncle hustled us all to the staircase that was built against the main inner wall of the house. We thought we were going to be bombed or gassed right away.

(Gaylor 2005) 


\section{Gas masks}

The General Civilian Respirator soon became a common article of personal material culture. The following account offers a generally representative perspective on the everyday nature of the gas mask, including a description of the object itself and the peculiar combination of sensory deprivation and the distinctive sensory environment it created:

It came in a tough brown cardboard box with a strap to hang it over your shoulder and you were supposed to 'take it everywhere with you'. That included to school and until nearly the end of the war putting your gas mask box on your shoulder became as much a part of going to school as brushing your hair and tying your shoes. The gas mask itself was made of black rubber with a plastic window and fitted over your face completely so as to make a tight seal across your forehead, down your cheeks, and under your chin. The chemicals to stop the gas were in a cylindrical protrusion like a large pig's snout hanging down and out at mouth level. When you breathed in the air came through this filter, when you breathed out it came out at the side of your mask, by your ears, making a 'rude noise' if you puffed vigorously. There was a plastic window to see through but after wearing the mask for a short time it got steamed up in a cool room. Of course, you could not eat or drink with this on and speech was hard to understand as it was muffled.

(Sudbury 2003)

Numerous narratives reflecting on this early period of the war describe children's first impressions of their gas masks, virtually all of them negative, and many describing the distinctive sensation of being strapped into it. These accounts include complaints about the smell, the feeling of rubber against the skin, the restricted vision, claustrophobia, and the inability to breath or speak properly: 'they smelled musty and rubbery, were uncomfortable to wear and allowed only limited vision' (Matthews 2003); 'There was a distinct rubber smell, and the air was forced out at the sides. It was warm inside the mask and condensation usually blurred the flexible eyepiece' (Millar 2003). Several training manuals from the time recommended spitting on the eyepieces to prevent them steaming up, a process familiar to swimmers and divers today. The sense of grumpy petulance in many of these accounts is similar to the common childish reaction to any form of restrictive clothing imposed upon them by parents or others: 'The part you looked out of steamed up and you could not breathe easily. You could not talk as it covered your whole face, and I hated it' (Dawes 2003).

Psychological studies have examined the often contradictory roles of material culture and emotion in the formation of memories. Conflicting theories of memory suggested that strong emotional responses might encourage or, conversely, impair the creation of clear and enduring memory associations. Mather's (2007) research aimed to address this issue by focusing on 'emotionally arousing objects' and found that while subjects formed 
clear memories of the objects themselves, their contexts and associated objects were less clearly recalled. In this context, children's strong emotional and aesthetic responses to gas masks arguably explain the clarity and strength of the memories associated with them, which several of the testimonies mention explicitly:

I remember vividly trying the gas mask on for the first time; the peculiar smell which rubber has albeit not an unpleasant odour; the tight feeling of the rubber around your forehead down your cheeks and under your chin, and the funny bit with everyone talking as if they had a peg on their noses.

(Clark 2003)

I can still recall the feeling of this monstrous rubber object being strapped on and my face feeling clammy and how the rubber edge fluttered against my cheeks when I blew out.

(Bourne 2003)

Not all the responses to the masks were negative: one testimony includes a description of hiding beneath a school desk - 'duck and cover' - while wearing a gas mask, and remarks that 'it was amazing the sense of security I felt with ... my gas mask on my face' (Cameron 2006).

Throughout the war British military intelligence attempted to discover the types of gas likely to be used in a chemical attack either in combat or in area bombing. Based on these discoveries a series of modifications were introduced for the General Civilian Respirator, including a series of additional filters which were attached to the original one, containing activated charcoal. This addition was recalled by many of those who were children at the time: 'The masks came in three sizes: large, medium, and small. Being a young lad, mine was a small. I've never discovered why, but after about two weeks we had to return to Grace Hill to have an extra filter taped to the end of the existing one. I appreciate that it was for a type of gas, but which one I don't know' (Francis 2003a). 'Soon after their issue, a man came round to the school and taped a second canister onto the main one. This was coloured green, and was made especially to combat Mustard gas' (Gibbons 2003).

\section{Alternative uses}

Youthful hooliganism during the Second World War often focused on material expressions of the conflict: so many air raid shelters were vandalized by children that some were padlocked during daytime (Calder 1992: 49). In this context it is unsurprising that young people explored alternative uses for their gas masks, some of which can be regarded as expressions of dissent. Philosopher Beth Preston has highlighted the distinction between an object's 'proper function', or primary, normal intended use, and its 'system function', or alternative possible 


\section{Gas masks}

uses (Graves-Brown 2007; Preston 2000). As many parents are aware, probably the single best way of exploring the system functions of a piece of technology is to give it to a young child. Narrative accounts of childhood in the Second World War include a wide range of uses that children found for their gas masks. One testimony recalls that 'a game of mine was to put on my gas mask and chase my sister around the house. Maureen would scream her head off. Mum would come and give me a good telling off' (Hayhurst 2005). A more nefarious use of the gas mask moved from the realm of costume into disguise: 'I was caught scrumping because adjacent to the school was the Headmaster's house and his garden with apple trees, irresistible and I really plucked up my courage, donned my gas mask and invaded the orchard!' (Cook 2005).

In several cases children employed their gas masks for more prosaic purposes, system functions that more closely resembled their proper functions: "the only time we used them was when we all sat around a tin bath and prepared onions and shallots for pickling' (Sharman 2003). Another account includes a healthily empirical approach to the issue of gas protection and the value of the gas mask: 'I tried it out once after my father had been to the loo - I came out choking, mind you whether the Germans could invent a gas stronger than that - I doubt phew! What I had proven to myself was - the damn things were ineffective' (Leveton 2004).

The question of play also raises other questions regarding the traumatic effects of warfare on young people and the importance of material culture in maintaining children's ability to control and manipulate the world around them. In this context the use of gas masks in play, pickling and petty larceny would have also been a means of 'domesticating' a potentially fearsome or traumatizing object. However, while using violent war materials such as shrapnel (see Chapter 2) in play might have been a means of re-inscribing a threatening object as a toy, a similarly playful approach to gas masks threatened to elide their potentially life-saving importance. To counteract this trend a wide-ranging educational programme was developed, the largest part of which focused on the classroom.

\section{The gas mask at school}

I think my mother tried to explain to me the danger of being gassed by the Germans but how is a small child able to understand what gas is?

(Pennington 2003)

Gas training was largely the responsibility of Air Raid Precaution wardens and the civil defence department of the Home Office as a whole. For children, however, a great deal of gas training and education took place in school, most of which had either reopened or relocated within a few months of the outbreak of war, albeit often on a half-time basis or less (Calder 1992). School gas training was unusual in comparison to most of the rest of the Home Front in that carrying a gas mask at all times was compulsory, and at the beginning of the war at least this was sternly and sometimes harshly enforced. 
Autumn Term at School started again in the second week of September, on the 14th, to find that the greatest sin on the calendar was not having your gas mask with you at all times. For a while every lesson began with a gas mask check. Later it became a registration ceremony which lasted until the last days of the war. If you had forgotten it, you were sent home to retrieve it. Gas Mask drills - putting them on, chin first and the straps over your head, staff in theirs checking straps - they smelt horrible, puffing and blowing to see that you had a good seal, moving around a little to get used to wearing them, became part of the timetable.

(Drake 2004)

Gas mask drills, in which the masks were rapidly donned and worn for everyday school activities (including, absurdly, gymnastics) were often combined with air raid drills, in which the children would file into the shelters and continue lessons underground (Hussey 2003).

On occasion our teacher would shout 'Gas, Gas.' Then we would grab our gas mask, which we always had to have with us, and put it on. When the teacher had her mask on, she would come round and check each one of us to make sure we had fitted it correctly. We children had our own way of checking. We knew that if you took a deep breath and expelled if forcefully it made a raspberry sound. As the teacher moved around the class she was surrounded by a cacophony of rude noises.

(Phillips 2003)

A very regular occurrence which took place during those days was the gas mask practice. Once a week, Mr Hurdle, our school headmaster would have us adorn the masks and we would run from the school to the church and back, a distance overall of about a mile.

(Brookings 2003)

This habit of blowing raspberries out of the side of the gas mask is one of the most common memories in memory narratives. It combines a sense of play with a distinctive aesthetic memory of the gas mask and a small element of subversion: 'Then we started all the boring air raid practices relieved only by making farting noises through our gas masks' (Cox 2003). This loud, rasping, slightly muffled noise of breathing and speaking through a gas mask is more familiar today thanks to Darth Vader. One account of gas mask practice in schools offers an extraordinarily vivid memory of the unpleasant sensory experience:

You had to first put your whole face into the rubber mask; the rubber was skin tight [so] as to not let any gas in. The teacher would then come up behind you and tighten up the web strapping so that it could not fall off if you were forced to run. It was I think almost impossible not to panic when one's head was encased in such a contraption the smell of rubber was 


\section{Gas masks}

choking. We were encouraged to play as normal and not to look down at the trunk of the mask but to look up at the sky and trees, anything to take one's mind off the fact that you had a mask on. By far it was easier said than done and I never kept mine on longer than five minutes, many children totally refused to put it on to the extent that they would lay on the ground kicking and screaming for their mummy and daddy.

(Parsons 2004)

From the teacher's perspective the gas mask would have been a particularly troublesome imposition: being as grimly uniform as the grim school uniform it would have made the students virtually impossible to distinguish. This was almost certainly what motivated the apple scrumper discussed above to don his gas mask in preparation for his crime.

Civil defence information was communicated to the general public through a dizzying variety of media including posters, information films, pamphlets, radio lectures, slogans and songs. For children there was a separate propaganda campaign based on cartoons, comic characters such as the 'squander bug' and similar means. The popular childhood activity of collecting and exchanging cigarette cards became a means of education, with several series providing advice on a range of topics: 'in September 1939 it was possible to collect cigarette cards about 'air raid precautions'; 'how to equip your refuge room'; 'how to put on your gas mask' and even 'how to put out an incendiary bomb'! (Scott 2003). Another effective method was to teach rhymes and aphorisms, some of which such as 'coughs and sneezes spread diseases' are such powerful memes that they endure into the present.

At school we became one big family as we scampered through the sunny meadows blackberrying on those lazy September days, tumbling over when our gas masks steamed up but forbidden to remove them, as we chanted: 'If you get a funny feeling and a smell of musty hay, You can bet your bottom dollar that it's phosgene on the way.' We memorised other gas-warning rhymes as we stomped along which I can no longer recall.

(Duerden 2005)

The comparison of phosgene to 'musty hay' dates back to the First World War, and it is entirely possible that the rhymes were of similar vintage, revived by teachers or family members who had fought on the Western Front (Jones and Hook 2007):

My father found a poem warning of the different types of gas:

\section{Beware Gas}

If you get a choking feeling and a smell of musty hay, You can bet your bottom dollar that there's Phosgene on the way. 
But the smell of Bleaching Powder will inevitably mean, That the enemy you're meeting is the gas that's named Chlorine.

If your eyes begin a twitching, and for tears you cannot see, T'isn't mother peeling onions but a dose of CAP.

If the smell resembles Pear Drops, then you better not delay, It's not the youngster sucking toffee, but that tear gas KSK.

Should you sniff a pungent odour as you're going home to tea, You can safely put your shirt on it, they are using BBC.

If you see an oily liquid on the roads be on your guard, It isn't where a bus was parked, but the wicked gas Mustard.

Peaceful Geraniums look pleasant in a bed. Dodge their scent in wartime. It's Lewisite, you're dead.

As an industrial chemist I now know these gases as: Phosgene is carbonyl chloride; Chlorine is chlorine; CAP is chlor-aceto-phenone; KSK is ethyl iodo-acetate; BBC is bromo-benzyl cyanide; Mustard Gas is dichloro-diethyl sulphide; and Lewisite is chlorovinyl dichlorarsine.

(Dart 2005)

An alternative version of this poem is quoted in Ali Smith's Winter (2017), and other versions are found in newspapers and accounts from the early years of the war.

\section{Live gas training}

We had to practice putting the masks on and taking them off properly regularly at school. Fortunately we never had to use them seriously, though my mother and I did once go to a demonstration in a caravan where we put our masks on and sat around while a man let off a capsule of tear gas and showed, by taking off his mask so that his eyes streamed, that our masks really were working.

(Sudbury 2003)

To keep people on their toes and aware of the possibility of a gas attack, someone from the military would drive up to a place where people were gathered, such as a shopping street, and throw out a tear gas grenade before driving away. The air raid wardens would have been tipped off and would appear wearing their gas masks and waving their warning rattles. Woe betide anyone who had left home that day without their gas mask!

(Hester 2005) 


\section{Gas masks}

From the late 1930s, the Home Office's Air Raid Precautions Department carried out a training programme for the use of gas masks in which members of the public, including school students, were systematically exposed to tear gas. Based around fixed and mobile gas chambers, this training aimed to educate the public in the value and efficacy of their gas masks. However, as we shall see, there were problematic discrepancies between the stated form and aims of these tests and their practical applications, including some excessively brutal training practices.

In 1936 the Air Raid Precautions Department of the Home Office established a training facility, the 'Civilian Anti-Gas School', at Eastwood Park in Falfield, Gloucestershire (Hansard 1936). The primary function of this school was to train civil defence staff from around the country as anti-gas instructors. The ten-day residential course prepared instructors to teach gas mask fitting, testing and classes for the civilian 'local anti-gas certificate'. Later a second school was established at Easingwold in Yorkshire (Bentall 1938). Alongside the instructors trained to First and Second Class Certificate standard at these schools, the Air Raid Precautions Department permitted suitably experienced members of the Red Cross and St John's Ambulance to carry out gas training, particularly in the early months of the war.

Biologist J.B.S. Haldane was part of the team that developed the first British respirators in the First World War and had experienced both gas attacks in that war and air raids in the Spanish Civil War when in 1938 he published A.R.P., his critique of the government provisions for civil defence. Several of Haldane's points focus on gas, including the contemporary absence of respirators for infants and young children. Amongst his proposals was that:

A gas chamber will be set up for every 10,000 people in towns, and everyone will have the opportunity of testing the existing respirators in an atmosphere of tear gas. Children will be taught at school. The question of whether the existing type of civilian respirator is adequate will to a large extent be decided on the result of these tests.

(Haldane 1938: 203-4)

\section{Gas vans and gas chambers}

By the time Haldane's book appeared a more modest scheme along these lines had already been put in place by the Home Office. A fleet of 35 gas vans or 'mobile gas chambers' were brought into service by the Home Office in 1936 and were operated by local police authorities, with the Metropolitan Police possessing six, and one being retained by the Civilian Anti-Gas School for training purposes. The stringent Home Office guidelines for the operation of gas vans stated that trainees should be admitted to the van in groups no larger than ten, for around three to five minutes each. The instructions are also clear that respirators should under no circumstances be removed in the gas chamber. Lifting the sidepiece of the mask to admit a small amount of gas was only permitted as part of a specific lesson on mask clearing, not 
as part of the general testing of the masks. However, this guideline was widely disregarded in practice.

The Home Office requested that wherever possible fixed gas chambers should be used for gas mask tests in preference to gas vans, due to their lower running costs. In many cases these chambers were existing gas-proofed structures adapted for this purpose, either for local authority use or by factories and firms for training their workforces. After the outbreak of war there was a renewed interest in gas training, and the Home Office began to encourage the construction of more, smaller gas chambers for training purposes. Guidelines including blueprints were published for the construction of these structures, based on a design for workmen's huts. The chambers were small: approximately nine by seven feet with an air-lock entrance, built of wood on a concrete base, and sealed with tape and creosote. The total volume of the chamber was approximately 500 cubic feet, small enough to be filled by a single gas capsule.

The gas used in these live tests was CAP or chloroacetophenone, now better known as CN gas or chemical mace, a widely used tear gas developed in the 1930s for law enforcement and riot control purposes. CAP was not extensively used in Britain in peacetime: Shoul has argued that public abhorrence to gas attacks based on memories of the First World War prevented its more widespread use (Shoul 2008). The effects of CAP are common to most tear gases or lachrymatory agents: tearing and irritation of the eyes, photophobia, and burning pains in the skin; in high concentrations it can also cause second degree burns (Thorburn 1982). CAP capsules were widely distributed by the Home Office for use in anti-gas training, with stringent rules governing their storage and transport. Inside the gas chamber or gas van, a capsule of CAP would be pierced and placed over a spirit lamp, releasing the gas (more properly a microparticulate solid) into the atmosphere. The instructor was equipped with a small bottle of olive oil to treat skin burns caused by over-exposure.

\section{Sense memories of the gas vans}

Accounts of these tests recorded in the People's War project archive shed light on a hitherto neglected dimension: their common and remarkable brutality when aimed at the public in general and children in particular:

I was in the A.T.S. and we were made to enter two types of gas chambers one of which was tear gas. Whilst we were in the gas chamber all of us had to remove our masks and experience just what it felt like to be in an attack. Needless to say we all emerged from those few moments with tear drops running down our cheeks, but a heck of a lot wiser.

(Danter 2005)

This exposure lasted just a 'few moments' but made a strong impression; in some cases these object lessons in the unpleasantness of gas were considerably 


\section{Gas masks}

harsher. A number of the accounts mention the involvement of the Home Guard, who might not have received the formal Home Office training:

My father, not content with looking after and drilling his Home Guard Platoon also trained us. When we heard a bang we had to fling ourselves on the floor and put our hands over the back of our necks for protection. When we hear him shout 'Gas' we had to put on our gas masks asap and not expect any help from him. Then he would check that we had done it correctly, which he did by putting a piece of loo paper on the bottom and making us breathe in to keep it there. He had a whole gas chamber to train the Home Guard in as well as us.

(Lee 2005)

Some of the more alarming accounts describe the practice of releasing tear gas unexpectedly in public places. It should be noted that while carrying a gas mask was strongly recommended, it was never legally required: anyone caught in a gas test without their respirator would have suffered considerably:

I recall shopping in Watford with my mother when there was a simulated gas attack - canisters of tear gas which had been placed in the gutters along the High Street were set off and the shopping area became filled with gas we put our masks on and took shelter in a shop until the gas dispersed.

(Tarling 2004)

One Sunday we found the Home Guard outside the church giving the townsfolk a taste of gas for practise. We had to get our masks on damn quick and walk through this thick swirling gas, up towards the park. I was a bit scared, but when I realised I had got through all right I tried to go back through it. I just missed a clip round the ear from a corporal and scarpered.

(G.J. Clark 2005)

The ethics and legality of these tests are probably questionable, but the intention was obvious: to educate a public that was increasingly cynical about the value of and need for gas masks. The surprise nature of these tests also undermines a key element in Haldane's original suggestion: that people be given the opportunity to test their gas masks, as well as O'Brien's statement that people were invited to test their masks (Haldane 1938; O'Brien 1955: 366). This distinction between choice and coercion in the civilian experience of gas mask tests is clearest in the records of gas tests in British schools, amply recorded in oral historical accounts:

Once we had our masks tested; we were led through an air raid shelter that the wardens had filled with tear-gas. Most of us noticed nothing, but Charlie Blower's mask didn't work. He just sat in class all morning with tears streaming down his face, then the teacher sent him home.

(Westall 1995: 73) 
They brought in something like a furniture-removal van, and they filled it with gas, and we all had to pass through wearing our gas masks in blocks of ten or twenty boys, and we were in it for about five minutes and then came out the other end. This was to prove that our gas masks worked or not. It must have been something like tear gas, not very lethal, but anyone afterwards who had tears in their eyes had their gas mask readjusted so that they fitted better.

(Smith 2007: 93)

In these cases exposure to tear gas was arguably a necessary precaution to prevent likely death or serious injury in a real gas attack. In other cases it could be a genuine accident:

In order to accustom us to the rather unpleasant sensation of wearing a mask, we were periodically instructed to put them on for ten minutes or so in class - on one occasion we had a mobile gas chamber parked on our playground and we were all required to sit in it for ten minutes or so to prove to ourselves the effectiveness of the masks. We were suitably reassured, but on return to our classroom the residue of gas on our clothing caused a few impromptu tears!

(Tarling 2004)

Testing children's gas masks under 'battle conditions' is mentioned in passing in a few published collections of testimonies such as these. In these examples the point of the exercise is to test the efficacy of the gas masks. The gas van was not the only means of education: some schools seem to have rigged up a temporary gas chamber within the school building itself for the same purposes.

One day, we were led into one of the larger rooms of the school, to be confronted with a strange-looking machine with flat cylinders with louvres. We were made to put on our gas masks and the machine was somehow turned on; we were told that this was to test our masks. I don't know what gas was used - probably tear-gas at worst.

(Gossling 2003)

\section{Brutality and backlash}

However, in a number of cases it is clear that the children were instructed to remove their gas masks and inhale the tear gas.

There was a van which came round to my school, and groups of six children would don their gas masks, each group taking its turn in the hermetically sealed van (that is once the door was shut). At first we sat there breathing through our gas masks in comparative comfort; then we had to take them off and experience the stinging sensation of 
the gas, which caused a buzzing in my ears and made my eyes water, before putting the gas masks on again and breathing steadily until all the gas was expelled.

(Palmer 2004)

In this case the vivid description of the unpleasant effects of tear gas suggests that it made a strong impression, which was surely the intention.

A van was brought to the school and filled with tear gas and we walked through it. Then for some reason, which was not clear to me, we had to go in the van and take our masks off. We were in and out pretty quick I kid you not.

(Bayley 2004)

There was a van in the yard and we were made to go in wearing our gas masks and then, when inside were asked to take them off for a few seconds. The van was full of tear gas and we all came out coughing and spluttering. I suppose they were trying to make us see the importance of having gas masks near us at all times, but we didn't appreciate the lesson.

(D. Taylor 2004)

One testimony described this vehicle in sinister terms:

The year was 1941. The appearance of the 'gas van' came as another surprise to us. All the children of the Borough had to visit the vehicle, which was painted a sombre black and parked in the shadow of the town hall.

(Chappell 2005)

He described the warden going around the van lifting the lip of people's gas masks so that they inhaled the gas.

In 1936 Major F.W. Ollis, head of the Civilian Anti-Gas School at Falfield, wrote to the Home Office Air Raid Precautions Department expressing his exasperation with the confusion around gas training and exposure to CAP. He noted in particular the problem of instructors and trainees 'fiddling with the mask and lifting the side so as to allow gas to enter'. The purpose of the tests, he argued, was to check for gas-tightness. Trainees should only be exposed to tear gas as part of a separate, more advanced lesson in clearing gas from the mask. He concludes that 'There is no objection whatever to this procedure, but it does need to be kept entirely separate from the C.A.P. test for gas-tightness, and that is why we do not like it combined with that test in any way' (Ollis 1936). As we have seen these instructions, issued by the nation's most senior gas instructor in 1936, were consistently ignored by local instructors who persisted in exposing trainees, including school children, to tear gas. 


\section{Chemical warfare victims in the family}

If the aim of the live tests was to impress the horrors of gas warfare upon children and the public, then this might have been a wasted effort. With more than 188,000 British servicemen wounded by gas in the First World War virtually everybody in the country would have known or heard about someone affected by gas (Jones and Hook 2007). The debilitating long term effects of chemical warfare are powerful and lasting: even mild exposure could cause permanent loss of the senses of smell and taste while blindness, scarring, lung damage and severe skin burns were also common.

My father had served in the Great War in the Machine Gun Corps (often referred to as the 'suicide squad'!), been wounded twice and sent home to convalesce, only to return again! He had been gassed, and winters were a nightmare for him, fighting for breath and eyes streaming, as his sight and tear ducts had been affected.

(Turner 2003)

Dad, on essential war work, would go off to do fire-watching, complete with tin hat and gas mask, at his place of work. As a lathe operator he was in a reserved occupation. He'd served in the Pioneer Corps in the First World War, joined up under age and finished up burying those who had been killed by poison gas in France and suffered with his chest and nose for the rest of his life as a result. We all had gas masks but fortunately did not need to use them for real.

(Keen 2005)

My Uncle Leslie ... had been gassed with mustard gas while acting as a stretcher bearer in 'no man's land', he took his gas mask off for a while because he could not see his way through the shell craters. He was a sweet man with beautiful eyes and thick black eyelashes. He eventually went completely blind after the Second World War, as a result of the mustard gas.

(Seymour 2004)

For the children and young relatives of these servicemen the potential impact of gas war, and the value of gas masks, would have been something learnt and known at a very early age. The capacity of chemical weapons to target the seats of the senses: the head, face and skin, would also have been terrifyingly obvious.

\section{Gas mask cases}

Hoskins' anthropological study of 'material memories' in Indonesia noted the preponderance of containers of various kinds amongst the objects her informants used. She suggested that containers such as bottles, bags and shrouds are a conscious or subconscious metaphor for the individual who creates a 


\section{0}

Gas masks

narrative out of the elements they hold within them (Hoskins 1998; cf. Peers 1999). In this context it is worth examining the cases which held the gas masks as interesting subjects of study themselves. The General Civilian Respirator came in a brown cardboard box on a string, worn over the shoulder. As one informant recalled, 'These boxes were in no way robust enough for schoolboy use, and parents soon had to buy stronger, usually metal, containers' (Edwards 2004) (Figure 1.2). Unlike the gas masks which were drearily alike, the gas mask case offered children the opportunity to proclaim or negotiate their individuality, wealth or status within their own social world.

Woolworths came up with a variety of alternative metal canisters. These resulted in a certain amount of rivalry at school as to who possessed the most desirable container - my own, finished in a rather dashing overall white enamel, enjoyed only a fleeting period of desirability, proving to be too small to take the later, modified gas mask.

(Tarling 2004)

For some children the only way they could afford to improve their gas mask cases was to have a parent sew a fabric or leather cover and shoulder strap: 'You could get a leatherette cover for the box to make it more waterproof and

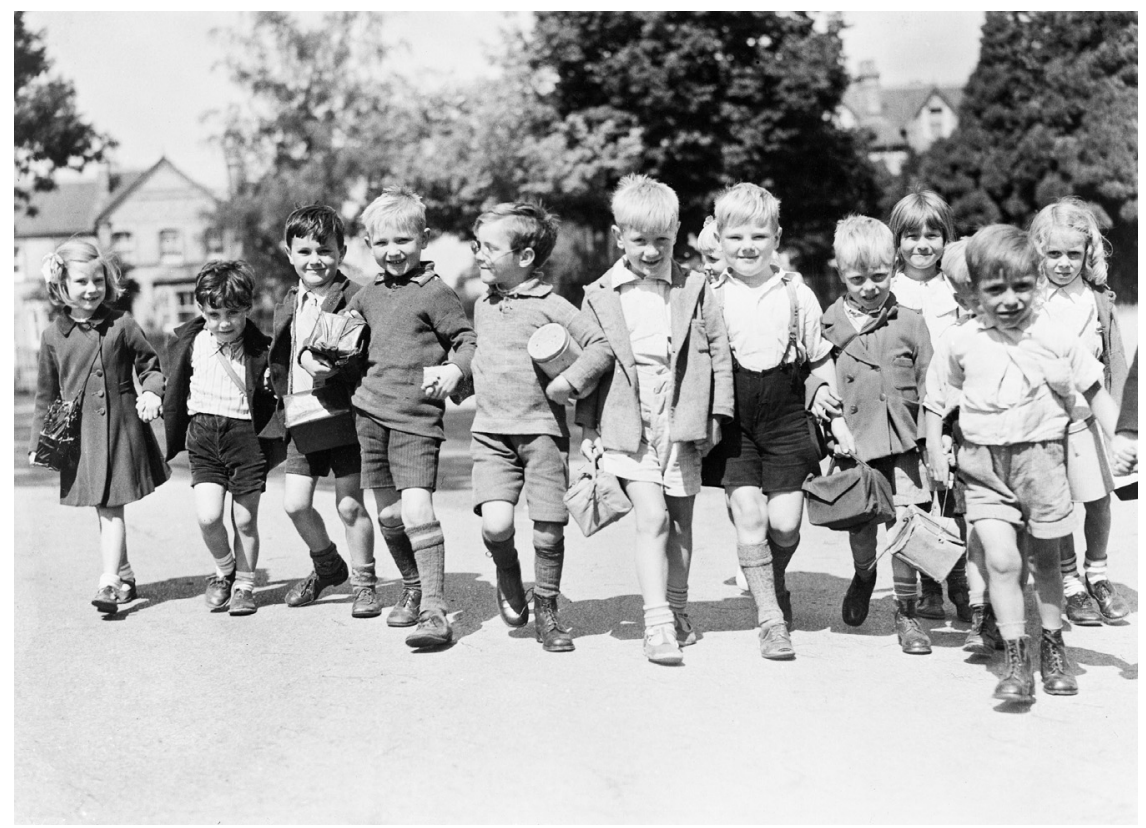

Figure 1.2 A group of young evacuees in Reading carrying their gas masks. A variety of cases, boxes and covers can be seen. (C) Imperial War Museum, D 824. 
a bit smarter looking' (H. Morgan 2005); 'the more expensive and elaborate ones became a status symbol at school' (Robertson 2005). The variety and hierarchies of cases on offer turned them into desirable accessories, analogous to expensive fashionable handbags: "After a while we looked upon them as fashion accessories and had all sorts of fancy containers. It was a competition, to make sure your friend did not have a better one than you!' (Hudson 2004). The commercialized aspect of this competitiveness did not escape notice: 'Manufacturers made a small killing by marketing tin tubes in which to store and carry the gas masks' (Hester 2005). Like the 'Mickey Mouse' masks, some of these commercially produced cases were specifically aimed at children, with some resembling toys or animals.

George Formby used to sing this funny song about his gas mask. In fact, at school, we competed to see who had the funniest gas mask case. They were all sorts of colours and different shapes. But the gas mask was really important.

(Feeney 2005)

The variety of cases and the near-ubiquity of the rectangular cardboard box or variations on this theme led to some innovative fakery: 'We had no problem, if we forgot it going to the cinema we got a brick from the bombed site and wrapped it in newspaper and took it under our arms, leaving it when we left.' (McBrias 2005).

Like the gas mask itself, gas mask cases in the hands of children developed an interesting range of 'system functions' to rival their intended 'proper function' of careful storage: 'they came in handy for swiping at other boys and storing illicit valuables like frogs' (Blanchard 2003). Another agrees: 'it came in very useful for swinging round my head and bashing up all my enemies' (Tookey 2004).

Slightly less violent uses included kicking the tin cases around like footballs, or swinging them on their straps to bash them together like giant conkers. As a result, 'the cases got so dented you couldn't get the gas-masks out!' (P. Kendall 2005). Others explored the musical potential inherent in the box: 'The brown cardboard box they came in with string to go around the neck was useful; with two sticks it made a very good drum as we marched up and down the street beating our drums and singing "The British Grenadiers" (Robins 2004).

Some of the most interesting and anthropologically rich accounts of gas mask cases are those in which they were used, in effect, as handbags. This refers back to Hoskin's study of containers and the biographical objects that they hold, and can be roughly divided into two categories: cases that held a gas mask and an assortment of other objects, and cases where the accumulated detritus had replaced the gas mask altogether. Ross describes an example of the former:

We were finally issued with gas masks, and my father, who was with the Post Office Cable Ships at the time, gave us two serviceman's gas mask cases. In this we kept our gas mask, sticky jam sandwiches, a bottle of 
tepid water and a load of old crusts and apple cores. Once we were nearly arrested by young army officer because we weren't supposed to have these cases. When he found out that my father was a seaman he realized they were not stolen, still he asked to have a look inside, and when he saw all the mucky food in there he made a face, and quickly left. (Ross 2005)

\section{Gas masks as uniforms}

The importance of the personalized and patinated gas mask case derives in part from its contrast to the drearily identical gas masks they contained. The sense of militarization in gas mask use resulted from both their physical uniformity and the militaristic discipline and brutal training that accompanied them. The conception of gas masks as uniforms is important, as Craik has observed: 'uniforms function through their delineation of hierarchy, status, authority and value, that is, by detailing differences in externally imposed behavioural codes and in generating responses of others to those codes' (Craik 2007: 37). In the case of children's gas masks these codes were rigidly enforced and reinforced through schooling and social pressures, including the threatening form of the policeman or air-raid warden.

However civilian gas masks in Second World War Britain also encoded a detailed social hierarchy within their uniformity. Firstly, and from the child's view most importantly, they encoded age: a baby might have an all-enveloping gas mask, but the distinction between a red 'Mickey Mouse' mask (ages two to five) and a smaller version of the adult's mask (roughly age five and upwards) was a terrifically important one, as several testimonies revealed. Gas masks clearly and visibly ranked the age and maturity of children at a point in their lives when even a quarter of a year age difference is widely noted and fiercely proclaimed. Amongst adults' masks as well there were distinctions: aside from the General Civilian Respirator there was a more comfortable and advanced Civilian Duty Respirator for emergency services and others, with glass eye pieces rather than a plastic window; there were also variants of the military respirator with its separate, longer-lasting filter box. As this study shows, gas masks fulfil Pollock's (1995) trinity of functions for a mask: to disguise, transform and display the identities of the wearer.

\section{Disposal}

In what ways did civilian gas masks end their active service in the Second World War? With some it ended before it began, in ignominy: in the months before the outbreak of war gas masks became a favourite souvenir of the Munich Crisis for American tourists to take home with them. While the proportion of the population carrying their gas masks in the street never rose above approximately 75 percent, anxious Home Office officials monitored changing attitudes and practices of gas protection in the general public through the Mass Observation data gathering project (Beaven and Griffiths 
1999; Harrisson 1976). At the time of the evacuation of the British army from Dunkirk in 1940, the percentage of the population carrying gas masks in the street rose from practically zero to around 30 percent; by August 1940 it had fallen to just ten percent (Calder 1992: 112). The attitude of this interviewee was largely representative of the population as a whole: 'If memory serves me correctly, as the war progressed we took a much more cavalier attitude to carrying gas masks and they were normally left at home' (Tarling 2004). From the memory sources it appears that gas masks were dumped in or on top of wardrobes and cupboards or under beds (Pilott 2003). 'The carrying of gas masks at first obligatory and involuntary eventually gave way to a sporadic carrying until finally our gas masks were stored under the stairs where they remained from the spring of 1942 to the end of the war' (Rhodes 2005). At the end of the war it was decided that a full recall and storage of gas masks would be too expensive and time consuming to be worthwhile, so only the more expensive versions such as the infants' and children's models were collected. As one account recalls: 'we were told to hand in our gas masks. Our depot was on City Road and I remember travelling there to take ours. For a long time we had not bothered with them and they had just gathered dust in a corner' (Phillips 2003). The gas masks' war had ended, if it had ever really begun.

\section{Discussion: discipline and punish?}

The General Civilian Respirator in the hands of the children of Second World War Britain took on a variety of often contradictory roles. In the context of school it represented bodily discipline and training and a conduit for various scales of misbehaviour. But the traditional forms of education, practice and training contrast sharply with the brutality of the live tests with tear gas. I believe the contrasting treatments reveal a conflict within the ethos of civil defence between the strategy of comforting reassurance and the perceived need for shock tactics to maintain awareness and vigilance. The former is in evidence in the following radio broadcast:

Are your little ones used to seeing you in your mask? Make a game of it, calling it 'mummy's funny face' or something of the kind. Then if the time comes when you really have to wear it, you won't be a terrifying apparition to the child.

(Westall 1995: 71)

Similarly, the design of the gas mask for young children was explicitly aimed at reducing fear. The so-called 'Mickey Mouse' mask for ages two to five featured 'a red rubber facepiece, blue container and bright eye-piece rims' to make it jollier and less sinister than the black devices for older children and adults (O'Brien 1955: 233). In light of this effort to make gas precautions familiar and comfortable for young children, why did the government develop 
a policy of live gas tests? The answer possibly lies in the widespread cynicism towards respirator technology and poor public responses to the official warnings that 'Hitler will send no warning - so always carry your gas mask'.

From the late 1930s and throughout the war, Mass Observation data was used to track the carriage of gas masks amongst the civilian population, in part as an indicator of morale (Harrisson 1976). Low levels of use were also believed to be at least in part a result of scepticism about the efficacy of the standard civilian respirator, despite its claim to protect against 'any of the known war gasses' (Home Office 1938).

Some of this scepticism may have been based on memories of the First World War, during which a series of partially or wholly ineffectual respirators were produced by private companies and the military. A substantial proportion of the male population, many now serving as ARP wardens, had witnessed or experienced gas attacks or their aftermaths and lived with the consequences. This experience would have provoked understandable concern about the general state of preparedness and the quality of protection available. It is in this context that we should consider the live gas tests that were carried out on the civilian population and particularly in schools.

Fear for the wellbeing of children, witnessed in practices such as mass evacuation, must also be considered in the context of the widespread fear of children going wild in wartime. The absence of fathers in the armed forces and mothers at work, combined with the closure of schools, created an atmosphere of moral concern that was not entirely misplaced, as Calder notes: 'In the cities, over a million children were left to run wild. Children ... turned to hooliganism - so often were public air raid shelters wrecked by children that the authorities were compelled to keep them locked' (Calder 1992: 49). In this context, the compulsory carrying and wearing of gas masks in schools can be seen as the imposition of quasimilitary discipline on a potentially anarchic element of the population. The brutality of the live gas tests can also be viewed as part of the same process: not to educate or warn British children about the dangers of gas, but to impose and reinforce discipline. In response to this, the children recreated their gas masks as a focus of resistance: a hiding place, a tool or a disguise; or else they discarded them. The disparities that emerged during the decadelong life of a gas mask between its 'proper functions' and its 'system functions' offer a vivid illustration of children's distinctive responses to a world at war and its most immediate material manifestation in their everyday lives. The clarity with which they recall them attests to the formidable synaesthetic impact of the gas mask itself.

The archaeologist Nathan Schlanger was living in Israel at the time of the first Gulf War, under 'increasingly credible and imminent' threat of chemical attack (Schlanger 1994: 274). Afterwards he reflected on his gas mask: its presence, principles and features, and his embodied relationship with it. Like the British children in the Second World War he lived under the constant threat of gas attack, but whereas their narratives were recorded 60 or more 
years after the fact, his recollections are much more immediate. Interestingly, however, the viscerally aesthetic response to the gas mask is nearly identical.

The 'brute' presence of this object on my face troubles me: For one thing, I am forced to take off my glasses in order to make room for it, and this not only gives me psychosomatic headaches but also makes me blind as a bat-with my hearing already swamped by the strident sirens, and my organs of taste and of smell thoroughly obstructed by the mask, I am left virtually senseless during these sensitive moments.

(Schlanger 1994: 276-7)

Chemical warfare attacks the sensorium; gas masks are its shield: just as a mask can disguise or transform identity, a gas mask disguises and transforms the senses. The narrative accounts in this chapter have shown that the memories of these sensory experiences endure with often startling clarity across more than half a century. 


\section{Collecting shrapnel}

When an anti-aircraft shell exploded, its casing disintegrated into fragments of jagged steel, some as much as four or five inches long and perhaps half-an-inch in width and thickness, and of course the brass timing-rings and nose-cones also became projectiles.

(Hill 2005b)

Our childish games and activities were almost inevitably war orientated, and we avidly collected soldiers cap badges, insignia, spent cartridge cases, shrapnel and all manner of like items. Greatly prized were the tail fins of incendiary (fire) bombs, which usually remained intact after detonation.

(Daniels 2005)

\section{Introduction}

In 1992, aged ten, I was tear-gassed during student riots at the University of Zimbabwe in Harare. I was collateral damage: my exposure was brief, and I experienced some pain in my eyes and nose. Far more irritating than the gas was the fact that a friend some years older than I had managed to acquire one of the used tear gas canisters and displayed it prominently in his bedroom: a rugged aluminium artefact with stencilled text and a sharp-edged perforation where the internal charge had burst it open. We had both been gassed, but he had a trophy, a souvenir, a material corroboration. Twenty-five years later I still remember that canister, its aura of derring-do and authentic experience, and my covetousness. If he had offered to sell it, what might I have paid? If he had suggested a trade, what might I have exchanged for it? And even if I had acquired it, would it have had even a fraction of the aura or satisfaction of one that I collected myself? These questions of value, meaning, materiality and memory form the basis of my study of children's collections of shrapnel and other souvenirs in Second World War Britain.

Anti-aircraft shells exploding at high altitudes scattered shards of red-hot steel across the towns and cities of Britain during the Second World War. For many school children collecting and trading this shrapnel became a popular 
social activity. In this chapter I want to examine these practices and processes of accumulation, exchange and disposal, looking at the aesthetic qualities that gave shrapnel fragments their value and significance. I will also examine other wartime collecting practices and look at the life histories of children's collections through accumulation, exchange and use, disposal and their afterlives in sense memories.

My scholarly interest in the study of children and material culture in the Second World War in general was sparked by oral histories of shrapnel collecting that I stumbled upon in my archaeological work. I was familiar with the concept, in theory at least, from the writings of Robert Westall and The Machine Gunners in particular: in the aftermath of air raids children would collect up the bullets, casings, fragments of shell and bomb that they found in the streets, and trade these fragments among their friends (Westall 2001). During my archaeological work on a range of Second World War sites in London, I carried out a programme of oral history interviews that aimed to use sites and artefacts as stimuli for reminiscences (Moshenska 2007b). The overwhelming majority of my interviewees, more than 90 percent, had been schoolage children at the start of the Second World War in 1939, so my questions focused on their memories of life on the home front including rationing, evacuation, war work and experiences of bombing. In discussions of socializing, play and everyday life in wartime a large number of the interviewees talked about their own memories of collecting shrapnel from the streets after air raids and trading the pieces for other fragments or for other toys or collectables:

When the sirens used to go we went into the shelters, and when it was all clear we used to come out looking for shrapnel come down in the streets still hot. You picked it up in your hands and it was still hot, where it was come from the guns ... you used to have the ack-ack guns driving round in the streets ... they couldn't do much, I suppose it was more for morale. You see they were shooting at the planes, and when those shells explode the shrapnel's got to come down hasn't it ... take it home, swap it around with the kids, 'give you my bit you give me that bit' ... I wish I'd a kept it, all the stuff, but you don't, do you?

(Interview with HA, Moshenska 2007b)

When the ack-ack ... where they were trying to shoot the bombers down, and the shells would explode, high up and shatter into smithereens, and that was called shrapnel, because it was all weird and wonderful shapes, and you could hear it come down on the roof, and you would hear a sort of tinkling sound in the evening when you were listening to the radio ... the next morning you go out in the garden, search for shrapnel, put it in a shoebox, and bring your best pieces to school and compare, yes it was like jewellery, you'd all be comparing your shrapnel.

(Interview with TS, Moshenska 2007b) 


\section{8}

Collecting shrapnel

These narratives chime with previous accounts in oral histories of the Second World War: 'As kids, we tried to find shrapnel. We'd find nose cones from shells and take them into school next morning like they were prizes. Even the teachers got excited - "where did you find that?" It was an adventure.' (Levine 2006: 409) (Figure 2.1). It became increasingly clear that shrapnel collections became the basis for a range of practices including displays, 'bragging rights', gifts, and trade and exchange and that these practices, like many aspects of childhood play, served a range of purposes including self-fashioning, socializing, learning and wellbeing. I learned that alongside shrapnel, children in the Second World War collected a wide range of war memorabilia including bullets and other munitions; buttons, badges and military insignia; fragments of crashed aircraft and an assortment of military-issue equipment gifted, traded and stolen from, or abandoned by, servicemen and women.

During my interviews with children of the Blitz, the significance of shrapnel collecting was highlighted by a number of intriguing factors and recurring themes: the roughly even numbers of men and women who remembered collecting shrapnel; the apparent near-universality of the practice and the vividness with which interviewees could remember individual items in their collections. Shrapnel collecting was evidently an important part of a wartime childhood, and

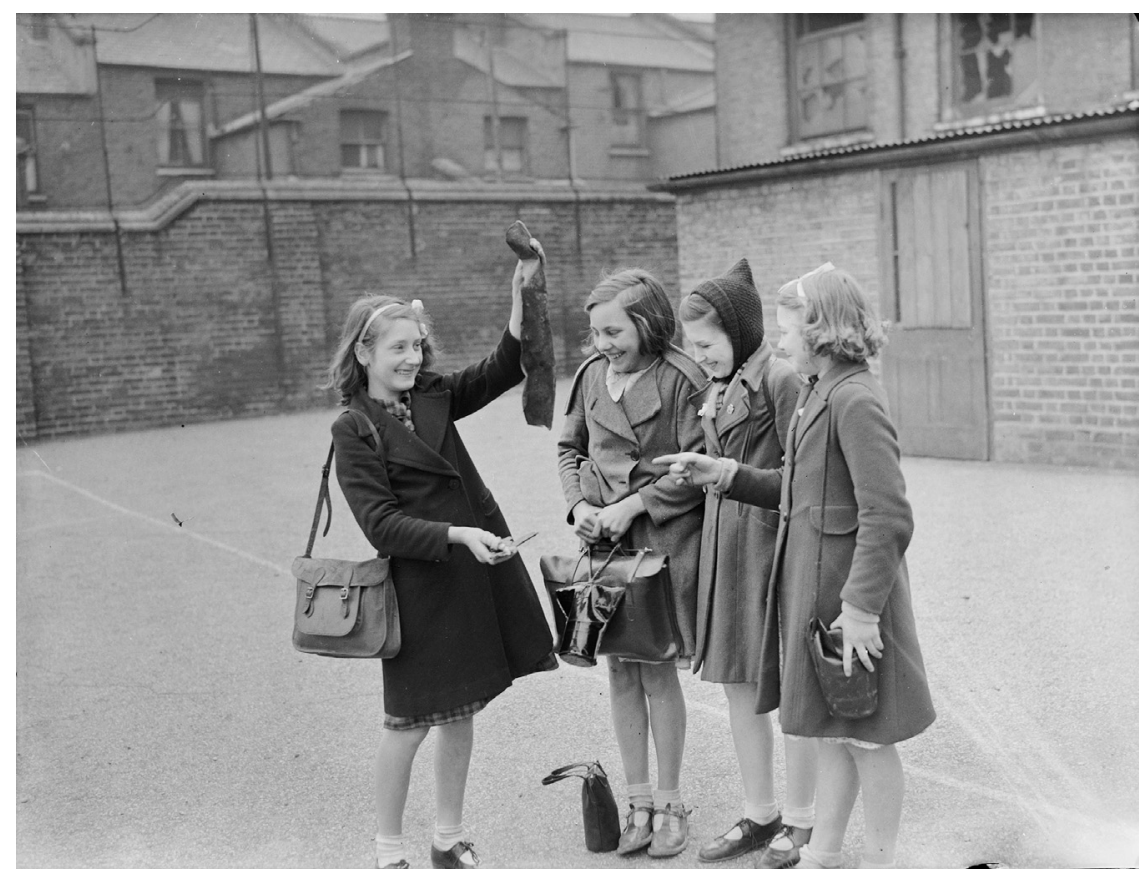

Figure 2.1 Pupils at Calvert Road School, South East London, admiring a fragment of metal collected after an air raid. Note gas mask cases. (C) Imperial War Museum, D 3160. 
compared to carrying gas masks and other impositions, it was a form of interaction with the material culture of warfare that appeared to have been driven entirely by the children themselves. This preliminary work indicated that shrapnel collecting was qualitatively different from other forms of collecting that children of this period routinely engaged in and that shrapnel collecting might have been above all a coping mechanism, a means for children to control or domesticate the material culture of violence by integrating it into their social practices and thereby negating its violent and alien qualities. It appeared that collecting shrapnel and other souvenirs was, amongst other things, a way for children to feel actively involved in the world-at-war on a par with the adults around them.

During my initial studies of shrapnel collections in Second World War Britain I found accounts of similar practices in other conflicts, other places and other periods, including 1980s Lebanon and contemporary Palestine. I have since spoken to people who spent their childhoods in conflict zones and have found numerous similar accounts of collections of bullets and mortar shell fragments, and practices of exchange and risk-taking behaviour that closely mirror those of wartime Britain.

\section{Children and collecting}

We collected bits of aircraft, shrapnel, nose cones from shells and the fins of incendiary bombs as boys these days collect 'Pokemon' cards and the like.

(Polley 2003)

As kids, we would collect the usual things like stamps, cigarette cards, conkers, and marbles. Also wartime collectables like shrapnel.

(Payne 2003)

The practice of collecting, the nature of collections and the character of collectors have been extensively studied by historians, anthropologists and sociologists from a range of different perspectives including examining collecting as a leisure activity, as a form of consumer behaviour, and from the perspective of the histories of antiquarianism and of museums (e.g. Baudrillard 2005; Belk 1995; 2006; Martin 1999; Pearce 1995). Collections have been interpreted in relation to cultures and practices of consumption, display and the creation of identities as well as through a range of psychological models. Research into collectors, collections and collecting offers a rich variety of entry points for studies of material culture: however, despite the rich and complex culture of the playground, along with the ever-increasing importance of children as consumers in society, there is surprisingly little contemporary research focused specifically on children as collectors (cf. Baker and Gentry 1996; Belk 2006; Cook 2001).

Danet and Katriel's influential study of adult and childhood collecting practices noted the paucity of research on child collectors after a brief boom in the 1920s and 30s (Danet and Katriel 1994a: 221). This earlier work, based on surveys carried out in the United States, is a valuable resource in the 
present context, particularly as it is relatively close in date to the Second World War (e.g. Whitley 1929; Witty and Lehman 1931). These studies examined patterns including the peak ages for collecting, gender variations in types and numbers of collections, different forms of acquisition and stated reasons for collecting (Whitley 1929: 260). Whitley's study includes 'pieces of metal' as a category of collection, and shows this to be an overwhelmingly male interest (Whitley 1929: 256), while Witty and Lehman's survey shows interest in 'objects associated with war' to be a popular and again an almost completely male phenomenon (Witty and Lehman 1931: 224). Both categories are to some extent useful analogues for shrapnel collecting. Belk contrasts early twentieth century children's collections with the results of more recent studies to highlight a move away from found objects such as seashells, buttons and stamps, popular in the 1920s and 30s, towards manufactured collections such as dolls, stickers and trading cards (Belk 1995: 54), although this may be a broadening of opportunities rather than a direct replacement.

Childhood and adult collecting practices differ in a number of ways: children tend to take a more hands-on approach to their collections than adults; carrying them around, handling them and allowing others to sort through them as a form of display (Gabriel 1974: 264-5). This introduces an inevitable element of entropy as cigarette cards or trading cards become dog-eared, fragile trinkets get scratched or worn out, and light-fingered acquaintances make off with prized items. The most important corollary of this is that for children collections are overwhelmingly social things - a means of interacting with others and of expanding their social spheres. Walter Benjamin recognized that children's collecting habits are subtly different with a tendency to touch, name and modify the objects in their collections more readily than adults (Benjamin 1999: 63). As Classen observed, the once common practice of touching and handling museum collections has virtually died out: 'the one kind of museum that consistently caters to the sense of touch in modernity is the children's museum' (Classen 2005: 284).

The relationship between material culture, memory and the senses is central to this book as a whole, and the accounts of shrapnel collecting from the People's War project archive provide insights into the powerful and distinctive aesthetics of shrapnel. While the collecting practices might have been sparked by the availability, variety, portability and durability of shrapnel, the factors that affected its value and its mnemonic impact are far more diverse. Shrapnel was a multisensory object that was heard, seen, smelt, touched and that could be experienced in transformation from hot and lustrous to cool and dull. The sensory dimensions of shrapnel collecting are considered in more detail below.

The theory that collecting can be a coping mechanism for children in traumatic environments is based on an understanding of collecting both as a social practice and as a process of ordering and controlling chaotic material culture. Baudrillard states that 'For children, collecting is a rudimentary way of mastering the outside world, of arranging, classifying and manipulating.' (Baudrillard 2005: 93). Belk agrees that 'By providing physical control of the 
objects in a collection, the 'illusion of control' ... of broader physical domains, people, and knowledge may occur' (Belk 1995: 70). In more general terms, Danet and Katriel argue:

Collecting is imbued with the theme of control, articulated both as striving towards controlling and as the fear of being controlled. A collector gains control over the objects that comprise his or her collection through the power of ownership, which is actualized in the right to handle, rearrange, and even sell items in the collection.

(Danet and Katriel 1994b: 32)

Pearce has suggested that collecting can help people get through difficult processes of transition: she highlights the prevalence of children's collecting and trading during adolescence and in the recovery from bereavement or illness, as well as its role in creating social frameworks (Pearce 1995: 237). This is to some extent a development of Winnicott's theory of the transitional object in the cognitive development of very young children, as well as the common childhood practice of assigning power and significance to objects whose presence has a positive effect on the owner's emotional state (Muensterberger 1994: 9; Winnicott 1953). Muensterberger argued that collections are often substitutes for people: distant or absent parents, or general loneliness; a view echoed by Pearce, who also recognizes the active role of the collection and the objects that constitute it in accumulating experiences and memories, and in negotiating the collector's encounters with the world around them (Muensterberger 1994: 25; Pearce 1995: 237).

Exposure to warfare has a traumatizing effect on children, varying in severity according to a number of factors including age, gender and family and social support. Exposure to bombing has been shown to be particularly traumatic, exacerbated by expressions of fear by parents and other adults (Freud and Burlingham 1943).

Five years after the end of World War II, some 1,200 British schoolchildren who had been exposed to air raids were examined. Some 18 percent still showed disturbances caused or aggravated by the war experiences. They had war-related fears and nightmares, sleep disturbances, and exaggerated psychophysiological reactivity to sirens, loud noises, and explosions. That percentage is similar to the prevalence of post-traumatic stress disorder (PTSD) diagnosed in combat veterans of World War II and the Vietnam War.

(Werner 2000: 212-3)

For children, war is often experienced in terms of a heightened sense of powerlessness, and perversely a degree of freedom, amidst the chaos and change in their social and material worlds. In this context, 'the calming effects of the collection have to do with control: one retreats from a situation in which one has lost control to one in which the collector dominates - if 
possible, totally' (Danet and Katriel 1994b: 41). In interviews and studies of collectors, both adults and children, many have traced the origin of their collection and their drive to collect back to traumatic events in their childhood including bereavement, loss and war (Muensterberger 1994: 10).

\section{What is shrapnel?}

In the morning of course we would go round picking up the shrapnel and they were quite treasures: I don't really know what I thought they were, I just knew it was shrapnel.

(Davies 2005)

When the anti-aircraft guns fired at the enemy airplanes more often than
not they would miss, but the shell would explode high up in the sky where
it did little else but maybe frighten the pilots of the aeroplanes. However,
the exploding shell would send little pieces of metal flying everywhere and
these of course came down to earth again which is one good reason why
you never went outside during an air-raid. These pieces of metal were
known as shrapnel and they rained down out of the sky and were often
about the size of your fist. The Air Raid Wardens wore metal hats so that
they did not get hurt if some landed on their head. We would collect these
pieces and it was 'good' if you had more or bigger pieces than your friend!

(Marsh 2003)

Shrapnel is quite clearly defined in the jargon of ordnance and gunnery: a shrapnel shell is a hollow shell filled with metal shrapnel balls, often identical to rifle or musket projectiles, designed to explode in flight spraying shot across a relatively wide area. It was principally an anti-personnel weapon, developed in the nineteenth century by the British Army. However, during the First World War trench warfare rendered shrapnel shells obsolete and production shifted to high-explosive shells; gradually the word 'shrapnel' came to be used to describe shell fragments, although this common usage remains controversial (Blakely 1952).

Amongst the children of the Blitz there is some disagreement about what constituted shrapnel. For most it was specifically the fragments of exploded antiaircraft shells, while for others it was a broader category incorporating bomb fragments, pieces of crashed aircraft or V1 flying bombs, bullets and even complete incendiary bombs. While all of these objects formed parts of many children's collections, shrapnel from anti-aircraft shells would have been the most common finds, and most likely this became a simplifying general term.

I suppose the real problem in these matters is that what goes up always comes down. Most of the shrapnel we collected started off as shells being fired up into the night skies by our own anti-aircraft guns and then coming rattling down on the tiles of our houses.

(Brownbridge 2004) 
A typical gun such as the British 3.7 inch could fire its 28 pound $(12.7 \mathrm{~kg})$ shells to 36,000 feet (11,000 metres) at a rate of 20 a minute (Routledge 1994: 87). Exploding at a predetermined height or flight-time, these high-explosive shells were transformed into clouds of shrapnel; hundreds of steel shards effective at a radius of about 20 metres (Wells 1995: 43). These sharp-edged, red-hot chunks of metal were capable of ripping through the fragile aluminium skins of aircraft into engines, cables, pipes, fuel tanks and crew members to destroy, damage or disable.

British AA Command was mobilized in the run-up to war, and emergency production of AA artillery began. However, by June 1940 the total of 1,204 heavy guns and 581 light guns for the whole country was pitiful, and fell far short of the planned 2,232 and 1,860 respectively (Overy 2000: 46). During the Battle of Britain anti-aircraft command estimated a hit-rate of one aircraft destroyed for every 2,444 shells fired; this was later revised to one in 1,798, a slight improvement (Harrisson 1976: 100). The shell fragments that missed their targets (and many that hit) fell to earth, landing on roofs, gardens and streets. On the unfortunate occasions that shells failed to explode at altitude, they were as deadly on their return as a falling bomb, or as problematic as any unexploded ordnance in an urban area. Bombing maps of the period show the frequency of these occurrences: along with the 1,493 bombs that fell on the borough of West Ham in London during the Second World War, some 201 anti-aircraft shells landed, with more than half of them exploding on impact (Demarne 1980: 52-3).

In comparison to other mass-produced commodities, the life of a shrapnel fragment followed an unusual trajectory. The high-explosive shell is more usually associated with the First World War, in which hundreds of millions were fired on all sides. Saunders' study of the cultural biographies of these artillery shells explores the relationships between people, the things they make and use, and the worlds they create:

Rich in symbolism and irony, shells were the mediators between men and women, soldiers and civilians, individuals and industrialised society, the nations which fought the war, and, perhaps most of all, between the living and the dead.

(Saunders 2002: 22)

Anti-aircraft shells in the Second World War were considerably less iconic, except perhaps to those who remembered the First: shrapnel falling nightly from the sky may have had an adverse impact on the mental health of shellshocked Great War veterans. In the manner of their use, their general ineffectuality and their physical remnants, the cultural lives of anti-aircraft shells mirrored those of the shells of 1914-18. First World War shells transformed industry and the social status of women in their production and shattered landscapes and men's bodies in their use; their fragmented steel remains mingled with the churned mud of the battlefield (Saunders 2002: 53-5). In 
contrast, anti-aircraft shells in the Second World War were produced on a relatively modest scale, as armament production focused on aircraft manufacture, and in their intended use caused few casualties. In their shattered, spent form they achieved far greater significance, mediating in the relationships of children to adults, to their peers and to the world around them.

As a collectable commodity, shrapnel is distinctive and peculiar. Some collectables such as trading cards or souvenir medallions are manufactured as collectables, while others such as belt buckles and toy animals are primarily created for other uses. There is an important distinction in collections between those such as football stickers which offer the possibility of completing a collection, and others such as stamp collections where the variety is too vast and ever-increasing to hope for anything even approaching a 'complete' set. Virtually all of these manufactured collectables are purchased by the collector, or in the case of childhood collections often purchased and gifted by family or friends. In contrast, collections of natural objects such as sea shells, fossils, conkers, pressed flowers, butterflies and other natural history specimens are often available for free (at least to the original collector), and most present a near-infinite set of minor or major variations in colour, size and form. They are typically collected outdoors as part of dedicated collecting trips.

Shrapnel from anti-aircraft shells does not fit easily into these categories. While shells are mass-produced to identical standards in dedicated factories, shrapnel is both manufactured and distributed by violent explosions at high altitudes. Shells do not burst uniformly or predictably, and the fragments of steel and brass created in these explosions vary considerably in size and shape. While the shells are smooth-sided with regular curvatures the shrapnel fragments show signs of the tearing and fracturing of the metal by the interior explosive charge, and some display iridescent colours like oil stains caused by the heat. Like conkers falling from trees, shrapnel fragments are picked up where they fall. Also like conkers, when first found they display a shiny surface that soon dulls over the following days. Like any other product of nature shrapnel displays an infinite diversity, and like sea shells or beach pebbles it cost nothing to pick up and take home. Possession of a particularly fine piece of shrapnel did not necessarily signal the wealth, status, or any skill or innate ability, although possession itself could impart status. In short, shrapnel is curious and distinctive in its close resemblance to natural rather than manufactured collectables, and in the equitability of its distribution. Free, abundant, endlessly diverse and continually in production, shrapnel was a perfect collectable for children of the Second World War.

\section{Collecting shrapnel}

The accounts of shrapnel collecting from the People's War project archive describe a range of practices and activities, but there are a number of common threads running through them, and I want to explore some of these in the following sections to build a clearer picture of this corner of the material world of wartime childhood. 
By the time the Blitz on British cities began, the Luftwaffe had largely shifted to night raids to reduce their losses in aerial combat. This caused less disruption to work and schooling and meant that most families were at home or in their air raid shelters when the anti-aircraft guns began their nightly programme of shrapnel-creation. Collecting shrapnel was therefore largely a morning activity:

After night time raids - because most of them seemed to be night time - I would often go out the following day to collect shrapnel from underneath the front garden hedges up and down the road in Montpelier.

(Hollier 2005)

The next morning, as always following an air raid, we would be out with our little carts scouring the bombed areas looking for the spoils of war. We would collect shrapnel, spent bullets and indeed any pieces of shining metal.

(Copeland 2005)

The morning after a raid we would make our way to school noting which streets had been hit, and carefully looking for shrapnel from the ack ack shells, it was still very warm!! This was used as a kind of currency at school, the most prized of which was a shell nosecap.

(Long 2003)

As described here, most shrapnel collecting took place on the morning walk to school, scouring streets, gardens, parks and any other open spaces. Some used 'little carts' mentioned above, others took their bicycles or even wheelbarrows to retrieve larger or more plentiful trophies. Others were even more imaginative: 'One day we found Jackie Cockerill riding his small tricycle about with a large magnet tied on a string behind, vainly hoping thus to collect any shrapnel which might escape his observation.' (Hill 2005a). The accounts above also begin to hint at the elaborate and apparently sui generis frameworks of value and exchange that governed the social world of shrapnel collecting. For some in the competitive world of shrapnel accumulation, the walk to school was too late, and several accounts describe making an early start: 'The highlight of the day after the raid was for my sister and I to go out early, before going to school to collect shrapnel, the bigger the lump, the better' (Peacock 2003). The early birds with the best chances of catching the shrapnel 'worms' were newspaper delivery boys whose schedule, coverage of larger areas and handy newspaper bag gave them a strong advantage:

One of the perks of delivering newspapers was that being out early we paperboys could pick up any war souvenirs left from the previous night's air raid. For example, we might come across the remains of an incendiary bomb, or more commonly shrapnel from anti aircraft shells. Often this was still hot and had to be handled with extreme care. The satchel for carrying the papers could end the round heavier than it began if the 
souvenir collection was plentiful. Bartering and swapping bits of shrapnel was a fairly regular schoolyard activity.

(Rich 2005)

My brothers and I were avid collectors of wartime souvenirs and we also became junior pyrotechnic experts. We helped older kids with newspaper rounds, getting up at 6 a.m. to collect items of shrapnel, which littered the local streets after a night of bombing.

(Scott 2003)

Not all schools were happy with their students arriving each morning weighed down with scrap metal: 'If we were caught with shrapnel in our pockets we were caned.' (Woolard 2004). There was a powerful and by no means unreasonable concern that children's curiosity about shrapnel and associated souvenirs was putting them at risk from unexploded ordnance and cluster munitions, discussed in more detail below, but the result was that many schools imposed bans on shrapnel collecting or trading in school hours and on school property: one account describes a 'big steel bin' placed outside the headmaster's office to collect the forbidden finds (Woolard 2004). The hazards presented by shrapnel are illustrated by the efforts of one school to remove it from their playing fields:

To find this shrapnel, we would line up across the playing field on our hands and knees and proceed along the field picking it up for subsequent removal and re-use in the war effort. If you missed any, your knees would be cut to ribbons - I still have the scars to prove it, even after all these years!

(Hewson 2004)

For those enthusiasts banned from collecting in the mornings, there were two options: wait until after school to begin the hunt, or collect the shrapnel on the way to school and stash it somewhere safe until it could be collected:

Walking home from school was always exciting because it was then that I would collect the bits of shrapnel that I had found in the street on the way to school that morning and which I had hidden in the front garden hedges of certain houses en-route. I never used the gardens of elderly gardeners as they would be sure to find my treasures as they clipped their privets.

(Anon. 2005a)

The violence and dangers of the hot steel rain of shrapnel presented hazards to anybody caught outside in an air raid, but this did not necessarily deter the more committed collectors. British soldiers on the Western Front during the First World War were known to venture out into no-man's-land during quieter moments in the conflict to collect shell nose cones. These sometimes contained aluminium and other components that could be carved into rings or crafted into other decorative products: one account from the time 
compared the soldiers to children building sandcastles on a beach (Saunders 2003: 131). While less hazardous than the Western Front, the shrapnel-showers of wartime air raids caused considerable numbers of casualties. In light of this, it is remarkable but perhaps unsurprising that some children would venture out in air raids precisely to collect shrapnel as it landed:

by then, with daylight raids and more than one 'alert' each night we were becoming a bit blasé, and rather stupidly coming out to collect fallen shrapnel, to show off at school - 'who's got the biggest piece?' ... Our shrapnel collecting game became even more stupid (on hindsight) for we now were standing out, watching for the tell-tale red hot lumps arcing down, dashing off to find it before 'it went out', and then the 'dare' to see who would pick it up first, and thus claim it.

(Noden 2005)

The description of shrapnel going 'out' presumably describes the fading of its red-hot glow to the point where it was almost safe to touch. Other equally hair-raising accounts describe children standing in the doorway of the air raid shelter to be able to spot the sparks made by the fragments of shrapnel hitting the ground, so they could retrieve them as soon as the all-clear sounded.

What did the typical shrapnel collection look like? Several accounts describe motley collections of shell-fragments and assorted other pieces of metal from the sky: 'We started collecting souvenirs. These were pieces of shrapnel, incendiary bomb tails, bits of shells, pieces of flares, machine gun bullet clips, etc. Each boy had a 'box of bits' some of which were quite heavy and razor sharp.' (Dart 2005). These boxes of bits were often tobacco tins or similar: 'I had a sweet-tin about 8'x5'x2' deep, full of shrapnel and fuse-rings, which made it very heavy'; 'At home, I had a whole box for my shrapnel collection in my toy cupboard.' (Hill 2005b; Cuthbert 2004). For the sake of portability some children began using their gas mask cases to carry their most prized shrapnel around, while others carefully assembled used cartridge cases and pieces of the disintegrating link belts for machine gun ammunition to make bandoliers of ammunition to wear or to display (Hawtin 2005; Long 2005) (Figure 2.2). In some cases, the collections outgrew their tins or boxes: John Martin recalled:

My brother and I collected trophies, bits of shrapnel, .303 rounds, fragments of crashed aircraft and we kept these in a small lean-to workshop that my father had built for us. We also collected unexploded ammunition until my father found it, called in the bomb squad and afterwards, placed our collection under strict surveillance!

(Martin 2006)

Along with model aircraft and homemade propaganda posters, shrapnel and fragments of military material culture were a popular subject for small displays or exhibitions, sometimes held formally in shop windows or by scout or 


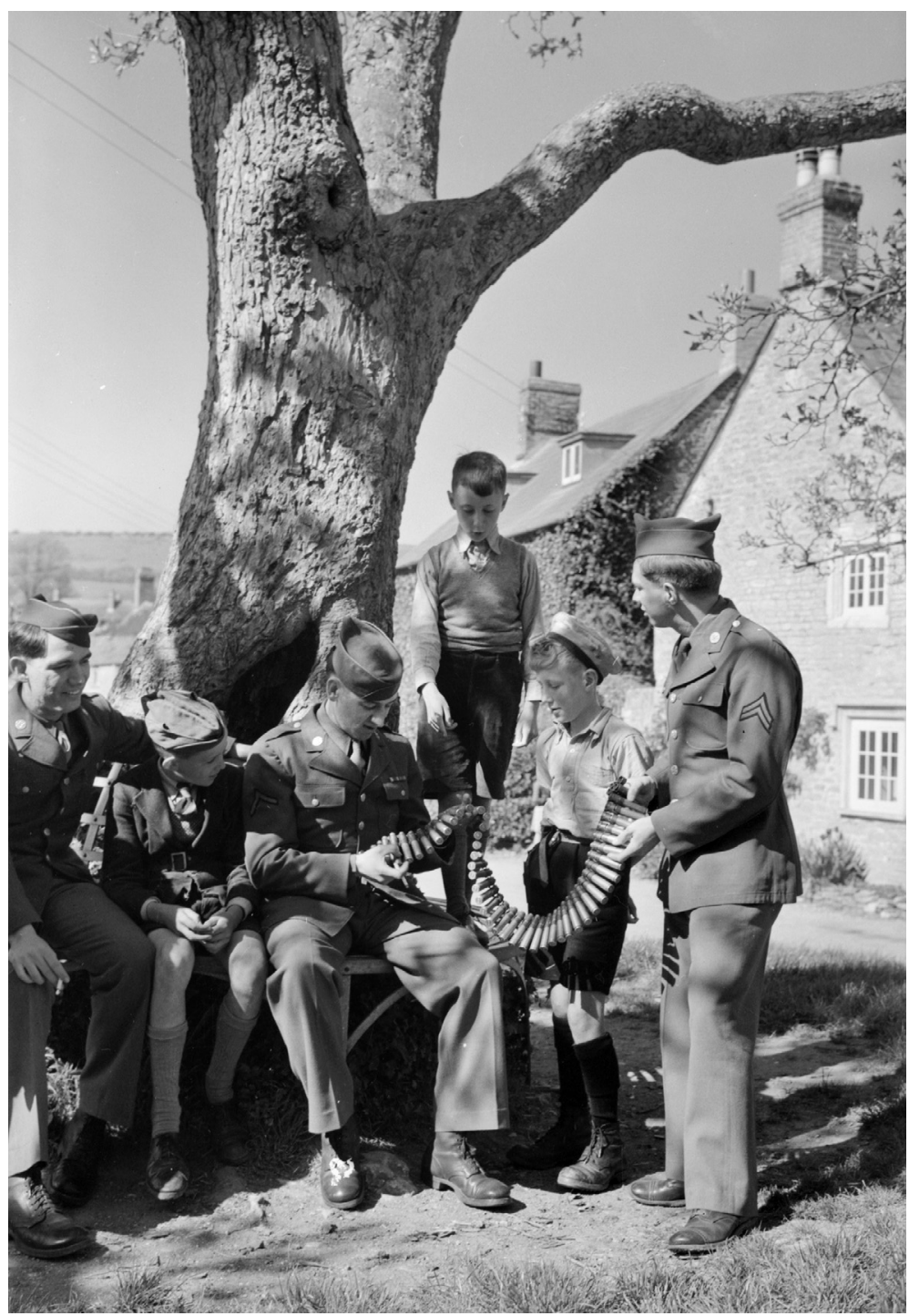

Figure 2.2 Children in Burton Bradstock, Dorset show American servicemen a machine gun belt that they had found on the local beach. It appears to be $.50 \mathrm{BMG}$ cases with M2 links. (C) Imperial War Museum, D 20122.

cadet troops as fundraising events for the war effort. Some were more informal but born of the same patriotic enthusiasm:

My friends and I collected bits and pieces from planes, shrapnel from shells, bullets from planes, etc. We held an exhibition in our shed, 
charging admission, the proceeds of which went to a war charity. There was no shortage of items for the exhibition!

(Whitehouse 2005)

As discussed earlier the collections of bullets, other souvenirs of war and scraps of metal in the United States in the early 1930s was an overwhelmingly male activity. It is interesting to note the contrast with shrapnel collecting and some of the contradictions in the evidence. Some of the narratives describe shrapnel collections as specifically male: 'All small boys had shrapnel collections' (D. Jones 2003a). Some girls took a business-minded approach:

We used to go out in the streets in the day and pick up shrapnel - bits of crumpled metal ... the boys used to think it was souvenirs. We girls weren't that much interested, but we used to collect it for the boys you know, every bit you had 'You give me that and I'll give you a sweet' you know ... that's the kind of thing we used to do with shrapnel - you want it - you give us one of your sweets.

(John 2005)

Despite this, women's first-hand accounts of shrapnel collecting during their wartime childhoods make up around one-third of the accounts in which the gender of the interviewee can be discerned. In several of these narratives the practice of shrapnel collecting is presented as clearly non-gender specific: 'us kids would go around collecting shrapnel'; 'It was something that all the children in my area did' (Townley 2005).

\section{Trade and exchange}

Shrapnel as material culture came to life in the lively economic market of the school playground, with elaborate networks of gifting, alliances, trade, barter, theft and fraud:

We, the children, passed the time playing such games as Kings, Hop-Scotch and Rounders, and in the early mornings we combed the side-streets on eighteen-inch wheels for pieces of shrapnel and the brass nose-cones of shells hurled aloft from the gun emplacement over in Costello's fields. The hotter the exchanges the night before, the greater our harvest, and many a large fragment of metal became the object of a swap, a bribe or a bullying. I was as cunning as a fox and as ruthless as a French general in those days; and I was afraid of nothing.

(Whitehead 2005)

The trade in shrapnel took various forms: sometimes it served as an opportunity to flaunt one's collection or a particularly prized item and to see what others had accumulated. Descriptions of shrapnel swapping often waver between the warmly 


\section{0}

Collecting shrapnel

social and the coldly economic, but in practice the two were never clearly defined. Like winning the lottery, a chance find could transform a child's status and power. David Robson encountered a huge pile of bomb shrapnel close to a bombed railway line, the large casing fragments twisted and coloured by the force of the detonation. Robson rushed home for a wheelbarrow to transport these treasures, anticipating the impact of this find on his schoolyard status:

Deals could be done and bargains struck with friends in exchange for other items of memorabilia. We all had keepsakes from convoys of soldiers passing along Elson Road for embarkation at Hardway, a quarter of a mile away. This could put me in a very favourable position, I thought to myself.

(Robson 2005)

Unfortunately for Robson his collection was confiscated by a policeman guarding the bombsite, as he reflected ruefully: 'I never did make it as a Wheeler Dealer'.' It is notable from many of the accounts in the People's War archive that the passage of time has obscured some of the intensity and sense of urgency around the shrapnel trade, leaving people wondering what all the fuss was about: 'Useless great chunks of metal really. We kept them in boxes for 'swapsies'. The things kids do.' (Nicholls 2005). Others try to contextualize their childhood shrapnel collecting in more familiar or modern terms by comparison with other forms of collecting: 'We used to collect shrapnel and there was a whole trading network going on, a bit like trading cards today.' (Burchmore 2005). Others compared shrapnel collecting and the practice of 'swaps' with stamp collecting (Bignell 2004) or conker collecting (Goodfellow 2005): the latter in particular resonates with the concept of shrapnel as a seemingly natural phenomenon, falling from the sky and quickly losing its original lustre.

Most anti-aircraft shell shrapnel was made up of the body of the shell: a low-quality steel that corroded quite enthusiastically and fragmented into a variety of ferocious shapes. Aside from this, many shells had a copper or copper-alloy 'drive band', a ring that engaged with the rifling grooves of the gun barrel to ensure obturation: fragments of these drive bands also became part of the shrapnel, but in relatively small quantities. Finally, the tip of the shell was made up of the fuse, most commonly a timer device pre-set so that the shell would detonate at a specific altitude. These were made up of various components including brass fuse rings with measurements marked on them: sometimes the entire fuse would be found intact, but more often the fuse rings or fragments of them were amongst the shrapnel picked up in streets and gardens. Each piece of shrapnel had a relative value based on a variety of factors:

A keen interest of my friends and I after raids was to collect shrapnel from the roads and gardens. We gathered masses of it and competed for the best piece. This was the largest and shiniest bit ... The very best and rarest piece 
was the remnant of a time-fuse, conical in shape with graduation marks around the surviving part of the circumference.

(Mundy 2003)

The fuse or nose cone of the shell was described as 'the prize': 'If you found the nose cone of a shell this was in the big league, a prized possession.' (Jacobs 2005; G. Johnson 2005). Some of the excitement of such a find can be heard even 60 year later:

My prize exhibit was a nose cone with three fuse band rings still attached. Yes, that's right, THREE! There were a few about in the various collections with two, but THREE! I had it because it came down in our back garden, narrowly missing my father, and I was the envy of many of my friends.

(Bill 2003)

Second in value to nose cones were individual pieces of the brass fuse or drive band: 'On arrival in the playground, we used to barter it, aiming to collect the best-shaped pieces, and especially brass, because it didn't rust.' (Cuthbert 2004). Other accounts refer to brass fragments as 'a special treasure' (Hill 2005a), while another states more specifically that 'In our street, one brass piece could be swapped for four or five silver bits. If there were markings of any kind on your shrapnel, you could have your own auction to secure the best price in other pieces to add to your collection' (van Gelderen 2003). Another agrees that 'It was good if it had a number on it.' (Fletcher 2005).

The market in shrapnel was not a closed one, and many of the narratives of trade and exchange show an overlap with other categories of collectable, both war souvenirs and other more common children's interests such as sweets and comics. The boy who brought a piece of crashed Dornier bomber into school was remembered as 'the envy of the class' (Dawkins 2004), while Mike Westcott recalled that 'On the way to school we would pick up shrapnel, which was sometimes still warm, and swap it in the playground for cigarette cards.' (Westcott 2005, and see also Taylor 2005). Shrapnel was a currency that could be obtained at no cost and exchanged with other children for items of more fixed economic value: in this way children could obtain toys or treats that they might otherwise have been less able or unable to afford: Arnold Long noted that 'I had a good stock of old Beano's and Dandy's because of my shrapnel collecting. A couple of big lumps were worth a comic.' (Long 2005). Ed Anderson agreed:

The rest of the boys of my age who were in the same class as me who had not been evacuated were full of war souvenirs such as pieces of shrapnel and badges from soldier's uniforms where they could get them. Billeted next door to us were two soldiers, one a Scottish chap called Jock, who was in the commandos and the other was an American who used to give 
us American comics which were like gold dust. If you had an American comic to swap you could get the largest piece of shrapnel going.

(Anderson 2005)

\section{Sense memories of shrapnel}

Accounts of shrapnel collecting in the People's War archive provide a vivid insight into children's encounters with material culture in general, and material cultures of conflict in particular. One of the most significant recurring themes in these memory narratives is the multisensory nature of children's encounters with shrapnel and how this affected not only their experiences of shrapnel but also the unstable and fleeting values that they placed on it, the life histories of shrapnel collections and the sense memories of shrapnel that endured from childhood into old age. I want to explore the full range of these sense memories in more depth to consider the social lives of shrapnel in wartime Britain.

Children's first encounters with shrapnel were most often as sounds: the firing of anti-aircraft guns, often close by, and the more distant detonation of their shells. As it fell to earth, shrapnel whistled through the air, tinkled on rooftops or crashed into roads. The desire to be the first to collect the finest pieces of shrapnel sometimes tempted children outside in air raids, particularly when there was a promising sound: 'We would hide in our houses during raids until a particularly loud clang indicated a "good" bit had landed in the road and then rush out to get it.' (Blanchard 2003). This desire for 'fresh' shrapnel understandably terrified parents:

I would often sneak outside to collect shrapnel which I could hear falling all around me - some of it was still warm when I picked it up so I must consider myself very lucky to have survived these expeditions but in those days nothing seemed to matter or frighten us. My mother gave me a good telling off when she found out that I'd been doing this. She must have been worried sick.

(Atkinson 2003)

Atkinson's account raises one of most curious aesthetic dimensions of shrapnel collecting: the widespread fascination with collecting shrapnel that still retained heat from the detonation of the shell: 'it was best and most valuable if the shrapnel was hot' (Grant 2004). Hot shrapnel was described as 'the real prize' or 'a bonus [that] made us the envy of all the other kids' (Peacock 2003; Purchase 2005). The sensation of hot shrapnel is one that several accounts recall: 'My brothers used to go out hunting the streets for shrapnel which was still warm. I remember I used to ask them for it and the feeling of warmth from it in my hand.' (Skinner 2004). Sometimes when discovered it was too hot to touch, and minor burns were common: 'At first we made mistakes trying to pick up bits that had only just fallen and were nearly red-hot but once bitten twice shy.'; 'It was often a dangerous practice to pick up shrapnel shortly after an air raid, as it was very hot and could burn the skin.' (Blanchard 2003; Hunt 2005). Like many sharpeyed young people, Bryan Burchmore had his eye on a particularly fine piece of shrapnel from the moment it landed and determined to get it: 
One day I was standing in the doorway to a shop when shrapnel began pouring down out of the sky. I remember one particular piece caught my eye, it was so bright and shiny and stood out from the rest. My aunt happened to be rushing past and she grabbed me and dragged me indoors to safety. Once the shower of metal had stopped, I ran out and grabbed the piece I'd had my eye on, it was so hot I burnt my hand in the process. I got such a telling off afterwards for just standing around staring amidst all that dangerous falling debris, as well as for burning myself! It was such a good piece though that it was worth it all!

(Burchmore 2005)

This obsession with the freshest and hottest pieces of shrapnel indicates a connection between value, the practices of collecting and displaying one's collection, and a sense of bravery, risk taking or having 'been there' amidst the worst of the bombing. Like so many values of commodities, this could be faked: Keith Robinson recalled that

There was great rivalry to see who could collect the largest piece of shrapnel after an air raid ... and even greater rivalry existed to see who could find a warm piece as this would be significant in it being from a recently exploded bomb. We then discovered that some clever kids were heating old pieces in the oven before coming into school!

(Robinson 2003)

The residual heat in shrapnel was a temporary quality, and fakes aside it cannot have been a factor in the protracted exchange processes that several of the interviews refer to. This aspect of value transcends the generally tactile nature of children's collections noted by Walter Benjamin, moving towards a more embodied approach to objects that corresponds with Howes' idea of 'skin knowledge ... the knowledge of the world one acquires through one's skin' (Howes 2005: 27). Howes observed that in the modern Western city children have considerably more physical contact with their environment than adults do (Howes 2005: 29). In this context the sensorial approach to shrapnel takes on greater significance as a child's way of knowing the world.

Another aspect of shrapnel that attracted young people, magpie-like, was the bright colour and iridescent shine of many of the fragments: 'The high temperatures experienced during the explosions sometimes produced beautiful rainbow colours on the metal, contrasting with the horrible twisted shapes and the evil intent of the munitions.' (D. Jones 2003). The heat of the explosion left steel shell fragments with a rainbow sheen like a layer of oil, and this was mentioned in several of the accounts, where shrapnel is described as 'Twisted and jagged lumps and clumps of metal with some glistening in all the colours of the rainbow ... Great care was taken to select the brightest and most colourful specimens.' while another simply says that 'some of it was really beautiful.' (Chance 2005; Robson 2005). Interestingly this brightness 


\section{4}

Collecting shrapnel

and colourful surface effect on the steel shrapnel fragments was only temporary: 'I had a large collection, but they soon rusted and were considered commonplace.' (Mann 2005). Some lost interest in collecting altogether:

During the early days of the Blitz, us messenger lads, (and most other lads I should say in the London area) we used to collect the shrapnel and keep it in cigarette tin boxes, as the pieces were tiny and very shiny. After a few weeks we lost interest 'cause the shrapnel became rusty - so we didn't bother anymore.

(B. Kendall 2005)

As with colour, the size of the fragments and their ferociously sharp edges were also factors in their value and desirability: 'the bigger and more jagged' or 'The more they were distorted and bent the better' (Berry 2003, Robson 2005). The sharp edges of the shell fragments had downsides as well: several accounts recall scrapes and cuts from shrapnel, and one noted that it 'made big holes in our pockets' (Bolton 2005). Inevitably, larger pieces were worth more than smaller ones: 'It was very prestigious to have the biggest and best bits of shrapnel and bomb' (Anon. 2005b); some gangs would decamp to the corner shop and weigh their collections of fragments to see which was biggest: a large piece could be traded for two or more smaller ones (Pollard 2005; Barnett 2003). One man recalled: 'I found a piece about eighteen inches long and everyone in school was jealous.' (Woodward 2003). Scientific studies of the detonation and fragmentation of 3.7 inch anti-aircraft shells carried out during the war showed that the vast majority of the resulting fragments weighed less than a quarter of an ounce, approximately seven grams, with only a small handful from any one shell weighing in at more than four ounces (about 113 grams) (Mott and Linfoot 2006 [1943]).

Even more fleeting than the warmth of shrapnel fragments or its iridescent colour was its smell: several accounts describe freshly picked-up pieces smelling of cordite, or 'the pungent odour of the burned TNT' (Mundy 2003). Cordite was the propellant used to fire the shells, while TNT and various other high explosives formed the charge inside the shell itself. As with gas masks, air raid shelters and other material cultures of conflict, the link between smell and the memory of shrapnel is a strong one: 'The smell of sulphur on the casings of these shells is something I shall never forget; it must have been imprinted.' (Woolard 2004).

From these accounts shrapnel emerges as a powerfully sensory object and one in a state of ongoing transformation: freshly forged it shines iridescent, giving off heat and a distinctive smell. There are risks in collecting: it can burn and its sharp edges can cut, but these same characteristics give it value. Over time it transforms: first the smell and then the heat fade from the fragments, the colours dull and finally the whole piece becomes coated in rust, its value and relating interest declining at a similar rate. 


\section{Other metal from the sky}

Many of the values assigned to shrapnel were based on aesthetics, broadly defined, while others were based more on rarity and novelty. Here overabundance as with any commodity could lead to a collapse in the market, as Ken Roberts discovered with regards to the tailfins of incendiary bombs:

we found bomb nose cones and, of course, hundreds of incendiaries. Yes, hundreds. Those which landed in the streets were harmless enough and simply burned weird shapes into the tarmac of the road surface; only the tail fins survived as recognisable souvenirs because the body of the bomb itself was highly combustible, composed of a magnesium alloy. They, too, soon ceased to be souvenirs as we piled them up; only our school friends who lived outside the city tended to show any interest in them.

(Roberts 2005)

This account hints also at the geographical divides such as those between urban, suburban and rural that dramatically shaped children's war experiences in diet, relative safety and levels of trauma.

While shrapnel from anti-aircraft shells was by far the most plentiful of the post-raid souvenirs littering the streets, parks and gardens of wartime Britain, there were a variety of other rarer but still common finds. The one most often described in the memory narratives (such as Roberts' above) was the tailfin section of incendiary bombs. These $1 \mathrm{~kg}$ weapons were made of a magnesium alloy ignited on impact by a small percussion cap and a thermite primer, burning at a heat of over 1,000 degrees. Often dropped in combination with conventional high explosive bombs, incendiary bombs were intended to start larger fires, for example inside the wooden roofs of houses. A great deal of basic Civil Defence advice, training and equipment was devoted to the disposal of these bombs, with buckets of sand to put them out, dustpan-like devices on long handles to pick them up and move them to safety and stirruppumps to put out the resulting fires. The incendiary bomb had no case, it was merely a tube-shaped cast of magnesium alloy, and when burned it left no trace. However, to stabilize them in their descent, the bombs were fitted with a small steel tailfin, and these could often be found partly or wholly preserved after the bomb had burned itself out.

They were not very big, about $35 \mathrm{~cm}$ long and if they fell onto the garden or anything that did not burn they soon burnt themselves out. In the mornings we young lads would run around the streets collecting the burnt-out bombs. This was very dangerous because we might have picked up one that had not gone off and we could have been very badly burned.

(Marsh 2003) 
Many young collectors benefited from the generosity or help of relatives and friends in acquiring the more sought-after souvenirs, like Gordon Payne's father:

I was lucky dad would collect incendiary bomb cases for me, discovered on his A.R.P. warden patrols. These were the tail fin part of the bomb, a circular tube about eight inches long and two and a half inches across ... So my safe incendiary bombs, supplied by my dad, were [a] very highly sort after commodity and could be used for swaps for other trophies.

(Payne 2003)

In many cases the magnesium body of the bomb would be only partially burned or would fail to ignite altogether, particularly if they landed on softer ground. One lucky thirteen-year-old paper boy found an undetonated incendiary on his morning round and took it to show his employer:

As always I kept a lookout for bits of shrapnel, after all this was the best time to find some, before ... the rest of the world was up and about. On this morning, quite unexpectedly, I came across an unexploded incendiary bomb. About 18 inches long, looking like an aluminium cylinder with a tail fin of another metal and painted in a drab khaki colour. WOW! A prize indeed. The bomb was carefully picked up and slipped into my pocket, where it went through the holes into the lining of the coat. As I walked it was a bit uncomfortable banging against my knee, but still, it was worth it, there weren't any such bombs in any of the collections I had seen. I finished the round and made my way back to the newsagent's shop to hand in my bag, but more importantly, to show him my new treasure. I thought there would be a reaction, but instead of a glow of envy, he almost shouted, 'Get that out of the shop!' A little taken aback, I retreated to the sound of my employer ordering me to take it to the police station, some 80 yards along the road. I reluctantly complied with his 'request', but strangely I received a similar welcome in the police station. 'Give that here,' said the sergeant, who took the bomb from me, deposited it in a bucket of sand that was by the wall and took it out to the yard. Sadly, that was the last I saw of what I thought was destined to be the crowning exhibit of my collection.

(Bill 2003)

Several accounts describe collecting these unburned bombs and either keeping them as souvenirs, trading them, or trying to ignite them, sometimes by filing them down and using the resulting magnesium powder in an improvised incendiary device of some kind (Graham 2003). Later in the war a further threat emerged as the tailfins of some incendiary bombs were filled with a small explosive charge to scatter the burning fragments further, or to kill or injure anybody trying to move or extinguish them. This made the collection of unignited bombs even more dangerous. 
Another rarer but desirable set of collectibles were bullets and shells and the associated casings, clips and ammunition belt links. These could be acquired in a number of ways and were particularly common in areas where military training or manoeuvres took place, or even where the Home Guard had been training. However, some were found, like shrapnel, scattered in the streets after air raids, particularly if there had been aerial combat between British and German aircraft: 'We got lots of bullet and cannon cases, shell nose-caps, bases, copper driving band, and even bits of spent rocket from anti-aircraft batteries of which we were not supposed to know the whereabouts.' (Scott 2003).

Later in the war both Britain and Germany began to use strips of metallic chaff, often referred to as 'Window', to blind ground-based and aerial radar systems by overwhelming them with false positive signals:

'Window' was simply strips of aluminium foil, about the size you would use to make Christmas decoration paper-chains from. The German aeroplanes would drop great bundles of it into the sky in an attempt to make it difficult for our Radar to be able to see them. We, the British, invented it and used it to great effect against the German Radar, but of course it was equally effective when the Germans used it against us! This was something else that we youngsters used to collect up in the morning after a raid.

(Marsh 2003)

There are a number of these references to picking up 'Window' for souvenir collections, including using it to create tinsel for Christmas decorations, as also indicated in the extract above. Several accounts refer to bales of chaff caught in trees or hedges, and its generally decorative appearance (Ford 2003; Peacock 2003).

\section{Stuff that can kill you}

While souvenir hunting was generally tolerated, police, military and civil defence personnel tended to restrict children from accessing the most promising (and often the most militarily significant or dangerous) sites such as air crashes. With the introduction of explosive charges in incendiary bombs, there was a rise in lethal and non-lethal injuries, including to children, and a number were also injured or killed by playing with bullets and shells. The greatest source of official concern came in 1940 when the Luftwaffe began to drop butterfly bombs, early cluster munitions that proved highly lethal and effective, particularly when dropped in urban areas such as Ipswich and Hull. These $2 \mathrm{~kg}$ devices looked like tin cans suspended under a winged metal spinner and were of a size, colour and appearance likely to interest young souvenir hunters. For this reason a considerable effort was made to make children aware of these and other dangerous devices, with poster campaigns and talks in schools: 
We were all told never to pick up anything - shrapnel is extremely sharp, some strange objects could be 'live.' A policeman stands in front of the infants class and holds up a brightly coloured small bomb which looked like a light bulb at the end of a stick topped with folding arms and he demonstrates how it unfolds and spins. He instructs us if we see one on the street, 'never ever to touch it, just run quickly and tell the first adult you see.'

(McGarry 2004)

These talks seem to have made a lasting impression, as many of the shrapnel-collecting children of the Blitz recall the warnings: 'I knew to be careful of the "butterfly bombs" ... but I never came across one - much to my disappointment.' , while another recalled that 'posters warned us not to touch was the butterfly bomb. This was a rather nasty idea - a small anti-personnel bomb with open "wings" which exploded on being handled. I saw one once and reported it to the police.' (Johnson 2005 and see also Chance 2005; Mann 2005).

Children's capacity to fiddle around with dangerous war material must have caused considerable official and parental anxiety, and some of the accounts are positively hair-raising. Unfired bullets were often deconstructed to extract the cordite charge, thrown into fires or fired by striking the primer: 'At school we used to put a live bullet in between a crack in the wall and then with a nail and another brick hit the firing pin and let them off! It's a wonder nobody was killed as this was very dangerous.' (Hawtin 2005, and see also Bloomfield 2004). Derek Copeland picked up a mysterious object, probably a flare of some sort, and displayed exactly the sort of behaviour that officials dreaded:

I picked up a shiny yellow metal tube-like object. Being very curious I rushed back home with it to show my parents. They were not at home so my curiosity took over. Poking a piece of metal down inside, I found a hard, white powder-like substance inside. What is it? Must have gone through my mind. Carrying it over to the fireplace and setting it down upright in the hearth was my next move. Then for some reason I began pushing paper and splinters of wood down inside and then setting fire to them. Nothing happened with my first attempts, so I kept on trying then something inside started to spark very brightly with a shimmering glow. Dropping it onto the hearth I made a hasty retreat. The glow turned into a whoosh of rocket like intensity, showering the room with sparks and clouds of white smoke. I was off like a shot.

(Copeland 2005)

There is inevitably a survivor bias in any study based on memory narratives, but some do describe injuries and fatalities amongst friends and peers, including from souvenir-based misadventures: 
My friends and I would go round the streets looking for shrapnel and shell nose caps but alas like the old saying 'curiosity killed the cat' became true to life when my friend Graham picked up a fire bomb and was badly injured including losing a hand.

(Taylor 2003)

As several accounts point out, shrapnel itself was highly dangerous: tales of injuries and near misses from falling shrapnel are remarkably common in the People's War archive, including head wounds where shrapnel hit or pierced steel helmets:

One night when Dad was out on A.R.P duty he came rushing into the house saying; 'I've been hit, I've been hit'. We thought he was joking. Dad went into the kitchen and switched on the light, and we followed him. He'd got blood pouring down his face. He had been standing in a neighbour's doorway when the shrapnel had hit his helmet. When he took it off the piece of metal had lodged in the helmet and pierced his head. If it had hit him with any more force he'd have had it. He didn't need a stitch or anything in the end.

(Braybrook 2005)

While bombing destroyed houses and infrastructure, shrapnel may have seemed a much more individual threat. The nine-inch long, pointed fragment that punctured a door and landed in a baby's pram, the heavy nose-cone that landed with a flash and narrowly missed another boy's mother or the rain of hot shrapnel that fell suddenly around a woman walking home one evening must have seemed like thunderbolts from the sky, aimed at these people personally (Morrison 2005; Speeding 2005). Skinner's recollections of his brothers' shrapnel collections included recalling a neighbour being hit by shrapnel (Skinner 2004). In these circumstances there is no doubt that children were well aware of the very real dangers of shrapnel. The fact that they carried on feverishly collecting suggests not only that the obvious dangers may have made both the shrapnel and the collecting process a more thrilling, subversive activity but that there was also a reassurance or a power to be had in laying hands on these powerful objects, still hot from the explosion, and domesticating them so definitively into comfortable, established childish networks of play and exchange.

\section{Deviant shrapnel-based behaviour}

The violence and destruction of war created any number of opportunities for the criminally minded or morally flexible, as the thriving black market and any number of blackout murders demonstrated. John Brownbridge and friends found themselves accused of vandalism that was actually due to shrapnel damage: 
Mind you, the war could be funny at times. One day old Mother Gutteridge up the road came out and told us off for throwing snowballs and smashing her front window. It actually turned out that my friend, Ronnie Gutteridge, became the proud owner of a shell cap which had gone clean through their window and buried itself in the floor boards behind their settee. Mrs Gutteridge didn't show her face for ages after that.

(Brownbridge 2004)

In fact, shrapnel-based vandalism was not uncommon, and with the passage of time some of those interviewed for the People's War project were willing to confess their cunning crimes:

the thing to do was collect it after an air raid, then if your street had what today would be called a miserable old git, the sort that wouldn't give you your ball back, then when the next air raid was on and you knew he would be in his shelter you would lob a piece of shrapnel through his window, the next day it was all around the shops how old so-and-so was nearly killed by a piece of shrapnel, not very nice but boys will be boys.

(Semple 2003).

The second is described more subtly:

As children we collected pieces of shrapnel and one lady was excitedly showing her neighbours a piece of shrapnel that had broken her window. She was a terrible misery to all us children, she was always harassing us! When someone pointed out that the shrapnel was a bit rusty she immediately blamed my mate Sid and I, but luckily I was in bed sick.

(J. Smith 2004)

One wonders what to make of the numerous accounts by those whose windows were broken by shrapnel: in how many cases was this the result of shellfire, and in how many was it the instrumentalization of shrapnel in settling childish scores?

The life histories of a great deal of the material culture of the Second World War on the British home front ended in the VE Day bonfires lit up and down the country: gas masks, blackout curtains, and an assortment of junk were ceremonially and joyously burned (this is worthy of study in its own right). One schoolboy decided that the bonfire in Hull's Pickering Park would be the ideal place to dispose of an undetonated incendiary bomb that had sat in his collection for several years:

You can imagine the rest. I was there on the night when the fire was lit and, eventually, when the incendiary went up and took the bonfire with it. I was blown off my feet as were so many of the crowd. I don't think anyone was seriously injured, but there wasn't a great deal left of the bonfire!

(Anon. 2005b) 


\section{Disposing of collections}

By the end of the war we must have collected about 2 to 3 hundredweight, which included 2 dud incendiary bombs. Thinking about it now, I never did know what eventually happened to our collection.

(Peacock 2003)

The life stories of children's shrapnel collections begin explosively at high altitudes, but where do they end? In my initial interviews not one of my informants had kept their shrapnel collection; many could not remember what happened to them, and several recalled throwing away the increasingly rusty lumps of metal in the years after the war. However, in the People's War sample a number of different possibilities emerge. Different accounts of collecting suggest a variety of trajectories, from fragments discarded as they rusted and lost their lustre, to those mentioned above hurled through the glass windows of unpopular neighbours. Again it is worth noting that most of the accounts in the People's War archive are recorded around 60 years after the events in question, and memories of such trivial matters as clearing out old rusty lumps of steel might have faded. What is interesting is the variety of end-of-life (or later life) stories of shrapnel and their implications for the changing attitudes towards shrapnel as souvenirs or household junk.

Most interestingly it appears that shrapnel was actively sought out by the authorities for recycling, and children were encouraged to donate their collections (Figure 2.3). In some cases this operated through the school, either collected by the teachers or placed in a special box by the school gates (Bailey 2004). Others recall that shrapnel 'was handed in to the A.R.P. warden, and it was put back to help the war effort' (Pagett 2005). Elsewhere the police station was a collection point: 'The nose cone of a bomb was secured to the wall there. We were told that the shrapnel was sent to Woolwich Arsenal to make new shells.' (Crone 2004). As shrapnel became less scarce, the joys of collecting seem to have faded as its putative value for the war effort increased: 'Every morning following a raid it was the custom to go out and pick up the shrapnel, literally by the bucketful. At first the pieces were regarded as souvenirs, but now there was so much that it became part of the "war effort" to pass in the collected metal for recycling.' (Roberts 2005). Like many wartime collection drives it is questionable how much use this material really was: the aim may have been to raise morale and a sense of participation, an important consideration in these initiatives (Calder 1992).

In some cases shrapnel collections or particular pieces seem to have been retained for a long time after the war: Dulcie Lawrence recalled that 'When my parents moved in 1970, they found boxes of it in the loft', while Nigel Haig's collection was lost in a house move 'much to my annoyance' (Haig 2003; Lawrence 2005). One man born in 1941 whose pram was hit by shrapnel recalled that 'it made a good door-stop for a while - and a topic of conversation!' (Speeding 2005). Several accounts of shrapnel that was retained discuss 


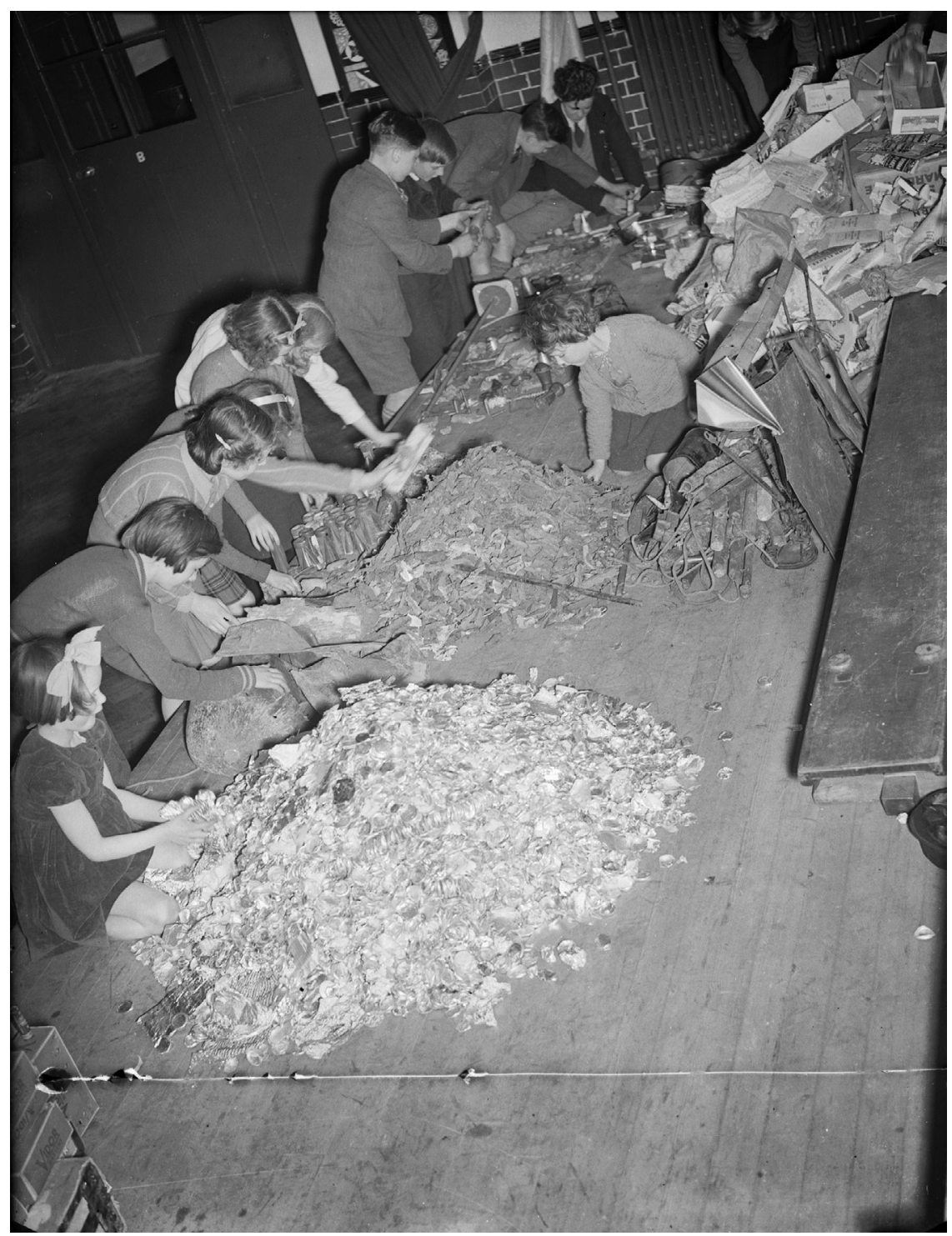

Figure 2.3 Pupils at Ancona Road School in South East London sort salvaged metal for recycling. Alongside milk bottle tops and sash window weights there is a heap of shrapnel fragments and a cluster of incendiary bomb tail fins. (C) Imperial War Museum, D 3166.

polishing and/or mounting the fragments, or turning them into trinkets of various kinds: 'I spotted a piece of shrapnel which turned out to be the nose cap of the shell. This I have kept ever since, highly polished, and have recently put it 
on a hardwood plinth.' (Francis 2003b, and see also Oates 2005). Keith Talbot was unusual in still possessing some 'odd bits' of shrapnel in a bag (Oates 2005), while Ralph Hill's collection was donated to Bruce Castle Museum in north London (Hill 2005a). One of the most evocative accounts of shrapnel retained is Doreen Kerry's description of her mother's old junk drawer:

Kids used to collect shrapnel in the war. When my mother died, we had a big drawer full of bits and pieces. And I said to my father, 'We can't sort this out'. So I tipped it all into the dustbin, literally. It was only after that that I realised there were bits of shrapnel and everything in there! Bits of the sewing machine! You should have seen it. I'll never have a drawer like that.

(Kerry 2005)

\section{Conclusion}

The overwhelming impression gained from these many varied narratives of wartime childhoods and shrapnel collecting is of children confidently integrating this violent material culture into their dynamic social worlds of trade, status, mischief and play. Shrapnel took its place alongside marbles, comics and trading cards in the cut-throat economy of the playground with remarkable speed and spontaneity.

What made shrapnel collecting different? One of the most significant properties of shrapnel was that it cost nothing: any child could accumulate a collection through a little hard work and canny trading, and children in poorer areas near factories or docks were likely to have a slight advantage due to the increased anti-aircraft protection in these strategic areas. Compared to the invisible night-fighters, anti-aircraft guns were a visible and very audible weapon 'striking back' at the Luftwaffe's night bombers, particularly in the early years of the war. The hard pieces of steel twisted, broken, discoloured and still hot from their high-altitude detonation reified this defiant energy and enabled one to possess it, like a coin flattened by a train. This possible association of shrapnel with power and resilience might explain another of its unusual properties: the speed with which it diminished in value from the fresher, hotter piece to the older rustier ones only good for breaking windows. The rate at which pieces lost their lustre would have been a factor in exchange and accumulation: shrapnel was in one sense a perishable commodity in the same way a new car rapidly diminishes in value.

The post-war lives of shrapnel collections reveal a great deal about their values and uses and the lives of the children who collected them. For the most part collections seem to have been discarded or forgotten: this is not uncommon behaviour in children whose attention spans even for their particular fascinations can be relatively brief and fleeting, and who are likely to associate certain forms of play and other activities as something to grow out of over the years of the war and afterwards.

To what extent did shrapnel serve a purpose that ended when the war ended? I think it is reasonable to suppose that for many children the 


\section{Collecting shrapnel}

collecting, ordering, controlling and integrating shrapnel into their comfortable and familiar worlds of play and exchange was a coping mechanism, a means to domesticate an otherwise terrifying material imposition into their everyday lives of hot metal fragments falling out of the sky. At the same time, collecting shrapnel was a positive means for children to engage with or participate in the war rather than to merely experience it passively. However, the clear associations of collecting with controlling and ordering, the "profane to sacred' transformation highlighted by Belk et al (1988), suggest that these practices had something to do with gaining power over the material culture that was killing and injuring so many people. The ability of children to adapt and cope in traumatic situations is remarkable, and it is important not to underestimate the element of straightforward fun in the shrapnel business: 'I guess today it might seem like a simple pleasure, but we all had such a good time swapping and trading and collecting those simple little pieces of metal.' (Burchmore 2005). 


\title{
3 Air raid shelters
}

My most vivid memory of WW2 was the time spent in an Anderson shelter.

(Bird 2004)

The first response to our bombing was the building of a communal air raid shelter and that was when the fun started, that shelter became, for me and my chums, a major part of our lives, we spent more time in it when there wasn't an air raid than ever we did when there was

(Conroy 2005)

\begin{abstract}
At about 11:15 the air raid sirens sounded the Alert and, as the only picture we had in our minds of an air raid was in the film of H.G. Wells 'The War of the Worlds' of about 1937 where a sky full of bombers filled the screen and the city was bombed to complete ruin [this is likely a misremembering of another Wells film, the 1936 Things to Come], we all hurried to the local public shelter recently built in the grounds of a school (once Sir Joseph Banks' home) at the bottom of our road. It was a square section, concrete tunnel, half buried in the ground. Anticlimax - nothing happened and all clear sounded.
\end{abstract}

(Dodds 2005)

\section{Introduction}

Whether at home, at school or at work, the air raid shelter was a material reminder of the threat of death from the air for young people in wartime Britain. Between the late 1930s and the end of the war, shelters were built in their millions by local authorities, the military, businesses, families and individuals. Today a significant proportion of these millions remain: designed to withstand bombs and shrapnel, many have weathered the passage of time to serve as reminders or memorials to the civilian experience of bombing. My aim in this chapter is to consider air raid shelters not as empty monuments but as extensions of the home. As lived, inhabited, social spaces the crowded, damp, noisy, often unhygienic air raid shelters were 
mostly built with the expectation of short-term use, but with the introduction of night bombing by the Luftwaffe they became places where families slept, ate and socialised. In the recollections collected by the People's War project the air raid shelter is a common focus of memory, and in particular sense memories: the smell of damp and of human bodies, the sounds of aircraft and bombing, and the sensation of bomb-blast provide powerful stimuli for recollection.

For children, air raid shelters were places of restriction and of opportunity. Air raids saw families crowd into cramped spaces, whether at home or in public shelters, characterized for children by long periods of boredom, frustration, discomfort and fear. In schools, air raid drills were strictly enforced, and many schools remained closed after the outbreak of war until adequate shelters had been constructed. Air raid warnings during lessons were more welcome as a break from the routine, and school shelters seem to have been experienced as more social spaces. Aside from the gas mask box on their shoulders, air raid shelters represented the most obvious material manifestation of the war in children's lives: brutal, blockish impositions in their familiar geographies. Their response, as with other war materials, was to integrate the air raid shelters into their childish worlds of play and socialising. Public shelters in particular became play spaces, dens, sources of privacy and objects of vandalism.

As the setting for children's experience of bombing and air warfare, air raid shelters are inextricably linked to their experiences and memories of trauma, injury and death. Many of the accounts recorded by People's War describe surviving near-misses or witnessing the deaths of family, friends and neighbours. The sense memories mentioned above are also capable of stimulating panic responses based on enduring trauma, and several accounts express regret that understanding of childhood trauma and therapy provision was not as advanced then as it is now. Children respond to the emotional expressions of adults around them, and one of the most significant factors in children's wellbeing in shelters was believed to be the ways in which parents or guardians expressed fear: this is shown in the variety of remembered responses to shelter life, ranging from terror to excitement (Figure 3.1). To examine the variation and significance of children's experiences and memories of air raid shelters, this chapter will consider a variety of different aspects of shelters and shelterers including shelters' construction and installation; the domestication of shelters as simulacra of the home through adaptation and ornamentation and their nature as 'gendered spaces'; children's pastimes and activities; health and wellbeing in the shelters and the sense memories of smell, sound, moisture and movement that characterize the memory narrative sources.

In moving from material objects to physical spaces, it is worth considering the work by Andrews et al (2006) on the significance of place in older people's oral histories of the Second World War. Their study, carried out around the same time as the BBC People's War project, focused on 12 people who had lived in the Devon town of Teignmouth during the war. The interviews focused on the geographical dimensions of everyday lives on the home front including foraging for food, socializing with friends and taking shelter during air raids. They concluded that oral histories based on older people's childhood memories of place offered distinctive 


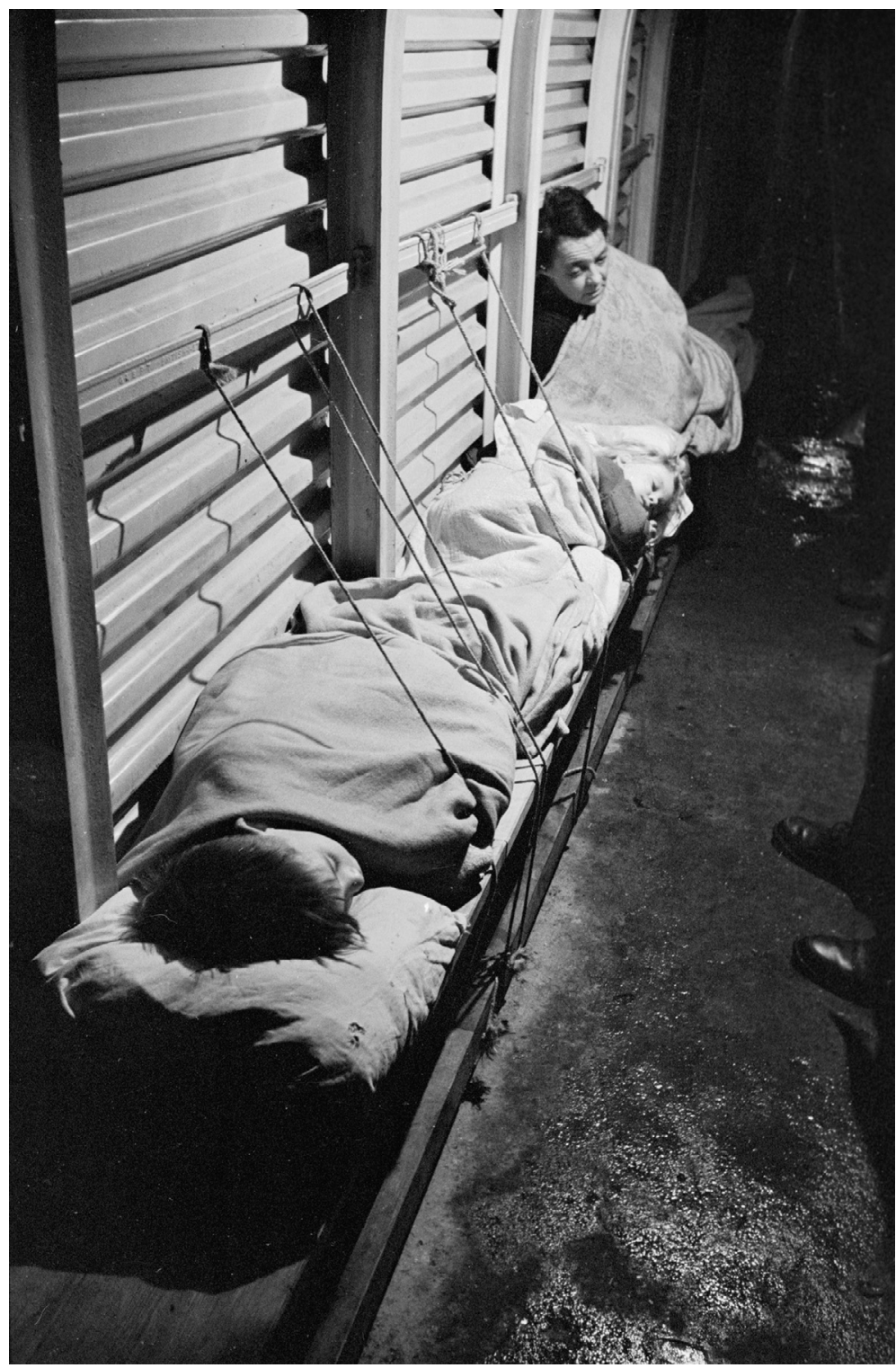

Figure 3.1 Two children sleeping on a bench inside an air raid shelter. Their mother tied ropes around them to prevent them falling onto the damp floor while they slept. (C) Imperial War Museum, D 1550. 
and valuable insights: 'stories that lie outside of, and might even conflict with, dominant narratives' (Andrews et al 2006: 170). One of the findings of this study was that children delighted in breaking the restrictions that war placed on access and control over space, particularly those related to safety regulations such as playing on anti-invasion defence structures and turning bombsites into play spaces (see the next chapter). Place and its materiality has a powerful impact on memory, as the stories in this and the following chapter demonstrate, and sense memories play a significant role in this: while Andrews et al do not discuss it specifically, several of the narratives they recorded make explicit reference to sounds and smells associated with particular places:

Many of the children were in their first few days of attending school. When they heard the explosions, machine gunfire and cannon shell fire, they screamed with such terror that I have never forgotten the sound. People who make war should be made to listen to that sound.

(Quoted in Andrews et al 2006: 164)

\section{Air raid shelters}

The concept of the air raid shelter is simple: a structure, excavation or arrangement of materials that is created, adapted or used to provide protection from attack from the air. The first aerial bomb was dropped from an Italian aircraft over Libya in 1911, and the history of air raid shelters began shortly thereafter. It is worth briefly reviewing the rich and contested story of air raid shelters in Britain, which ranges across the histories of public policy, architecture, science and technology, public health, radical politics and modern art. It is a fascinating topic that cannot be adequately summarized in a brief introduction to a related topic, so I recommend the works of Haapamaki (2014), Grayzel (2012), and the foundational official history by O'Brien (1955) as introductions to the field.

The bombing of Britain began in 1914 with attacks by aircraft of the German navy. Strategic bombing by both army and navy zeppelins began in early 1915, and from 1917 by heavy bombers, both by day and by night. During the raids many took shelter under railway arches, in basements, crypts, and, as in the Second World War, in the London Underground. At the height of the raids as many as 300,000 Londoners were taking shelter in the Underground, and another 500,000 used basements, cellars and other refuges. The oldest surviving purpose-built (as opposed to improvised or adapted) air raid shelter in Britain dates from 1916: after a fatal zeppelin attack on Cleethorpes, Lincolnshire local councillor Joseph Forrester built a substantial concrete structure behind his house measuring roughly four by five metres, with walls a half metre thick. Today the shelter, converted to a garage with the addition of a large doorway later in its life, is a Grade II listed structure.

Between the First and Second World Wars the bomber aircraft rose to prominence in military doctrine, in colonial strategies of control, and in the popular and political imaginations. The fear of the bomber as analyzed by 
Holman (2014) was a powerful cultural force, with a widespread impression spurred by popular culture and apocalyptic thinking that a single 'knockout blow' by a bomber force could flatten an entire modern city in a matter of hours, killing hundreds of thousands and bringing a nation to its knees. In the 1930 s as the spectre of war loomed ever larger, scientists and politicians in Britain and other western nations looked with interest and concern at the uses of bombing in war: at the gas bombing of Abyssinian troops by Italian aircraft in 1936; the bombing of Canton and Shanghai in China by the Japanese military in 1938 and the bombing of Barcelona and Madrid during the Spanish Civil War (Holman 2014).

In Britain, the official approach to civil defence in the period after the First World War saw the formation of an Air Raid Precautions subcommittee to the Committee on Imperial Defence, based on the findings of a study of a hypothetical war with France. Already at this point in the 1920s there was a concern that public morale was at equal or greater risk than industry and infrastructure in the event of air warfare. When the provision of air raid shelters was first raised at the subcommittee in 1926, it was questioned whether it would raise or lower civilian morale in wartime (Grayzel 2012: 144). Throughout the interwar period and well into the opening years of the Second World War, civil defence policy was powerfully (and occasionally catastrophically) shaped by a widespread mistrust of the masses and their ability to remain steadfast in the face of danger. The 1937 Air Raid Precautions Act placed the obligation to provide protection onto local authorities, although the bulk of the substantial new costs were borne by central government. The focus of activities at this point was on building infrastructure and recruiting and training personnel: in amongst these requirements was the construction of air raid shelters for the public. The passage of the Civil Defence Act in 1939 created a further obligation for factories, mines and other workplaces to provide air raid shelters for their staff, and allowed local authorities to requisition properties for civil defence uses.

Air raid shelters were one part of a great flurry of air raid precautions measures during this period, including the need to 'black out' buildings to discourage night-time bombing; the recruitment and training of specialist and volunteer rescue, fire and first aid teams and the infrastructure around the manufacture, distribution, fitting and training of gas masks (see Chapter 1). It is important to note that throughout the pre-war period and into the first year of the war, it was widely anticipated that poison gas bombs would be used alongside or instead of incendiary and high explosive bombs: this caused tensions in the ARP planning processes as subterranean shelters were deemed more effective against high explosive but at far greater risk from gas (Grayzel 2012: 145-6). Many of the advertisements in this period by construction and engineering firms offering private air raid shelters highlighted their gas-resistance and the provision of air filtration systems. While the ARP subcommittee debated the necessity of public air raid shelters into the late 1930s, as Grayzel (2012: 147) notes: 'the primary unit left to face the air war remained the household.' 
The Munich Crisis of 1938 raised the possibility of imminent air war, and in parts of the country local authorities belatedly began to prepare for bombing. In many areas this amounted to little more than the digging of trenches in parks and public spaces to provide basic protection from shrapnel and falling buildings. However, by the outbreak of war most of these trenches had filled with stagnant water, been filled in for public safety, or been improved with the addition of floors, walls and roofs of wood, concrete and/ or steel. During this period the focus shifted in part to domestic shelters and the minister responsible for air raid precautions, Sir John Anderson, initiated the development of the corrugated steel domestic air raid shelters that came to be known as 'Andersons'.

\section{Building the Anderson shelter}

From early 1939 more than 2 million Anderson shelters were installed in gardens across the country, initially given free to families earning less than $£ 250$ per annum and sold for $£ 7$ to any above this threshold. In the People's War reminiscences, the Anderson shelters feature in numerous stories, with many particularly strong memories of their arrival and installation, which often caused disruption and distress, although Margaret May remembered using the curved side-sections as a slide when they were first delivered (May 2003). Brian Brooks, aged four years old at the outbreak of war, recalled seeing a public display of the Anderson shelter in Fulham aimed at informing the sceptical public of its value and safety, particularly in comparison to their own warmer, dryer homes. Soon afterward his family received their own Anderson shelter, built by the local council in his family's back garden in East Acton:

Our shelter, installed by the council, was just a tin box with a hole in it, in a hole in the ground - no door, weather or blast protection, not even a means of climbing down inside. Our old kitchen chair had to have the back sawn off to become a step stool; the back was higher than the entrance ledge and tripped us or got kicked over ... The floor was concrete with a round dip sunk in one corner to collect moisture (!) and the sides were concrete up to three feet, ground level. Concrete was a rather grand name for what was little more than sand and water, I broke a piece off just by prodding it and was told off for 'damaging' the Air Raid Shelter! If I could damage it what would those Jerries do to it?

(Brooks 2005a)

The widely-expressed sense of shelters as somewhere secure and safe, despite their discomforts, is notably missing from this account. The rush to build shelters in huge numbers across the country led to a shortage of building materials and many rushed jobs of this kind. The demand for cement for construction in the period before and after the outbreak of war led to flaws in the construction of public air raid shelters, many of which subsequently 
collapsed with catastrophic consequences when exposed to blast during air raids. Having established the flimsiness of its construction, Brooks explored his family's Anderson and found it stark and cavernous to a small child:

But for grown-ups it was a struggle, hitting their heads on the sharp edges of the small entrance, and the sticking-out nuts and bolts everywhere. Much later Mr. Stephens showed me the pamphlet he got with his shelter kit, with recommended installation of a flight of stairs, full height door, splinter-proof blast wall and weatherproof porch protecting the entrance, wooden floor, etc., which he had done.

(Brooks 2005a)

The basic steel Anderson was a blank canvas for augmentation and improvements of this kind, and some were improved with the addition of wooden duckboard floors, underfloor drainage, covering to prevent the build-up of condensation in the interiors, and other interior fittings. The more domestic additions are discussed in more detail below. The instruction booklet that accompanied the Meccano-like construction kit for the Anderson shelter, entitled 'Directions for the Erection and Sinking of the Galvanised Corrugated Steel Shelter' (Home Office 1939), gave a very detailed step-by-step guide including advice on appropriate locations and provisions for drainage. However, some recipients like David Berry's father were reluctant to follow these instructions:

Receiving such directions was anathema to my father, as was digging a 4foot deep, $8 \times 4$ feet hole. A bit of lateral thinking was required - or any sort of thinking to get out digging that damn hole. Solution: erect the shelter in the front room - which is just what he did! Poor Mother was in despair; it has to be said that our front room was not a 'front room' in the Victorian sense, but it was our dining room and now it was three parts occupied by this corrugated iron monstrosity. I don't know what happened to persuade Father to take it down; it must have been something pretty formidable for his mind was not easily changed, particularly when it concerned his more outlandish ideas. But it was dismantled and the hole in the garden dug.

(Berry 2003)

From reports at the time and numerous reminiscences, it is clear that many newly installed shelters quickly filled with groundwater, to depths varying from a few inches to several feet, and even well drained shelters could be cold and damp even in warm weather. Alan Merryweather's father took the precise opposite approach to David Berry's, moving the outdoor shelter indoors:

I well recall the warm and sunny day in 1939 that a man came to dig the hole for our Anderson shelter in the back garden at 88 College Road, Kensal Rise, London. Mum gave him a cup of tea and a piece of fruit 
cake. Often partly flooded, always damp and cold, my Father learned that it was possible to dismantle the shelter and re-erect it inside the house. He decided to do this - probably with the help and guidance of our builder Mr Bierton, who lived a few doors away. Floorboards in the living room were sawn up (no solid floors in those days), and the shelter was re-erected on the house foundations about 18' (half a metre) below floor level. Two bunks were constructed inside and thereafter, it was a warm, moreover a dry place to go during air raids. After the war the shelter was taken away and the floorboards replaced.

(Merryweather 2004)

The preference for indoor shelters was common: in some areas families were offered options including an Anderson shelter, wooden or steel props to reinforce a shelter room or basement within the house, and for terraced streets with cellars some local authorities offered to knock low doorways between the interconnecting cellars and install small doors, so that householders could escape from beneath the rubble of their collapsed homes by moving into neighbouring cellars. Some people chose to reinforce their understairs cupboards, as the triangular constructions were rightly believed to be the most stable part of the building: 'On the newsreels of that time most structural damage shown to housing had left this area of the property mostly untouched.' (Anon. 2004). Many of these shelter provisions, including the Anderson shelters themselves, were based quite sensibly on the low probability of a direct hit compared to the far greater probability of homes collapsing or getting badly damaged by the blast or earthquake-effects of a nearby explosion, as well as the risk from flying glass, debris and shrapnel.

\section{Private shelters}

Private air raid shelters had been marketed for several years leading up to the Second World War for those who possessed the means and the space to construct them. Building contractors, concrete fabricators and manufacturers of reinforced doors, air filtration equipment and assorted other features advertised their products and services to the nervous and air-minded. It is difficult to tell how many such shelters were constructed, and the degree to which they conformed to, or deviated from, the recommended designs outlined in a range of official and industry publications (e.g. Lee 1940). Hugh Morgan's engineer father built a subterranean shelter beneath their garage:

It had walls and roof of reinforced concrete slabs with an entrance opposite the house chimney breast, this being the part of the house most likely to remain standing in the event of a direct hit. He filled the space between the shelter and the garage walls with earth or sandbags. My parents and my sister and I slept in it throughout the worst of the blitz, three on mattresses on the floor and one in a bunk.

(H. Morgan 2005) 
Joan Shepherd's family's neighbour Mr Bowey was a builder who had constructed a substantial and completely subterranean shelter in his garden, which he offered to share with neighbours:

It was sunk into the garden, so its top was level with the soil, save for a small parapet made of two rows of bricks. It must have been about twelve feet long and nine feet wide. It had a concrete roof and floor, brick walls, and doors at either end with steps leading down from ground level. Heavy wooden benches, perhaps four or five feet deep, allowed we children to lie fully stretched on them while older folk sat on the edge. A couple of chairs completed the furniture. The shelter was lit and I feel sure there was, also, a thermos stove on which hot drinks were prepared. Mr and Mrs Bowey kindly invited our family, and a few other neighbours, to use their air raid shelter when the siren sounded. Perhaps, a dozen people did so, including five or six children. We went as we were dressed. If we were not sleeping, we talked or read books, and I remember the sweets and biscuits we had. Sometimes, we would be in the shelter for a couple of hours. It was cold, yet it was also comfortable.

(Shepherd 2005)

Brenda Maitland's family took the threat of bombing seriously enough to build their own shelters: her uncle built a brick and concrete shelter beneath the dining room floor, which he excavated for the purpose. Her father took the more traditional approach and paid a building firm to construct a brickbuilt, semi-sunken shelter in the garden. This private shelter cost her family $£ 250$, a significant amount at a time when average house prices were between $£ 600$ and $£ 700$ (Maitland 2005). Not all privately built shelters were quite so professional: particularly in the period before Anderson shelters were distributed, which varied across the country, many households followed the official encouragement and constructed their own makeshift shelters from available materials. Geoffrey Dodds and his friend had dug a huge hole in their back garden sandpit, stopping only when they hit the roots of the nearby apple tree. Before they had a chance to fill in the hole, war had been declared:

Dad changed his mind and 'Might as well make use of that hole'. He had bought a load of broken red concrete from the recently demolished Great West Road cycle track, (the new one was to be twice the width), intending to lay a garden path. Instead, he enlarged the hole, lined it with concrete blocks, made dog-leg entrance steps, put an old door over the top and finished it with more concrete blocks laid loosely over that. Inside, wooden boards were laid over blocks to make benches. Thus, we had the first private air raid shelter in our road. 
When night air raids began and families started to spend whole nights in their shelters, Dodds' father enlarged their home-made shelter, widening the steps, and adding new concrete, along with facilities for lighting.

The instruction manual for the Anderson shelter suggested working with neighbours to cluster shelters together in pairs or in fours across garden boundaries to ensure better drainage as well as a thicker layer of protective earth over the shelters. In many cases neighbours also clubbed together to buy or build private shelters. Jean Graham's parents worked with both sets of neighbours to convert their garage into a shelter for the six adults and six children. They reinforced the walls and external doors with tea chests filled with sand and gravel, topping these off with sandbags up to and over the roof: the result was described as 'not pretty' but 'very effective' (Graham 2005). Some enterprises were even stranger: John Hunter's father teamed up with 'the other able bodied men in the six households in the terrace' to build a community shelter on a patch of waste ground. They dug a three-foot deep hole and used it to partially bury the wooden body of a derelict London bus that had been abandoned there previously, using the excavated earth to cover the bus. The interior was wood-lined, structurally reinforced and fitted out by a neighbour who worked as a carpenter, including bunks for the children and a toilet area with a bucket. As Hunter recalled, 'The shelter was christened "The Band wagon" [Band Waggon] after the radio show starring Arthur Askey. We spent many nights in the Band wagon and although it would have afforded little protection against any close bomb, it is clear to me now that the adults gained much comfort from just being together.' (Hunter 2005).

One of the recurring themes in the accounts of shelter-building is the emphasis on fathers. In the context of the time it is natural that the men in the families would have taken the lead in the manual work of digging, building and burying the shelters, but nonetheless it is interesting quite how many stories emphasize this point, particularly as it relates to the pre-war and early wartime period: in a significant proportion of these cases the fathers were likely to have been called up soon afterwards, part of a transformation of family life and gender dynamics that was to have significant ongoing impacts on families and on society as a whole both during and after the war. The effects on children left behind were also significant, and it is possible that this might have retrospectively coloured the reminiscences of fathers providing shelter for their families before being called up to serve, although it is impossible to gauge this in any accurate way. The masculine-gendered dimension of air raid shelter construction is particularly notable in comparison to the feminine-gendered activities such as sewing siren suits or transforming the shelter into a homelike, domestic and domesticated space, discussed in more depth below.

\section{Taking shelter}

By the time the bombing of cities began in earnest in the late summer of 1940 most of urban Britain had experienced air raid warnings and spent time in their home, work or school shelters. From October 1940 the Luftwaffe 
switched to night raids, and the experience of sheltering was transformed: as well as running back and forth from classrooms to shelters in the day time, young people in Britain found themselves woken or lifted from their warm beds and rushed into their home or communal shelter, tired and often grumpy and bewildered. Raymond Porter recalled that he and his brother would resist their mother's instructions to take shelter, leading to arguments and ultimately 'she would grab us to get us down the shelter' (Porter 2005). Some resisted successfully: John Earthy recalled that 'I would get sick of the shelter and smuggle myself back to the house. My mother would come and fetch me and bring me back down again' (Earthy 2004). In Yvonne Worrall's recollections the timing of the raids was more regular and reasonable, and the children's behaviour more orderly:

Every evening around seven o'clock the siren would go and we would quickly put on as much warm clothing as we could as it was always cold and damp in the shelter, when we were ready Mum would say, 'right, are we all ready?', and the four of us would stand at the door, Mum would put the light out and she would open the door, in the winter it was freezing. Then we would make our way down the path to our neighbours' shelter. Meanwhile, the guns were banging away at enemy aircraft whilst searchlights criss-crossed the sky. The smell of cordite was everywhere, and the sky was red from bombs that had dropped before we got into the shelter.

(Worrall 2005)

Like so many accounts by children of this period, the memories of colour and smell provide an intensity to this story indicative of the powerful relationship between memory and the senses, particularly for children recalling stressful or traumatic events.

Many of the recollections describe the material culture associated with taking shelter: the briefcase of birth and marriage certificates, insurance documents and other important papers that families were encouraged to take with them for safekeeping; the thermos flasks of tea and packets of sandwiches and the paraffin lamps, candles or torches used for lighting and heating in the cold shelters. One set of objects that stands out in the recollections are the child-sized siren suits. These one-piece outfits, similar in shape to a romper suit or an over-large boiler suit, had the advantage that they could be donned quickly and easily over night clothes, providing warmth to the wearer and a modicum of modesty:

We used to go into underground shelters which were in Coatham road, so when the sirens went off at night, you didn't want to get out of your warm, cosy bed, so you put your siren suit on which was very much like the snow suits that little ones wear these days, you put your pillow under your arm and you trudged along to the air raid shelter and just lay down on these awful wooden plank seats and tried to sleep.

(Blackburn 2005) 
Siren suits could be bought off-the-peg or homemade to a pattern: Brian Brooks recalled that his mother made his siren suit from an old coat bought at a jumble sale and that 'Awake or asleep I was stuffed into it and was ready for the shelter. It smelled a bit of moth balls.' (Brooks 2005b). This is echoed in Eileen Whitmore's account that siren suits were 'so named so that when a siren sounded, my mother could quickly put us in this suit so whatever we were wearing, she could zip us up and off we went. Then carry us down and put us in the Morrison Shelter' (Whitmore 2004). Some of the memories of siren suits recall going to sleep already wearing them in anticipation of an air raid (e.g. Brooks 2005b), while for others donning the suit was part of the nightly ritual, along with the sounds and smells of bombing: 'I would ... stand up on my bed, wait for my mum to come in, put on my siren suit and then down to the shelter' (Valerie 2005).

The most famous siren suit wearer was Winston Churchill, who was known to wear his day and night, and to even wear it as a pseudo-uniform for official meetings. The children's siren suit appears again and again in recollections of this period as a symbol and artefact of the child in the air raid shelter. As with the musty, cold shelter many of the memories of the siren suit are sense memories. Julie Allen recalled her mother purchasing her royal blue siren suit from Kennards department store in Croydon:

It was always ready for me to quickly slip on over my pyjamas so that we could get down to the shelter as quickly as possible. They also had hoods to keep your head warm. I really liked mine and it was all fleecy inside with buttons down the front. I remember Mum calling me to get out of bed and pop the suit on.

(Allen 2005)

Despite this sense of order, sometimes in the rush to take shelter the exhausted, half-asleep parents had insufficient time to properly prepare themselves, their families or their things. Margaret Adin recalled one such air raid:

One night we were all settled in nicely - our next-door neighbours, my mother, auntie and myself, when Mum suddenly said 'Where's John?'. He was my baby brother and slept in a wicker clothes basket in readiness should the siren go off. He had been forgotten in the rush on this occasion and there was a dash to fetch him from the house.

(Adin 2004)

\section{Passing time in the shelters}

To consider the air raid shelter as part of the material culture of wartime childhood, we need to consider them not as bare structures but as inhabited spaces. Whether used for just a few minutes during a 'false alarm' air raid warning or occupied from dusk to dawn, the shelter shaped and mediated children's 
experiences of the world at war and provided a platform for them to enact their own practices of play, rest, socializing, sleeping and passing time. Accounts of shelter life from both younger and older children illuminate these practices.

The larger public air raid shelters ranged in size from the standard 50-person shelters in streets, parks and other public spaces, to factory basements, railway arches and purpose-built underground tunnel networks holding hundreds or thousands of people. They were naturally more lively, sociable spaces than the family shelters, with better facilities for sanitation as well as the space and electric light for reading and other activities. Eileen Blanchenay was a teenager in north London during the V1 attacks later in the war, and recalled spending days and nights in the brick surface shelter across the road from her family's flat, which effectively became their home for around three months. She described how, after spending the day with her friend, they would return to their respective homes to change into their shelter outfits of old warm clothes, put their hair in curlers beneath a woollen snood, then meet up in the shelter: 'We brought our blankets and pillows and we really enjoyed it, and we talked and laughed until we were told to go to sleep by everybody else. The light was kept on all night but we got used to sleeping like that' (Blanchenay 2004).

Part of the motivation for families to effectively set up home in the larger public shelters was to avoid the disruption and lost sleep involved in moving from home to shelter every time the sirens sounded. Tom Ebert's account of his family's time in the crypt of All Saints Church in Poplar describes the experience of many families in London's East End and other heavily bombed areas where public shelters became homes-from-home, as he describes it: "we found a "billet" in the crypt of "All Saints" church in the East India Dock Road ... The vicar allowed people to shelter in the crypt and it was always crowded.' (Ebert 2003). Ebert described the hierarchy within the shelter where families who had been there longer occupied cosy alcoves in the crypt, originally designed as family mausoleums, with stone shelves padded with blankets and eiderdowns and used as bunkbeds. He recalled that at the height of the Blitz he and his mother and sister stayed in the crypt for 57 days and nights, returning home only to wash and change their clothes. Ebert's memories of the shelter, like many others, focus on the stifling and unpleasant atmosphere created by so many bodies in such a small, enclosed space and the risks involved in obtaining fresh air during a raid:

At times during the night with all those people in the crypt and the doors at either end shut tight, the air became foetid. When this happened all lights were ordered to be put out and gangs of men waved the large double doors back and forth to create a through draught of fresh air. One young lad sitting at the entrance during one of these procedures during a raid received a stray bullet in the arm. He returned from hospital a hero with his arm in a sling and the offending bullet in his pocket which he showed to all and sundry. All we young urchins then tried for a seat near the doorways the next time the sirens went so that we could receive a 
'wound of honour' and a spent bullet as a souvenir. I can't remember the toilet arrangements - just as well!! I think tea was brewed by a charitable organisation - probably the 'Sally Ann' (Salvation Army) and there was a mobile canteen at times in the churchyard but we mainly provided our own food and it certainly wasn't a cooked meal because there were no cooking facilities in the crypt. Rumours abounded down there, one in particular I remember was of an A.R.P. warden trying to get the occupants into the open air during a lull in the bombing in the early hours of one morning to get the crypt tidied up and fresh air circulating. He was immediately labelled as a 'Fifth Columnist' whose evil plan was to get us outside where the Nazi fighters could machine gun us!

(Ebert 2003)

Later in the war All Saints Church was badly damaged by a V2 missile strike.

Many public shelters were adapted to the unexpected overnight residential use. Joyce Snipp and her family spent their nights in a large public shelter in Lewisham, installing themselves after their evening meal and staying the whole night. The shelter was made more homely with rugs, a stove for heating and tea-making and pin-ups pasted on to the walls. Initially they slept on the floor and the benches, but later bunks were installed, and a system of numbered tickets introduced so that locals were guaranteed a space. Later still a sink and portable oven were installed with occupants of the shelter contributing a modest fee for their use (Snipps 2004). As this was a larger public shelter, further support in catering was provided by the Salvation Army.

This home-making in the shelter is explored in more depth below, but the impact on children was important. Looking back on life as a six year old in the Blitz, one account describes how cushions and blankets 'appeared' in the shelter, and parents encouraged singing as a distraction during air raids: they note that 'I don't remember feeling afraid', which was no doubt the intention (Anon. 2004). Children's recollections of public shelters include feelings of cold, hunger and exhaustion, but also 'a mixture of fear from the bombs, together with the excitement of being able to stay up each night in the shelter with other families' (Styan 2004). Food is a focus of several recollections of shelter life, as part of family life and social life: Joan Styan recalled that:

With our mother we used to take our cheese sandwiches (which always seemed scrumptious) and Smiths crisps containing little blue bags of salt, together with a bottle of Tizer in the shelter and have midnight feasts with the other children which was exciting and alleviated some of the fear.

(Styan 2004)

From the recollections it seems that compared to the larger public sites, private shelters allowed for a stronger continuity of normal family life, but the sense of isolation could also be troubling, as Brian Brooks notes: 'I liked it when we had more grown-ups in the shelter, I think Mum did, too. They would laugh 
and swap news and talk about work. I think my Mum missed her old work friends.' (Brooks 2005b). Several accounts describe playing cards or board games in the shelter to pass the time, including Ludo, Rummy and Newmarket. Like so many features of the war, many people and children in particular found themselves able to adapt quite quickly to the noise of the raids, the lights of the public air raid shelter and other distractions to get a relatively good nights' sleep.

Many of the memories of the smaller domestic shelters describe the intensity of a family packed into a close space together. Tired of cold, dark, late-night trips indoors to use the toilet, Philip Shapiro's family upgraded from their Anderson shelter to a Morrison table shelter, and found the temperature at least to be an improvement:

With a large mattress and plenty of cushions and blankets, it was quite cosy, especially as my father kept the stove going throughout the night, although with four of us, Father, Mother, my sister and myself, somewhat overcrowded. One of the disadvantages of nights in the table shelter was that my father suffered from chronic asthma and burned various powders such as Potter's Asthma Powder and smoked Potter's Asthma cigarettes. The smoke from these was, for us, far more life-threatening than the bombing!!

(Shapiro 2003)

Some recall a sense of safety inside their shelters, with the close presence of family a reassurance, and others recall the sense of adventure of being up late and out in the dark.

Aside from the public and the private shelters, many young people spent air raids sheltering at their schools (Figure 3.2). The provision of air raid shelters in schools was a strict requirement, and in many areas schools were closed for various periods at the outbreak of war if they could not provide adequate protection, with classes either suspended or taught in homes and other places. Gordon Rollins' school in Rugby was one of those affected:

at the start of the war I was not allowed to attend school for 6 weeks as I did not live within 5 minutes walking (not running) distance of the school. This was an official declaration as in the event of an air raid I would not be able to reach home before the bombs started dropping! I was then able to attend school again as school air raid shelters had been constructed alongside the 'Black Path' joining the end of Hill Street to York Street. Each time the Air Raid Warning was sounded the whole school was marched to the air raid shelters. Once there the Headmaster - Mr Harvey - conducted spelling bees. Whether this was to continue our education or to take our minds off what was happening outside I am not sure.

(Rollins 2003) 


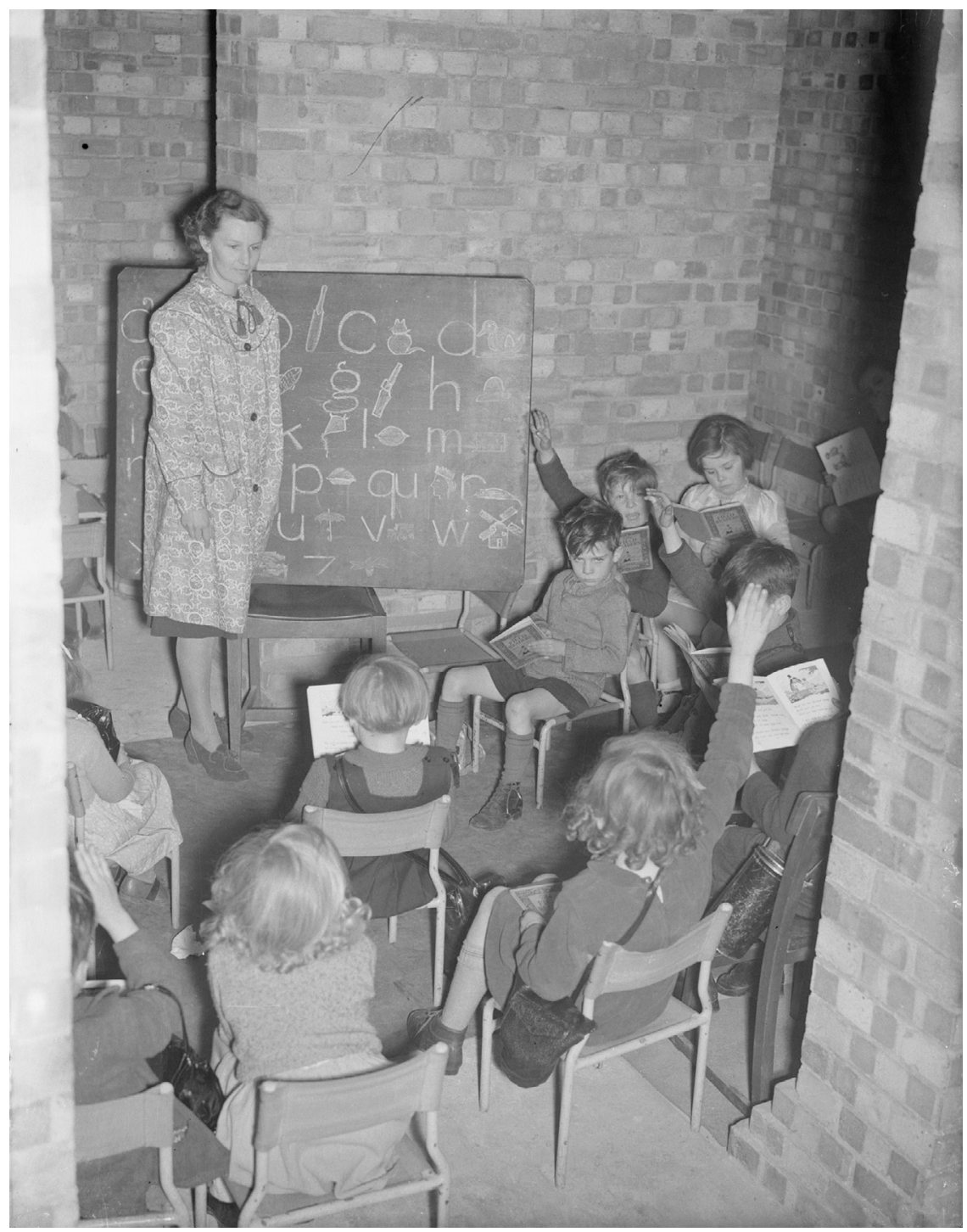

Figure 3.2 Lessons continue in the basement air raid shelter at Greek Road School, South East London. Several of the children are carrying their gas mask cases. (C) Imperial War Museum, D 3161.

Hanging over these restrictions was the memory of the bombing of Upper North Street School in Poplar in the First World War, when a 50kg bomb killed 18 young children and injured dozens more. School shelters, like the majority of public shelters, were designed to hold up to 50 people: the size restriction was an arbitrary one designed to limit mass-casualties in a direct 
hit. The dark, oblong shelters with seats down each side made it difficult for teachers to continue lessons during raids, although I have excavated a school shelter with long-division problems still chalked on one of the end walls (Moshenska 2007a). Some persisted: Hugh Morgan recalled that in his shelter 'like a long Anderson', 'There were benches facing each other along each side and during raids we'd sit on these with our knees touching, and a teacher at one end conducting the lesson. It was great fun.' (H. Morgan 2005). Others found the raids less edifying: 'Once in the shelters you could see nothing and hear little of any action outside. We played pocket chess and innumerable card games and it soon got very boring.' (D. Smith 2004). For some, the distraction from lessons was a welcome one:

We used to sing a lot in the shelter and play games on paper or play cats cradle (a game with string). If the teachers weren't looking, we varnished each others nails ... Sometimes we went down 3 times a day, even if they turned out to be a false alarm. We prayed that it would happen during our maths lesson!

(Shannon 2004)

Many teachers, adept at managing school children, found ways of keeping order and preventing panic during air raids. The insistence on regular air raid and gas mask drills aimed to make taking shelter a relatively straightforward, orderly and routine process, and some children were given designated roles to sound the alarm, light the lanterns inside the shelters, or similar 'busy work'. Jean Hopkinson recalled the positive effects of these efforts:

I can remember the air raid shelters and how, as a child I loved to go into them. In the classroom there was a device which acted as an Alarm. This consisted of a light which would flash if there was a raid and a little hammer. The child who was sitting at the desk where the alarm was would take hold of the hammer and start to bang it if the light flashed. This was the signal that we should go the shelter. What a commotion each of us had a number of which shelter we should go to. On hearing the hammer, we would all leave our desks and run to our allocated number, where the teacher would be waiting. I loved the shelter because when we got there we were given a lollipop. Lessons carried on as normal, whatever we were doing continued in the dim light of the shelter, but it was all the more enjoyable - because of the lolly!

(Hopkinson 2004)

Another account recalled that if children were in the shelters for more than two hours the teachers would come round and give them a sweet (Anon. 2005c). In some places there were similar arbitrary rules surrounding school attendance and overnight air raids so that if there had been raids overnight school started an hour later than usual to allow students to get more sleep. 


\section{Shelter play}

One of the most significant recurring themes throughout this study is children's transformation of the material culture of war into objects of play. This practice takes a variety of forms, from creative reimagining to deliberate subversion, and can serve a variety of practical purposes and psychological needs. Many of the stories of wartime childhood describe using air raid shelters as play spaces, and this takes a variety of forms. Some of these are relatively straightforward references to the shelter as a 'den', able to take on any number of identities:

The brick air-raid shelter built at the end of our small cul-de-sac made a wonderful play area for the children who lived in the street. It became a house, a palace, a log-cabin, a battleship, a tank, a prisoner-of-war camp and many other things as our imaginations took flight.

(Hammond 2005)

The accounts of play tend to be associated with positive memories of the shelters, but the forms of play vary with age. The 'den' or play-space seems to be associated with younger children, as in this account by Ray Jones which like many such stories focuses on the sense memories of touch, darkness, echoing sounds and smell of damp:

We children loved the shelter. It was our play den. We ran down the ramp and through the door, feeling our way along the dark tunnel inside, making ghostly noises and squealing to frighten each other, our voices echoing in the narrow space; then climbing the ladder at the far end, up the shaft and out of the hatch into the fresh air, then back down the ramp again and into the dark shelter, smelling of damp earth, where we would play hide and seek, lying down under the benches and holding onto each other, giggling, our hearts beating with fear

(R. Jones 2003)

This account is particularly interesting as it describes the children confronting a specific fear (of the dark), of the excitement of being scared and scaring others in a relatively safe and controlled environment, and of how this fear was mastered through shared play. Jones goes on to discuss the uses of the shelter by slightly older children as somewhere to go for 'a secret smoke in the dark', and for the even older ones to take their girlfriends 'away from prying eyes' (Jones 2003). He also notes, slightly less pleasantly, that it became a dog toilet, but the smell of urine was a nearly ubiquitous one in public shelters. Another similar account by John Conroy describes how 'the shelter was taken very seriously by the adults, but not by us kids. It became a kind of youth club.' (Conroy 2005). In this case, the shelter was associated with a specific war game: 
Close to the shelter was a set of swings, and my first recollection of shelter play, as I call it, was connected to those swings. For some fortunate reason most of the girls in our group were older than the boys. A game evolved whereby the boys on the swings were Spitfire pilots who got shot down and parachuted off the swings, the girls were the nurses who took us wounded pilots to the hospital, (the shelter) to tend to our wounds ... as we all got older the games got better, even though the boys were a bit puzzled at first, none more so than me but I do know that the shelter became more popular than the swings ... As time went by and we all got older the air-raid shelter at the end of the street was put to good use and perhaps, no, we did grow-up more quickly than we might otherwise have done.

(Conroy 2005)

This sense of the public air raid shelter as a secret space providing concealment for illicit behaviour was a very common one at the time, and alongside moral concerns there was a particularly widespread problem of children vandalizing public shelters that led to many public shelters remaining locked during the daytime. Air raid shelter play was not without its risks: Michael Collier described playing in a brick-built surface shelter on a pavement where the door opened directly onto a road: 'On one occasion I was run over by a lorry as I ran out of that door, I must have been six or seven at the time, fortunately I got off with a cut on the head and a slightly bruised foot.' (Collier 2005).

Children playing out on the street or in parks were under strict instructions to find a nearby shelter if the air raid siren sounded, including asking for shelter in people's homes. Philip Hillman and his cousin took full advantage of this, and on their way to the nearby park they would spot affluent-looking homes.

if the air raid siren sounded we would cycle like mad to the pre-destined house and enquire innocently if we could shelter. We had learnt that the more affluent the house the more 'goodies' were hoarded in the shelter. We of course took full advantage of this, and when the 'all clear' sounded we were very reluctant to leave. We never went back to the same house again but the next time chose a different one to try!

(Hillman 2005)

This cunningly acquisitive approach to taking shelter echoes the more militantly political actions of the Stepney Tenants' Defence League, a communist-influenced local community group who campaigned for better air raid shelters in working class areas, and once orchestrated an occupation of the luxurious deep shelters beneath the Savoy Hotel by working class East Enders to draw attention to the disparity between the meagre and unsafe public shelters and the opulence available to the wealthy. 


\section{4}

Air raid shelters

Air raid precautions made their way into a variety of children's games and activities: Anne Tester recalled a game she and her cousin would play with their rather elaborate dolls' house which was fitted with electric lights and drawing curtains: 'With it we played out all the wartime activities that were part of our ordinary lives and the games always featured an irate warden (always played by my cousin), who would shout at us to "put those lights out!"” (Tester 2005).

\section{Making oneself at home}

In the gendered space of the air raid shelter, the work of providing protection through buying, building or assembling the shelter fell overwhelmingly to men, while the role of women as home makers was to make them feel like homes (Butler 2018). Sometimes this division is made explicit in the memory narratives: 'We dug and sodded and sweated till it was in, then my mother took over, she removed the airing cupboard doors which fitted like a glove and made two beds, with lots of chintz and pink distemper it looked really cute.' (Stone 2003). Just as this gendered division of shelter labour reflected wider social practices, so the shelters themselves came to resemble miniatures or simulacra of the home: following Grayzel, Butler (2018) explores the ways in which the creation of secure, familiar domestic space of the shelter allowed women to assume and perform specific prescribed wartime gender roles. This transformation served a number of different purposes: it provided activities and a sense of 'getting stuck in'; it provided practical comforts such as drinks and soft furnishings that made the experience of taking shelter more pleasant; and for children (and certainly for some adults), it provided a sense of reassurance and continuity. Anne Rudhall recalled that her grandmother 'had an Anderson shelter in her garden in Perry Barr, which she carefully camouflaged with soil and flowers. It was lovely in there as she had made it look like a little house inside.' (Rudhall 2006). Joan Prewer's account shows some of the many different ways that her shelter were made homely:

The shelter inside was warm and cosy with home-made rugs on the floor. Different styles of chairs and stools were arranged around a small table which had candles, matches, books and games on it. An old wind-up gramophone stood on a wooden upturned box which had tins of food and papers stored in.

(Prewer 2004)

Rugs on the floor, furniture, food, lighting, heating and music went a long way to creating a welcoming atmosphere. Like Prewer, numerous reminiscence accounts describe their Anderson shelters as 'cosy', often for similar reasons: May (2003) found cosiness in good heating and light from an oil lamp and stove; Pearson (2004) found it in a carpeted floor and cushions on the beds; while five-year-old Annabel's Anderson shelter was 'made cosy with thick 
blankets and pillows, and a thick curtain cut us off from doorway drafts'. This last account gives a reasonably comprehensive list of the objects to be found in a well-appointed Anderson shelter, 'with bunk beds down both sides to sleep four, a small table by the entrance with a primus stove, cups and tea. Under the table were tin mugs and plates, spare torch and matches, a small box of first aid stuff, and a bottle of water' (Annabel 2003). The concrete or earth floors of the Anderson shelters were commonly made more homely with the addition of wooden boards, carpet offcuts or a rug. William Willis watched his mother make rag rugs to cover the floor and the bunks of the shelter:

in the shelter it was cold and damp. It smelled of mould, mothballs, candle wax and stale food. Mum had made rugs for us to lie on and to make the cold cement floor a little more homely. There was no spare cash to buy carpet or extra bedding, even if we had sufficient coupons. So the rugs were made from old clothing and Hessian sacks. Mum would cut old disused clothing into oblongs, about 1'x 2' each. She would then fold the cloth into a final size of 1' $\mathrm{x} 1 / 2$ ' and then sew them onto the sack, using different colours, textures and patterns to create individual designs. No two were ever quite the same. We had some examples of these in our home for many years after the war.

(Willis 2004)

In the earlier, daytime air raids many people took picnics, snacks or flasks of tea with them into the shelters, but with the move to night raids more people were eating meals underground: Bill Cole recalled the near-permanent residents of his local underground station: 'Families would stay down there while the husband went off to work or while the wives would venture out to get some food and cooked it on little Tommy Cookers.' (Cole 2005). Many shelterers ensured that they kept a supply of water for drinking, tea-making and washing, with the job of keeping it topped up often delegated to the children (e.g. Hubbard 2005). When raids could be expected every night, as at the height of the Blitz in London, supplies of food were often kept in the shelter: Joan Offord recalled that her family's Anderson contained 'a food tin which could contain biscuits, tinned milk, sugar, tea, cake etc. which we would replenish the following day' (Offord 2005).

As with so many aspects of the war, canny businesses emerged to provide aftermarket additions to the stark, standardized material culture of war. The largest range of these was probably the variety of metal gas mask boxes and oilcloth covers for the standard cardboard gas mask cases, but similarly enterprising businesses offered ways of improving or augmenting your Anderson shelter, as Brian Brooks recalled:

what about the entrance opening? A curtain wouldn't have lasted very long or have worked very well. Fortunately, my Mum said, at such times 'cottage industries' appear to meet the needs. Mr Cuddiford, our ARP Warden, found a local retired man from the Shepherds Bush side of Old 
Oak Common Lane, who looked about a hundred years old to me, who made shelter doors from old fence panels, etc. for half-a-crown (2 shillings and 6 pence $=12 \mathrm{p}$ ) [actually $12.5 \mathrm{p}$ ]. Ours was four or five vertical strips with two narrow horizontal cross-pieces on the inside; these had small block pegs on the ends that could be turned outwards to hold the door in the entrance. Two old drawer handles helped with dragging the door into place. It was painted lumpy blue, and I thought it looked very smart. A small diamond shaped hole cut near the top and covered by a piece of perforated zinc (from an old meat safe) passed for ventilation. But showing light during the blackout wasn't allowed, so later even that had to be covered with a little drawing-pinned curtain.

(Brooks 2005a)

Apart from games and toys - 'a box with games and jigsaws' - there was no distinctively childish artefact of the shelter aside from the siren suits discussed earlier (Adin 2004), yet in making the shelter homely a great deal of thought often went into the needs of the children, and as expected this practical and emotional labour fell to the mothers:

I remember that for us the whole thing of hiding in the shelter was rather exciting. It was probably because our parents tried everything possible to make it easy for us, and because we were also mixing and living with other people. My mum and the other women laid some sheets and carpets on the cold cement floor, and they hung on the walls pictures of film stars and people to make the shelter cosy.

(Coppins-Moroney 2005)

The impression of the shelter as a cosy and secure miniature or mirror of the home stands in stark contrast to other viewpoints of the shelter as a cold, damp, terrifying inversion of the domestic space. Part of the aim in 'domesticating' the Anderson shelter was to transform somewhere that seemed uncomfortably 'outside' into a homelier 'inside' space, but these efforts were easily undone by rising ground water, the bitter cold, and unwelcome fauna: several accounts mention spiders in the shelters being more frightening than the bombs (e.g. Maitland 2005), and even inducing families to flee: 'It was during one very bad raid that we saw a spider and me and my Mum and 2 sisters ran out in the garden. Dad went berserk, said we should be more frightened of the bombs! This often happened, we were all scared of creepy-crawlies.' (Brown 2005).

The domesticity of the shelter, and of the Anderson shelter in particular, was a strong reflection of its occupants' social class, not least as only those in possession of a large enough garden could install one. For the residents of the poorest slums in parts of Glasgow, London's East End and elsewhere, the available public shelters were often as poorly built and equipped as their homes and some, such as the enormous Tilbury Shelter in Stepney, with its thousands of overcrowded residents in deeply unhygienic conditions, became a byword for the looming crises of public morale, order and health. 


\section{Smell and sense memories}

I remember when the German bombers came over, us children knew the difference in the sound, then the siren at the top of our road would go, deafening ... I can still remember the noise of the bombing in the distance, and the musty smell of the air raid shelter.

(Valerie 2005)

One of the recurring themes in descriptions of air raid shelters in the accounts of wartime childhood is the variety of sense memories, including memories focused on the shelter itself such as smell and dampness, and memories of air warfare mediated through the shelter, such as the sounds and physical sensations of explosions. I want to look in more depth at these sensory dimensions of childhood experiences of air raid shelters starting with smell, although as we will see many memory narratives combine or blend the different senses in describing the shelters. Fred Clark's account of his family's Anderson shelter is a striking example of this, covering smell, damp, sound, restricted space and feelings of safety and security:

The memories that come back to me when I was taken into the shelter are that of a smell of dampness and candle wax, candles being our source of lighting. I believe that there was a radio and some form of bedding. I can remember the air-raid sirens warning us to take shelter, the crump of explosions, and anti-aircraft fire, searchlights sweeping and probing across the night sky also the distant glow from the bombing, depending how near this was, waiting for the all-clear siren, my mother's remarks such as 'some poor sods are getting it heavy tonight, it looks like it could be the docks' ... The shelter was not a place that you would want to spend much time in, because most of it was submerged into the ground it suffered from dampness and condensation making rusty marks down the interior walls, which were made from curved corrugated iron sheets covered with earth at the top set on a small concrete base and inner wall, so the interior was a damp smelly and a cramped space but offered a feeling of safety when bombing was near ... On the grassy section in front of our houses, another shelter was built, this was a flat roofed shelter probably for the use of the flats. Our family did not use this shelter and I have no memory of it being used much, I can remember going in to look around, it was very dim, there were some tiered bedding along the walls. It smelt quite damp with more than a hint of urine, it was often used as a play area and was not very clean.

(F. Clark 2005a)

As mentioned earlier, a great deal of early air raid precautions work focused on the risks of poison gas, and for this reason many public air raid shelters were built with limited ventilation, and most could be made superficially airtight with heavy doors and other materials. While this was not the case with 
domestic shelters and many other public shelters, the efforts to maintain the blackout with doors and heavy blankets could also restrict airflow in and out of the shelters.

The smell that most affected the public shelters was the stench of tens or hundreds of bodies, at a time when bathing was generally not as frequent as today, even before the restrictions of the shelter are taken into account, as one man recalled: 'we would get up feeling very dry and grubby having slept fully clothed all night'. This combined with the common overcrowding of the shelter and the lack of ventilation mentioned above created what one account of a boarding school shelter called 'a tremendous smelly fug', noting that 'In the mornings the clean cold air outside was delightful as we emerged blinking and dishevelled and carried our blankets up to the dormitories to hang over our beds to air.' (D. Smith 2004). Looking at the recorded reminiscences there were several other specific smells that were associated with the shelters: several accounts mention the lamps, fuelled with oil or kerosene, that were used for light and heat and 'the continued smell of the earth and muskiness of bedding that had been left down there' (Worrall 2005).

The smell and generally unpleasant atmosphere of some shelters actively deterred the public from making use of them: in fact many shelters, particularly those built in a hurry during the Munich Crisis or the early years of the war, were deemed unfit for purpose in a variety of ways, with flooding one of the most common. Several of the accounts describe baling water out of the shelters before they could be used, but most seem to have not unreasonably deemed the water-filled shelters too unpleasant to use, as Bill Cole recalled:

Most of the underground shelters, like the one in Bedlam Park, were smelly and always damp, so hardly anyone was willing to use them. This was lucky as one night Bedlam's shelter did get a direct hit and no one survived.

(Cole 2005)

Within the shelters the body heat and exhalations of the resident population created an atmosphere that was as moisture-rich as it was pungent, and numerous accounts of Anderson and public shelters describe the problems with damp: 'we had electric lights in the shelter, so you could see the constant rivulets of condensation running down the corrugated iron frame of the shelter '; 'Condensation collected on the concrete walls and slowly trickled or dripped on to our blankets.' (Worrall 2005).

Given the close connections between autobiographical memories and smells, it is unsurprising that many of the accounts of air raid shelters mention these sensations. Roy Keen noted this in relation to the smell of the temporary toilets installed in Aldwych underground station for those taking shelter there: 'The shelter toilet arrangements consisted of large metal drums surrounded by canvas curtains to give some privacy. The drums were filled with a strong disinfectant and even today if I smell that same disinfectant I am mentally transported back to that time immediately.' (Keen 2005). This 
chimes with my own experience of inviting wartime pupils of a North London primary school to visit the newly excavated school air raid shelter: several of them specifically mentioned how the musty smell brought back very vivid and powerful memories. The memories of the shelters are of course tied to other senses, memories and emotions, as with Patricia McGowan's account:

The entire area of the shelter smelled dank and very earthy and at first it was unpleasant but gradually our nostrils became used to the odour and we even associated this smell with safety, as this was the place where we could have some hope of escaping death or injury.

(McGowan 2004)

The mustiness, mould and damp of the shelters also contributed to ill-health, in particular respiratory problems. Maurice Westcott's mother contracted pleurisy, while Yvonne Worrall's sister suffered from whooping cough: she noted that 'As children, we were always tired, had colds that would today be called bronchitis, they never went away. If you had a childhood illness, you still sat in the shelter.' (Worrall 2005; Westcott 2005). Another common health problem, particularly in public shelters, was scabies, a contagious skin condition caused by infestation with a burrowing mite, as Harold Pollins recalled:

in those circumstances, with people huddled together in air raid shelters, dirt was commonplace and many people found themselves itching. The cause proved to be scabies, occasioned by a parasite that bore into the skin ... I remember my family suffered from this and we went to the doctor who told us it was scabies which was something of a shock, as we knew or were told that it was a disease related to dirt, and it was shaming to be caught up in it. He advised that to the next baths we had we should add sulphur. This made the water go yellow but it did the trick of killing the parasite. The word scabies was thought too brutal to use. Instead people called it 'Shelter rash'.

(Pollins 2005)

The government commissioned research into the transmission and treatment of scabies from entomologist Kenneth Mellanby, who recruited conscientious objectors as his test subjects, and identified several successful courses of treatment.

\section{Soundscapes}

Alongside smells, the sense that children of the Second World War most commonly associated with the air raid shelter was hearing. Hidden in these deliberately windowless spaces the air war could be heard but not seen, and the variety, intensity and emotional and psychological impacts of these sounds is clear from the accounts in the People's War archive, such as Joy Caswell's memories of one specific evening raid: 
I can vividly remember running down the garden, hearing the sirens and what sounded like guns going off. The German planes made an awful loud pounding noise ... It sounded as if these guns were being fired and bombs were being dropped non-stop. The ground shook so badly and one large brick came through the roof of our house. The force of the bomb blast also blew out most of the windows in the back of the house ... The noise of the bombing that evening will remain with me forever.

(Caswell 2005)

I have previously explored the issue of soundscapes of air warfare in more depth (see Moshenska 2017), but here my focus is on the air raid shelter as mediator and as the space where the sounds and sensations of the bombing war were experienced. Brian Brooks described the extraordinary, overwhelming sensory experience of the air raid:

It had been quietish for a night or two and, although dressed ready for the Anderson shelter in my siren suit, I was asleep on Mum's bed in the back bedroom. I woke up being pulled from the bed by my sister Beryl. I was puzzled as the 'black-out' and curtains were gone from the window and I could see lots of criss-cross black lines against bright red flames ... the noise of crackling, pops, bangs and a roaring sound followed by a 'whoosh cruummppp' suddenly filled my ears. Someone was shouting at me from a long, long way away 'Wake up ... come on ... Hurry ...' Stumble down stairs - cold air on face outdoors - suddenly wide awake. In the few yards to the shelter I took it all in, the searchlights, the exploding shells, the red clouds - the smell of smoke and burning - and a wall of fire on Long Drive (the street behind our house). And the noise - crack-crack-crump and spang-pertanggg of AA guns and rockets (on Wormwood Scrubs), aircraft engines, crackling roaring and bangs from the fire - and bells. I was pulled into the shelter entrance as Mum ran up with Jasmine, bag and blankets. As I looked back at Mum I saw it all again, reflected in our windows - bright flashes of shells, flames and sparks jumping up, lighting up clouds of smoke.

(Brooks 2005c)

While the smell of the shelter might invoke memories most clearly, the sounds that the sheltering children heard seem to have created the most powerful and affecting recollections. The typical soundtrack of an air raid began with the warning siren, or in some areas a bell or similar. This was the signal to take shelter, and from then on the sounds would be muffled by the shelter: the approach of aircraft; the firing of the anti-aircraft guns (and occasionally, as above, rockets); followed by the sound of bombs, and finally the all-clear signal on the air raid siren. Sometimes the bombers would come in waves, and there would be periods of calm between the sounds of engines, guns and bombs. With the arrival of the V1 flying bombs in 1944, a new soundtrack emerged: following the warning would come the rattle of a solitary pulse-jet engine, the 
simple and cheap propulsion unit for the missile. When the engine cut out there would be a tense silence before the sound of the explosive impact.

As part of the discipline of aircraft recognition (see Chapter 5), many young people learned to recognize the difference between the sounds of different aircraft, in particular 'the very distinct undulating pitch of the engines of the German bombers, the curious rhythm of the unsynchronised twin engines which contrasted with the single engine or synchronised pair on the British fighters that intercepted the attackers' (Collier 2005). As well as the bombers there was the sound of the bombs themselves, some of them equipped with whistles to strike fear. Brenda Maitland recalled the sound of a near miss:

Night after night we spent in the shelter, listening to the sound of antiaircraft guns, the steady throb of German planes going overhead, and the awful piercing whistle of a bomb coming down. One night a bomb screamed towards us, with a deafening whistle. It seemed to take forever before it reached the ground and then, silence. We clutched each other in terror. It had not exploded.

(Maitland 2005)

As with so many potentially traumatic aspects of the war, the attitude and behaviour of parents and other adults provided a model and a framework of understanding for children. One girl recalled that her father rarely joined the family in the air raid shelter, as he was generally either at work or firewatching on the factory roof:

He sometimes got home in the early dawn. When he was there, he was reassuring and confident. 'Safer in here than the trenches,' he said. I didn't know what the trenches had been like then. 'Listen to the guns,' he said. 'That's our lot shooting down their bombers.' I wasn't afraid. I went to sleep lulled by the noise of our Ak Ak bringing down the enemy from the sky.

(Annabel 2003)

Of course, not all of the sounds of the air raid shelter were sounds of air warfare: numerous accounts, particularly of public shelters, describe families bringing gramophones, radios and musical instruments both as ways to pass the time and to help muffle some of the sounds of aircraft, guns, bombs and sirens. With a bit of imagination even the shelters themselves could make some noise: Eileen Whitmore and her sister Grace waited until the all-clear siren had sounded before they leapt onto their steel Morrison shelter and tapdanced loudly on its roof: 'As the roof of it was made of metal it made a smashing sound.' (Whitmore 2004).

For the most part the soundscape of the shelter, particularly the public shelters, underground stations and other more social spaces was the sound of the crowd: talking and yelling; children and babies playing, crying, shouting; and the full range of bodily noises (Figure 3.3). As Bill Cole noted, 'There 


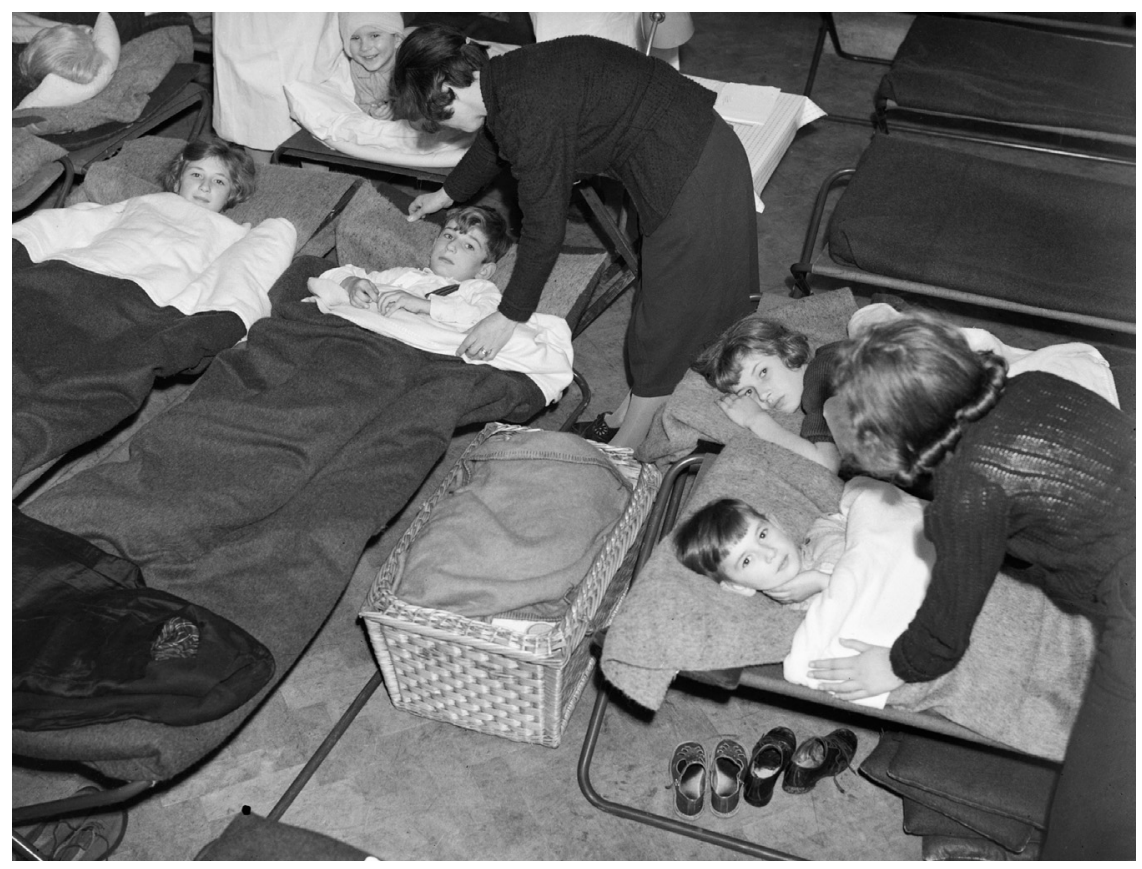

Figure 3.3 Children being put to bed in the air raid shelter of John Keble Church, Mill Hill. (c) Imperial War Museum, D 1439.

were babies crying and children running around, and coughing, and snoring, it was a wonder people slept at all' (Cole 2005). At the excavation of a school air raid shelter one of the former students I interviewed told me that although metal buckets were provided in separate compartments for use as toilets, no child was willing to use it as the noise echoed in the shelter leading to great embarrassment and ridicule: accordingly, he and many other children emerged from the shelter, particularly after long warning periods, in extreme discomfort but stubbornly unwilling to be heard urinating so loudly.

When the bombs and guns stopped, the aircraft departed, and the all-clear siren sounded, the change could be striking, and particularly at night the silence could seem almost unnatural. Yvonne Worrall described how 'If we were lucky, we would get the all clear around three o'clock and manage to get some sleep till eight, then we would go off to school. It was eerie, the quietness after so much noise, like you had suddenly gone deaf' (Worrall 2005).

\section{Explosions}

The extremely high volume of the sounds from bombs and anti-aircraft guns could move it from the heard into the felt; from an auditory to a fully embodied experience. The majority of bombs dropped from German aircraft 
were $50 \mathrm{~kg}$ or $250 \mathrm{~kg}$ high explosive bombs, and their detonation created a shock wave through the air and through the ground, as well as the effects of blast and shrapnel in the immediate vicinity. The blast could shatter windows and doors but the shock wave could also cause significant damage including structural collapse and could shake shelters to their foundations:

Our house was bombed during the winter of 1941 and I was only fourteen years old. The building was in Golborne Road, North Kensington; I lived there with my parents, my brothers and sisters, but we all survived because at the time of the bombing we were hidden in the air raid shelter nearby with another family. When the bomb exploded the shelter shook and all the children started to cry, it was a terrible and frightening moment.

(Coppins-Moroney 2005)

Anderson shelters such as this one could better withstand this sort of impact: the earth insulated them, and the corrugated steel structure could flex and bend without breaking. In contrast, brick-built shelters were often more fragile: Roy Keen described seeing 'the dust being shaken out of the brick walls as the explosions occurred close by and at the same time seeing a sign on the wall saying "Happy Christmas"! (Keen 2005). Another recalled the noise of the nearby anti-aircraft artillery as well as the bombs:

The sound grew louder, and as it did the anti-aircraft guns started to fire. They sounded very close as they were mobile and moved around to get the best advantage for firing at the planes. The gunfire grew louder and louder and then the bombs started to drop and explode all around us. The air raid shelter shook and then rocked from side to side but managed to stay intact.

(Gloria-Jean 2005)

Many of the accounts like this record the sense of rocking or riding a wave of the explosion. One described 'that extraordinary feeling of the earth coming up and going back down again, and coming up and going back down again' and another compared it to 'rocking like a ship at sea' (Hird 2005). Tom Ebert's account of riding the shockwaves in an Anderson shelter describes both the sensation and the terror of bombs falling so close by:

The explosions came nearer and nearer until at last they were upon us, and the bombers were overhead. I recall terrified screams from the women and children every time bombs landed near us (which was frequently) and everybody being thrown into heaps side to side by the concussion waves of the explosions through the earth. I know that I kept breaking into hysterical laughter which turned into tears every time there was an explosion. The bombing seemed to go on for hours and hours but now and again in an infrequent lull in the bombing, we had to open the door of the shelter to get fresh air.

(Ebert 2003) 
One of the more curious pieces of material culture associated with the shockwave effects of bombing was the 'India rubber' mouth guard that was worn between the teeth to prevent biting one's own tongue in the shock of an explosion. In one account, it is worn only by a grandmother, while another entire family is described 'sat shivering, india rubbers in our mouths' and noted that they were also meant to stop teeth being damaged by biting down too hard, again as an effect of the shock waves (Anon. 2005d; Tonsor 2003). Sometimes the rubber mouth guard would be attached to a handkerchief to assist in its retrieval, if it were accidentally swallowed in the shock of the explosion (Shaw 2012: 183).

\section{Bombing, death and trauma}

Very few of the public or private shelters provided for the British population were capable of surviving a direct hit even with a relatively small bomb. The image of the London Underground stations as impermeable to bombs belied the relatively shallow depth of many of the platforms: more than 60 people were killed at Balham station on 14 October 1940 when a $1,400 \mathrm{~kg}$ bomb penetrated almost ten metres below the road surface, causing the underground tunnel to collapse and destroying water mains and sewers. Some of the most powerful memories of the shelters are of those who survived near-misses or direct hits. Roy Keen experienced a near-miss in his family's Anderson shelter that landed directly across the road, killing several neighbours and tearing away the heavy wooden door to the shelter, as he recalled: 'I had a fit but soon recovered.' (Keen 2005). Bernard Hubbard's father had been seriously wounded in the First World War and was too old for military service, so he was at home with his family on 28 April 1942 during a daylight air raid on Norwich.

That particular day, while we were in the shelter, we suddenly heard 'planes and then bombs dropping like rain. My house collapsed on to the shelter and my father's head was very, very badly damaged. There was so much blood and he died in the shelter. For two and a half days my stepsister, my mother and me sat in the shelter. We were up to our necks in water because a water main had been hit and as a result everything had become flooded. I was only ten years old at the time and I felt I was going to drown. The air-raid wardens finally dug us out. We then discovered that not only had my Dad died in the raid, but many children in the street had as well. Many of these children had been my friends.

(Hubbard 2005)

Such a long delay in being dug out was unusual but not unknown. Alongside air raid wardens and the fire brigade, the civil defence teams included light and heavy rescue squads, who searched for survivors in bombed buildings. Usually made up of council employees and tradesmen, these teams would attempt to secure the more unstable ruins, turning off gas and water and removing rubble 
and debris. The need to proceed with caution in structures threatening further collapse meant that rescue work was often slow, and in many cases only corpses could be recovered. It is notable how, in describing some of the most horrifying and traumatic events of their childhoods more than 60 years earlier, Hubbard like many of the people whose memories are recorded in the People's War archive seems to revert to a more childish language.

One day before the Balham Tube bombing a large public shelter in Stoke Newington, North London, received a direct hit from a bomb that passed through the block of flats above before detonating in the shelter itself. The shelter beneath the Coronation Avenue buildings was believed to be safe, and several hundred people used the three rooms, sitting or lying on narrow benches.

We had settled down as usual, when there was a dull thud, a sound of falling masonry, and total darkness. Somebody lit a torch - the entrance to the next room was completely full of rubble, as if it had been stacked by hand. Very little rubble had come into our room. Suddenly I felt my feet getting very cold, and I realised that water was covering my shoes. We were at the end of the room farthest from the exit. I noticed my father trying to wake the man in the bunk above him, but without success - a reinforcing steel beam in the ceiling had fallen down and was lying on him. The water was rising, and I started to make my way to the far end, where the emergency exit was situated. Everybody seemed very calm - with no shouting or screaming. By the time I got to the far end, the water was almost up to my waist, and there was a small crowd clambering up a steel ladder in a very orderly manner. Being a little more athletic than some of them, and very scared, I clambered up the back of the ladder to the top, swung over, and came out into the open. It was very cold and dark, and I was shivering. The air was thick with brick dust, which got into my mouth, the water was squelching in my shoes. I still dream of, and recall, the smell of that night, and the water creeping up my body.

(Anon. [Edison] 2003)

Around 160 people died in the shelter that night, and Lawrie Edison and his family were amongst the relatively few survivors (Loewe 2012). Like many young people in the Blitz Lawrie and his sister exhibited a range of trauma responses both at the time and later, and up to the present.

My sister said she was alright, until she went up into our parents room the next morning, and saw soldiers arriving outside, with shovels - then she started crying (she was 15 years old). A few days later, I saw men wearing gauze masks bringing out bodies, and placing them in furniture vans. Having seen bodies since, this is the only thing that comes back in my dreams - the furniture vans and the water.

(Anon. [Edison] 2003) 
The theme of fear and lasting trauma appear frequently in memory accounts of children in air raid shelters. Just as the shelters became associated with the sounds of air raids, they were also the spaces in which many of the most violent and traumatic events were experienced or witnessed, such as those described above, and these emotional and psychological legacies are part of the life history of shelters. Children's experiences of trauma were powerfully mediated by parental responses, and many parents made efforts to protect their children from awareness of some of the violent realities, risks and their own fears, with varying degrees of success. When Salisbury experienced its first air raid warning, Margaret Goulding's mother wrapped her in a blanket and hid in the understairs cupboard:

She told me many years later about this episode, and how she had sat there with a small torch trying to read the leaflet 'what to do if there is an air raid', and shaking with fear. She said I was very quiet, but then suddenly asked her when we were going to die - which upset her even more, and she never forgot that moment.

(Goulding 2005)

Some of the traumatic responses are specifically associated with sense memories of air raids, one of the most common being the sound of the air raid siren, including its use in the closing credits of the television show Dad's Army. Roy Keen whose sense memories of the shelters were sparked by the smell of disinfectant (discussed earlier) found that even decades after the war ended the sound of a siren used to summon volunteer firefighters in the far north of Scotland that sounded similar to the air raid warning could trigger a panic attack (Keen 2005). Cultural attitudes to mental health played a damaging role in keeping people from seeking what limited help was available, both at the time and later:

Trauma counselling?? Non-existent ... The nearest we would have got to it would be remarks on the lines of 'You're alive, ain't yer? Be thankful! Plenty of poor sods who ain't' and as we didn't realise we were traumatised - we got on with it!! However, even now, aged 70, if I hear the sound of an air raid siren on the television I become emotional and choke up, so there must be something in this counselling.

(Ebert 2003)

In response to the heavy bombing of Southampton in 1940, seven-year-old Margaret May came to believe that the family's Anderson shelter was the only place of safety, and became reluctant to leave it for any reason. Her family tried to lure her out by bringing out her Christmas present and placing it by the back door of the house. As she recalled, 'I ran up the garden, took a peek, said "Yes, it's nice" and ran back to the shelter' (May 2003). Shortly afterwards she was evacuated to rural Dorset, where on requesting to sleep in the air raid shelter, she was pointed to the ditch at the end of the garden and persuaded to sleep indoors. 


\section{Afterlives of shelters}

By the end of the Second World War the threat of German air raids had declined, and attacks with V1 missiles had tailed off as their launch sites were overrun by Allied troops, although they and the highly destructive V2 attacks continued until late March of 1945. With the end of the war, the air raid shelters had reached the ends of their useful lives. Many public air raid shelters were demolished, particularly the flimsily-built brick surface shelters, while some of the subterranean shelters beneath parks and playing fields were merely sealed with concrete, and I have had some interesting experiences opening and exploring these (see Moshenska 2007a; 2013). Larger shelters returned to their original uses as basements, cellars and warehouses, while some of the purpose-built tunnels were transformed into storage spaces and in a few cases into underground mushroom farms. The steel Morrison shelters were easily dismantled and removed leaving little trace beyond scuffed floors, while the Anderson shelters buried in gardens presented a greater challenge. Some local councils tried their luck 'selling' the shelters to the homeowners, most of whom called their bluff and invited them to remove the shelters at their own cost. In many cases the shelters were dug out of the ground and the modular steel panels reused, with the curved roofs most often transformed into garden sheds with wooden end panels, doors and windows:

I remember when we took it out, later after the war, my father decided to take it out of the ground and made it into a shed - a lot of people did this - and he painted it green. I don't know where he got the green paint from. He was up a ladder painting the top and I was behind him, and he came off the ladder, the paint went up in the air and it landed all over me. They cut my hair to get as much of this green paint off as possible and then washed my hair in this paint stripper/turps to get the rest out.

(Porter 2005)

These often lasted for many decades: David Britton's father had his Anderson shed until the 1980s (Britton 2005). Joan Shepherd's neighbours had built their own shelter out of concrete, and this also lasted until the 1980s when it was demolished with pneumatic drills.

Where air raid shelters in Britain have survived into the present, it is generally through ignorance or apathy rather than deliberate attempts at preservation. Installed or constructed in the panic of pre-war or early wartime preparation, often by private contractors, many shelters have left minimal documentary evidence, and those that were deemed unusable or relatively little-used due to location, water levels or other reasons have often been forgotten. A few of the larger tunnel shelters have been opened as museums including those in Stockport and the Chislehurst Caves in Kent. Some schools have preserved their air raid shelters and open them for teaching use or on special occasions, but health and safety concerns often prevent their use. The greatest amount of interest in air raid shelters operates on local levels, with amateur historians and historical societies working to map, study, visit 
and preserve shelters. The most notable such organization is Subterranea Britannica, a study group for man-made underground spaces of all kind. Despite this, I would argue that air raid shelters are one of the most neglected categories of heritage sites in Britain today, and there is a significant need for greater scholarship of their architectural, social, cultural, political, artistic and medical histories, as well as greater national scale concern for their preservation and presentation to the public. Much of the significance of shelters and their value of material reminders of wartime life can be demonstrated in this account by Brian Brooks:

Suddenly the war in Europe was over, and we had no need to shelter from air raids anymore, which seemed very strange at first. Some of my friends' families, who had paid for their Anderson shelters, dug them up and put them on the surface. With doors fitted they made useful garden storage sheds. (One or two can still be seen in old gardens.) I wanted to get into and use our shelter. I thought I could store things in it, and play war-games, but when I pulled the door away the shelter was full of black water and was extremely smelly. It was obviously dangerous, so the door had to be wedged in place with stakes, to stop my young sister Jasmine, aged five, falling in. Unfortunately that was the very last time I saw inside it. It had been in our garden for more than half my life, for as long as I could remember, in fact -a large pile of earth that I played round and now finally, on. At long last I could climb on it without 'damaging' it! When it first arrived it was taller than me, now I could easily look over the top. It was, and always had been, part of my childhood 'landscape'. Then -as suddenly as it had arrived -it was gone. I got home from school one day and went out the back - there was just bare lumpy earth where it used to be. Mum said the Council men just smashed the 'concrete', pulled out the corrugated iron, put the earth back, and straight on to the next one. It was gone in no time at all she said, smiling and obviously pleased. The garden suddenly looked big and it was strange to be able to look, and walk, straight across it. Mum wanted to put grass seed down, and perhaps make another rockery; to put it back to the way it looked before the war. Although I was only ten, I understood that adults wanted to wipe-out the war-time things, the reminders of bad times and unpleasant memories. But I remember feeling an uneasy sense of loss at its disappearance. I had lost something large, reassuring and protective. I think we owed it a lot, and I would have liked to have seen our shelter go ... But it was still down there - the remains of the crumbly concrete floor and walls, a pin-up picture of 'Jane' of the Daily Mirror, a toy Spitfire, and a lot of my childhood - noisy, exciting, anxious, precious and very, very lucky - yes, a sheltered childhood.

(Brooks 2006)

Here is the air raid shelter as a symbol of wartime childhood: an object of play; a scale to measure oneself against; a hazardous place; a familiar and comfortable part of a child's geography; a source of security and protection and finally - even in its absence - a repository of memories. 


\section{Discussion}

Air raid shelters were artificial or artificially delineated spaces that, like gas masks, were experienced by British children as direct material impositions into their everyday lives. While the gas masks could be ubiquitous in their presence but only rarely worn, many children (varying greatly by location) spent considerable amounts of time inside air raid shelters, particularly in the early years of the war and again later, following the beginning of the V1 attacks in 1944. Shelters were created, adapted and crafted into gendered spaces to a similar if not greater degree than the family home, and in many respects aimed to replicate the familiarity and comfort of the home through fittings, decorations and creature comforts. This was the case both in private shelters where the space could be more easily and totally controlled and also in public shelters where private spaces were often claimed or marked out with blankets or simply by near-permanent occupation.

Children's experiences of air raid shelters were complicated and varied, ranging from positive feelings of safety, cosiness and fun through to devastating trauma, terror, injury and death. These extremes and the diversity of lived experience that they enclose are encoded in the memories examined in this chapter, and it has been particularly interesting to note the variety and raw power of the sense memories associated with air raid shelters, some of them functions of the materiality of the shelters themselves, and others relating to the shelters as the medium through which most people experienced the air war. The overwhelming sense memory relating to the shelters was smell: the damp and musty smell of earth, humidity, restricted airflow, chemical toilets, unaired or mildewed bedding and the stench of unwashed human bodies pressed into a small unventilated space for extended periods of time. This barrage of powerful sensations combined with the emotional intensity of the experience of bombing seems to have created enduring memories in many children who experienced them; memories easily brought to mind by those same smells. The second powerful memory of wartime childhood in the air raid shelter was sound: the warning sirens and the engines of approaching aircraft, then the louder sounds of artillery and bombs exploding, and at the extremes the shockwaves of the exploding bombs that moved beyond the audible to shake buildings, shelters and bodies.

More than the bombsites, the schools under wartime restrictions or the places of evacuation, the air raid shelter was the most significant defining part of most children's geographies of war. As inhabited spaces, purposeful structures and frameworks for imaginative play they stand out amongst all forms of the material culture of childhood in wartime for their sensory impact and enduring mnemonic power. There is a great deal more work to be done on these fascinating spaces across more than a century of air warfare spanning the globe and continuing into the present day. 


\section{Bombsites}

But perhaps my most vivid wartime recollection of all - were the bombsites. Blanketed with brambles and clumps of pink willowherb, we peered down the gaping craters, littered with crumbling bricks, pipes and planks and wondered about the houses which had once stood there and the families who had lived in them. And for many children of my generation, these ruins became our personal playgrounds. Of course we all knew that they did not really belong to us, but in our childish fantasies we liked to think that they did! In my mind's eye, I can see them still and oh, there were so very, very many of them.

(Noble 2004)

\section{Introduction}

The ruins of bombed buildings in Second World War Britain were disorderly, marginal spaces in the urban landscape. During and after the war they proved fertile ground for weeds and wildlife, as well as for artistic and literary representations of violence and loss. But while the works of John Piper, Henry Moore, Rose Macaulay and others represent one vision of wartime urban ruin, the literature of wartime childhood in the works of Jill Paton Walsh, Robert Westall and Michelle Magorian has instead emphasized young people's anarchic, joyous and sensory engagements with bombsites (Agnew and Fox 2001; Macaulay 1996; Stansky and Abrahams 1994). Like the willow herb that had sprung up in the ruins of bombed homes, the children who rampaged across the rubble were a symbol, a celebration and a cause of this disorder and fertility.

Architectural ruins have a rich intellectual and cultural history. From the unfinished Tower of Babel and the fragments of ancient Rome to the shell of Oradoursur-Glane and the twisted wreckage of Ground Zero, ruins have served as symbols of human folly, wickedness and failure, but also as sites of nostalgia and romance (Macaulay 1996; Woodward 2002). In recent years a growing number of geographers, photographers, anthropologists and archaeologists have turned their attention to the modern ruins left in the wake of war, economic decline and environmental catastrophe (Dawdy 2010; Edensor 2005; González-Ruibal 2008). 
These ruins of modernity or supermodernity in Bhopal, Banda Aceh, Beirut and Detroit are often discussed in negative terms, categorized alongside mass graves and concentration camps as spaces of abjection, trauma, 'super-destruction' and the 'failure of modernity' (González-Ruibal 2006; 2008). My aim in this chapter is to offer a counterpoint to these foundational studies, weaving together narratives of young people's often ambivalent encounters with bombed buildings in Second World War Britain to create a more subtle way of conceptualizing ruins as literally and figuratively fertile spaces of anarchy, play, transformation, freedom and ecology, and for the creation of enduring and often treasured memories. Following Dawdy and Edensor, ruins emerge from this study as neither abject nor romantic, but as living, multi-layered spaces of human activity and experience.

The ruined buildings that came to characterize urban landscapes in wartime Britain were a considered outcome of German military strategy. The strategic bombing of British cities during the Second World War was intended to destroy industry, infrastructure and housing, and to kill civilians, diminishing the capacity of the surviving population to work and fight (Overy 1982). The ARP wardens, police, fire brigade and rescue squads focused on recovering casualties from the bombsites, then deterring looters, salvaging usable materials, and converting the newly available spaces into resources for civil defence and fire fighting (O'Brien 1955). With gas and water leaks plugged, and bodies and valuables recovered, the shells of homes and workplaces were most often left in ruins where weeds took over.

The children of Britain approached this landscape of ruins with a very different mind set. Throughout the war years and long afterwards, as attested by photographs, memories, memoirs and censorious contemporary accounts, children used bombsites as adventure playgrounds. Despite official and parental disapproval and the inherent dangers involved, the ruins of urban Britain played host to the full range of childhood activities including creative and destructive play, war games, gang fights, den-building, looting, arson, collecting, hoarding, sexual experimentation and general socializing (Figure 4.1).

In this chapter I examine the bombsite through the eyes of war children as a physical space, a social place, an ecological and entropic process, and as a marginal 'disordered space'. I attempt to piece together the nature and broader significances of this interaction of people and place, with its necessary reimagining of concepts of play, transgression, ecology, risk and the unhomely. At the same time, I am interested in the adult responses to children's appropriation of bombsites which included intense scrutiny, violent punishment and, on occasion, thoughtful reflection. I am particularly interested in the social and educational reformers who saw in children's play on bombsites a model for healthy play, psychological development and recovery from trauma, and ultimately for the construction of 'formal' adventure playgrounds in post-war Britain. My examination of bombsite playgrounds is focused on three questions: what kind of spaces were these? How did children interact with and recreate them? What were the social and psychological implications of these interactions? 


\section{Bombsites}

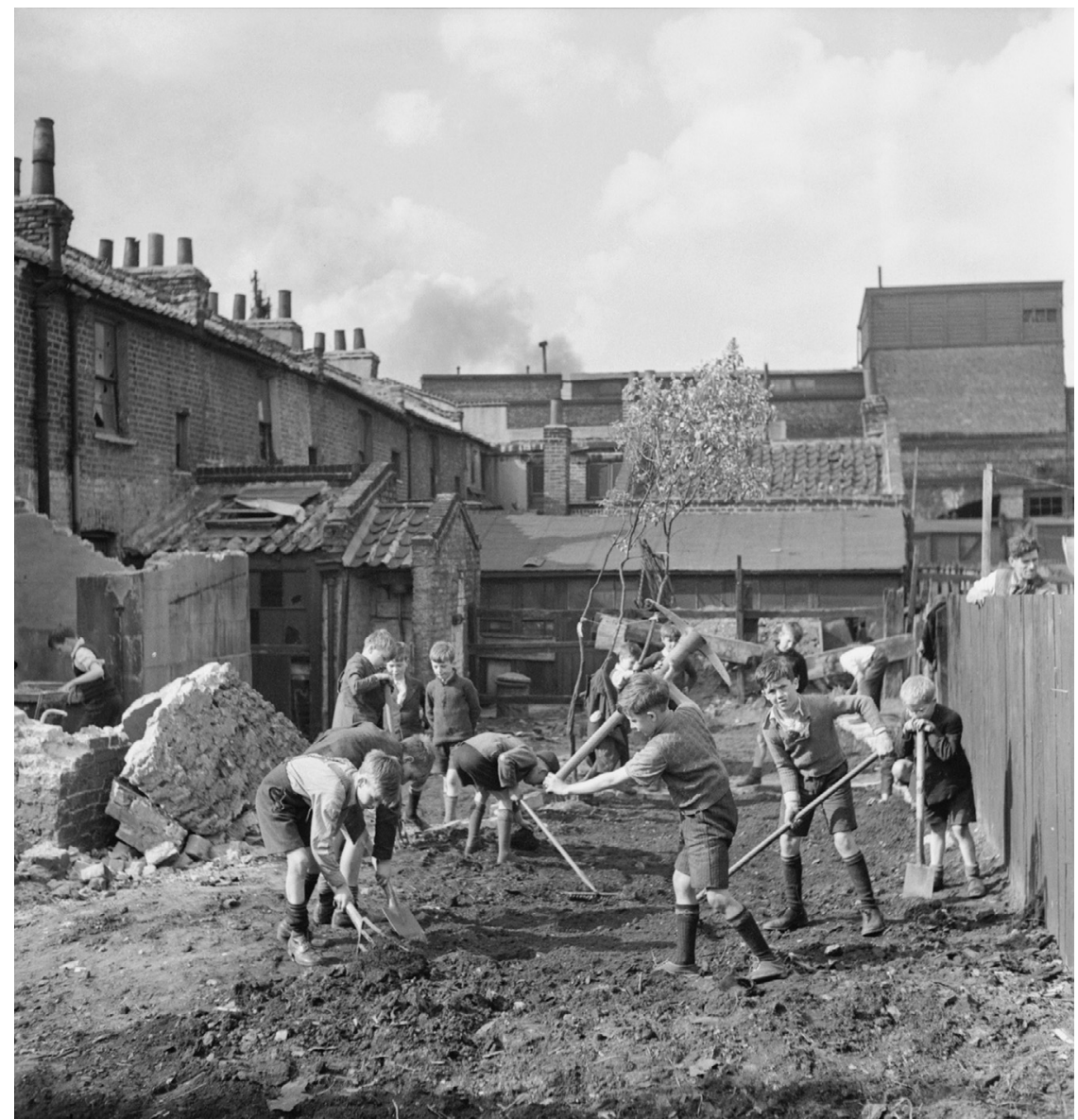

Figure 4.1 Children working on a makeshift allotment on a London bomb site. (C) Imperial War Museum, D 8957.

\section{Creating bombsites}

The transformation of a building into a bombsite was in some respects a very rapid process. In other respects the creative process continued in the hours, days, weeks and years after the moment of detonation as search and rescue efforts gave way to infrastructure repair, salvage and general clearing up. Following these anthropic efforts, the bombsites began their second transformation, an ecological one, as the omnipresent purple rosebay willowherb colonized the ruins. The creation of a bombsite begins, however, with a bomb.

The vast majority of the bombs dropped on Britain by the Luftwaffe during the Second World War were general purpose weapons such as the Sprengbombe Cylindrisch 50 or 250,50 or $250 \mathrm{kgs}$ in weight respectively and 
fitted with a short-delay fuse (Price 1997). They were fin-stabilized to fall nose first, while the fuse and relatively strong steel casing enabled the bomb to bury itself in the ground before exploding, thus maximizing the structural damage caused by the blast. Approximately half of the weight of the bomb was the explosive charge, typically a mixture of Amatol and TNT. With no propellant or guiding mechanism these bombs followed a parabolic trajectory, with the initial forward velocity provided by the aircraft causing the bomb to strike the ground at an angle. At the moment of detonation the solid explosive charge of the bomb was transformed into a high temperature, high velocity gas, causing blast damage in its immediate vicinity and seismic effects over a larger area. Further damage was caused by bomb fragments and other material projected outward from the detonation with considerable speed.

The effects of a bomb on buildings varied considerably, based on the size of the bomb, the construction of the building and its distance from the point of detonation. Most were capable of completely annihilating a building leaving only a crater in the earth. At short range the walls of buildings could be pushed in or sucked out by the blast causing structural collapse. At longer range the tremors caused by subterranean detonation could shake buildings to the point of collapse. At a slightly greater distance these tremors might distort the walls without causing catastrophic failure, and bomb fragments and other debris could destroy windows, doors and roofs. At an even longer range the damage might be limited to broken windows and roof tiles. Any of these could cause death or serious injury to inhabitants with flying glass and falling debris amongst the most common causes. Even an apparently slightly damaged house might be found to be structurally unsafe following bombing and require demolition (O'Brien 1955).

Following the explosion various emergency services converged on the site. The local air raid wardens were usually first to arrive, followed by the fire brigade, ambulance and the heavy and light rescue squads as required. Fires caused by the bomb or by ensuing gas leaks were extinguished and survivors were located either in the wreckage, in nearby shelters or elsewhere. In some cases the efforts to find survivors trapped in the rubble would continue for days, as emergency services found resources stretched by a constant stream of urgent callouts. Surviving residents often attempted to recover possessions from the ruins of their homes with the help of salvage teams, and looting was not uncommon leading to police or air raid wardens declaring bombsites out of bounds, and guarding some sites. As the fire brigade rolled up their hoses, the wardens and rescue teams would begin to clear the debris from the street and pavement, usually stacking it back onto the rubble of the house (O'Brien 1955). The bombsite had reached the next stages of its life as a fleeting spectacle and an enduring presence in the urban landscape. Within hours or days the children would begin to take ownership of the new and entrancing space that had emerged in their familiar environment. 


\section{Bombsites}

\section{Sense memories}

Bombsites are aesthetic spaces in both senses of the term. First, as the subjects of art, literature and other forms of representation they invite critical response and understanding. Second, they are experienced - by children in particular - through the world of the bodily senses. This second category is of particular interest, as it highlights not only the ways in which children and adults encounter the material world at war but the ways in which memories of ruins are constructed and maintained. Young people and young children in particular tend to engage with the material world with the full range of their senses, particularly before they have been impressed with the enlightenment concept of 'look but don't touch'. Children approach new spaces and objects in a more tactile way, touching and smelling and grasping and tasting in ways that adults have been taught to find odd or distasteful (Buck-Morss 1993). In this process of learning to know the world, children form strong memories and impressions of the world around them. It is unsurprising that so many of the accounts of bombsites and playing on bombsites recall the sensory experience of those sites, particularly the smells:

I have to admit it was childlike morbid curiosity that led me with two or three other friends to walk to Putney to see the destruction. By the time we got there the bomb scene had been vastly tidied up, but the fire service and Civil Defence were still in attendance and hosepipes and other rescue paraphernalia littered the scene. The smell of dust, dirty water, the cabbagey smell of gas, a whole concoction of smells that in those days you associated with newly destroyed buildings, hung around the area.

(Clavey 2004)

Others recall 'the peculiar smell around the ruins' (Broughton 2005) and 'the smell of escaping gas and brick dust and burst drains. It seemed to permeate the air everywhere' (Forrest 2004a). McGarry (2004) recalled that bombsites were 'a playground for us children that often smelled of burnt wet wood' and the 'air that tasted of ashes'. One former Blitz child recalled the difference in smells between London and the rural evacuation areas, the former

covered in bombsite brick dust, the smell stayed in your nostrils and the dank lingering smell of gas from totally demolished houses. People with their heads bent low, scurrying to and from work, not knowing if their house would be still be left standing when they got back. The smell had gone now, and we were left with the sweet aroma of summer flowers and fresh cut grass.

(Payne 2003)

Sense memories can also be connected to trauma and traumatic acts of remembering: 
Eclipsing all these memories was the awful stench of fire and water after our home had been set alight by incendiary bombs. Even now, on those rare occasions when my nostrils are assailed by the same combination of smells, I visualise that damp, smoke-blackened scene in all its grim clarity.

(Smith 2006)

The smell of a bombed house is quite unique, something like wet plaster and damp wood, and I have only very occasionally smelt it since, usually when passing by buildings being demolished on building sites.

(Blanchard 2003)

The smell of plaster that Blanchard alludes to is a common memory of children who were bombed out or who explored bombed houses, as Clark (2005b) notes: 'The most recently damaged houses and shops had a very strong smell that I recall, the smell was one of damp plaster.' The involuntary autobiographical memories are not always unpleasant ones, as Wallis (2005) points out:

The mornings were pungent with the smell of brick dust from the buildings bombed the night before. Even now, when I smell that smell of smashed bricks, I remember the blitz. It heralded new exciting bombed buildings to play in and a day of adventure to come.

(Wallis 2005)

It is easy to forget the degree of trauma that children suffered during the bombing of British cities in the Second World War, with rates of PTSD thought to be comparable with that of soldiers in combat (Werner 2000: 212-3). The memories brought up by the smells associated with bombsites - as well as sounds, tastes and other sensations - have in many cases remained painful throughout their lives:

About six houses in the street were destroyed and some families totally wiped out. For several years after the war I played on the bomb site with the other kids in the street. Unlike many other children who remained in London for most of the war, that one experience left me with nightmares of bombers coming over in great fleets (I can picture them now in my mind) and these went on for a number of years. Also, I took a long time to get used to the sound of my mother's Hoover as it reminded me too much of an air raid siren.

(Butcher 2003)

The sense memories of the freshly bombed building - plaster, burning and gas - were not the same as the sights, sounds and smells of an older bombsite that nature had begun to reclaim:

Two things stand out as being with me throughout the war. One was the smell - possibly of gas polluted clay soil that seemed everywhere - and the 


\section{Bombsites}

other was a plant, one I now know to be rose-bay willow herb, that seemed to thrive on every bombsite as well as in the ruins of the old school. Oh yes, and there is another - there were many more butterflies!

(Hassall 2005)

The bombsite as a marginal, disordered space attracted wildlife, wild plants and wild children, and it serves us well to consider them all as part of a natural ecology of urban ruins.

\section{Disordered spaces/uncanny ruins}

How can we better understand the relationship between a bombsite and its environment? Why have bombsites and other ruined or derelict places proved so attractive to children? Cloke and Jones (2005) suggest that children are instinctively attracted to 'disordered spaces':

childhood is associated with places and spaces which are seen to be outside of adult control and ordering, where the fabric of the adult world has become scrambled or torn, and the flows of adult order are disrupted or even abated.

(Cloke and Jones 2005: 312)

Furthermore, they argue that such places, once common in rural spaces and urban environments alike, have been diminished by the ordering and commoditization of children's play. Cloke and Jones draw upon a range of sources to examine the correlation between childhood, nature, disorder and the romanticist conflation of these categories. They draw explicit attention to the bombsite as a disordered space of childhood, referring to 'the unequivocal and disastrous disorder of the bomb sites of Second World War London' (Cloke and Jones 2005: 318). While Cloke and Jones are reluctant to subscribe to simplistic dualisms of adult/child, order/disorder, indoors/ outdoors, they recognize the inevitably adversarial nature of the relationship founded in children's common desire to disorder space that they do not, ultimately, control. The greater part of their argument focuses on naturally disordered spaces, many of them in nature, but they also examine the phenomenon of disordered spaces created by adult agency, including spaces of conflict, which they regard as 'the form of adult ordered space most hostile to childhood' (Cloke and Jones 2005: 325). Despite this apparent hostility they recognize:

the disruptions caused by war can open up 'new' and different orders in which childhood can find its own space ... the bomb sites of London and other cities became celebrated childhood spaces even before they were colonized by nature.

(Cloke and Jones 2005: 325, emphasis in original) 
This analysis suggests an opening up of the categories of ordered and disordered space. As we shall see in this chapter, both children and nature colonized and transformed abandoned bombsites; arguably children can be regarded as a part of the process of natural disorder or entropy. Bombsites were not static sites but places in transition. In this context, children are not disordering adult space, but neither are they reordering violently disordered adult space. Thus while the concept of disordered childhood space expounded by Cloke and Jones is a useful analytical and descriptive tool, it is too crude to fully unravel the complexity of children's relationship to bombsites.

Despite the sense of escapism amidst the flowers and ponds in many of the accounts of bombsite play and adventure, there is a recurring sense of unease - either experienced at the time or in retrospect - of playing games on sites of death and destruction, often surrounded by uncanny reminders of the former residents:

The weeds, called rosebay willow herbs (although I didn't know what they were called at the time) were as tall as I was. They grew thickly all over the rubble. You suddenly came across a doorstep with pretty tiles. I didn't think then, how sad that someone's home had been razed to the ground. Bombed buildings were just words to me and I didn't realise their literal meaning. If a house had been bombed at the end of a terrace, on the sidewall you could see the floor layers and fireplaces half way up the wall.

(Ison 2005)

When Macaulay described ruined houses with 'empty window sockets' (Macaulay 1996: 453) she tapped into a language of physical injury and the human body that is often used to describe the destruction of buildings. Vidler (1992: 69) examines the use of body metaphors in architecture and the natural extension of this language to describe demolition and adaptation in terms of dismemberment. Vidler's study focuses on what he calls 'the architectural uncanny', drawing on Freud's work on the uncanny or unheimlich (which also translates as un-homely or un-hidden). Freud defined the uncanny in a variety of terms, many of them decidedly material, such as dismembered limbs and body parts encountered in isolation from the rest of the body, and more generally the revelation of things which should, properly, have remained hidden. In this sense the bombsite is an inherently uncanny space: the body/house laid bare and fragmented, the private interior of the home rendered public and the fabric of the structure torn apart (Figure 4.2). The ways in which children in the Blitz responded to bombsites reveals a number of different responses to this phenomenon, including horror and discomfort or merely a sense of unease:

very often a building had some of its exterior walls reduced to piles of bricks, exposing the interior rooms with beds and furniture tattered and broken like a dolls house that had suffered from a childs temper tantrum. I can remember seeing rows of houses where the damage caused by blast 


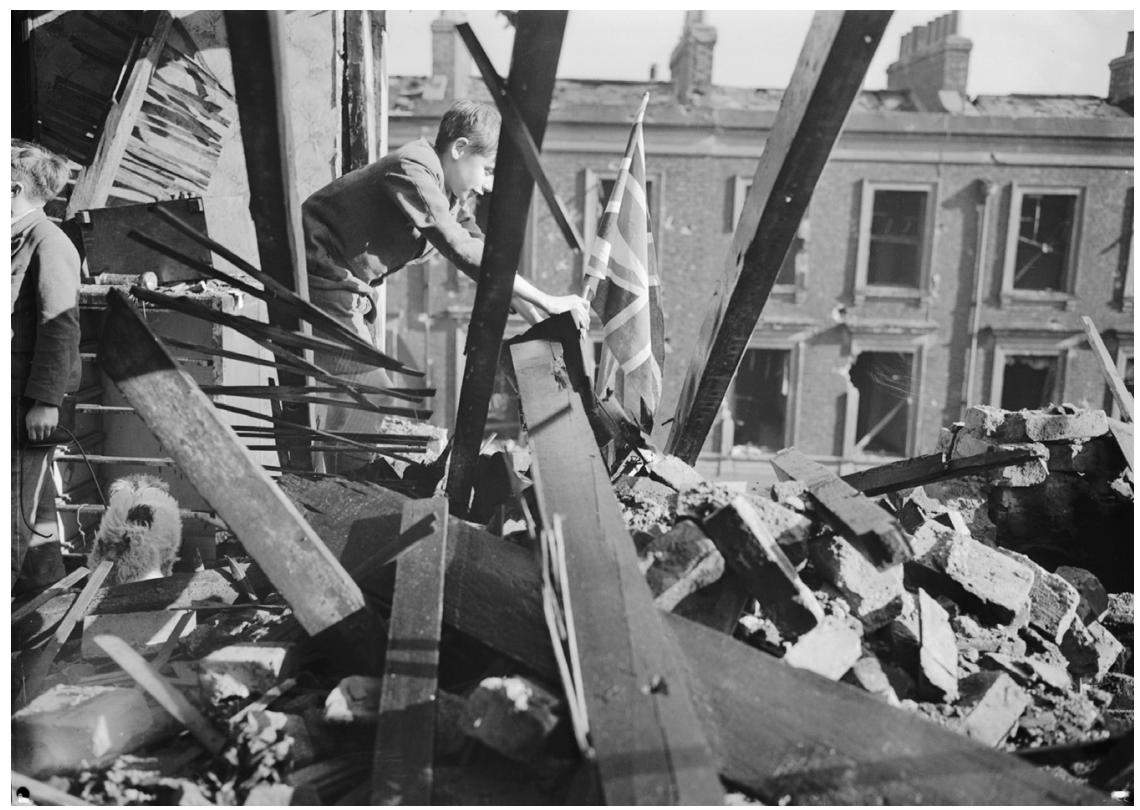

Figure 4.2 A child plants a Union Flag in the wreckage of his home, destroyed in an air raid on London. C) Imperial War Museum, D 1303.

had a peculiar effect, as if a giant hand had scooped out the roof timbers and tiles leaving the dividing walls in the loft space between each house. Bomb blast did strange things, a building could have severe damage but sometimes fragile articles like mirrors or vases remained intact and standing on mantlepieces whilst devastation was all around.

(Clark 2005)

We went one day after the blitz and a policeman told us to go and have a look at something. The house was in complete ruins but there [was] a picture on the wall that was perfectly in place. It was uncanny.

(Ollerenshaw 2005)

Many of the memory narratives that recall playing in ruins include a retrospective understanding - more than half a century on - that their wild playground had been the ruin of a home just like their own:

I did see bombed houses in other places and it was always strange to see in some cases the way the stair case would still be there, clinging to the exposed inside walls with the wallpaper peeling down and hanging off.

(Simon 2005) 
This callousness (perhaps better understood as numbness) extended from the remains of buildings to the remains of their inhabitants, which in many cases remained undiscovered within the ruins until their smell revealed their presence:

During daylight hours my friends and I would play, in our naive childish manner, among the sometimes smouldering debris of bombed houses, houses which the day before we had seen standing complete. It just seemed natural to us. Occasionally we discovered the odd finger, an ear or some other small pieces of a human casualty, but it never registered with us, death was not a thing with meaning although we recognised the objects; we would pick up such items and throw them at each other.

(Ronnie 2003)

The fascination with bombsites was by no means limited to children, with many people taking trips to newly-bombed areas to see the ruins, although here again the difference between adult and child experiences of the sites are sensory: parents went to look, children went to look, touch, smell and taste.

Whenever there was a new bombsite my mother would take me to see it. It seems rather ghoulish now, but other people did the same. We'd see houses demolished, beds hanging half-out of upper floors. There was the odd plank placed across gaps that we could cross to get a better view.

(H. Morgan 2005)

Mary never struck me as being particularly morbid but she had to go and see every new bomb-site in the locality. This was at first when the devastation was fairly isolated. I still remember the smell of the soot at bombed houses and how the wallpaper seemed always to look as though the decoration had been neglected ... Bedroom walls looked all wrong with no floors to keep them company and the chaos of beams and floorboards and heaps of bricks I found very disconcerting. We saw all sorts of houses, large and small, posh and mean, but I always felt the same sense of foreboding.

(Tanker 2003)

It is unsurprising that in many cases bombsites could be creepy for children with active imaginations and perhaps a better understanding of the deaths that may have taken place there. Equally, that same sense of the uncanny - of the hidden revealed, the body dismembered - could have been a part of the attraction and the thrill of exploring these marginal spaces and staking a claim to them:

There was the fascination of going into a freshly bombed building. I suppose it was the silence and the emptiness where there had been noise and activity. I shall never forget one building in particular. It was a cloudy day and having clambered over the debris, I found myself in a long, large factory room. I started to walk around this room, marvelling 
at the stillness and silence, when I suddenly felt very scared. I turned around and got out as quickly as I could. Imagination? or indigestion maybe, but all these years later, I can remember that cold fear and it still sends shivers down my spine.

(Wallis 2005)

\section{Bombsites as (dangerous) playgrounds}

Tales of childhood adventures amidst the bombed ruins abound in memory narratives of life in the Second World War. Like gas masks and air raid shelters, bombsites are sites of memory: catalysts for stories and debates around the experience of childhood in a world at war (Moshenska 2009). In surveying these memory narratives, a number of recurring themes emerge, the most common and prominently expressed being the direct comparison between bombsites and playgrounds, particularly adventure playgrounds.

With us being children, it was quite exciting in a way when we did eventually get bombed. Wherever there was a bombsite we would go and inspect it. In fact it was a little bit like an adventure playground. It was our playground in a way.

(Feeney 2005)

One of our favourite playgrounds now was 'the wreckage' this was the bombsite of four houses that had gone down in Stanhope Avenue, at the end of our road. Most of the rubble had been cleared, but there was still plenty left for us to build dens and play on.

(Mathieson 2006)

The key to this comparison is obvious: despite parental and official discouragement, a large proportion of children used bombsites as places to play, alone and with others. The resources that the bombsites offered, their inherent danger, their aesthetics, ecology and architecture all contributed to their value and significance in children's lives. However, by forbidding children to play on them the air raid wardens and concerned parents predictably succeeded only in making bombsites more alluring. As McCain (2003) recalled: 'Yesterday a home - today a bomb site. A place we were definitely not allowed to play, even though we longed to.' One of the recurring themes in accounts of bombsite playgrounds is fond memories of the pleasure that they brought into children's lives: 'the bombs constantly blew up other houses all around us and as I grew up, I had all these wonderful ruins to play in' (Lord-Castle 2004). According to Jackson (2005) 'There was lots of good climbing stuff', while Powell (2005) whimsically describes 'loads of kids playing in the rubble for weeks, swinging round lampposts on ropes never knowing the heartache just the joy and comradeship of youth'. Some accounts describe in more detail the games that children played, many of them war-games. Martin Kirby recalls: 
In these ruins (some quite dangerous) we played many games - tin can copper, run outs etc. I had a Dinky collection and a friend had a vast Dinky army collection and we played 'wars' in the weeds of the ruins. It was great fun!

(Kirby 2005)

Kozlovsky's (2007) study of the bombsite roots of adventure playgrounds highlights Marie Paneth's work with troubled and disruptive children during the Blitz. Paneth (1944) treated violent outbursts as pathological rather than criminal acts in the young and sought to study them to understand their psychological roots. Following the violent destruction of her play centre Paneth reviewed her methods and proposed working with these children on a specially designated playground/bombsite, based in part on Freud's idea that playing can allow children to repeatedly replay traumatic events and eventually to master them. As Paneth noted of the site:

It is a damaged bit. Its very existence is a reminder of damage and destruction. A sore spot and harmful to all of us. But it could be put to good use even before the war is over. It seems to me it could have a very healing effect if one were allowed to build upon the very spot where damage has been done.

(quoted in Kozlovsky 2007: 22-3)

Bombsite playgrounds mark a point of transition in the infrastructure of children's play between the pre-war official playgrounds for 'fixed play' on swings and slides, and the post-war adventure playgrounds built on urban wastelands and on bombsites. Children playing on bombsites might have had access to a park with fixed, modular, metal play equipment but many would not, and others might have lost their parks to anti-aircraft guns, balloons and searchlights. The post-war adventure playground movement was rooted at least in part in adult observation of bombsite play with its emphasis on creation, transformation and risk (Cranwell 2003). Today an adventure playground of this period, with its rough wood, crates, scaffolding and hand-tools looks terrifyingly dangerous for young children, but compared to the dangers inherent in exploring bombed houses these were negligible, as attested by the numerous tales of childhood injury and death:

Nearly every street had at least one bombed house we could play in, we climbed on roofs, we dropped from upstairs windows, climbed over rubbish and wreckage with our wooden guns, hid in cellars, and to us the bomb damaged areas were just somewhere to play. I remember one time we were playing in an old terraced house in Gaylor Street known locally as 'Hatties', and a lad was playing with us, he was upstairs and he fell down through the rafters, fell through the rafters on the ground floor, and ended up in the cellar, and the amazing thing is he only twisted his ankle. 


\section{Bombsites}

But we never really appreciated the danger in what we were doing, it was just the environment we lived in.

(Maher 2004)

Amongst the dangers of a world at war, bombsites presented a specific set of hazards for curious children. Even relatively complete-looking buildings were often rendered structurally unsound by bomb damage, and ruins of all kinds were liable to collapse without warning. Broken gas mains and the wooden remains of roof structures created a fire risk while broken sewage pipes and rotting organic material presented a biohazard. Meanwhile unexploded munitions - bombs, incendiary bombs and anti-aircraft shells - presented a consistent and enduring risk of death and injury (Jappy 2003). Accounts of playing in bombsites are peppered with reminders of the risks involved, often recalled with amazement years later.

This bombed house made a tempting playground for us children, but it was unsafe and we were forbidden to go in there, but I remember climbing in on more than one occasion. The temptation to climb about on a derelict building should not be underestimated by any caring parent. How we didn't have serious accidents I can't imagine. I suppose some children must have done.

(Wright 2003)

Some accounts are comical, such as John Garrett's account of his 'war wound' sustained by cutting his leg on a broken toilet while rampaging through a bombsite (Garrett 2003). Others however include reference to death and serious injury from playing on bombsites:

My friends and I could find other more exciting things to do. Tarzan was all the rage at that time, and as a lot of bomb damage was being repaired following the raids, one of our favourite games was swinging on the hoist ropes used by builders. One such site was at the bottom of Gloucester Street, my pals and I were playing Tarzan, one friend that we always called Davis was swinging, when all the bricks stacked above began to fall, we called 'lookout!' but it was too late, he was hit by all the bricks and was rushed to hospital. The next morning at school assembly the head teacher Miss Davies told us that Davis had died and all the children in assembly had to promise to never play that sort of game again. As children in the war years we lived with danger but we could never see it. Playing on the bombsite was a huge past [sic] time.

(Hulbert 2005)

Clearly even the risk of serious injury or death was rarely enough to deter children from taking ownership of bombsites as play spaces, as Noel Froggatt (2005) recalled: 'despite the warning notices on the side of the ruins we still 
played there ignoring the dangers as if they didn't exist'. But as Ernest Curd notes in his account of bombsite near-injury, risks can seem diminished in a world at war:

One day, during one of these war games, my mate Bobby Dove managed to get up to the first floor of a bombed-out house. Suddenly, without any warning, the floorboards gave way and Bobby came crashing down to the ground. We all rushed over, but he was completely unharmed. So we just carried on with the game ... I don't think any of us appreciated how dangerous our games were, any more than we gave much thought to the war. We didn't really realise what was going on. My friend falling through the floorboards was an added bit of excitement, but at the time it didn't seem out of the ordinary. It certainly didn't stop us playing on the bombsites!

(Curd 2005)

Several accounts of bombsite play recorded in the early twenty-first century draw comparisons between the freedom to play dangerously in the war years and the more protective attitude towards children and risk in contemporary society. As Forrest (2004b) observed: 'We seemed to be completely unsupervised. But then apart from the danger of the War, children could wander around, in safety, in those days.'

Like the adventure playgrounds that they helped to inspire, bombsites provided a wealth of materials and spaces for children to explore different forms of play and other activities. The disorder and adaptability of urban ruins and the abundance of brick and timber meant that children could manipulate the very topography of the sites to fit their individual imaginations and collective endeavours. From the narratives that I have collected there appear to be a range of different types of games played on bombsites, depending in part on the age and sex of the children involved, including role playing and organized sports.

One of the most common activities recalled in the memory narratives was war games, as one young boy recalled: 'the war affected the games we played, too. We would wage war on the kids from the next street, building our own trenches in the ruins of bombed-out houses, flying our homemade flags and throwing stones at each other.' (Curd 2005). Smith (2006) acknowledged that 'Even our games reflected war', recalling:

playing among the ruins (there were at least two houses just a little way up the road from us that were badly damaged but rebuilt so that one would never know) with a wooden tommy-gun whilst wearing a cast-off service hat sequestered from an uncle.

(Smith 2006)

The most famous depiction of war games on a bombsite is undoubtedly Cecil Day-Lewis's popular children's book The Otterbury Incident (1961), in which a group of school boys act out elaborate ambushes and manoeuvres on a 


\section{Bombsites}

bombsite - the 'Incident' of the title - to thwart the efforts of a gang of local criminals. As in this case, the games were often a little too serious or physical, when war games became a substitute for gang fights or territorial disputes:

The bombed houses became great places to play, when they were cleared of rubble, on a housing estate like ours. There had been a land mine fall early in the war opposite our house which had destroyed about eight semi-detached houses. A place to build huts, a place for our 'war games', some got really rough, with stone throwing, luckily no one was hurt, well not badly. It was not built on until quite a long time after the war.

(Lewington 2004)

Similarly Marshfield's (2005) reference to 'brick fights, building defence walls out of the rubble, rushing forward with dustbin lids for shields' sounds a little rough. In contrast Osborne (2005) recalled that 'We mostly played Cowboys and Indians'. Studies of adventure playgrounds showed that in many cases children built miniature houses, in one case 'converting 10,000 feet of used timber into shacks in a matter of days' (Claydon 2003). Many of the more elaborate games on wartime bombsites seem to have followed this pattern of domestic play, such as the rather charming scene of cooperation and music that Payne recalled:

Another harmless activity we did was on one of the cleared bombsites; we would all built [sic] a clubhouse made from recycled timber and old lino to make a waterproof roof. The only money we spent was for a few nails and candles. Boys and girls of all ages lent a hand. We had a collection of musical instruments like xylophones, ocarinas, mouth organs, biscuit tin drums, and maracas made from co-co tins part filled with rice. We would all sit around and play the instruments as best we could. It must have sounded like a bit of a din but we all enjoyed it, and all lit by a dim candlelight.

(Payne 2003)

The younger children also engaged in more conventional domestic role-play, creating simulacra of their homes and adopting adult roles, as Chancey (2006) recalled: 'All the children in the area would meet on the bomb damage site to play mums and dads and build houses using the old bricks.' (Chancey 2006). Taylor's account describes how the truncated ruins of a block created child-sized homes to play in:

One of my favourite playgrounds, where my friends and I played with our dolls, was the cleared site of a block of flats that had been bombed killing 92 people in one raid. These former homes were like life-size plans, with rooms and doorways, where we played 'mothers and fathers'. We could push our dolls' prams along the passages to visit our dolly-friends.

(J. Taylor 2004) 
Some of these games became more elaborate, with Young (2005) describing building a shop out of the debris on a bombsite, and selling broken household goods and stone 'sweets'. It is worth noting that none of these activities were unique to British children during the war: German children were just as keen on collecting shrapnel and also "played in the ruins of the bombed buildings, building little houses and making walls with the fallen bricks.' (Seldon 2005).

Despite the dangers and inconveniences, some bombsites were used as open spaces for organized sports: in practice these were most often sites that had been levelled or cleared of rubble in preparation for rebuilding. Duggins (2005) describes playing cricket with wickets chalked on the wall of a bombed-out house, while Campbell (2003) recalls the 'debris' being used as football pitches. Some of the play was of a more destructive nature, and here the already-ruined nature of the bombsite may have given the children license to further disorder it:

We also explored the shells of the bombed houses, clambering up the strewn stairs looking down through holes in the floors, opening cupboards, breaking everything we could. Bill and I were smashing glass lamp-shades in one house when a policeman came in and shocked us rigid

(Marshfield 2005)

Skipp's (2005) account recalls that local children burnt scrap wood in the bombsite beside his house, in one case threatening to smoke or burn his family out of their home. Bombsites could also be spaces for experimenting with dangerous chemicals and intriguing artefacts such as bullets and incendiary bombs, as Greenaway (2003) recalled: 'I used to play on a bomb site in Water Lane with a Junior School friend, letting off home-made fireworks of a sort. The romance of chemistry sets!' But aside from these more destructive activities, the overwhelming majority of children's play on bombsites appears to have been balanced between the disorderly - climbing, war games and the like - and the orderly - attempts to replicate their home environment. Whatever the form that the play took, the over-riding sense remains that children's curiosity about the new spaces that had opened up their local environment was tempered by a desire to domesticate them, to master them through what Kozlovsky (2007) and others have called 'junkology', or play in ruins (Figure 4.3).

\section{The ecology of bombsites}

Rose Macaulay's Pleasure of Ruins (1996) explores at length the fascination and enduring cultural significance of romantic architectural ruins. The final few pages of the book are devoted to a note on 'new ruins', written only a few years after the Second World War. In this note Macaulay reflects on the new ruins of bombed cities and their lifecycle as nature reclaims them: 


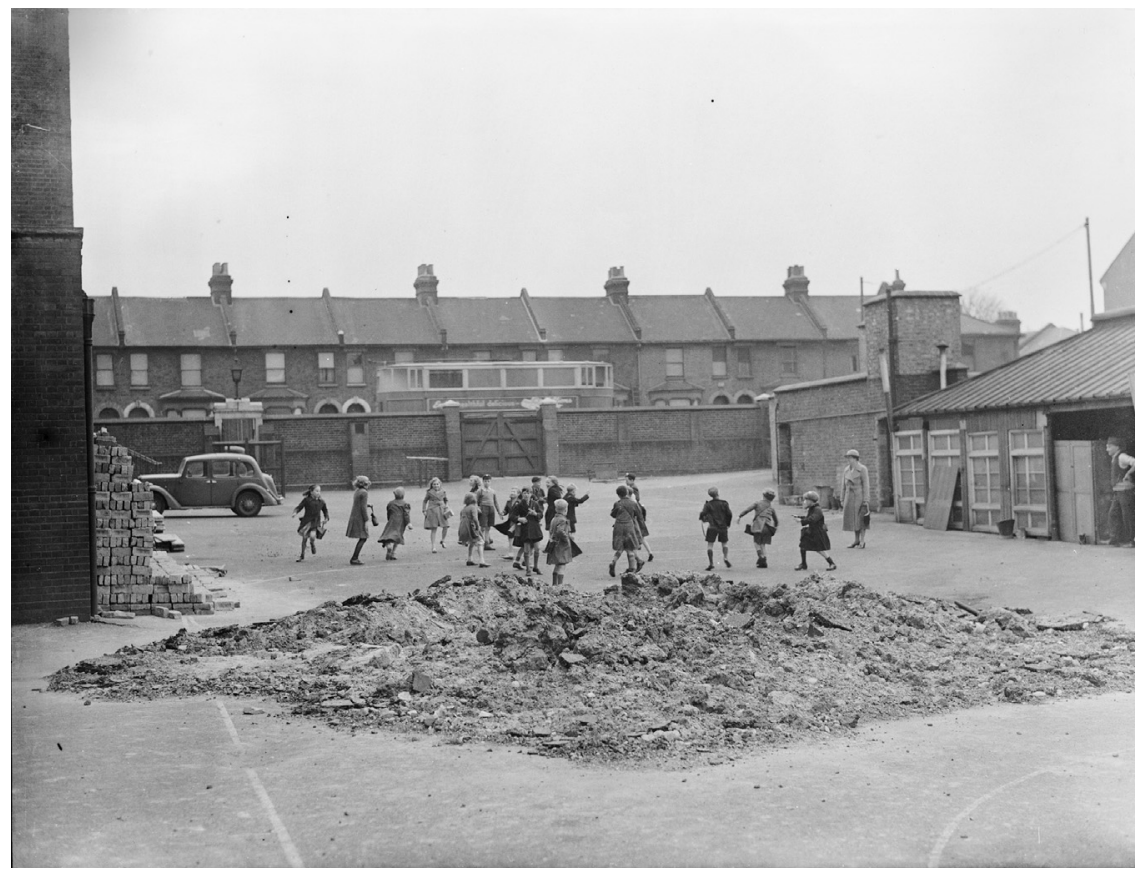

Figure 4.3 Children playing next to a bomb crater full of rubble in the playground of Lombard Wall School, South East London. (C) Imperial War Museum, D 3170.

new ruins are for a time stark and bare, vegetationless and creatureless; blackened and torn, they smell of fire and mortality. It will not be for long. Very soon trees with be thrusting through the empty window sockets, the rose-bay and fennel blossoming within the broken walls, the brambles tangling outside them.

Macaulay's timescale is a little pessimistic. Depending on the time of year most bombsites had sprouted a healthy crop of weeds within weeks of an air raid, most commonly the tall, purple rosebay willowherb that became popularly known as 'bombweed' or 'fireweed'. Richard Mabey notes that rosebay thrives on burnt ground to the extent that: 'the summer after the German bombing raids of 1940 the ruins of London's homes and shops were covered with sheets of rosebay stretching, according to some popular reports, as far as the eye could see' (Mabey 1996: 236).

Rosebay willowherb was one of many plants that colonized the newly available land. In May 1945 the director of Kew Gardens, E.J. Salisbury, gave a public lecture on the wild flowers growing on bombed sites in London, noting the prevalence of species such as coltsfoot and Oxford ragwort. Most but by no means all of these plants were spread by wind borne seeds, as 
Salisbury noted, with others 'long buried and springing to life, some brought in horses' nosebags, some on muddy boots or the tyres of motor-vehicles, some on clothing, and some "escapes" from gardens, including a Peruvian plant from Kew' (Anon. 1945: 2). Altogether more than 150 species of plant were found on bombsites in London and dutifully catalogued. Without this understanding of the rich ecology of bombsites it would be easy to imagine them as the blackened ruins of war as they appear in newsreels, but the bombsites that British children rampaged across were often far from bleak or sterile: they were 'mellowed' (McGarry 2004) or 'softened' (Bettie 2003):

The ruins were quickly tidied and then they mellowed: bombed areas were flattened, turning green with weeds between the piles of bricks and jutting metal pieces, puddled with innumerable muddy pools whenever it rained, obliquely crossed by shortcut paths

(McGarry 2004)

I can remember a wasteland of ruins, cellars and broken walls softened by the Budleia and Willow Herb which grew there. The ruins were inhabited by cats who emerged with tribes of kittens in the hope of being given food.

(Bettie 2003)

The presence of stray cats is a reminder that the ecology of the bombsites was not limited to the plant life, not least due to the natural ponds that appeared in craters and holes where the underlying clay prevented rapid drainage:

Like all the kids we played amongst the willow herb in the dangerous ruins. We and our friends 'owned' bomb-craters which remained for years after the end of the war. The water filled ones were very educational -with dragonflies, water-boatmen, water-spiders and so on.

(Nightingale 2003)

The other source of water on many bombsites were the emergency water supplies: large containers, many of them metal tanks but others built from the bricks on the ruins and lined with pitch and marked 'EWS' in white letters so that they could be found in the blackout more easily by the fire brigade, who often had trouble finding water sources in the midst of air raids (Tidmarsh 2005). These became another home for wildlife, occasionally with some outside help:

Where one of the big bombs had dropped in Bristol after the November blitz they put in a water tank so that the fire service could fight the fires. As kids we used to go to the local pond by the brickworks and catch newts and sticklebacks and put them in this tank. By the end of the war it was alive with newts. 


\section{Bombsites}

Many accounts of bombsite play allude to the presence of plants, animals and insects on the sites. In some cases they were actively useful: one account mentions blackcurrant, gooseberry and raspberry bushes growing on a bombsite that provided welcome afternoon snacks (Clark 2005), while for others the presence of wildlife reinforced the sense of bombsites as disordered, marginal spaces with a greater sense of privacy and non-urbanism. Children in wartime were regarded by many in authority as wild and unruly, in need of strong and even militaristic discipline. In light of these attitudes and the natural attraction of children to disordered spaces, I think it is reasonable to suggest that children on bombsites be considered part of a disorderly urban ecology of ruins that encompasses plant, insect and animal life.

There is a growing appreciation of urban ruins as ecologically vibrant and productive spaces: informal or semi-formal parks, nature reserves or smallholdings (e.g. Dawdy 2010; Edensor 2005; Hinchcliffe et al 2005). While several of these studies conceptualize the fertile ruin largely in terms of (adult) human activity it is better, I would argue, to view nature and culture on the bombsite as mutually constitutive - at least for as long as the site remains (formally) abandoned. This aligns with studies of ruins such as those by Macaulay (1996) and Woodward (2002) which have regarded the encroaching wildlife as part of a continuous process of entropy, ruination or transformation.

\section{Conclusion}

From Barcelona to Berlin to Beirut, the urban bombsite has become one of the iconic traces of twentieth century warfare. In a century when the bombing of civilian populations became the new way of waging total war, many hundreds of thousands if not millions of homes have been reduced to rubble and ash by bombs dropped from aircraft (Tanaka 2009). These bombsites are the foundations, literally and figuratively, of much of modern urban life and culture. The architect and planner Patrick Abercrombie looked at the ruins of London and saw the ground plan for a new modernist metropolis; Albert Speer planned to build the grandiose neoclassical Germania on the rubble of Berlin, even as it was being blasted to pieces around him (Tiratsoo 2000). Artists and writers from Henry Moore and Virginia Woolf to Picasso and Sebald recognized the imaginative fertility of ruins. In this chapter I have tried to see past the military, political and cultural histories of bombsites to look at them through the eyes of the children who inhabited them. The firstperson accounts that form the basis of this study were recorded some 60 years after the war had ended, but the lively emotions and fine-grained details in the accounts that I have drawn upon are a reminder of the social and psychological significance of bombsites to children in warzones.

In my introduction to this chapter I posed several questions for the study of bombsite playgrounds. What kinds of spaces were bombsites? As I have tried to show, they were many things to many children, often at the same time: 
playgrounds, climbing walls, natural resources and nature reserves. They were dangerous, exciting, disordered, hidden, marginal, wild and contested. How did the children interact with these complex spaces and recreate them for their own uses? They rebuilt them, using the raw materials of bricks and wood; they staked claims to them, named them, set fire to them, planted seeds, visited them, and in the course of all this, they explored them with the full range of their senses, forming memories that endure into the present. What were the social and psychological outcomes of their games and adventures? Playing on ruins allowed many of the children of wartime Britain to engage in destructive, violent and physical activities for which they had no other outlet. Equally it provided them with a space that they could physically make and remake to suit their imaginations and needs for specific games and activities. This control over the ruins and the sense of ownership that their marginal status allowed was a powerful and important factor, as some educators recognized, of helping children traumatized by war to work through their fears and regain a sense of control in a world where the physical and social landscapes around them were subject to sudden, violent changes. In this sense the legacy of the bombsites was the adventure playground movement that they inspired and enabled.

The gradual processes of urban rebuilding in the decades after 1945 might not have matched the imaginative hopes of Abercrombie or Speer, but they systematically erased the vast majority of the bombsites in urban Britain and the few that remained - mostly churches - were preserved in a very tidy manner, what Stone (2004: 139) has referred to as 'the best possible state of ruin': no rubble, and certainly no rosebay willowherb. To find the bombsites of Second World War Britain we are better off looking in photographic archives, in the child psychology literature of the period and in the memory narratives left behind by those who lived and played on the ruins.

As you read this, somewhere in the world there are houses being pounded into rubble by bombs and artillery: today as I write it is Syria. As I have learnt from studying children's lives in wars across the world in the twentieth and twenty-first centuries, some things are constant. When the gunfire and explosions die down the children will be collecting and swapping cartridge cases and shrapnel fragments, and they will be exploring the new ruins and the older ones. The flowers will not be the ones that grew on the ruins of the Blitz, but the rest is pretty much the same. 


\section{Aircraft down to earth}

\section{Introduction}

On my bookshelf I have a set of six blue quarto-sized hardback books, battered and well loved, a gift from Michael Kenton, a late relative who was a young boy during the Second World War. Aircraft of the Fighting Powers was a multi-volume work published over the course of the war and aimed at the aviation enthusiast and aero-modeller (Cooper et al 1941). The volumes contain a host of beautiful advertisements for aircraft manufacturers and model aircraft manufacturers, uneasily juxtaposed. The main part of each volume is a series of descriptions of military aircraft, friend and foe, from all combatant nations including Russia, Japan and Italy. Each aircraft is illustrated in silhouette in front, side and plan view at 1/72 scale (one inch equal to six feet), with cross-sections given for the fuselage and wings. The books aim to educate and inform about the specifications and abilities of the various aircraft, but also to aid in aircraft recognition and aero-modelling. Michael was an avid model maker as a child of the Blitz and explained to me how he would carve and sand the delicate aerofoil shapes from balsa wood before gluing and painting. The pages of fold-out plans are stained here and there with glue, where Michael rested a model on the paper to check the alignment of a wing or elevator. The success of Aircraft of the Fighting Powers and similar publications rested on the enthusiasm with which children like Michael, mostly boys, would spend their pocket money on aircraft-themed toys, books, magazines, cards and the materials to build models.

This fascination with aircraft and flight, sometimes termed 'airmindedness', was a powerful force in British culture during the 1930s. Airmindedness was a primarily nationalist, militarist mind-set focused around the concern that Britain was ill-prepared for the 'knock-out blow' that air power would deliver in a coming World War, but it also drew on a widespread awe at the technological triumphs of aviation in global transport and travel, and in high-profile international air races such as the Schneider Trophy. In the inter-war years airmindedness was actively promoted through competitions and substantial cash prizes for iconic long-distance flights or speed records (Hamilton 1994: 38-9). Young people, primarily boys, in Britain in the Second World War 
grew up in an airminded society and imbibed militaristic air power propaganda from their very first 'Biggles' stories: for the majority, the air war on the Home Front would be their most intense and immediate experience of the conflict. Their fascination with aircraft shines out in accounts of wartime life:

Towards the end of the thirties, I had developed a serious interest in aviation and remember well cycling out to Dyce Airport to see the latest Hawker fighter aircraft, aggressive looking biplanes and the last to be produced before the Hurricane and Spitfire arrived on the scene.

(Hall 2005)

Well of course it was wartime, and I think nearly every young lad, I was 14 years old, was pretty interested in aeroplanes at that time, I mean they were everywhere.

(Crawley 2006a)

This youthful passion for aviation that grew out of an airminded society was nurtured by government, industry and popular culture. Following the outbreak of war, the aircraft and men of the Royal Air Force would achieve hero-status amongst young people. Some would go on to serve in the RAF or other flying branches of the armed forces, while many others would be employed in the vast industry that grew up around the air offensive against the Third Reich in the latter years of the war. For most young people, particularly those living in cities, the aircraft that they idolized and feared would remain tantalizingly out of reach.

The notion of British airmindedness is a fairly recent and contested one. Historian of technology David Edgerton (1991) has tried to overturn what he regards as an inaccurate and misleading perspective on the relationship between England and the aeroplane. The popular view as Edgerton describes it is that England lagged behind other nations in its development of air power between the wars, due to a lack of martial spirit amongst the electorate and a governmental unwillingness to invest. Only in the face of aggressive war did this sleeping giant of a nation awake and begin to prepare for air warfare, with the driving force coming from private enterprise and individual initiative. Instead, Edgerton presents a wealth of evidence for England's 'over-enthusiasm' for aircraft, showing that throughout the Second World War an already formidable aircraft industry (with far greater capacity than Germany's, even in 1940) grew to dominate the national economy. He suggests that aspects of the development of the welfare state were in response to the labour needs prompted by this vast growth of aircraft production. Overall in Edgerton's view 'the commitment of England to the aeroplane exemplifies a commitment to armed force, science, technology and industry' (Edgerton1991: xiv-xv). Edgerton diagnoses an ideology of what he calls 'liberal militarism': a response to the mass casualties of the First World War, emphasizing the use of technology rather than manpower in the pursuit of aggressive warfare, as well its value as an economical means to police the more remote parts of the Empire such as Iraq and Afghanistan. 
Brett Holman's study of British airmindedness focuses on the popular notion that unstoppable waves of bomber aircraft would inflict a 'knock-out blow' at the outset of any modern war, a theory that rose to prominence during the $1930 \mathrm{~s}$ and only faded, he argues, when the Blitz of 1940-41 singularly failed to produce any such effect (Holman 2014). Holman examines the rise of airmindedness and its careful, deliberate promotion by forces including the right-wing press and the burgeoning aviation press (which, he notes, was also markedly right-wing). Helen Jones has noted the significant role of WE Johns' Biggles books featuring the eponymous heroic airman in stimulating airmindedness amongst young boys, alongside a steady stream of aviation-themed action movies (Jones 2006: 125). Holman is rightly cautious about making sweeping characterizations of British public opinion about air power in the pre-war and war years, despite the wealth of sources such as Mass Observation. However he notes that 'the rapid growth in popularity of the Hendon Air Pageant and Empire Air Day, first held in 1920 and 1934 respectively, demonstrate an interest in the RAF on the part of the public, though ... It may simply have been a love of spectacle which drew such large crowds.' (Holman 2014: 170). This interest and its impact on young people is well-attested in reminiscences:

My lifelong interest in aircraft began at this time and was no doubt connected with the fact that my father was interested in aircraft. Before WWII he used to cycle to the Hendon Air Displays and would describe aerobatics with enthusiasm and also the exploits of Klemm [Clem] Sohn the Birdman. We once cycled to an airfield near Ashford, which must have been the Heathrow grass field as it was a short distance from the end of Clockhouse Lane. I was around 9 or 10 years old at the time and remember that they were singleengined aircraft in camouflage colours with RAF roundels but the type I cannot remember. Most likely they were Fairey Battles or Hurricanes.

(Armstrong 2005)

So many accounts of wartime childhood attest to the awe, fascination, fear and adoration inspired by aircraft. Particularly in the early years of the war in Britain that were mostly fought defensively, the aircraft of the RAF were the most visible and tangible manifestations of the nation's ability to defend itself and to strike back. Crucially however, the aircraft themselves were not very tangible. For a small minority, as we will see, it was possible to get close enough to an aircraft through lax airbase security or acquaintance with aircrew, and some boys managed to get to explore and even fly in aircraft as part of Air Training Corps cadet programmes. For the majority of children aircraft remained 'up there', visible as silhouettes and vapour trails and distinctively audible, but out of reach:

I seemed to be totally detached from what was taking place above me as though it was an entertainment. It was, of course, extremely exciting, but all the time nothing came straight at me (and nothing ever did) there was no fear. The nearest I came to being hit by anything was a falling .303 
round, which I could hear sometimes landing in the grass as I lay on my back to watch ... The abiding impression is of total confusion. Vapour trails at high altitude and, as the bomber formations were broken up, things happened lower down, with aircraft wheeling around in all directions and machine gun fire over the engine noise. We soon learned to distinguish between the sound of the Merlins in our Hurricanes and Spitfires and the Daimler Benz engines of the ME109's and 110's. The sound of the Merlin engine will get me rushing from the house to this day. My young brother and I became experts in aircraft recognition, as did most schoolboys. After all, this was our war.

(Martin 2006)

At first it was exciting: air battles through the long, hot summer of 1940 seemed to hold little menace for a ten-year old. The drama though was real enough with the roar and whine as engine notes changed as the combatants wheeled about the sky and with occasional falling parachutes, brilliant white against the bright blue sky and the billowing whiteness of the clouds.

(Bayliss 2003)

These accounts are typical of many: the fascination, thrill and sense of distance from the air war; the view from the ground, looking up; the nascent skills of aircraft recognition; and the multisensory theatre of aerial combat in spectacle and sound (Figure 5.1).

From a material culture perspective, the aircraft-as-object was not generally experienced in a tangible way like some of the other types examined in this volume. The visual and auditory aspects are significant and are explored in more detail in Chapter 3. My aim in the remainder of this chapter is to explore the various ways in which children in Second World War Britain experienced, materialized and mastered aircraft in their work (including war work), their play, their actions and their interactions.

The first part of the chapter looks at the practice of 'aircraft recognition', the skill of observing often tiny, distant, fast-moving aircraft and ascertaining their type (and more importantly, whether they were friend or foe). Aircraft recognition was a hugely popular activity amongst young people, particularly boys, during this period with official clubs and even examinations and certificates for dedicated enthusiasts. This was supported by a wealth of books, most notably The Spotter's Handbook by Francis Chichester (1941), and Aircraft Recognition by RA Saville-Sneath (1941) and by a huge variety of materials including flashcards, posters, cigarette cards and dedicated magazines. Aircraft recognition was practiced by both adults and children, and was formalized into the activities of factory rooftop 'spotters', the Royal Observer Corps and the training of air cadets.

The second and largest part of this chapter examines simulacra of aircraft: the hugely popular practice of aero-modelling, building toy aircraft, flying and static models. Like aircraft recognition, aero-modelling created a sizeable 


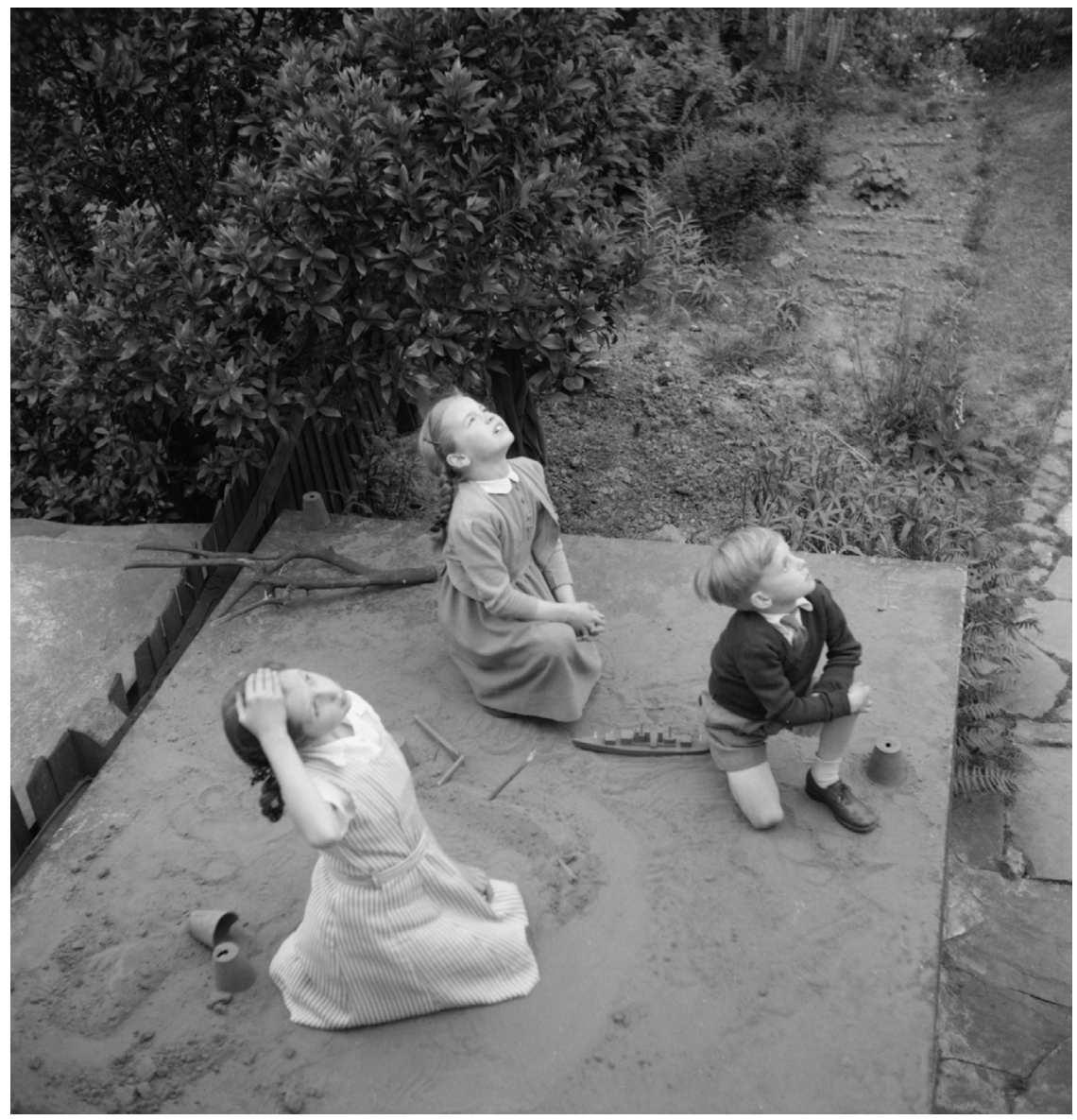

Figure 5.1 Children playing in a layer of sand on the roof of their air raid shelter stop to watch aircraft pass overhead. C) Imperial War Museum, D 20623.

industry of wooden models, kits, plans, accessories, magazines and books supported by a number of model shops nationwide. As with aircraft recognition, there is also a suggestion that government support was provided to encourage a hobby seen as being good for morale, encouraging airmindedness and generally supporting the war effort. Aero-modelling was not just a solitary activity: children engaged their models in mock air battles, clubs were formed for flying models in particular, and in some places public exhibitions of models were held as fundraisers for the war effort. Some models even incorporated materials from crashed aircraft in their construction, suggesting an almost magical connection between the real and the simulacrum.

The third and final part of the chapter looks at the rare but precious interactions between young people and actual aircraft. As mentioned above, 
some boys experienced joy-rides in aircraft as part of Air Training Corps cadet schemes, while others were able to climb inside and explore aircraft at public displays or at airbases. Many others encountered aircraft only in their crashed and broken state, their wreckage spread across beaches, agricultural land, homes, gardens and streets. Some of these encounters included interactions with weapons and human remains, and in most cases were motivated by curiosity or driven by souvenir hunting: the collection of aircraft wreckage was part of the militaria collecting obsession detailed in the chapter on shrapnel. For some young men who grew to adulthood in wartime a childhood interest in collecting and aeromodelling could lead to service, and sometimes injury and death, inside or alongside real aircraft in the armed forces.

\section{Aircraft recognition}

... you had to be sixteen to be required to firewatch, but I did help out once when younger, as it was thought that my aircraft recognition skills would be useful. Being able to tell 'one of ours' from 'one of theirs' was a useful art in those days. With several friends I joined the Erith branch of the National Association of Spotters' Clubs. A Govt. magazine 'Aircraft Recognition' was issued, together with quite well-made model aircraft in the popular $1 / 72$ nd scale. We would have talks and quizzes, and could take tests where we were shown one view only, head-on, side or plan, of an aircraft for one second only and had to identify it correctly, including in some cases the actual Mark number. The pass mark was $90 \%$, no less. Class 3 involved 40 basic types, Class 2 the same plus 60 more and Class 1 the same 100 plus another 30 Russian and Japanese types. We all passed Class 1, which just shows what enthusiasm can do!

(Wooderson 2006)

This brief reminiscence illustrates a number of significant features of aircraft recognition as a wartime activity that appealed to children and became a consistent part of youth culture for the duration of the war. Aircraft recognition emerged out of a combination of airminded enthusiasm and wartime necessity, in particular the employment of rooftop 'spotters' on workplaces. Aware of the risk of excessive lost production during air raids, many workplaces began to place 'spotters' on their rooftops so that workers could stay at their stations after the sirens sounded, only taking shelter when the spotters reported aircraft close by or nearly overhead. Historian Helen Jones has described the emergence of spotters' clubs on a grassroots, local level early in the war and their growth with government support. Some were based on existing groups such as model aircraft and glider flying clubs, and the growth was supported by The Aeroplane Spotter magazine and its editor Peter Masefield. The National Association of Spotters' Clubs was formed in May 1941, and by the end of 1942 there were more than 500 clubs nationwide with 
thousands of members, many of them holding or working towards certificates based on the tests described in the account above. Jones notes that spotters clubs were just one aspect of the clubs and societies, or 'associational life', common to civil society in Britain at the time and which enjoyed a modicum of government support and interference.

I was very keen on aircraft and had several books on identification and knew all the armament details etc. At the age of 8 or 9 I entered a competition on aircraft identification when 20 or so local shops placed an aircraft model in their window which had to be identified. I got through to the final and found at the event, where we were shown slides of aircraft, all the other contestants were teen-agers mainly from the Air Training Corps and I remember being furious because a British aircraft which I could identify I had ruled out because it had German markings and when I complained to the others afterwards I was regarded as being really naïve.

(Heathcote 2003)

Many accounts of aircraft enthusiasm such as the one above recall the competitive nerdiness of young spotters. Aircraft recognition fits firmly within the category of 'interests' in child psychology, and at the level of investment and emotional intensity described above can be described as an Extremely Intense Interest: 'A substantial proportion of normally developing young children become fascinated with particular categories of objects or activities. They display a passionate, sometimes bordering on obsessive, attraction to items in their interest category' (DeLoache et al 2007: 1579). Extremely Intense Interests are often apparent at quite a young age, are fairly long-lasting, manifest themselves in a number of different settings and are reasonably common amongst young children. The focuses of the interest vary considerably but common categories include trains, planes and other vehicles, and dinosaurs.

Helen Macdonald has explored the strong connections and overlaps in terminology, philosophy and practice between aircraft recognition and bird spotting, both of which grew to prominence in the 1930s (Macdonald 2002). The phenomenon is also heavily gendered, with up to six times as many boys displaying these behaviours compared to girls (DeLoache et al 2007; Johnson et al 2004: 339). Certainly the overwhelming majority of accounts of airmindedness and aircraft recognition in the People's War archive are from men, and there is a gender divide here that is stronger than for other material cultures of childhood in the Second World War. Most of the psychological studies of these intense interests focus on very young children below school age, but many of the behavioural patterns are common to contemporary childhood practices amongst older children, such as memorizing technical details about fictional worlds, games, sporting figures and teams, vehicles and similar categories. Aircraft recognition fits firmly within these categories, as in the account below from a self-proclaimed 'gen kiddy': 
Well if you are an enthusiast it was just a matter of reading so many papers and books. There were so many books on aircraft recognition, and of course you had the real things flying around you like bees round a honey pot, so it wasn't difficult. I was very, very interested, and I became, even though I say it myself, quite a 'gen kiddy' as regards aircraft recognition. I was a member of the National Roof Spotters Association where I qualified for three National Certificates on Aircraft Recognition.

(Crawley 2006a)

\section{Literature and ephemera}

The popularity of aircraft recognition both drove and was driven by the production of a wealth of printed materials. The most common were books and series such as Gibbs-Smith's Aircraft Recognition Manual, the Aircraft of the Fighting Powers discussed earlier and similar volumes of cutaway plans, silhouettes, photographs and technical specifications.

When [my father] came home on leave during his time away from Dunstable, he would purchase 'Aircraft Recognition' books for me, I believe from Smith's on the London stations. These volumes each had a description of $20-30$ different aircraft with photographs and silhouettes. I eventually had a collection that covered British; American; German; Italian and Japanese aircraft and in the case of the British and German aircraft, 3 or 4 volumes of each. My friend and I studied these assiduously so that on one occasion when we were invited into the warden's post in Edward St., we surprised the wardens by being able to immediately identify the model aircraft they had hanging in their room, these were official aircraft recognition models and were painted black.

(AW Morgan 2005a)

For me I was usually buried in borrowed copies of Aeromodeller or Aircraft of the Fighting Powers and occasionally I managed to acquire the odd copy of the official publication Aircraft Recognition, which was supplied to the forces; when I won a prize for English at school in about 1942 I can remember my disappointment at getting a copy of Peter Pan; what I really wanted was R.A. Saville-Sneath's Penguin book, Aircraft Recognition, Part 1!

(Dilly 2005)

Alongside these relatively expensive books there were a number of different magazines, focused variously on aircraft recognition (The Aeroplane Spotter, Aircraft Recognition), aero-modelling (Aero Modeller), and general aviation interest (Aeroplane, Flight). Some of these publications also marketed additional literature and resources for the airminded youth: Flight sold aircraft identification wallcharts of British, German and American types; sets of collectable postcardsized photographs with new types being added continuously and even a set of 
identification tables printed on waterproof celluloid. Other ephemera included flash-cards to use in teaching, learning and practicing aircraft recognition and improvised plotting devices such as the one described in this account: 'One of my possessions was a cardboard device that one held at arm's length, consisting of two arms pivoted together at the bottom. A list of aircraft types was printed up one side and when you had identified a type and moved the cardboard arms so they appeared to touch its wingtips you could read off its altitude on a scale' (Dilly 2005). Canadian troops stationed in the UK were routinely shaken-down by local children for the Aircraft 'Spotter' Series of cards that came attached to Canadian Sweet Caporal cigarette packets: "these were highly collectable and the cry "Got any Sweet Caps" followed any soldier with a "Canada" shoulder flash. We were after the packets rather than their contents and much enthusiastic swapping took place in order to get a complete set of silhouettes' (Dilly 2005).

\section{Cadets}

The boundaries between aircraft recognition as childish enthusiasm and as valuable civil defence or military knowledge often blurred. Certainly there was an official view that schoolboys with aircraft recognition posters on their walls were honing useful skills as the RAF pilots of tomorrow, a view shared by many of the boys themselves. The importance of aircraft recognition might have loomed large in the minds of the boys, but it is unlikely, as some thought in retrospect, that the government gave tacit or material support to aeromodelling as a useful element of the war effort:

There weren't many toys available at that time. None that used war resources. You could still buy balsa wood model aircraft. I think it was available because we were in effect learning to identify aircraft and it kept kids' morale up. There was no such thing as plastic. I actually made some rather good models. We managed to get cellulose paint to finish them off, little tins of it. They were nearly as good as the Airfix kits that you can get nowadays. We made Spitfires, Hurricanes, Typhoons, Blenheims, Messerschmitt and other German planes.

(Bukin 2005)

In 1938 the Air Defence Cadet Corps was founded at the initiative of retired RAF Air Commodore John Chamier, then Secretary of the Air League, founded in 1909 as the Aerial League of the British Empire. Chamier's campaign was successful and large numbers of young men signed up to the Corps, taking part in activities including military drill and physical fitness training, as well as learning about military aircraft and aviation in general. Part of the purpose of the ADCC was to encourage and prepare boys for service in the RAF and Fleet Air Arm. Official interest in the Corps from 1940 led to its takeover by the government from 1941 as the Air Training Corps with clearer connections to the RAF. Aircraft recognition was one of the principal formal activities of 
the ATC, as attested in John Crawley's account below. Crawley was a member of the National Roof Spotters Association and held certificates in aircraft recognition but had been excluded from military service due to a curvature of the spine. He became an ATC aircraft recognition instructor following a chance meeting with the Commanding Officer of his local cadet squadron:

I got talking to him and he brought aeroplanes into the conversation, and I think he was a bit surprised that I was able to talk to him on very near equal terms on modern aircraft. He said, 'Where have you got all your knowledge from?' I said, 'Oh, I'm just an enthusiast. I'm an aircraft recognition enthusiast.' I told him I'd got this certificate and that and he said, 'Ah, you are just the man we are looking for!' I said, 'Oh, yes!' He said, 'Well, I'm the Commanding Officer of 134 Squadron of Bedford Air Training Corp, and we haven't got anybody to instruct air cadets on aircraft recognition.' He said, 'Would you be interested?' So I said, 'Oh, well I can't think of any reason why not.' So that was the start of it ... As I say I used to go along purely for aircraft recognition and then I became so involved and interested I was doing a class one night a week and building model aircraft ... one day the $\mathrm{CO}$ called me into his office and said, 'Ah, Crawley,' he said, 'I think I've got a job for you!' I said, 'Oh, yes Sir!' he said 'well, it might be up your street on the other hand it might not.' I thought, tell me more, Sir. He said, 'I've had a request from a Mrs. Monk and she is the Commandant of the Girls Training Corp, and they meet at the Shire Hall on a Friday night. She wondered if one of my people could go along and instruct her girls on aircraft recognition and since that is your particular forte I'm offering you the job.'

(Crawley 2006a)

For a more detailed discussion of the airminded youth organizations including the ADCC, ATC and Air Scouts see Adey's Aerial Life (Adey 2010) which considers their role in the training and shaping of future airmen's minds and bodies.

Aircraft recognition in the UK was taught using a system known as WEFT in which students learn to identify the distinctive wings, engine(s), fuselage and tail of the various aircraft types, based largely on profile drawings. This system was adopted in the US and elsewhere, but was criticized in a later review of training methods as unsystematic, overemphasizing the more easily named characteristics of the aircraft, and for generally bearing little relation to the views of aircraft as they were likely to be encountered in the wild (Vicory 1968).

Various types of model aircraft made of wood, bakelite and rather fragile starched cloth buckram were used in aircraft recognition training by the military and civil defence organizations. These generally rather crude models were usually built to 1/72 scale, and painted matt black or grey. Government orders for these commercially-made models through the Ministry of Aircraft Production consumed the bulk of production by commercial model kit 
companies such as Lines Brothers, whose FROG and Penguin brands were the forerunners of today's Airfix and similar moulded plastic assembly kits: as Hamilton notes, 'in mid-1941 contractual requirements amounted to 200,000 models' (Hamilton 1994: 106). High-quality, expensive models were also commissioned from Woodason Aircraft Models, either for display or for use as a model in training films and photographs. Several accounts of ATC aircraft recognition training include aero-modelling as a way of improving understanding of different types, as well as an introduction into aeronautics. A few accounts describe instructors blindfolding students who were required to identify aircraft types by handling scale models.

\section{Aero-modelling}

Despite these sizeable government orders for recognition models, by far the largest market for model aircraft of all kinds was young people, and a decentsized industry built up to meet the demand for flying and static models of the latest types and marks of aircraft.

One of the things which came to the fore in the late 1930s was aeromodelling, constructing both flying and nonflying models. Of the latter were the kits made by the 'Skybird' firm, these being shaped wood with diecast lead engines and guns etc. and requiring a considerable amount of finishing to obtain a perfect result ... Later came the first plastic kits, nicknamed FROG but trading as Penguin. There were truly remarkable kits with a wealth of detail. Perhaps their only drawback was the tendency for the cement, supplied in a little sealed bottle, to dry up whilst on the shop shelf. The range of aircraft types of the period was outstanding. Who can now remember such types as the Short Singapore flying boat, Armstrong Whitworth Scimitar fighter, Hawker Demon fighter and the Fairey Gordon torpedo bomber, to name but a few from these kit manufacturers. Most toy or model shops at this time stocked balsa wood in various sizes for making flying model kits for these were also plentiful.

(Whitworth 2016: 20)

Skybird was part of an Air League campaign aimed specifically at encouraging airmindedness amongst British children. Model makers were encouraged to join one of several hundred local 'Skybird League' modelling clubs and to read The Skybird magazine, later integrated into The Aero-Modeller. Within a few years of the Skybird League's foundation in 1933 the hobby of aero-modelling had grown considerably among young people, contributing directly to the later success of the ADCC and the ATC (Hamilton 1994: 51-3). The account quoted above contains many salient features of pre-war and wartime aero-modelling including the interest in both rubber-powered aircraft and gliders built from balsa wood and the smaller, more detailed static models. Like aircraft recognition but far more tangible, aero-modelling enabled young people to materialize, to grasp and to master aircraft that would otherwise have remained beyond their 
reach. Aero-modelling was also a craft: selecting and obtaining materials; carving, cutting and whittling the wooden components; gluing, sanding and painting them; and preparing them for flight or display. All of these required patience, a steady hand and attention to detail, whether the aim was airworthiness or exact replication. Several accounts detail these craft elements and the difficulties in achieving the expected standards of excellence:

I could go to a shop in Church Street, Marylebone, where I could buy 'Kiel Kraft' balsa kits for model aeroplanes. I saved my pocket money as the small kits cost $6 \mathrm{~d}$ each for planes such as a Spitfire or Hurricane up to about $1 \mathrm{~s} 6 \mathrm{~d}$ or $2 \mathrm{~s}$ for bigger aircraft such as a Lancaster bomber or Sunderland flying boat. In retrospect, I realise that my friends and I did not shape the wings and fuselages very well when making them. This was brought home to me when I saw a set of similar models displayed at 'Bletchley Park' museum; these too had the same child-like faults in their construction.

(AW Morgan 2005b)

One of my school chums at Rush Green school ... he also liked to make model aeroplanes but he could never get used to the idea that you had to trim the balsa wood patterns into smooth shapes before the model was assembled, he used to stick the parts together straight from the box.

(Tait 2003)

There was also a definite social element to model making, with model aircraft clubs catering largely to those making flying models. These clubs often brought together people of different ages (one account mentions a range of 'perhaps 10 to $35^{\prime}$ [Wesley 2003]) and levels of skill in building and flying: like many hobbybased clubs the exchange of skills, advice, tools, materials and even finished models was central to the attraction and success of these groups. The main purpose remained the pleasure of building and flying models:

Several of us boys in the London Road area formed a 'gang', the principal activity of which was model aircraft making. Some were solid models, others flew. My brother Brian spent hours and hours building a balsa wood frame, paper covered, flying model (I think an 'Ajax') which was powered by elastic driving a propeller. We had the use of a sports field next to our house, but on the first outing the whole structure of the plane concertinered when the elastic was overwound! Other planes were lost in the trees. We also spent a lot of time learning plane recognition.

(Joscelyne 2005)

Aircraft and aero-modelling magazines of the period contain advertisements for model kits, plans and a huge assortment of products and parts including glues, dopes for treating the paper or cloth coverings on wings, paints, wood, and rubber lubricant which promised 'more miles per turn'. For younger 
children, the social element of aero-modelling was more closely associated with model aircraft as toys, to be built and then played with, possibly alone but more often with friends or siblings.

My friends and I started collecting small scale aircraft models (1/72nd scale) and one Saturday afternoon Tom and I made an airfield in the back garden, by a bend in the path, by flattening the soil (it was spring) and using our model fighters to fly off and 'intercept the enemy' - and return successfully! After Tom went home that evening I realised that he had left his model Spitfire behind.

(Anon. 2005e)

We played with homemade wooden model aeroplanes or sometimes Dinky Toys of Spitfires and Hurricanes, and made loud 'aeer' sounds as we weald [sic] them out in our living room.

(Cronin 2003)

One boy recalled his distress at the loss of his wooden models when his home was bombed:

Inside the house all the ceilings were down without exception, this was a big blow to me as I had made a great many balsa wood model aeroplanes, Spitfires, Hurricanes, Dorniers, Heinkels etc., and they had all been suspended from my bedroom ceiling which at that time was the box room, and of course I lost them all.

(Tait 2003)

Scale model aircraft were not only made by children: the trope of servicemen making models for their children or friends is familiar from films such as Memphis Belle. Aircraft models in wood, brass or aluminium standing on plinths or ashtrays are a common form of 'trench art' from the Second World War up to the present, serving as souvenirs or as formal or informal gifts between individuals or units. For young people in wartime Britain model aircraft were commodities that could be sold or gifted, and talented model makers could do good business. Access to tools and materials was key: one former evacuee recalled that the father of his host family possessed a workspace with high quality woodworking tools, and was given permission to carve model aircraft: 'I was allowed to hang some of these in the bedroom and to supplement pocket money sold some to school friends not so gifted'; the models sold at $1 \mathrm{~s} 6 \mathrm{~d}$ each, which he noted was three weeks' worth of pocket money, so clearly a profitable business (Sutton 2003). Another boy recalled that one of his school teachers would carve beautiful model aircraft and sell them to the boys for one shilling each: "He made me a "Lysander", all the other boys wanted "Spitfires". I had to be different!' (Gould 2005) (Figure 5.2). With many young people employed in war work, there were 


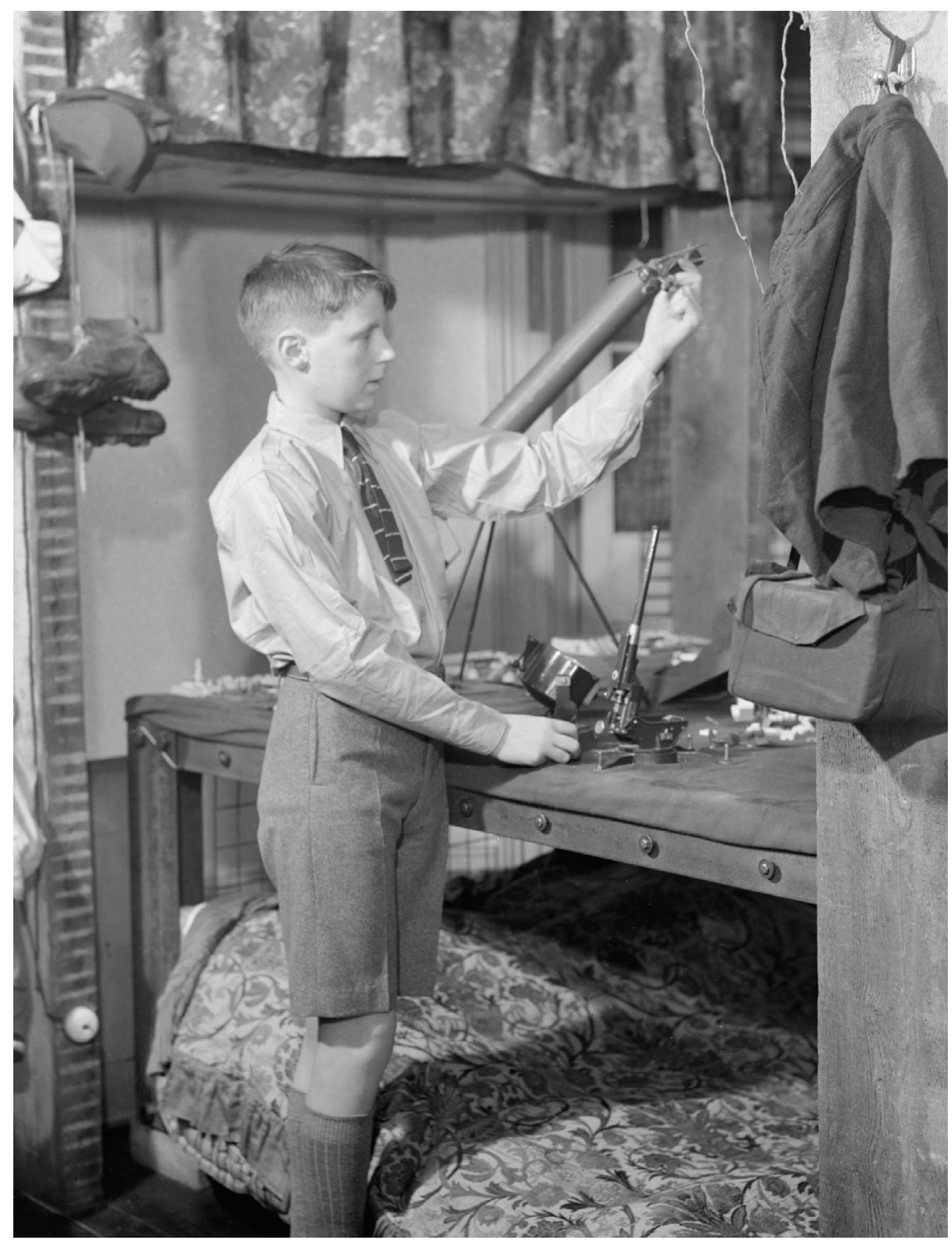

Figure 5.2 In this photograph, originally intended to advertise the shirt and shorts, a 12-year-old boy stands next to his Morrison air raid shelter and plays with a 1/72 scale model of a Westland Lysander aircraft. Behind him on top of the shelter sit models of an anti-aircraft gun and a searchlight, while a gas mask hangs to the right. C Imperial War Museum, D 13081. 
inevitable temptations to use workplace tools and materials for aero-modelling: a risky business as one young man discovered.

Early in February 1944 I landed myself in a spot of bother by doing 'homework' during working hours, in this instance, carving out a wing for a model aircraft from some very hard wood supplied with the model kit; no plastic in those days! It was early evening and almost finishing time and I decided to use the large vice on my bench to make things easier, thinking all the bosses would have gone home by then. Suddenly Joe Taylor, the works foreman strode by and obviously saw everything. Next morning I was summoned to the works manager's office and given a real telling off as homework jobs could be a criminal offence leading to court, however as it was my own wood and being in the Air Cadets, I escaped lightly.

(Whitworth 2016: 67)

\section{Modelling materials}

The materials used in aero-modelling varied considerably. The early FROG plastic kits were expensive, so most model makers either carved their models from pre-cut blocks of hardwood or worked from detailed scale plans and whatever raw materials they could get their hands on:

We made model aeroplanes from firewood and finished them with perspex cockpits, gun turrets, paints and transfers from the model shop and mounted them on stands made from a bicycle spoke and a screw top treacle jar lid. If you were lucky you could sell them through the model shop for a few pennies. We also made elastic-powered planes from balsa wood, tissue and tape

(Lacey 2005)

Warcraft model aircraft company in Dewsbury, West Yorkshire, is an example of the many small model-making companies that sprang up in response to popular demand. Worfolk's Toy Shop was a well-known local business, and George Worfolk was remembered by his nephew David Reid as a clever and talented model maker, exempted from military service due to the after-effects of childhood rheumatic fever. During the war Worfolk began manufacturing model kits using the brand-name Warcraft. Local boy Sam Whitworth, an enthusiastic aero-modeller, recalled that Warcraft kits like many others at the time provided modellers with hardwood components, roughly cut to shape, that required carving and sanding to finish (Whitworth 2016: 34). Whitworth recalled that Dewsbury had two model shops in this period, both of them run by men who were themselves enthusiastic aero-modellers, and Reid mentions an eight foot scale model Lancaster bomber that George Worfolk built. Reid also notes that model aircraft manufacturers, including his uncle, were in receipt of government subsidies: 'The reason was simple: they wanted models to be made so that children, adults and members of the armed forces would recognise friendly aircraft from foe' (Reid 2004). It is not 
clear whether this subsidy is distinct from the orders given to kit manufacturers by the Ministry of Aircraft Production for hundreds of thousands of aircraft recognition training models, noted earlier (and see Hamilton 1994: 106-7).

Some modelling materials such as rubber were restricted due to their uses in war work. Balsa wood for model making remained available, although some accounts like Whitworth's above mention restrictions on balsa wood once it began to be used in the construction of the 'Wooden Wonder', the innovative lightweight De Havilland Mosquito aircraft. Even this did not necessarily cut off the supply: John Heygate's father ran one of the many small engineering firms building components for aircraft, and through his connections 'regularly acquired bundles of softwood off cuts from a factory situated on Slough trading estate that was making Mosquito Fighter Bomber Aircraft; lots of wood used in the construction.' (Heygate 2004).

This provides a viewpoint into a much larger and more interesting phenomenon: the construction of model aircraft from materials taken from actual aircraft. This is mentioned in several accounts, many of which focus on the rare and desirable Perspex, the clear acrylic glass used in aircraft windshields, window and gun turrets: 'The boys were mad about making model aircraft. We once saw an aeroplane crash at Buck Pike and pinched its perspex for our models' (Vail 2004). Model makers used the easily-worked material to fabricate tiny windshields for their models, but also to create transparent discs to imitate a spinning propeller, and to create 'invisible' stands to simulate a flying model. Whitworth (2016) recalled softening fragments of Perspex in boiling water before moulding them into the desired shape of a model aircraft windshield.

There was great excitement when a German bomber came down in a field near to Ruffold Farm and there was always great competition between the boys to collect the perspex for making rings and model aircraft.

(Wakeford 2003)

Sites of crashed aircraft were visited eagerly by us schoolboys and pieces of debris were carried home as trophies, to be displayed and perhaps swapped in the playground. Highly prized were sections of alloy pipelines or pieces of perspex from which objects such as rings could be easily fashioned with the most rudimentary tools.

(Baylis 2003)

Nor were these young people averse at putting themselves in considerable danger to acquire these materials: John Martin recalled stealing wire from an unexploded V1 flying bomb that crashed in his local recreation ground.

The doodlebug's warhead had been removed by the bomb disposal boys and it was some time before the airframe was taken away. It lay all broken open with its innards exposed, including two pressure bottles used to house the propellant. These were wrapped in hundreds of yards of piano wire - a material totally unobtainable in wartime. As superkeen aero-modellers, my 
brother and I seized the opportunity to surreptitiously cut off enough wire to make the undercarriage legs for more rubber-powered model aircraft than we could ever be able to make!

(Martin 2006)

Like the shrapnel and associated war materials discussed in Chapter 2, making models with materials taken from crashed aircraft moves beyond simple expedience into the realms of sympathetic magic: such a model might be imbued in the minds of its child owners with the aura of the aircraft, its dynamism and power.

\section{Display}

In February 1941, The Aero-Modeller magazine offered its readers some tips on how to hold a successful exhibition of model aircraft. The advice is aimed at Air Defence Cadet Corps units, and notes that such exhibitions might be held to recruit members or gain publicity or to fundraise for the unit or for other causes. Displays of this kind were fairly common in wartime Britain, often presented in the windows of disused shops with a mixture of educational posters, propaganda, examples of incendiary bombs and firefighting equipment, pieces of crashed German aircraft and other wartime ephemera. As the war progressed, these displays became more common as part of specific fundraising efforts such as 'Wings for Victory Week', with accounts of 'a display of model aircraft in the greenhouse of a neighbour to raise money to help Aberdeen's "Buy a Spitfire" appeal. The boys who made the models were all thrilled when the popular Lord Provost Thomas Mitchell paid a visit to the display and we got our photographs in the Press and Journal.' (Hall 2005). Some of these National Savings Campaigns included model and postermaking competitions aimed at children, with prizes of cash or National Savings stamps (Millar 2003). One young child even found himself part of the display:

In August 1940 I was taken shopping by my mother and aunt in Sunderland, County Durham. I was just over two years old and I was wearing a replica RAF uniform that had been made by my mother and aunt from one of my father's cut-down uniforms. That day Binns, a large Sunderland department store, had dedicated one of its shop windows to collecting for the Spitfire Fund, collecting money from the public to help build Spitfire fighter aircraft for the RAF. The shop window had a collection of model aircraft displayed. The store manager saw me and asked my mother if he could 'borrow' me to enhance the shop window display. My mother agreed, and I sat in the shop window for some time playing with the model aircraft and entertaining the shoppers outside.

(Matthews 2005)

Displays of this kind were part of the social aspect of model-making discussed earlier, where modellers could inspect and admire one another's work, exhibit their own best efforts, and socialise. Aero-Modeller provides very detailed instructions: 
If therefore you decide to hold an exhibition of your models, which can be padded with judicious A.D.C.C. propaganda, find a hall in the best possible position and easily accessible, and well placard it with lively posters.

(Rippon 1941: 101)

The article suggests working with a local journalist to ensure positive news coverage, inviting a local dignitary to open the exhibition, and even goes as far as to suggest the wording for posters and the appropriate volume for background music. More usefully, it suggests that alongside the display of models, the cadets might demonstrate model-making in action: 'Demonstrations of covering, making up and testing rubber motors, etc., or shaping and assembling solid scale models, will always command attention' (Rippon 1941: 102).

One such exhibition caused trouble for aero-modelling enthusiast John Crawley, mentioned earlier in relation to his aircraft recognition work. During a 'Wings for Victory Week' event Crawley displayed several dozen of his model aircraft in the window of his workplace in Bedford, close to RAF Twinwood Farm, as he recalled: 'We used to see Beaufighters from Twinwoods doing circuits and bumps around Bedford, and they'd come over quite low and they all had like a double arrow head aerial fitted on the nose with various little stalk aerials on the wings' [probably the Serrate radar detector] (Crawley 2006b). Crawley's display included a large 1/48 scale wooden model of one of these Bristol Beaufighters, painted all black and with tiny wire radar aerials attached, like the night-fighters flying out of the RAF station. At this point the existence of airborne radar was still officially being kept secret, and an irate RAF officer visited Crawley's workplace and demanded to know where he had learned about radar. Crawley pointed out that the aerials were visible on Beaufighters flying practice circuits in daytime over Bedford at low altitude, but the officer insisted that either the aerials or the model be removed from display.

Military security wasn't the only objection to aero-modelling. In the early 1930s, Ron West, thoroughly airminded and set on a career in the RAF, met stern resistance from his father. Fielding West was a remarkable man who began working as a coal miner as a child and became Labour MP for Kensington North and later Hammersmith North. West recalled that his father, 'an ardent socialist and pacifist', objected strongly to his love of aircraft and his chosen career: 'If I was caught reading an aircraft book, or making a model, then he would destroy it and send me to my room' (West 2005). Ron joined the RAF as an apprentice at the age of 15 , shortly after his father's untimely death.

\section{Real live aircraft}

An RAF Spitfire crash landed on Central Park, we kids all tried to get near it, but the nearest we could get to it was the fence in the Dagenham road opposite the Hospital gates, it was frustrating standing at the fence looking at this wonderful aeroplane, but not able to touch.

(Tait 2003) 
From aircraft recognition flashcards to painstakingly painted wooden scale models, airminded children in Second World War Britain strove to materialize the aircraft that most of them could only see and hear from a great distance. Jim Tait's account above is indicative of the war child's yearning to touch, to physically explore and to master the awesome power of the aircraft, in this case the iconic Spitfire. In the pre-war period aviation enthusiasts could visit air shows and civilian airfields, but these opportunities declined with the outbreak of war. Over the course of the war years the transformation of Britain's air war from defensive to devastatingly aggressive created more and more opportunities for young people to encounter real aircraft and even to fly in them. One of the attractions of the ADCC and ATC was the prospect that cadets would get to fly in gliders or powered aircraft. Accounts from a wartime air cadet back this up: 'The ATC gave many of us our first air experience whilst at summer camps. We had trips to Oxfords, Ansons, and Wellingtons, in the latter whilst at RAF Edzell.' (Hall 2005). John Holcombe's memories of the ATC include playing the drum in the band, learning to shoot with small calibre rifles, and model aircraft building in the ATC's own workshop. Flight experience came on the annual week-long camp at RAF Kidlington (now Oxford Airport): 'I flew in Hawker Hectors, which towed a Hotspur glider, and in Airspeed Oxfords. This was at Kidlington and was enjoyable as the food was much better than the civilian population was getting' (Holcombe 2005). Some of the recollections of interacting with aircraft collected by the BBC People's War project are markedly multisensory, reinforcing the notion that smell in particular is closely connected to memory, as in Martin Dilly's account of exploring RAF Blackbushe in Hampshire:

The first day we went there my mother picked blackberries while I wandered about on the airfield (nobody seemed to mind reasonablybehaved small boys then); it was the sight and the smell of rows of camouflaged Hotspur training gliders and Whitley bombers, used as tugs, that got me hooked on aircraft for life. The smell of warm aircraft, with their doped ply and fabric, and the aromatic fumes of 'proper' high octane aviation fuel (probably 130 octane then) cast a spell that brought me and my long-suffering mother back to that airfield as often as I could persuade her to pedal there, and kept me involved with aviation in various forms ever since.

(Dilly 2005)

He seems to have enjoyed an unusual level of access to the airfield: security on RAF bases was typically too tight for casual visitors to wander in, even children. American airbases were usually more open and friendly, but the British personnel at Blackbushe were happy for nine-year-old Dilly to explore a number of different aircraft inside and out: 
Seeing that I was fascinated by the aircraft there, they often helped me into cockpits, and I have a vivid memory of the long belts of .50 calibre machine gun ammunition running in tracks along the inside of the fuselage of a Mitchell in which I sat; the cockpit of a Mosquito into which I climbed seemed pretty cramped, even to a nine year old. Bostons were regulars too, and later on Warwicks, equipped with air-sea rescue lifeboats slung under the fuselage. Other special excitement came when I was lifted up to look into the waist gunner's window of a B-17 Flying Fortress, and when I noticed a Liberator fitted with an anti-submarine Leigh light under one wing. Stirlings and Lancasters visited and there were various USAAF Mustangs, Thunderbolts and Cessna Cranes and Bobcats. On being allowed into a troop-carrying C-47 Dakota, I remember being amazed at the sight of piles of comics on the seats along the fuselage sides, and realising that this was the preferred reading matter of grown-up soldiers, or at least American ones.

(Dilly 2005)

Aside from these rare and unusual exploits, children's most common close encounters came in the aftermath of air crashes, when aircraft or fragments of aircraft fell close to their homes, schools or workplaces. In these cases, the most common aim was souvenir hunting: what better addition to a painstakingly curated collection of shrapnel, bullets and badge caps than a swastika cut from the tail of a German aircraft? A group of British children's discovery of a crashed German bomber aircraft forms the basis of Robert Westall's popular children's novel The Machine Gunners (Westall 2001): set in the north east of England in 1941, the children recover a machine gun from the wreck and construct a secret base to house it. Westall later published a volume of first-person accounts of wartime childhood, Children of the Blitz (1995), based in part on stories sent to him by readers of The Machine Gunners: it included hair-raising accounts of children's encounters with crashed aircraft and heavy weaponry, some even more powerful than the machine gun in the novel. From the BBC People's War archive, Reg Tomes' account of an air crash near Withernsea in the East Riding of Yorkshire has many elements in common with this. A group of local boys went to investigate the crash of a low-flying mine-laying aircraft in 1941: the crew has survived with minor injuries and had been taken prisoner, but a British bomb disposal team were killed by an explosion of the mines carried in the aircraft. Having witnessed the explosion, the boys returned the following day:

The RAF procedure was to put a guard on crashed aircraft, but the boys could see no sign of them. 'We went along the ditch until we got to the wreckage.' Reg said. 'The fuselage of the aircraft was straddling the ditch, and the tail, which had broken off, was some distance away, the cabin was intact, and there were two machine guns inside. The front gun was damaged, 
but the rear gunner's weapon appeared to be okay. There was also a cannon, but I can't remember where we found that. There were bits and pieces lying about all over the place, and we began picking them up. I got a Luger pistol, another chap got the radio transmitter, and others got the clock out of the dashboard, the altimeter a helmet and flying gloves. One of the lads had a hacksaw, and cut the swastika out of the tailfin.' The boys then turned their attention to the machine gun. They unbolted it from its mounting, unaware that the oddly-shaped object that they were clambering over to get into the aircraft was another landmine. They also took two ammunition pans and the cannon, with 200 rounds of ammunition for it. 'Why?' said Reg, 'I don't know. We were kids and there was a war on.' The lads took their booty home fastened to their bicycles.

(Tomes 2005)

Inevitably some of the boys were caught in possession of a terrifying quantity of weaponry, but not before they had test-fired their newly acquired arsenal and installed it as makeshift anti-aircraft guns in a church tower. The gang was arrested and their hoard of souvenirs confiscated but as Tomes recalled 'We appeared in court, and luckily we had a vicar in these days who said what nice lads we were - air minded, patriotic boys, and we virtually got away with it.' (Tomes 2005). As the war progressed the number of air crashes increased, particularly during the strategic bombing campaigns later in the war. Several accounts describe the increasingly lax security at these crash sites, with bored solitary guards quite happy to let children clamber all over and inside the aircraft and even taking away souvenirs. Brian Smith remembers himself and his friends as 'little vultures': 'The large numbers of crashed aircraft meant that there was only a perfunctory presence of guards at the crash sites. Us kids made hay acquiring souvenirs of bullets, perspex, Aluminium, parachute silk etc.' (BN Smith 2004).

The guards were there for a number of reasons, aside from discouraging looting or dangers to the public. German aircraft shot or forced down over Britain in reasonably good condition went to the researchers at the Royal Aircraft Establishment at Farnborough for evaluation and where possible were returned to flying condition. More badly damaged examples were often displayed to the appreciative public as trophies of war, or as part of fundraising efforts: Hamilton (1994: 108) notes that a Messerschmitt was displayed in East Croydon Station carpark, with interested members of the public paying $6 \mathrm{~d}$ towards the Spitfire Fund to view it.

Nine-year-old Ben Halligan and his friends were swimming in a canal when they witnessed a Spitfire crashland in a nearby field and assisted the pilot in removing the ammunition belts from the wings in case of fire or explosion. As he recalled:

The young pilot did a wonderful thing after we got dressed, he let each of us climb into the cockpit and have a few minutes sitting there with our imaginations. Do not forget that the Spitfire was the fastest plane in the 
world at that time. When the mechanics came they decided to take it away by road, they towed the plane across the field to the gate, and I was sitting in the cockpit, in my imagination. I must have shot down at least twenty German planes in that five minutes!

(Halligan 2005)

This experience, remembered fondly more than 60 years later, fulfilled what was most likely the dream of all young aero-modellers and plane spotters: to have a real-life Spitfire, albeit a broken one, as the prop for their imaginations and their games.

Inevitably some encounters with air crashes included the bodies of the crew. The velocity and violence of the impact together with subsequent fires and explosions of fuel, ammunition or bombs often resulted in the near-annihilation of the bodies. British military guidelines counted just $7 \mathrm{lb}(3.2 \mathrm{~kg})$ of recovered human tissue, or any fragment of skull or spine, as proof of death, and often airmen's coffins were returned to their families with ballast of sand or earth to disguise the meagre fragmentary remains within (Moshenska 2014). Some of the accounts of bodies encountered at air crash sites are surprisingly lackadaisical: 'The charred bodies of the four-man crew lay within the wreckage. We spent some time examining bits and pieces of the aircraft and also helping ourselves to several souvenirs, but after a short time the home-guard and police arrived' (Varley 2005). In others the horror is apparent, as in Terence Cartwright's account of witnessing the destruction of a Lancaster bomber:

We saw its black silhouette disappear below the horizon of the railway embankment and a split second later a tremendous orange/red/black mushroom of fire clawed its way into the Blue sky, followed by a delayed hollow booming thud. Our legs came back to life, and with childish visions of heroic rescue of airmen from burning wreckage we sped down Station Road ... The site of the crash was covered in a layer of smoke, but as we got nearer we were confronted with an incredible sight ... Our hopes of rescue vanished as we jumped over the small brook and ran to the edge of the main smoking crater. As we looked into this pit, ammunition was exploding, sending puffs of ash into the air like a volcano ready to erupt. We were not sure if any bombs were in there, so we retired to a safer distance. It was then that I saw that the local 'Bobby' had arrived. He was looking at what I thought was a meaty bone a dog had brought into the field. He had a strange shocked look in his eyes and when he said, 'Don't touch it' the tone of his voice prompted me to look again ... With a numbing sense of shock I realised I was looking at what appeared to be a human shoulder blade! I then saw a sock ... inside was half a foot ... Up to this point it had been as if it was all a dream, but now reality and shock began to filter through my brain and I felt sickened, sad and helpless.

(Cartwright 2004) 
Edinburgh in Gavin Russell's account of his wartime childhood was not heavily bombed or otherwise affected by the war, and he recalled seeing Spitfires, Hurricanes and Lightnings flying far overhead. At the annual military displays in an Edinburgh park he and his friends were finally able to get up close to real life fighter aircraft, and the sensory memories of this experience remained powerful:

Once a year the army used to set up camp on the Links Meadows just around the corner. In a morale booster for the civvies, they had tanks, brown tents, fighter planes, barrage balloons, guns, and searchlights to overwhelm my senses with such a thrilling strangeness I can see and smell it all now ... For little lads who had only seen our fighters in aircraft recognition books or distant in the sky, the sight of these well-worn beasts close to (up the steps for a look in the cockpit of the proud Spit) was a visit to scallywag's heaven or better. My heightened senses were awash with the reality of every aluminium rivet, the joystick with its gun button and black, oily guns, guns, guns.

(Russell 2003)

As he makes clear in this account, this glorious 'reality' of the aircraft made tangible was a fulfilment of the wishes normally satisfied at second hand through books and models, or at a great distance. To be able to touch the Spitfire, to smell it, to experience its materiality and the violent presence of its weaponry were extraordinary and memorable experiences, even though the aircraft sat silent and static on display. Russell's account supports my argument that the identification books, flashcards, posters, flying models, scale models and other aviation ephemera were components in a childish sympathetic magic aimed at drawing the combat aircraft down to earth in tangible, controllable forms to be admired and worshipped. 


\section{Conclusion}

War is an abstract concept for a child, but they can stand on top of the ruins of a bombed house and hold a piece of shining hot shrapnel in their hand. As this book has demonstrated, these and other things can come to represent not only the violence and destructive power of war but also the possibility of taming and mastering it. Based on the studies laid out in the previous chapters I am confident that I have achieved the first set of aims laid out in my introduction: to illuminate some of the most significant aspects of the material culture of childhood in Second World War Britain, as they were experienced at the time, and remembered after a lifetime. In doing so, I have explored the integration of these materials into children's existing worlds of play and social interaction, and the ways in which material things came to mediate relationships with friends, families, teachers and others. I have demonstrated the power of this same material culture to stimulate the bodily senses - most notably smell, sound and touch - and to evoke powerful and enduring memories.

The experience of childhood in Second World War Britain cannot be reduced to five things, or to any discrete set of objects, events, or experiences. The memory narratives that form the core of this book represent the diverse childhoods shaped by wartime society and the gender, age, health, class, education, physical location and family ties of the children in question. Above all of these divisions and categories there is the theme of children in war as victims, vulnerable before the forces of geopolitics and industrialized violence. What I have found in these memory narratives, again and again, is evidence of children as not merely victims but conscious actors in wartime society: of keen young patriots desperate to contribute to the war effort that is tearing apart their families; of young people forming friendships and playing childish games amidst the flying shrapnel and burning buildings; and of children seizing hold of things - objects, people, places - that might help them cope with the world at war around them.

Turning from the children to the material culture, I have found narratives that refer to things and places in passing, as illustrations or familiar reference points, and I have also encountered stories that wrap themselves tightly around the material worlds of wartime childhood, allowing them to shape 


\section{Conclusion}

their form and direction. In my historical anthropological study of these narratives I have taken up González-Ruibal's (2008: 259) challenge to critically examine the value of '500 micro-histories about as many micro-events', and attempted to show - as he suggests - the power of material culture illuminated, thrust forwards, and made manifest through the accumulation of narratives of affect, abjection and the senses.

\section{A final story}

Of the hundreds of memory narratives of wartime childhood gathered in the BBC People's War archive, none has affected me as powerfully as Ronald Nichol's account of the bombing of Rush Green Emergency Hospital in Romford, Essex in June 1944. Like many of the accounts in this archive, Nichol's memories of the war focus on objects and places: his father's Home Guard uniform and helmet; playing on bombsites near his home; collecting shrapnel after air raids on the nearby RAF Hornchurch airbase; sleeping in the family's Morrison table shelter and being cautioned against playing with booby-trapped cluster munitions. Living close to Hornchurch, aircraft were a constant presence: 'I can still remember the sound and sight of several Spitfires taking off low over Cecil Avenue; later in the war I sat in the garden and watched the high flying Tempests diving on V1 flying bombs' (Nichol 2004). In 1944 Ronald was admitted to the isolation hospital with whooping cough: the night before he was due to be released he awoke to find his bed covered in broken glass and the ward around him in ruins. His recollections of the event are sense memories: 'Acrid smoke and the sharp crack of anti-aircraft guns completed my awareness of the moment', and the sound of explosions and flying glass and brick as his rescuers carried him to the hospital air raid shelter wrapped in a blanket (Nichol 2004). Two nurses and six patients at the hospital were killed.

In the shelter were a group of children 'whimpering and howling' at the sound of explosions while nurses comforted them, one of whom pointed at Nichol and noted approvingly that 'Ron was not crying'. He fell asleep in the shelter and awoke to find himself in a hospital bed with bandaged hands and knees and the next day saw the ruins of his ward and the 'row of blanket covered stretchers' of those who had been killed. A fireman who had been working in the wreckage approached him

'Were you in that building?' He asked, 'Are these things yours?' In his hand he held my tiny red racing car and my blue and maroon striped elastic belt with a snake head for a buckle. I thanked him and he tussled the hair on my head and strode off back into the still smoking rubble.

(Nichol 2004)

The numbness that Nichol felt in the aftermath of the bombing did not wear off. He described a V2 missile that damaged his family home, covering them all in dust and broken glass, and another that hit his school, blasting dirt and debris across the children in the playground: 
Teachers were huddling us into the side of the building. Many of the kids were crying, cut by flying debris. Just as the night in the hospital shelter I went through both incidents feeling nothing, I just sat and observed. If I remember right, some of the children and teachers were killed. The fire brigade came and the ambulances carried away some people.

(Nichol 2004)

Nichol described how after these experiences his childhood became marked with strange behaviour, including petty theft and an obsession with staying either inside or close to the family's Anderson shelter. He recalled sitting inside the shelter and, for no particular reason, setting fire to a pile of newspapers kept there as damp-absorptive floor covering, before being rescued from the flames by his father.

When it came to writing his memories of the war Nichol was surprised by his wife's horrified reaction to his experiences: 'You were raised in a war zone.' This reaction helped him to grasp the enormity and horror of his childhood in wartime and its enduring impact, including the numbness to emotion that he finally came to recognize as a dissociative disorder that had lasted his entire life. $\mathrm{He}$ concluded his account of his wartime experiences with a note of empathy: 'When I watch (reluctantly) the news of bombings and war on TV I watch for the children, the ones with the blank faces and vacant look in their eyes.' (Nichol 2004).

\section{Trauma}

After his initial rescue, Nichol sat quietly in the shelter, as the nurse noted approvingly. No doubt his stunned, numbed response would have confirmed the view of Miss HE Howarth, a regional representative of the Mental Health Emergency Committee, who observed in 1941 how:

Quite the most general observation about the children is that they stand up extraordinarily well to a life of disturbed nights and even to the extreme emergency of being bombed out, buried or having to leave a burning home. Teachers, parents and ambulance drivers all remark upon it. The children at first are dazed, but soon adjust to a new life.

(Howarth 1941)

The study of British children's traumas and the full complexity of their psychological responses to bombing, family separation and other aspects of wartime life is beyond the scope of this study, but it was a lively field of research during wartime and remains an area of historical interest (e.g. Croft 2016; Shapira 2013), and often linked to the study of morale (e.g. Jones et al 2004; Mackay 2002). Some clinicians did recognize the adverse impact of air raids on children, and the common delay in the onset of symptoms that often hampered diagnoses, but the majority of studies focused their concern on the perceived harms of the mass evacuation schemes at the start of the war, where 
many young children were separated from their families for extended periods of time (e.g. Bodman 1944; Pritchard and Rosenzweig 1942). There was also a related strand of work looking at play therapy for children affected by the war, a field developed in interesting directions by Marie Paneth in her work with violent and disruptive young people playing on bombsites that contributed to the adventure playground movement, discussed briefly in Chapter 4 (and see Paneth 1944). As Shapira (2013) notes, some of the most significant work on the impact of war on children was carried out in London by Anna Freud and her team at the Hampstead War Nurseries, working with children who had been separated from their families or affected by bombing, evacuation and time spent in air raid shelters.

In future studies of children and the material culture of conflict, I believe that collaborations or overlaps with the studies of historical trauma and child psychology would be illuminating, productive and mutually beneficial areas to develop. There is a considerable amount of recent research on the psychological impacts of conflict on children and young people, as well as evidence that the patterns of material relations outlined in this book have clear analogues in contemporary conflicts (e.g. Barenbaum et al 2004; Ehntholt and Yule 2006; Macksoud 1992; Macksoud and Aber 1996; Vizek-Vidović et al 2000).

\section{Future developments}

I would not claim to have invented the principle research method employed in this book, the historical anthropological study of material culture through archived oral histories, but I do not believe that it has been previously employed systematically to this degree. Nor would I make extravagant claims for its value or efficacy beyond what I have been able to demonstrate in the substance of this study, not least given the dearth of similar studies in the decade since I first published on this subject. Nevertheless, I think it is worth closing with a brief consideration of potential future directions for research building on the themes and methods that I have employed.

As stated in the introduction, the primary disciplinary context for this book is the interdisciplinary study of the material culture of conflict as pioneered by Nicholas Saunders, his collaborators and students (e.g. Saunders 2004; 2012). This field has recently and notably expanded beyond the study of the First World War to explore a range of twentieth and twenty-first century conflicts worldwide (see e.g. Breithoff 2012; 2015). Despite the impressive range and variety of this work, there has been virtually no discussion of the distinctive material cultures of children in war, and no studies that take it as a primary focus. In part, this can be allied to the general dearth of gendered perspectives and studies that explicitly focus on women's experience of war (but see papers in Cornish and Saunders 2014 for studies of gendered and racialized bodies in conflict). The material culture of modern conflict is a relatively new and small field with a vast scope and potential, so it is not surprising that some areas are better developed than others. Nonetheless, work focused on childhood offers 
considerable potential for interdisciplinary research, a remarkable range of sources ranging from toys to the uniforms of child soldiers, and a powerful social, political and affective impact. I would be very interested to see material culture focused research looking at:

- children's lives under military occupation, for example in First World War Belgium, 1970s Northern Ireland or contemporary Palestine

- children's experiences of urban conflict, from the Warsaw Ghetto to the strongholds of Islamic State in Syria

- children's lives in landscapes of guerrilla warfare

- schools and education in wartime

- child soldiers and child participants in irregular warfare and civil conflicts

- child refugees and migrants, both accompanied and unaccompanied

- war-themed toys and games, from prehistory to the present

- weapons and equipment designed specifically for children or young people, such as the infant gas mask or the Heinkel 162 Volksjäger aircraft.

These are just a few of the possible directions for this research, and even within each of these categories there is a wealth of potential for different methods, sources and disciplinary frames.

Over the years of working on this project I have talked with people who spent all or part of their childhoods in more recent conflict zones: in the former Yugoslavia during its disintegration; in Northern Ireland during the Troubles; in Israel under missile-fire during the Gulf War. The strangest and most striking of these were people roughly my own age - children of the 1980s - who had lived through conflicts such as the Iran-Iraq war and whose stories of rushing to their air raid shelters as sirens sounded, of gas mask practice and of collecting and exchanging fragments of missiles and bombs were practically identical to the stories that my grandparents told about the London Blitz.

From these first-hand accounts of more recent conflicts and from news reports, memoirs, diaries, studies by psychologists, aid workers and others, I have begun to see some of the phenomena that I have outlined in this book from a small-scale historical anthropological perspective begin to emerge as universal or near-universal patterns in the material worlds of wartime childhood. Quite aside from the possible directions for further material culture anthropological research outlined above, I believe that this field of study can shed light on the experiences of children traumatized by war, and potentially contribute to their treatment.

\section{Horror}

Several famous photographs have come to illustrate the popular history and heritage of Second World War Britain. St Paul's Cathedral shines white in black smoke; Coventry Cathedral lies in ruins; a cheerful milkman walks through the debris of an air raid and three-year-old Eileen Dunne sits in her hospital bed, her head wrapped in bandages, clutching a soft toy and staring 


\section{Conclusion}

directly into the camera. This picture by society photographer Cecil Beaton featured on the cover of Life magazine and has become an iconic part of Blitz heritage. The image of the child in war has long been a symbol of innocent victimhood, tragedy and moral outrage. On his return from Spain during the Civil War, J.B.S. Haldane drew on this sense of horror and outrage as he summarized the findings of his trip and their significance for Britain in the coming war:

I hate having to write this book. Air raids are not only wrong. They are loathsome and disgusting. If you had ever seen a child smashed by a bomb into something like a mixture of dirty rags and cat's meat you would realize this fact as intensely as I do ... I hope ... that the people of Britain will never see what I have seen in Spain.

(Haldane 1938: 11)

The image that Haldane conjured and those that Beaton and other photographers captured appeal to our supposed humanistic instincts to protect children from harm. A similar effect can be seen in the media coverage and discussion of the images of dead refugee children washed up on the European shores of the Mediterranean.

Even at a much further remove than Haldane from the realities of war, the horrors of childhood in wartime can sometimes leap from the page or the screen. During this research, I have often left my desk for a quiet walk in the park, cried in my office, or sought out mind-numbing relief from the sadness and disgust evoked by the stories that I work with. A few, like Ronald Nichol's account of his traumas described above, have affected me particularly powerfully. This sort of emotional response is normal, healthy, and worthy of acknowledgement. It has a natural place within all scholarship that makes claims of critical rigour and contemporary relevance. 


\section{Bibliography}

\section{Publications}

Adey, P. 2010. Aerial Life: Spaces, Mobilities, Affects. Chichester, UK: WileyBlackwell.

Agnew, K. and G. Fox. 2001. Children at War from the First World War to the Gulf. London: Continuum.

Andrews, G.J., R.A. Kearns, P. Kontos and V. Wilson. 2006. 'Their finest hour': older people, oral histories, and the historical geography of social life. Social \& Cultural Geography 7(2): 153-177.

Anon. 1945. Flowers on bombed sites: wind-borne wild plants. The Times, 3 May.

Appadurai, A. 1986. Introduction: commodities and the politics of value. In A. Appadurai (ed.) The Social Life of Things: Commodities in Cultural Perspective. Cambridge: University Press, 3-63.

Ashford, D. 2013. London Underground: A Cultural Geography. Liverpool, UK: Liverpool University Press.

Baker, S.M and J.W. Gentry. 1996. Kids as collectors: a phenomenological study of first and fifth graders. Advances in Consumer Research 23: 132-137.

Baldwin, S. 1932. The bomber will always get through. The Times. 11 November.

Banksy. 2006. Wall and Piece. London: Century.

Barenbaum, J., V. Ruchkin and M. Schwab-Stone. 2004. The psychosocial aspects of children exposed to war: practice and policy initiatives. Journal of Child Psychology and Psychiatry 45(1), 41-62.

Barker, M.E. 1926. Gas mask development. Chemical Warfare 12(7): 11-15.

Baudrillard, J. 2005. The System of Objects. London: Verso.

BBC. 2003-2006. WW2 People's War: An Archive of World War 2 Memories. www. bbc.co.uk/ww2peopleswar.

Beaven, B. and J. Griffiths. 1999. The Blitz, civilian morale and the city: mass observation and working class culture in Britain, 1940-1941. Urban History 26: 71-88.

Belk, R. 1995. Collecting in a Consumer Society. London: Routledge.

Belk, R. 2006. Collectors and collecting. In C. Tilley, W. Keane, S. Küchler, M. Rowlands and P. Spyer (eds) Handbook of Material Culture. London: Sage, 534-545.

Belk, R., M. Wallendorf, J. Sherry, M. Holbrook and S. Roberts. 1988. Collectors and collecting. Advances in Consumer Research 15: 548-553.

Bell, A.H. 2008. London Was Ours: Diaries and Memoirs of the London Blitz. London: I.B. Tauris. 
Benjamin, W. 1999. Illuminations. London: Pimlico.

Bentall, W.C. 1938. Air raid precautions in relationship to the general practitioner. Post-Graduate Medical Journal 14(156): 331-334.

Berntsen, D. 1996. Involuntary autobiographical memories. Applied Cognitive Psychology 10: 435-454.

Blakely, H.W. 1952. Shrapnel, semantics and such. Combat Forces Journal. March 1952.

Bodman, F. 1944. Child psychiatry in war-time Britain. Journal of Educational Psychology 35(5): 293-301.

Breithoff, E. 2012. The many faces of the Chaco War: indigenous modernity and conflict archaeology. In N.J. Saunders (ed.) Beyond the Dead Horizon: Studies in Modern Conflict Archaeology. Oxford: Oxbow, 146-158.

Breithoff, E. 2015. Conflict Landscapes of the Chaco War. Unpublished PhD Thesis. University of Bristol.

Brown, M. 2009. Wartime Childhood. Oxford: Shire.

Buck-Morss, S. 1993. Dream world of mass culture: Walter Benjamin's theory of modernity and the dialectics of seeing. In D.M. Levin (ed.) Modernity and the Hegemony of Vision. London: University of California Press, 309-338.

Burke, P. 1987. The Historical Anthropology of Early Modern Italy: Essays on Perception and Communication. Cambridge: Cambridge University Press.

Butler, S. 2018. English women at home during the Second World War: Anderson shelters as domestic spaces. Journal of International Women's Studies 19(1): 94-107.

Calder, A. 1991. The Myth of the Blitz. London: Jonathan Cape.

Calder, A. 1992. The People's War: Britain 1939-1945. London: Pimlico

Chichester, F. 1941. The Spotter's Handbook. London: George Allen \& Unwin.

Classen, C. 2005. Touch in the museum. In C. Classen (ed.) The Book of Touch. Oxford: Berg, 275-286.

Claydon, P. 2003. The vernacular of play. In N. Norman (ed.) An Architecture of Play: A Survey of London's Adventure Playgrounds. London: Four Corners Books.

Cloke, P. and O. Jones. 2005. 'Unclaimed territory': childhood and disordered space(s). Social and Cultural Geography 6(3): 311-333.

Cook, D.T. 2001. Exchange value as pedagogy in children's leisure: moral panic in children's culture at century's end. Leisure Sciences 23: 81-98.

Cooper, H.J., O.G. Thetford and D.A. Russell. 1941. Aircraft of the Fighting Powers (Volume 1). Leicester, UK: Harborough.

Cornish, P. and Saunders N.J. (eds) 2014. Bodies in Conflict: Corporeality, Materiality, and Transformation. Abingdon, UK: Routledge.

Craik J. 2007. Uniforms exposed: the proliferation of uniforms in popular culture as markers of change and identity. In G. Mentges, D. Neuland-Kitzerow and B. Richard (eds) Uniformierungen in Bewegung. Berlin, Germany: Waxmann Verlag, $37-55$.

Craik, J. 2003. The cultural politics of the uniform. Fashion Theory 7: 127-148.

Cranwell, K. 2003. Towards a history of adventure playground 1931-2000. In N. Norman (ed.) An Architecture of Play: A Survey of London's Adventure Playgrounds. London: Four Corners Books.

Croft, H. 2016. Rethinking civilian neuroses in the Second World War. In P. Leese and J. Crouthamel (eds) Traumatic Memories of the Second World War and After. Basingstoke, UK: Palgrave Macmillan, 95-116. 
Danet, B. and T. Katriel. 1994a. No two alike: play and aesthetics in collecting. In S. Pearce (ed.) Interpreting Objects and Collections. London: Routledge, 220-239.

Danet, B. and T. Katriel. 1994b. Glorious obsessions, passionate lovers, and hidden treasures: collecting, metaphor and the romantic ethic. In S.H. Riggins (ed.) The Socialness of Things: Essays on the Socio-Semiotics of Objects. New York: Mouton de Gruyter, 23-62.

Dawdy, S.L. 2010. Clockpunk anthropology and the ruins of modernity. Current Anthropology 51(6): 761-793.

Day Lewis, C. 1961. The Otterbury Incident. Harmondsworth, UK: Puffin.

DeLoache, J.S., G. Simcock and S. Macari. 2007. Planes, trains, automobiles - and tea sets: extremely intense interests in very young children. Developmental Psychology 43(6): 1579-1586.

Demarne, C. 1980. The London Blitz: A Fireman's Tale. London: Parents' Centre Publications.

De Nardi, S. 2014. An embodied approach to Second World War storytelling mementoes: probing beyond the archival into the corporeality of memories of the Resistance. Journal of Material Culture 19(4): 443-464.

De Nardi, S. 2017. The Poetics of Conflict Experience: Materiality and Embodiment in Second World War Italy. London: Routledge.

Domanska, E. 2006. The material presence of the past. History and Theory 45: 337348.

Edensor, T. 2005. Industrial Ruins: Spaces, Aesthetics and Materiality. Oxford: Berg.

Edgerton, D. 1991. England and the Aeroplane: An Essay on a Militant and Technological Nation. London: Macmillan.

Ehntholt, K.A. and W. Yule. 2006. Practitioner review: assessment and treatment of refugee children and adolescents who have experienced war-related trauma. Journal of Child Psychology and Psychiatry 47(12): 1197-1210.

Emigh, J. 1996. Masked Performance: The Play of Self and Other in Ritual and Theatre. Philadelphia, PA: University of Pennsylvania Press.

Freud, A. and D. Burlingham. 1943. War and Children. New York: Medical War Books.

Gabriel, J. 1974. Children Growing Up: The Development of Children's Personalities. London: University of London Press.

Gardiner, J. 2005. The Children's War: The Second World War Through the Eyes of the Children of Britain. London: Portrait.

González-Ruibal, A. 2006. The dream of reason: an archaeology of the failures of modernity in Ethiopia. Journal of Social Archaeology 6: 175-201.

González-Ruibal, A. 2008. Time to destroy: an archaeology of supermodernity. Current Anthropology 49(2): 247-279.

González-Ruibal, A. 2012. From the battlefield to the labour camp: archaeology of Civil War and dictatorship in Spain. Antiquity 86: 456-473.

Graves-Brown, P.M. 2007. Avtomat Kalashnikova. Journal of Material Culture 12: 285-307.

Grayzel, S. 2012. At Home and Under Fire: Air Raids and Culture in Britain from the Great War to the Blitz. Cambridge: Cambridge University Press.

Haapamaki, M. 2014. The Coming of the Aerial War: Culture and Fear of Airborne Attack in Inter-War Britain. London: I.B. Tauris.

Haldane, J.B.S. 1938. A.R. P. London: Victor Gollancz/Left Book Club. 
Hamilton, T. 1994. Identification Friend or Foe: Being the Story of Aircraft Recognition. London: HMSO.

Hansard. 1936. House of Commons debate on air raid precautions. HC Deb 18 June 1936. Vol 313 cc1153-6.

Harrisson, T. 1976. Living Through the Blitz. New York: Schocken.

Hinchliffe, S., M.B. Kearnes, M. Degen and S. Whatmore. 2005. Urban wild things: a cosmopolitical experiment. Environment and Planning D: Society and Space 23: 643-658.

Hinton, D.E., V. Pich, D., Chean and M.H. Pollack. 2006. Olfactory-triggered panic attacks among Khmer refugees. In J. Drobnick (ed.) The Smell Culture Reader. Oxford: Berg, 68-81.

Holman, B. 2014. The Next War in the Air: Britain's Fear of the Bomber, 1908-1941. Abingdon, UK: Routledge.

Home Office. 1938. Air Raid Precautions Handbook No. 1: Personal Protection Against Gas. London: HMSO.

Home Office. 1939. Directions for the Erection and Sinking of the Galvanised Corrugated Steel Shelter. London: HMSO.

Hoskins, J. 1998. Biographical Objects: How Things Tell the Stories of People's Lives. London: Routledge.

Housden, S. and J. Zmroczek. 2007. Exploring identity in later life through BBC People's War interviews. Oral History 35(2): 100-108.

Howarth, H.E. 1941. Impressions of children in a heavily bombed area. Mental Health 2(4): $98-101$.

Howes, D. 2005. Skinscapes: embodiment, culture, and environment. In C. Classen (ed.) The Book of Touch. Oxford: Berg, 27-39.

Hussey, S. 2003. The school air raid shelter: rethinking wartime pedagogies. History of Education Quarterly 43: 517-539.

Jappy, M.J. 2003. Danger UXB: The Remarkable Story of the Disposal of Unexploded Bombs during the Second World War. London: Channel4 Books.

Johnson, K.E., J.M. Alexander, S. Spencer, M.E. Leibham and C. Neitzel. 2004. Factors associated with the early emergence of intense interests within conceptual domains. Cognitive Development 19(3): 325-343.

Johnson, M. 1999. The new post-medieval archaeology. In G. Egan and R. Michael (eds) Old and New Worlds. Oxford: Oxbow, 17-22.

Jones, E., R. Woolven, B. Durodié, and S. Wessely. 2004. Civilian morale during the Second World War: responses to air raids re-examined. Social History of Medicine 17(3): 463-479.

Jones, H. 2006. British Civilians in the Front Line: Air Raids, Productivity and Wartime Culture, 1939-45. Manchester, UK: Manchester University Press.

Jones, S. and R. Hook. 2007. World War I Gas Warfare Tactics and Equipment. Colchester, UK: Osprey.

Joy, J. 2002. Biography of a medal: people and the things they value. In J. Schofield, W. G. Johnson and C.M. Beck (eds) Matériel Culture: The Archaeology of Twentieth Century Conflict. London: Routledge, 132-142.

Kopytoff, I. 1986. The cultural biography of things: commoditization as process. In A. Appadurai (ed.) The Social Life of Things: Commodities in Cultural Perspective. Cambridge: Cambridge University Press, 64-94.

Kozlovsky, R. 2007. Adventure playgrounds and postwar reconstruction. In M. Gutman and N. de Coninck-Smith (eds) Designing Modern Childhoods: History, 
Space, and the Material Culture of Children; An International Reader. New Brunswick, NJ: Rutgers University Press, 171-190.

Kozlovsky, R. 2013. The Architectures of Childhood: Children, Modern Architecture and Reconstruction in Postwar Britain. London: Ashgate.

Küchler, S. 2002. Malanggan: Art, Memory and Sacrifice. Oxford: Berg.

Law, J. 2002. Aircraft Stories: Decentring the Object in Technoscience. Durham, NC: Duke University Press.

Lee, D.H. 1940. Design and Construction of Air-Raid Shelters: In Accordance with the Civil Defence Act, 1939, and for 'Unspecified' Areas and Other Purposes. London: Concrete Publications.

Levin, D.M. 1993. Introduction. In D.M. Levin (ed.) Modernity and the Hegemony of Vision. London: University of California Press, 1-29.

Levine, J. 2006. Forgotten Voices of the Blitz and the Battle of Britain. London: Ebury Press.

Lindqvist, S. 2002. A History of Bombing. London: Granta.

Loewe, C. 2012. Just Like the End of the World. London: Timeline

Longden, S. 2012. Blitz Kids: The Children's War Against Hitler. London: Constable.

Mabey, R. 1996. Flora Britannica. London: Sinclair-Stevenson.

Macaulay, R. 1996. The Pleasure of Ruins. New York: Barnes and Noble.

Macdonald, H. 2002. 'What makes you a scientist is the way you look at things': ornithology and the observer 1930-1955. Studies in History and Philosophy of Science Part C: Studies in History and Philosophy of Biological and Biomedical Science 33(1): 53-77.

Mackay, R. 2002. Half the Battle: Civilian Morale in Britain during the Second World War. Manchester, UK: Manchester University Press.

Macksoud, M.S. 1992. Assessing war trauma in children: A case study of Lebanese children. Journal of Refugee Studies 5(1): 1-15.

Macksoud, M.S. and J.L. Aber 1996. The war experiences and psychosocial development of children in Lebanon. Child Development 67(1): 70-88.

Martin, P. 1999. Popular Collecting and the Everyday Self: The Reinvention of Museums? London: Leicester University Press.

Mather, M. 2007. Emotional arousal and memory binding: an object based framework. Perspectives on Psychological Science 2: 33-52.

Mayall, B. and V. Morrow. 2011. You Can Help Your Country: English Children's Work During the Second World War. London: Institute of Education.

McKinstry, L. 2007. Spitfire: Portrait of a Legend. London: John Murray.

McKinstry, L. 2009. Lancaster: The Second World War's Greatest Bomber. London: John Murray.

McKinstry, L. 2010. Hurricane: Victor of the Battle of Britain. London: John Murray.

Moshenska, G. 2007a. Unearthing an air-raid shelter at Edgware Junior School. London Archaeologist 11(9): 237-240.

Moshenska, G. 2007b. Oral history in historical archaeology: excavating sites of memory. Oral History 35(1): 91-97.

Moshenska, G. 2009. Resonant materiality and violent remembering: archaeology, memory and bombing. International Journal of Heritage Studies 15(1): 44-56

Moshenska, G. 2010. Working with memory in the archaeology of modern conflicts. Cambridge Archaeological Journal 20(1): 33-48.

Moshenska, G. 2013. Uncovering the past: air raid shelter excavations. Britain at War $76,77-80$. 
Moshenska, G. 2014. 'Token scraps of men': white lies, weighted coffins, and second world war air-crash casualties. In P. Cornish and N.J. Saunders (eds) Bodies in Conflict: Corporeality, Materiality and Transformation. Abingdon, UK: Routledge, 133-142.

Moshenska, G. 2017. Moaning minnie and the doodlebugs: soundscapes of air warfare in Second World War Britain. In N. Saunders and P. Cornish (eds) Modern Conflict and the Senses. Abingdon, UK: Routledge, 106-122.

Mott, N.F. and E.H. Linfoot. 2006[1943]. A theory of fragmentation. In D. Grady (ed.) Fragmentation of Rings and Shells: The Legacy of N.F. Mott. New York: Springer, 207-216.

Muensterberger, W. 1994. Collecting: An Unruly Passion. Psychoanalytical Perspectives. Princeton, NJ: Princeton University Press.

Noakes, L. 2009. The BBC's 'People's War' website. In M. Keren and H.H. Herwig (eds) War Memory and Popular Culture: Essays on Modes of Remembrance and Commemoration. London: McFarland, 135-149.

O’Brien, T. 1955. Civil Defence. London: HMSO.

Ollis, F.W. 1936. Letter to Kirwan, 30 Nov 1936. TNA HO 45/18170.

Overy, R.J. 1982. The Air War 1939-1945. New York: Stein and Day.

Overy, R.J. 2000. The Battle. London: Penguin.

Paneth, M. 1944. Branch Street: A Sociological Study. London: G. Allen \& Unwin.

Pearce, S.M. 1995. On Collecting: An Investigation into Collecting in the European Tradition. London: Routledge.

Peers, L. 1999. 'Many tender ties': the shifting contexts and meanings of the S BLACK bag. World Archaeology 31: 287-302.

Phillips, D. 2009. The Great War 'Trench Club': typology, use and cultural meaning. In N.J. Saunders and P. Cornish (eds) Contested Objects: Material Memories of the Great War. Abingdon, UK: Routledge.

Pollock, D. 1995. Masks and the semiotics of identity. Journal of the Royal Anthropological Institute 1: 581-597.

Preston, B. 2000. The function of things: a philosophical perspective on material culture. In P.M. Graves-Brown (ed.) Matter, Materiality and Modern Culture. London: Routledge, 22-49.

Price, A. 1997. The Luftwaffe Data Book. London: Greenhill Books.

Pritchard, R. and S. Rosenzweig. 1942. The effects of war stress upon childhood and youth. The Journal of Abnormal and Social Psychology 37(3): 329-344.

Rippon, C.A. 1941. Calling all Air Cadets. The Aero-Modeller, February, 101-103.

Rose, S.O. 2003. Which People's War? National Identity and Citizenship in Wartime Britain 1939-1945. Oxford: Oxford University Press.

Routledge, N.W. 1994. History of the Royal Regiment of Artillery: Anti-Aircraft Artillery, 1914-55. London: Brassey's.

Saunders, N.J. 2000. Bodies of metal, shells of memory: 'trench art' and the Great War re-cycled. Journal of Material Culture 5(1): 43-67.

Saunders, N.J. 2002. The ironic 'culture of shells' in the great war and beyond. In J. Schofield, W.G. Johnson and C.M. Beck (eds) Matériel Culture: The Archaeology of Twentieth Century Conflict. London: Routledge, 22-40.

Saunders, N.J. 2002. Memory and conflict. In V. Buchli (ed.) The Material Culture Reader. Oxford: Berg, 175-180.

Saunders, N.J. 2003. Trench Art: Materialities and Memories of War. Oxford: Berg. 
Saunders, N.J. (ed.) 2004. Matters of Conflict: Material Culture, Memory and the First World War. London: Routledge.

Saunders, N.J. (ed.) 2012. Beyond the Dead Horizon: Studies in Modern Conflict Archaeology. Oxford: Oxbow.

Saunders, N.J. and P. Cornish (eds) 2009. Contested Objects: Material Memories of the Great War. Abingdon, UK: Routledge

Saunders, N.J. and P. Cornish (eds) 2017. Modern Conflict and the Senses. Abingdon, UK: Routledge

Saunders, N.J. and N. Faulkner. 2010. Fire on the desert: conflict archaeology and the Great Arab Revolt in Jordan, 1916-1918. Antiquity 84: 514-527.

Saville-Sneath, R.A. 1941. Aircraft Recognition. London: Penguin.

Schlanger, N. 1994. The trials of a gas mask: an object of fumbling. Configurations 2: 275-300.

Shapira, M. 2013. The War Inside: Psychoanalysis, Total War, and the Making of the Democratic Self in Postwar Britain. Cambridge: Cambridge University Press.

Shaw, F. and J. Shaw. 2012. We Remember the Blitz. London: Ebury.

Shoul, S. 2008. British tear gas doctrine between the world wars. War in History 15(2): $168-190$.

Smith, A. 2017. Winter. London: Hamish Hamilton.

Smith, L. 2007. Young Voices: British Children Remember the Second World War. London: Penguin/Imperial War Museum.

Smith, M. 2000. Britain in 1940: History, Myth and Popular Memory. London: Routledge.

Stallworthy, J. 1996. The Poems of Wilfred Owen. London: Chatto.

Stansky, P. and W. Abrahams. 1994. London's Burning: Life, Death and Art in the Second World War. London: Constable.

Stone, M. 2004. A memory in ruins? Public Archaeology 3: 131-144.

Summerfield, P. 1997. Gender and war in the twentieth century. The International History Review 19(1), 3-15.

Summerfield, P. 1998. Reconstructing Women's Wartime Lives: Discourse and Subjectivity in Oral Histories of the Second World War. Manchester, UK: Manchester University Press.

Sweet, M. 2011. West End Front: The Wartime Secrets of London's Grand Hotels. London: Faber \& Faber.

Tanaka, Y. 2009. Introduction. In Y. Tanaka and M.B. Young (eds) Bombing Civilians: A Twentieth-Century History. New York: New Press, 1-7.

Thorburn, K.M. 1982. Injuries after use of the lacrimatory agent chloroacetophenone in a confined space. Archives of Environmental Health: An International Journal 37(3): 182-186.

Tiratsoo, N. 2000. The reconstruction of Blitzed British cities, 1945-1955: myths and reality. Contemporary British History 14(1): 27-44.

Vicory, A.C. 1968. A Brief History of Aircraft Identification Training. Washington, DC: George Washington University Human Resources Research Office.

Vidler, A. 1992. The Architectural Uncanny: Essays in the Modern Unhomely. Cambridge, MA: MIT Press.

Vizek-Vidovi囚, V., G. Kuterovac-Jagodić and L. Arambašið. 2000. Posttraumatic symptomatology in children exposed to war. Scandinavian Journal of Psychology 41(4): 297-306. 
Wells, M.K. 1995. Courage and Air Warfare: The Allied Aircrew Experience in the Second World War. London: Frank Cass.

Welshman, J. 2010. Churchill's Children: The Evacuee Experience in Wartime Britain. Oxford: Oxford University Press.

Werner, E.E. 2000. Through the Eyes of Innocents: Children Witness World War II. Oxford: Westview.

Westall, R. 1995. Children of the Blitz: Memories of Wartime Childhood. London: Viking.

Westall, R. 2001. The Machine Gunners. London: Macmillan.

Whitley, M.T. 1929. Children's interest in collecting. Journal of Educational Psychology 20: 249-261.

Whitworth, S.H. 2016. Chariots of Wrath: Engines, Aviation \& Equitation (2nd edn). Scarborough, UK: Farthings Publishing.

Winnicott, D.W. 1953. Transitional objects and transitional phenomena: a study of the first Not-Me possession. International Journal of Psycho-Analysis 34: 89-97.

Winter, J. 1998. Sites of Memory, Sites of Mourning: The Great War in European Cultural History. Cambridge: Cambridge University Press.

Witty, P.A. and H.C. Lehman. 1931. Sex differences: collecting interests. Journal of Educational Psychology 22(3): 221-228.

Woodward, C. 2002. In Ruins. London: Vintage.

\section{BBC WW2 People's War sources}

Adin, M. 2004. The air raid shelter in the garden. BBC WW2 People's War article A3335672. www.bbc.co.uk/history/ww2peopleswar/stories/72/a3335672.shtml.

Allen, J. 2005. Fond memories of the siren suit by a child in Penge. BBC WW2 People's War article A4522439. www.bbc.co.uk/history/ww2peopleswar/stories/39/a 4522439.shtml.

Anderson, E. 2005. Precious things 1941. BBC WW2 People's War article A4086047. www.bbc.co.uk/history/ww2peopleswar/stories/47/a4086047.shtml.

Annabel. 2003. The Anderson Shelter. BBC WW2 People's War article A2035351. www.bbc.co.uk/history/ww2peopleswar/stories/51/a2035351.shtml.

Anon. [Edison, L.]. 2003. Coronation Avenue, Stoke Newington, in the Blitz. BBC WW2 People's War article A2090026. www.bbc.co.uk/history/ww2peopleswar/stor ies/26/a2090026.shtml.

Anon. 2004. Our Air Raid Shelter. BBC WW2 People's War article A2927072. www. bbc.co.uk/history/ww2peopleswar/stories/72/a2927072.shtml.

Anon. 2005a. Schoolboy in North London. BBC WW2 People's War article A5811761. www.bbc.co.uk/history/ww2peopleswar/stories/61/a5811761.shtml.

Anon. 2005b. Hull's last incendiary? BBC WW2 People's War article A4260179. www. bbc.co.uk/history/ww2peopleswar/stories/79/a4260179.shtml.

Anon. 2005c. My air raid shelter memories. BBC WW2 People's War article A4244140. www.bbc.co.uk/history/ww2peopleswar/stories/40/a4244140.shtml.

Anon. 2005d. Hold an indiarubber between your teeth. BBC WW2 People's War article A5977902. www.bbc.co.uk/history/ww2peopleswar/stories/02/a5977902.shtml.

Anon. 2005e. The day the war came home. BBC WW2 People's War article A4438938. www.bbc.co.uk/history/ww2peopleswar/stories/38/a4438938.shtml.

Armstrong, K. 2005. War memoirs of a schoolboy 1939-1945. BBC WW2 People's War. www.bbc.co.uk/history/ww2peopleswar/user/08/u1703708.shtml. 
Atkinson, G. 2003. A youngster's view of the blitz in West London. BBC WW2 People's War article A1956873. www.bbc.co.uk/history/ww2peopleswar/stories/73/a 1956873.shtml.

Bailey, P. 2004. Remembering a walk to school in 1940: in New Southgate, North London. BBC WW2 People's War article A2754984. www.bbc.co.uk/history/ww2p eopleswar/stories/84/a2754984.shtml.

Barnett, J. 2003. What goes around comes around. BBC WW2 People's War article A2021059. www.bbc.co.uk/history/ww2peopleswar/stories/59/a2021059.shtml.

Bayley, K. 2004. Memories of growing up in Liverpool during WW2. BBC WW2 People's War article A2023750. www.bbc.co.uk/history/ww2peopleswar/stories/50/a 2023750.shtml.

Baylis, T. 2003. A Kentish schoolboy's memories of war. BBC WW2 People's War article A1949079. www.bbc.co.uk/history/ww2peopleswar/stories/79/a1949079.shtml.

Berry, D. 2003. A Plymouth Andersen shelter tale. BBC WW2 People's War article A2002285. www.bbc.co.uk/history/ww2peopleswar/stories/85/a2002285.shtml.

Bettie. 2003. My childhood and WW2: Bristol. BBC WW2 People's War article A2052442. www.bbc.co.uk/ww2peopleswar/stories/42/a2052442.shtml.

Bignell, B. 2004. The Blitz in Bristol. BBC WW2 People's War article A2216963. www.bbc.co.uk/history/ww2peopleswar/stories/63/a2216963.shtml.

Bill. 2003. Collecting shrapnel - and bombs - in wartime London. BBC WW2 People's War article A1144964. www.bbc.co.uk/history/ww2peopleswar/stories/64/a 1144964.shtml.

Bird, K. 2004. Our Anderson shelter. BBC WW2 People's War article A3176417. www.bbc.co.uk/history/ww2peopleswar/stories/17/a3176417.shtml.

Blackburn. 2005. Wire, bombs and pows. BBC WW2 People's War article A4485099. www.bbc.co.uk/history/ww2peopleswar/stories/99/a4485099.shtml.

Blanchard, W. 2003. War through a boy's eyes: in Liverpool. BBC WW2 People's War article A2013698. www.bbc.co.uk/history/ww2peopleswar/stories/98/a2013698.shtml.

Blanchenay, E. 2004. Doodlebug. BBC WW2 People's War article A2338418. www. bbc.co.uk/history/ww2peopleswar/stories/18/a2338418.shtml.

Bloomfield, J. 2004. No bullets allowed in class. BBC WW2 People's War article A3181367. www.bbc.co.uk/history/ww2peopleswar/stories/67/a3181367.shtml.

Bolton, B. 2005. War stories from East Hull. BBC WW2 People's War article A4372689. www.bbc.co.uk/history/ww2peopleswar/stories/89/a4372689.shtml.

Bourne, R.A. 2003. A young girl's war in Falconwood and Edenbridge. BBC WW2 People's War article A1940168. www.bbc.co.uk/ww2peopleswar/stories/68/a1940168.shtml.

Braybrook, V. 2005. Dad's near miss. BBC WW2 People's War article A4040164. www.bbc.co.uk/history/ww2peopleswar/stories/64/a4040164.shtml.

Britton, D. 2005. Our back garden air raid shelter. BBC WW2 People's War article A4425761. www.bbc.co.uk/history/ww2peopleswar/stories/61/a4425761.shtml.

Brookings, M. 2003. Child in a small village during the war years. BBC WW2 People's War article A1971038. www.bbc.co.uk/history/ww2peopleswar/stories/38/a1971038.shtml.

Brooks, B. 2005a. East Acton: Anderson Shelter, summer 1939. BBC WW2 People's War article A7266963. www.bbc.co.uk/history/ww2peopleswar/stories/63/a 7266963.shtml.

Brooks, B. 2005b. East Acton: raids and shelter life 1940. BBC WW2 People's War article A7238982. www.bbc.co.uk/history/ww2peopleswar/stories/82/a7238982.shtml.

Brooks, B. 2005c. East Acton blitzed! February 1944. BBC WW2 People's War article A6981582. www.bbc.co.uk/history/ww2peopleswar/stories/82/a6981582.shtml. 
Brooks, B. 2006. East Acton: goodbye Anderson shelter. BBC WW2 People's War article A8489677. www.bbc.co.uk/history/ww2peopleswar/stories/77/a8489677.shtml.

Broughton, F. 2005. How different life could have been. BBC WW2 People's War article A4086704. www.bbc.co.uk/ww2peopleswar/stories/04/a4086704.shtml.

Brown, J. 2005. Creepy-crawlies in the Air Raid Shelter. BBC WW2 People's War article A3712367. www.bbc.co.uk/history/ww2peopleswar/stories/67/a3712367.shtml.

Brownbridge, J. 2004. Fear and fun for children during the war. BBC WW2 People's War article A2853263. www.bbc.co.uk/history/ww2peopleswar/stories/63/a2853263.shtml.

Bukin, D. 2005. Wyre Forest evacuation, V1s, VE Day. BBC WW2 People's War article A4784673. www.bbc.co.uk/history/ww2peopleswar/stories/73/a4784673.shtml.

Burchmore, B. 2005. Shrapnel collecting in Hastings. BBC WW2 People's War article A5472100. www.bbc.co.uk/history/ww2peopleswar/stories/00/a5472100.shtml.

Butcher, G. 2003. Family experience of WWII. BBC WW2 People's War article A2148365. www.bbc.co.uk/ww2peopleswar/stories/65/a2148365.shtml.

Cameron, J. 2006. A Scottish child's view of WW2. BBC WW2 People's War article A9900004. www.bbc.co.uk/ww2peopleswar/stories/04/a9900004.shtml.

Campbell, J.C. 2003. Blitz! BBC WW2 People's War article A1921042. www.bbc.co. uk/ww2peopleswar/stories/42/a1921042.shtml.

Cartwright, T.C. 2004. Lancaster Bomber crash on Thurnby Lodge, Leicester. BBC People's War article A2480014. www.bbc.co.uk/history/ww2peopleswar/stories/14/a 2480014.shtml.

Caswell, J. 2005. Swindon during a bombing raid. BBC WW2 People's War article A4107458. www.bbc.co.uk/history/ww2peopleswar/stories/58/a4107458.shtml.

Chance, L. 2005. A six year old's memories. BBC WW2 People's War article A3943019. www.bbc.co.uk/history/ww2peopleswar/stories/19/a3943019.shtml.

Chancey, R. 2006. 'Meet you down the bomb debris' a story from Tufnell Park. BBC WW2 People's War article A8892976. www.bbc.co.uk/ww2peopleswar/stories/76/a 8892976.shtml.

Chappell, J. 2005. A boyhood in wartime England: part 6. BBC WW2 People's War article A4418994. www.bbc.co.uk/history/ww2peopleswar/stories/94/a4418994.shtml.

Clark, F. 2005a. War - a boy - London (The Anderson Shelter). BBC WW2 People's War article A3755496. www.bbc.co.uk/history/ww2peopleswar/stories/96/a3755496.shtml.

Clark, F. 2005b. Bombed houses and bomb sites. BBC WW2 People's War article A4029833. www.bbc.co.uk/ww2peopleswar/stories/33/a4029833.shtml.

Clark, G.J. 2005. 1940 evacuation. BBC WW2 People's War article A4032271. www. bbc.co.uk/history/ww2peopleswar/stories/71/a4032271.shtml.

Clark, P. 2003. Childhood memories of the Second World War: Durham. BBC WW2 People's War article A1966476. www.bbc.co.uk/ww2peopleswar/stories/76/a1966476.shtml.

Clavey, B. 2004. Keep smiling through. BBC WW2 People's War article A2310427. www.bbc.co.uk/ww2peopleswar/stories/27/a2310427.shtml.

Cole, B. 2005. The Blitz in the Elephant and Castle, London and my family's removal to Feltham, Middlesex after being bombed out. BBC WW2 People's War article A6287367. www.bbc.co.uk/history/ww2peopleswar/stories/67/a6287367.shtml.

Collier, M. 2005. My wartime childhood. BBC WW2 People's War article A3998640. www.bbc.co.uk/history/ww2peopleswar/stories/40/a3998640.shtml.

Conroy, J. 2005. My war was all fun and games. BBC WW2 People's War article A6538296. www.bbc.co.uk/history/ww2peopleswar/stories/96/a6538296.shtml. 
Cook, P. 2005. My wartime memories of Bedford as a part 1: outbreak of war and going up to Bedford Modern School. BBC WW2 People's War article A5961413. www.bbc.co.uk/ww2peopleswar/stories/13/a5961413.shtml.

Copeland, D. 2005. Recollections of my early years - part 3 bombs over Fulwell. BBC WW2 People's War article A4399068. www.bbc.co.uk/history/ww2peopleswar/stor ies/68/a4399068.shtml.

Coppins-Moroney, A. 2005. Life in an air-raid shelter. BBC WW2 People's War article A3932651. www.bbc.co.uk/history/ww2peopleswar/stories/51/a3932651.shtml.

Cox, P.C.S. 2003. A child's war: in Coventry. BBC WW2 People's War article A2097317. www.bbc.co.uk/ww2peopleswar/stories/17/a2097317.shtml.

Crawley, J. 2006a. Wartime memories of an aeroplane enthusiast living in Bedford Part One. BBC WW2 People's War article A8821163. www.bbc.co.uk/history/ww2p eopleswar/stories/63/a8821163.shtml.

Crawley, J. 2006b. Wartime memories of an aeroplane enthusiast living in Bedford Part Three. BBC WW2 People's War article A8821488. www.bbc.co.uk/history/ ww2peopleswar/stories/88/a8821488.shtml.

Crone, D. 2004. Belvedere boy. BBC WW2 People's War article A2680986. www.bbc. co.uk/history/ww2peopleswar/stories/86/a2680986.shtml.

Cronin, G. 2003. Childhood memories of WW2 in Hammersmith. BBC WW2 People's War article A1948854. www.bbc.co.uk/history/ww2peopleswar/stories/54/a 1948854.shtml.

Curd, E. 2005. Falling through the Floor in Fulham. BBC WW2 People's War article A4078488. www.bbc.co.uk/ww2peopleswar/stories/88/a4078488.shtml.

Cuthbert, J. 2004. World War 2 and my life in Hull. BBC WW2 People's War article A2972360. www.bbc.co.uk/history/ww2peopleswar/stories/60/a2972360.shtml.

Daniels, J. 2005. One child's war part two 1941-1944. BBC WW2 People's War article A7271318. www.bbc.co.uk/history/ww2peopleswar/stories/18/a7271318.shtml.

Danter, B. 2005. Early wartime thoughts, ATS and army post. BBC WW2 People's War article A2061299. www.bbc.co.uk/history/ww2peopleswar/stories/99/a2061299.shtml.

Dart, M.E.J. 2005. Schoolboy memories: raids and evacuation. BBC WW2 People's War article A7366106. www.bbc.co.uk/history/ww2peopleswar/stories/06/a7366106.shtml.

Davies, R. 2005. A schoolgirl evacuee finds happiness in Stratford. BBC WW2 People's War article A4111363. www.bbc.co.uk/history/ww2peopleswar/stories/63/a 4111363.shtml.

Dawes, D. 2003. War through the eyes of a child: Plymouth Blitz. BBC WW2 People's War article A2050453. www.bbc.co.uk/ww2peopleswar/stories/53/a 2050453.shtml.

Dawkins, J. 2004. A childhood in London: life in Potters Bar. BBC WW2 People's War article A2781254. www.bbc.co.uk/history/ww2peopleswar/stories/54/a2781254.shtml.

Dilly, M. 2005. The war from an air-minded boy's viewpoint. BBC WW2 People's War article A5282921. www.bbc.co.uk/history/ww2peopleswar/stories/21/a5282921.shtml.

Dodds, G. 2005. Air raid shelters. BBC WW2 People's War article A3724724. www. bbc.co.uk/history/ww2peopleswar/stories/24/a3724724.shtml.

Drake, C.H. 2004. Wakefield and WWII. BBC WW2 People's War article A2642726. www.bbc.co.uk/ww2peopleswar/stories/26/a2642726.shtml.

Duerden, U. 2005. Essex village 1939-1945. BBC WW2 People's War article A4291048. www.bbc.co.uk/ww2peopleswar/stories/48/a4391048.shtml.

Duggins, G.T. 2005. A six year olds memory of WW2. BBC WW2 People's War article A4315826. www.bbc.co.uk/ww2peopleswar/stories/26/a4315826.shtml. 


\section{Bibliography}

Earthy, J. 2004. Leyton Blitz. BBC WW2 People's War article A3061405. www.bbc.co. uk/history/ww2peopleswar/stories/05/a3061405.shtml.

Ebert, T. 2003. My bomb story: living in Poplar, East London, during War. BBC WW2 People's War article A1940960. www.bbc.co.uk/history/ww2peopleswar/stor ies/60/a1940960.shtml.

Edwards, H. 2004. Some memories of schooldays in Swansea during WW2. BBC WW2 People's War article A2669141. www.bbc.co.uk/ww2peopleswar/stories/41/a 2669141.shtml.

Feeney, W. 2005. Salford and Manchester docks were always attacked and we lived nearby. BBC WW2 People's War article A4248542. www.bbc.co.uk/ww2peopleswar/ stories/42/a4248542.shtml.

Fletcher, B. 2005. I hid behind the door to hear the declaration of war. BBC WW2 People's War article A4400740. www.bbc.co.uk/history/ww2peopleswar/stories/40/a 4400740.shtml.

Ford, B. 2003. A little girl's war in Guildford: watching the bombing, queues, D-Day activities. BBC WW2 People's War article A2092871. www.bbc.co.uk/history/ww2p eopleswar/stories/71/a2092871.shtml.

Forrest, H. 2004a. Schoolday memories of wartime years, Chapter 3. BBC WW2 People's War article A2733950. www.bbc.co.uk/ww2peopleswar/stories/50/a 2733950.shtml.

Forrest, H. 2004b. Schoolday memories of wartime years, the final chapter. BBC WW2 People's War article A2734012. www.bbc.co.uk/ww2peopleswar/stories/12/a 2734012.shtml.

Francis, H. 2003a. Reminiscences of a Folkestone schoolboy in wartime: part 1. BBC WW2 People's War article A1137494. www.bbc.co.uk/history/ww2peopleswar/stor ies/94/a1137494.shtml.

Francis, H. 2003b. Reminiscences of a Folkestone schoolboy in wartime: part 2. BBC WW2 People's War article A1138862. www.bbc.co.uk/history/ww2peopleswar/stor ies/62/a1138862.shtml.

Froggatt, N. 2005. Buzz bombs, gas masks \& condensed milk. BBC WW2 People's War article A4397484. www.bbc.co.uk/ww2peopleswar/stories/84/a4397484.shtml.

Garrett, J. 2003. War wound. BBC WW2 People's War article A2061578. www.bbc.co. uk/ww2peopleswar/stories/78/a2061578.shtml.

Gaylor, S. 2005. Wartime memories: London Blitz. BBC WW2 People's War article A3545930. www.bbc.co.uk/ww2peopleswar/stories/30/a3545930.shtml.

Gibbons, L. 2003. Through the eyes of a nine-year-old: Folkestone. BBC WW2 People's War article A1244026. www.bbc.co.uk/ww2peopleswar/stories/26/a 1244026.shtml.

Gloria-Jean. 2005. My worst night in the air raid shelter. BBC WW2 People's War article A3559953. www.bbc.co.uk/history/ww2peopleswar/stories/53/a3559953.shtml.

Goodfellow, I. 2005. What happens in the war. BBC WW2 People's War article A7570460. www.bbc.co.uk/history/ww2peopleswar/stories/60/a7570460.shtml.

Gossling, T. 2003. Memories of World War 2 - in Croydon. BBC WW2 People's War article A1956224. www.bbc.co.uk/history/ww2peopleswar/stories/24/a1956224.shtml.

Gould, R.E. 2005. The Vauxbelets College, evacuated from Guernsey, restarts in Hale. BBC WW2 People's War article A5201984. www.bbc.co.uk/history/ww2peopleswar/ stories/84/a5201984.shtml.

Goulding, M. 2005. Gas masks and shelters. BBC WW2 People's War article A4435959. www.bbc.co.uk/history/ww2peopleswar/stories/59/a4435959.shtml. 
Graham, J. 2005. Our air raid shelter. BBC WW2 People's War article A5467917. www.bbc.co.uk/history/ww2peopleswar/stories/17/a5467917.shtml.

Graham, R. 2003. Roy Graham-war memories. BBC WW2 People's War article A2067158. www.bbc.co.uk/history/ww2peopleswar/stories/58/a2067158.shtml.

Grant, P. 2004. Evacuated from Hull to Scotland. BBC WW2 People's War article A2238167. www.bbc.co.uk/history/ww2peopleswar/stories/67/a2238167.shtml.

Greenaway, D. 2003. Childhood in wartime Twickenham. BBC WW2 People's War article A2063044. www.bbc.co.uk/ww2peopleswar/stories/44/a2063044.shtml.

Haig, N. 2003. A small boy's war in Gravesend. BBC WW2 People's War article A2025695. www.bbc.co.uk/history/ww2peopleswar/stories/95/a2025695.shtml.

Hall, L. 2005. From Aberdeen schoolboy to pilot. BBC WW2 People's War article A5812607. www.bbc.co.uk/history/ww2peopleswar/stories/07/a5812607.shtml.

Halligan, B. 2005. The Spitfire. BBC WW2 People's War article A4145609. www.bbc. co.uk/history/ww2peopleswar/stories/09/a4145609.shtml.

Hammond, S. 2005. Childhood memories of WW2. BBC WW2 People's War article A6345515. www.bbc.co.uk/history/ww2peopleswar/stories/15/a6345515.shtml.

Hassall, A. 2005. Childhood memories of the war in London. BBC WW2 People's War article A7562711. www.bbc.co.uk/ww2peopleswar/stories/11/a7562711.shtml.

Hawtin, D. 2005. Wartime in Wellesbourne Mountford. BBC WW2 People's War article A6557312. www.bbc.co.uk/history/ww2peopleswar/stories/12/a6557312.shtml.

Hayhurst, W. 2005. Wartime memories. BBC WW2 People's War article A5179070. www.bbc.co.uk/ww2peopleswar/stories/70/a5179070.shtml.

Heathcote, J. 2003. WW2 Experiences of a Hertfordshire schoolboy. BBC WW2 People's War article A1899417. www.bbc.co.uk/history/ww2peopleswar/stories/17/a 1899417.shtml.

Hester, B. 2005. Recollections of the Second World War part 4. BBC WW2 People's War article A4217726. www.bbc.co.uk/ww2peopleswar/stories/26/a4217726.shtml.

Hewson, G. 2004. School days: Sutton-on-Hull, East Yorkshire. BBC WW2 People's War article A2721458. www.bbc.co.uk/history/ww2peopleswar/stories/58/a2721458. shtml.

Heygate, J.T.N. 2004. Radio \& tv trade; and evacuation from Slough. BBC WW2 People's War article A2700370. www.bbc.co.uk/history/ww2peopleswar/stories/70/a 2700370 .shtml.

Hill, R.W. 2005a. 1940-1942. BBC WW2 People's War article A4532627. www.bbc. co.uk/history/ww2peopleswar/stories/27/a4532627.shtml.

Hill, R.W. 2005b. The Blitz. BBC WW2 People's War article A4532573. www.bbc.co. uk/history/ww2peopleswar/stories/73/a4532573.shtml.

Hillman, P. 2005. 'Please can we shelter?' - advantages of being prepared. BBC WW2 People's War article A5387376. www.bbc.co.uk/history/ww2peopleswar/stories/76/a 5387376.shtml.

Hird, T. 2005. 14th November 1940 - the Coventry Blitz. BBC WW2 People's War article A5398806. www.bbc.co.uk/history/ww2peopleswar/stories/06/a5398806.shtml.

Holcombe, J. 2005. Evacuated with North Kensington Central School. BBC WW2 People's War article A5973906. www.bbc.co.uk/history/ww2peopleswar/stories/06/a 5973906.shtml.

Hollier, M. 2005. Bombing in Monpelier. BBC WW2 People's War article A4420702. www.bbc.co.uk/history/ww2peopleswar/stories/02/a4420702.shtml.

Hopkinson, J. 2004. Schooltime in the shelter. BBC WW2 People's War article A2758728. www.bbc.co.uk/history/ww2peopleswar/stories/28/a2758728.shtml. 


\section{Bibliography}

Hubbard, B. 2005. Air raid on Norwich. BBC WW2 People's War article A3803997. www.bbc.co.uk/history/ww2peopleswar/stories/97/a3803997.shtml.

Hudson, G. 2004. My memoirs of WW2. BBC WW2 People's War article A3393399. www.bbc.co.uk/ww2peopleswar/stories/99/a3393399.shtml.

Hulbert, R. 2005. My dad and me. BBC WW2 People's War article A5491145. www. bbc.co.uk/ww2peopleswar/stories/45/a5491145.shtml.

Hunt, D.E. 2005. The war in Ruislip Manor Part 2. BBC WW2 People's War article A3946863. www.bbc.co.uk/history/ww2peopleswar/stories/63/a3946863.shtml.

Hunter, J. 2003. The air raid shelter, Winchmore Hill. BBC WW2 People's War article A2008955. www.bbc.co.uk/history/ww2peopleswar/stories/55/a2008955.shtml.

Ison, C. 2005. Wartime in Coventry. BBC WW2 People's War article A5496221. www. bbc.co.uk/ww2peopleswar/stories/21/a5496221.shtml.

Jackson, D. 2005. A close shave. BBC WW2 People's War article A4837061. www. bbc.co.uk/ww2peopleswar/stories/61/a4837061.shtml.

Jacobs, J. 2005. Childhood memories of Weaste in Wartime. BBC WW2 People's War article A4463985. www.bbc.co.uk/history/ww2peopleswar/stories/85/a4463985.shtml.

John, S.C. 2005. Schooldays in Splott. BBC WW2 People's War article A4487420. www.bbc.co.uk/history/ww2peopleswar/stories/20/a4487420.shtml.

Johnson, B. 2005. Hitler bombed our school. BBC WW2 People's War article A4108835. www.bbc.co.uk/history/ww2peopleswar/stories/35/a4108835.shtml.

Jones, D. 2003. Child's eye: collecting shrapnel. BBC WW2 People's War article A2055881. www.bbc.co.uk/history/ww2peopleswar/stories/81/a2055881.shtml.

Jones, R. 2003. The air raid shelter, its uses and abuses, in the Black Country. BBC WW2 People's War article A2018710. www.bbc.co.uk/history/ww2peopleswar/stor ies/10/a2018710.shtml.

Joscelyne, B. 2005. Ben's childhood memories of the war in Braintree. BBC WW2 People's War article A5149578. www.bbc.co.uk/history/ww2peopleswar/stories/78/a 5149578.shtml.

Keen, R. 2005. My war as a youngster. BBC WW2 People's War article A4379114. www.bbc.co.uk/history/ww2peopleswar/stories/14/a4379114.shtml.

Kendall, B. 2005. Tiny and shiny. BBC WW2 People's War article A5253022. www. bbc.co.uk/history/ww2peopleswar/stories/22/a5253022.shtml.

Kendall, P. 2005. The life of a child on the Home Front. BBC WW2 People's War article A4093508. www.bbc.co.uk/ww2peopleswar/stories/08/a4093508.shtml.

Kerry, D. 2005. A happy evacuation. BBC WW2 People's War article A7074579. www.bbc.co.uk/history/ww2peopleswar/stories/79/a7074579.shtml.

Kirby, M. 2005. Play, death and theft in WW2. BBC WW2 People's War article A5063564. www.www.bbc.co.uk/ww2peopleswar/stories/64/a5063564.shtml.

Lacey, M.D.B. 2005. An evacuee in Witney. BBC People's War article A5955663. www.bbc.co.uk/history/ww2peopleswar/stories/63/a5955663.shtml.

Lawrence, D. 2005. A childhood during the war. BBC WW2 People's War article A4388510. www.bbc.co.uk/history/ww2peopleswar/stories/10/a4388510.shtml.

Lee, P. 2005. Bournemouth, bombs and my two brothers. BBC WW2 People's War article A3526535. www.bbc.co.uk/history/ww2peopleswar/stories/35/a3526535.shtml.

Leveton R.D. 2004. Memories of WW2: a child in north Birmingham. BBC WW2 People's War article A2798742. www.bbc.co.uk/ww2peopleswar/stories/42/a 2798742.shtml.

Lewington, P. 2004. An 'old' boy's story. BBC WW2 People's War article A2365571. www.bbc.co.uk/ww2peopleswar/stories/71/a2365571.shtml. 
Long, A. 2005. Tin hats and toy guns (Chapter 3). BBC People's War article A4576836. www.bbc.co.uk/history/ww2peopleswar/stories/36/a4576836.shtml.

Long, K. 2003. Growing Up in London 1939-1945. BBC WW2 People's War article A2065402. www.bbc.co.uk/history/ww2peopleswar/stories/02/a2065402.shtml.

Lord-Castle, R. 2004. Being a baby in wartime. BBC WW2 People's War article A3307259. www.bbc.co.uk/ww2peopleswar/stories/59/a3307259.shtml.

McBrias, M. 2005. V.E. Day, 'In the Mood'. BBC WW2 People's War article A4141090. www.bbc.co.uk/history/ww2peopleswar/stories/90/a4141090.shtml.

McCain, M.E. 2003. A strange kind of normal: one little girl's experience of the Plymouth Blitz. BBC WW2 People's War article A2020753. www.bbc.co.uk/ww2peop leswar/stories/53/a2020753.shtml.

McGarry, J. 2004. Further snippets from living next to Devonport Dockyard. BBC WW2 People's War article A2286867. www.bbc.co.uk/history/ww2peopleswar/stor ies/67/a2286867.shtml.

McGowan, P. 2004. An air raid incident from World War Two. BBC WW2 People's War article A2869770. www.bbc.co.uk/history/ww2peopleswar/stories/70/a 2869770.shtml.

Maher, H. 2004. War years in Collyhurst Manchester. BBC WW2 People's War article A2884845. www.bbc.co.uk/ww2peopleswar/stories/45/a2884845.shtml.

Maitland, B. 2005. A daylight air-raid in Filton, Glos. BBC WW2 People's War article A3493578. www.bbc.co.uk/history/ww2peopleswar/stories/78/a3493578.shtml.

Mann, G. 2005. For a nine-year-old wartime was fun. BBC WW2 People's War article A4280078. www.bbc.co.uk/history/ww2peopleswar/stories/78/a4280078.shtml.

Marsh, M. 2003. Starting school during the war. BBC WW2 People's War article A1979391. www.bbc.co.uk/history/ww2peopleswar/stories/91/a1979391.shtml.

Marshfield, A. 2005. A child's war, part 2. BBC WW2 People's War article A5356244. www.bbc.co.uk/ww2peopleswar/stories/44/a5356244.shtml.

Martin, J.S. 2006. Some snapshots from the memory. BBC WW2 People's War article A8934672. www.bbc.co.uk/history/ww2peopleswar/stories/72/a8934672.shtml.

Mathieson, W. 2006. First car ride, first party. BBC WW2 People's War article A8790104. www.bbc.co.uk/ww2peopleswar/stories/04/a8790104.shtml.

Matthews, D. 2005. The Spitfire Fund. BBC WW2 People's War article A4423466. www.bbc.co.uk/history/ww2peopleswar/stories/66/a4423466.shtml.

Matthews, N.J. 2003. WW2 in Somerset and Croydon. BBC WW2 People's War article A2040977. www.bbc.co.uk/ww2peopleswar/stories/77/a2040977.shtml.

May, M. 2003. My war memories - by Margaret May. BBC WW2 People's War article A1951661. www.bbc.co.uk/history/ww2peopleswar/stories/61/a1951661.shtml.

Merryweather, A. 2004. Our indoor Anderson shelter. BBC WW2 People's War article A3271006. www.bbc.co.uk/history/ww2peopleswar/stories/06/a3271006.shtml.

Miles, B. 2005. After the Bristol Blitz. BBC WW2 People's War article A4292796. www.bbc.co.uk/ww2peopleswar/stories/96/a4292796.shtml.

Millar, D. 2003. My earliest memories: a child in Birkenhead. BBC WW2 People's War article A2040427. www.bbc.co.uk/history/ww2peopleswar/stories/27/a2040427.shtml.

Monteith, A. 2005. Omagh during the war: a childhood memoir. BBC WW2 People's War article A3662110. www.bbc.co.uk/ww2peopleswar/stories/10/a3662110. shtml.

Morgan, A.W. 2005a. My father's time in the UK and the Far East. BBC WW2 People's War article A3914967. www.bbc.co.uk/history/ww2peopleswar/stories/67/a 3914967.shtml. 


\section{Bibliography}

Morgan, A.W. 2005b. Interludes in Essex and London. BBC WW2 People's War article A3917649. www.bbc.co.uk/history/ww2peopleswar/stories/49/a3917649.shtml.

Morgan, H. 2005. Bomb shelters in Epsom, walks on Bodmin Moor: A wartime childhood. BBC WW2 People's War article A4330685. www.bbc.co.uk/history/ ww2peopleswar/stories/85/a4330685.shtml.

Morrison, D. 2005. Prized shrapnel from a V1 Doodlebug. BBC WW2 People's War article A6179628. www.bbc.co.uk/history/ww2peopleswar/stories/28/a6179628.shtml.

Mundy, A. 2003. Infant on the Home Front: In Norbury. BBC WW2 People's War article A2117611. www.bbc.co.uk/history/ww2peopleswar/stories/11/a2117611.shtml.

Newman, D. 2003. A wartime kid's personal story. BBC WW2 People's War article A2115794. www.bbc.co.uk/ww2peopleswar/stories/94/a2115794.shtml.

Nichol, R. 2004. What is a kid like me doing in a place like this: The Blitz in Hornchurch. BBC WW2 People's War article A2316124. www.bbc.co.uk/history/ ww2peopleswar/stories/24/a2316124.shtml.

Nicholls, J. 2005. War in Kensington. BBC WW2 People's War article A4049462. www.bbc.co.uk/history/ww2peopleswar/stories/62/a4049462.shtml.

Nightingale, C. 2003. Bombs: V1s and V2s, London and Oxford. BBC WW2 People's War article A2007352. www.bbc.co.uk/ww2peopleswar/stories/52/a2007352.shtml.

Noble, H. 2004. The story of Bevin's Babes: Chapter 3. BBC WW2 People's War article A2872730. www.bbc.co.uk/ww2peopleswar/stories/30/a2872730.shtml.

Noden, B. 2005. Wartime memories of Kingstanding, Birmingham. BBC WW2 People's War article A7568616. www.bbc.co.uk/history/ww2peopleswar/stories/16/a 7568616.shtml.

Oates, A. 2005. Life during the war. BBC WW2 People's War article A4131028. www. bbc.co.uk/history/ww2peopleswar/stories/28/a4131028.shtml.

Offord, J. 2005. My Portchester shelter. BBC WW2 People's War article A3691046. www.bbc.co.uk/history/ww2peopleswar/stories/46/a3691046.shtml.

Ollerenshaw, J. 2005. VE Day. BBC WW2 People's War article A3980522. www.bbc. co.uk/ww2peopleswar/stories/22/a3980522.shtml.

Osborne, C. 2005. And so away again. Part 2. BBC WW2 People's War article A6899692. www.bbc.co.uk/ww2peopleswar/stories/92/a6899692.shtml.

Pagett, L. 2005. The Blitz in Vauxhall. BBC WW2 People's War article A4126691. www.bbc.co.uk/history/ww2peopleswar/stories/91/a4126691.shtml.

Palmer, M. 2004. The war in the west - a child's perspective. BBC WW2 People's War article A3253475. www.bbc.co.uk/history/ww2peopleswar/stories/75/a3253475.shtml.

Parsons, E.S. 2004. A lifetime remembered part 1: the 'phoney' evacuation. BBC WW2 People's War article A2913356. www.bbc.co.uk/ww2peopleswar/stories/56/a 2913356.shtml.

Payne, G. 2003. Doodlebugs at playtime: a childhood in wartime Kent - gas masks, raids, home defence and pea shooters. BBC WW2 People's War article A1944876. www.bbc.co.uk/history/ww2peopleswar/stories/76/a1944876.shtml.

Peacock, B. 2003. A boy in the Blitz. BBC WW2 People's War article A1939070. www.bbc.co.uk/history/ww2peopleswar/stories/70/a1939070.shtml.

Pearson, D. 2004. The Anderson shelter. BBC WW2 People's War article A3263870. www.bbc.co.uk/history/ww2peopleswar/stories/70/a3263870.shtml.

Pennington, P. 2003. War memories: a childhood in Twickenham. BBC WW2 People's War article A2015092. www.bbc.co.uk/ww2peopleswar/stories/92/a2015092.shtml.

Phillips, D. 2003. Wartime memories: childhood in Shirley. BBC WW2 People's War article A2051326. www.bbc.co.uk/ww2peopleswar/stories/26/a2051326.shtml. 
Pilott, H.R.J. 2003. A south-east Londoner's story - part 1. BBC WW2 People's War article A2043118. www.bbc.co.uk/ww2peopleswar/stories/18/a2043118.shtml.

Pollard, B. 2005. Liverpool memories. BBC WW2 People's War article A3939681. www.bbc.co.uk/history/ww2peopleswar/stories/81/a3939681.shtml.

Polley, A. 2003. The time of my life: WW2 childhood memories. BBC WW2 People's War article A2001420. www.bbc.co.uk/history/ww2peopleswar/stories/20/a2001420.shtml.

Pollins, H. 2005. Shelter rash. BBC WW2 People's War article A4325258. www.bbc. co.uk/history/ww2peopleswar/stories/58/a4325258.shtml.

Porter, R. 2005. Growing up in Northfleet during the war. BBC WW2 People's War article A4057418. www.bbc.co.uk/history/ww2peopleswar/stories/18/a4057418.shtml.

Powell, E. 2005. Liverpool to London and badk [sic] -wartime travels. BBC WW2 People's War article A4010257. www.bbc.co.uk/ww2peopleswar/stories/57/a 4010257.shtml.

Prewer, J. 2004. The shelter. BBC WW2 People's War article A2800306. www.bbc.co. uk/history/ww2peopleswar/stories/06/a2800306.shtml.

Purchase, R. 2005. Weymouth war memories. BBC WW2 People's War article A3793764. www.bbc.co.uk/history/ww2peopleswar/stories/64/a3793764.shtml.

Reid, D. 2004. Recollections of the end of the Second World War by David Reid. BBC WW2 People's War article A2377640. www.bbc.co.uk/history/ww2peopleswar/stor ies/40/a2377640.shtml.

Rhodes, J. 2005. Effie's war in Lincolnshire - part 2. BBC WW2 People's War article A3981846. www.bbc.co.uk/ww2peopleswar/stories/46/a3981846.shtml.

Rich, D. 2005. A boy's eye view of WW2 (part 4). BBC WW2 People's War article A6656097. www.bbc.co.uk/history/ww2peopleswar/stories/97/a6656097.shtml.

Roberts, K. 2005. The Anderson shelter. BBC WW2 People's War article A6661514. www.bbc.co.uk/history/ww2peopleswar/stories/14/a6661514.shtml.

Robertson, T. 2005. WW2 as seen through the eyes of a Greenock schoolboy. BBC WW2 People's War article A3939410. www.bbc.co.uk/ww2peopleswar/stories/10/a 3939410.shtml.

Robins, T. 2004. Tony's war. BBC WW2 People's War article A3193201. www.bbc.co. uk/ww2peopleswar/stories/01/a3193201.shtml.

Robinson, K. 2003. The war years in Nottingham: nightly air raids and the ARP. BBC WW2 People's War article A1927703. www.bbc.co.uk/history/ww2peopleswar/stor ies/03/a1927703.shtml.

Robson, D. 2005. Was this the youngest contribution to World War 2? BBC WW2 People's War article A7824099. www.bbc.co.uk/history/ww2peopleswar/stories/99/a 7824099.shtml.

Rollins, G. 2003. Life in Rugby in World War Two. BBC WW2 People's War article A1124894. www.bbc.co.uk/history/ww2peopleswar/stories/94/a1124894.shtml.

Ronnie. 2003. The war years as a child in Liverpool. BBC WW2 People's War article A2027387. www.bbc.co.uk/ww2peopleswar/stories/87/a2027387.shtml.

Ross, G.W. 2005. 1939-1945 through the eyes of a child. BBC WW2 People's War article A4893393. www.bbc.co.uk/history/ww2peopleswar/stories/93/a4893393.shtml.

Rudhall, A. 2006. A child in Birmingham and the air raid shelters. BBC WW2 People's War article A8175053. www.bbc.co.uk/history/ww2peopleswar/stories/53/a 8175053.shtml.

Russell, G. 2003. War Games: Childhood memories in Edinburgh. BBC WW2 People's War article A2014309. www.bbc.co.uk/history/ww2peopleswar/stories/09/a 2014309.shtml. 


\section{Bibliography}

Scott, R. 2003. My 7th Birthday surprise: 3rd September 1939. BBC WW2 People's War article A2049275. www.bbc.co.uk/history/ww2peopleswar/stories/75/a2049275.shtml.

Seldon, K. 2005. Childhood in Germany. BBC WW2 People's War article A6359394. www.bbc.co.uk/ww2peopleswar/stories/94/a6359394.shtml.

Semple, J.T. 2003. A child's experience of war in South East London. BBC WW2 People's War article A1950347. www.bbc.co.uk/history/ww2peopleswar/stories/47/a 1950347.shtml.

Seymour, M. 2004. Playing with the rabbits Chapter 3 (Part 1): family life in Bristol. BBC WW2 People's War article A2203741. www.bbc.co.uk/ww2peopleswar/stories/ 41/a2203741.shtml.

Shannon, R. 2004. My war years in Rayleigh. BBC WW2 People's War article A3289412. www.bbc.co.uk/history/ww2peopleswar/stories/12/a3289412.shtml.

Shapiro, P. 2003. My personal WW2 story: a child in Sidcup. BBC WW2 People's War article A2098785. www.bbc.co.uk/history/ww2peopleswar/stories/85/a2098785.shtml.

Sharman, R.L. 2003. War time childhood in Surbiton. BBC WW2 People's War article A2045288. www.bbc.co.uk/ww2peopleswar/stories/88/a2045288.shtml.

Shepherd, J. 2005. A superior air raid shelter. BBC WW2 People's War article A5734460. www.bbc.co.uk/history/ww2peopleswar/stories/60/a5734460.shtml.

Simon, D. 2005. Domestic life in war time Britain. BBC WW2 People's War article A4447569. www.bbc.co.uk/ww2peopleswar/stories/69/a4447569.shtml.

Skinner, E.R. 2004. A war baby's memories of Bexley, London and Yorkshire. BBC WW2 People's War article A2796870. www.bbc.co.uk/history/ww2peopleswar/stor ies/70/a2796870.shtml.

Skipp, R.J. 2005. London in War Time. BBC WW2 People's War article A3518985. www.bbc.co.uk/ww2peopleswar/stories/85/a3518985.shtml.

Smith, B.N. 2004. A boy in wartime Cambridgeshire. BBC WW2 People's War article A2808029. www.bbc.co.uk/history/ww2peopleswar/stories/29/a2808029.shtml.

Smith, D. 2004. A Reedham boy's view of the war. BBC WW2 People's War article A2337716. www.bbc.co.uk/history/ww2peopleswar/stories/16/a2337716.shtml.

Smith, J. 2004. A teenager in London. BBC WW2 People's War article A3421469. www.bbc.co.uk/history/ww2peopleswar/stories/69/a3421469.shtml.

Smith, P. 2006. Recollections of a war-time childhood. BBC WW2 People's War article A8770692. www.bbc.co.uk/ww2peopleswar/stories/92/a8770692.shtml.

Snipps, J. 2004. Life in the air raid shelter: in Lewisham. BBC WW2 People's War article A2804681. www.bbc.co.uk/history/ww2peopleswar/stories/81/a2804681.shtml.

Speeding, B. 2005. My lucky escape. BBC WW2 People's War article A4136663. www. bbc.co.uk/history/ww2peopleswar/stories/63/a4136663.shtml.

Stone, G. 2003. The Anderson shelter. BBC WW2 People's War article A1087977. www.bbc.co.uk/history/ww2peopleswar/stories/77/a1087977.shtml.

Styan, J. 2004. Air raids in London. BBC WW2 People's War article A2756289. www. bbc.co.uk/history/ww2peopleswar/stories/89/a2756289.shtml.

Sudbury, G. 2003. A child at war: West Wickham. BBC WW2 People's War article A2021482. www.bbc.co.uk/ww2peopleswar/stories/82/a2021482.shtml.

Sutton, P.H. 2003. Youthful experiences in London. BBC WW2 People's War article A2018288. www.bbc.co.uk/history/ww2peopleswar/stories/88/a2018288.shtml.

Tait, J. 2003. A small boys view of WW2. BBC WW2 People's War article A2014705. www.bbc.co.uk/history/ww2peopleswar/stories/05/a2014705.shtml.

Talbot, K. 2005. Ice cream in war time. BBC WW2 People's War article A3894528. www.bbc.co.uk/history/ww2peopleswar/stories/28/a3894528.shtml. 
Tanker. 2003. Aunt Mary's war. BBC WW2 People's War article A2072657. www.bbc. co.uk/ww2peopleswar/stories/57/a2072657.shtml.

Tarling, R. 2004. Gas masks. BBC WW2 People's War article A3337210. www.bbc.co. uk/ww2peopleswar/stories/10/a3337210.shtml.

Taylor, D. 2004. How I saw the second world war part 2. BBC WW2 People's War article A2853038. www.bbc.co.uk/history/ww2peopleswar/stories/38/a2853038.shtml.

Taylor, J. 2004. War through the eyes of a very young child. BBC WW2 People's War article A2693036. www.bbc.co.uk/ww2peopleswar/stories/36/a2693036.shtml.

Taylor, P. 2003. My experiences as a nine year old from 1939 to 1945 . BBC WW2 People's War article A2128853. www.bbc.co.uk/history/ww2peopleswar/stories/53/a 2128853.shtml.

Taylor, P. 2005. A Redditch childhood. 1937-1946. BBC WW2 People's War article A5533661. www.bbc.co.uk/history/ww2peopleswar/stories/61/a5533661.shtml.

Tester, A. 2005. Memories of WW2 through the eyes of an 8-14 year old (Part 1). BBC WW2 People's War article A3864954. www.bbc.co.uk/history/ww2peopleswar/ stories/54/a3864954.shtml.

Tidmarsh, J. 2005. A boy growing up in wartime. BBC WW2 People's War article A5819376. www.bbc.co.uk/ww2peopleswar/stories/76/a5819376.shtml.

Tomes, R. 2005. The gunners. BBC WW2 People's War article A4421422. www.bbc. co.uk/history/ww2peopleswar/stories/22/a4421422.shtml.

Tonsor. 2003. Anderson shelter. BBC WW2 People's War article A1994222. www.bbc. co.uk/history/ww2peopleswar/stories/22/a1994222.shtml.

Tookey, P. 2004. A girl in Falconwood. BBC WW2 People's War article A2275616. www.bbc.co.uk/ww2peopleswar/stories/16/a2275616.shtml.

Townley, S. 2005. The bombing of Penwith Rd. BBC WW2 People's War article A5885832. www.bbc.co.uk/history/ww2peopleswar/stories/32/a5885832.shtml.

Turner, B. 2003. My war. BBC WW2 People's War article A2062171. www.bbc.co.uk/ ww2peopleswar/stories/71/a2062171.shtml.

Vail, B. 2004. Evacuated from Leeds to Wales. BBC WW2 People's War article A3224837. www.bbc.co.uk/history/ww2peopleswar/stories/37/a3224837.shtml.

Valerie. 2005. My childhood memories of World War II. BBC WW2 People's War article A4048256. www.bbc.co.uk/history/ww2peopleswar/stories/56/a4048256.shtml.

van Gelderen, P. 2003. A child's war: coloured glass and shrapnel. BBC WW2 People's War article A2029024. www.bbc.co.uk/history/ww2peopleswar/stories/24/a2029024.shtml.

Varley, M. 2005. The 'not so quiet' evacuation. BBC WW2 People's War article A4358559. www.bbc.co.uk/history/ww2peopleswar/stories/59/a4358559.shtml.

Wakeford, T. 2003. A wartime boyhood in Cranleigh. BBC WW2 People's War article A2006740. www.bbc.co.uk/history/ww2peopleswar/stories/40/a2006740.shtml.

Wallis, C.G. 2005. Memories of a childhood in London during the Blitz. BBC WW2 People's War article A4196469. www.bbc.co.uk/ww2peopleswar/stories/69/a 4196469.shtml.

Wesley, J. 2003. A stricken fortress. BBC WW2 People's War article A2160406. www. bbc.co.uk/history/ww2peopleswar/stories/06/a2160406.shtml.

West, R. 2005. Airplane crazy - 1. BBC WW2 People's War article A5185190. www. bbc.co.uk/history/ww2peopleswar/stories/90/a5185190.shtml.

Westcott, M. 2005. Schooldays in wartime Plymouth. BBC WW2 People's War article A7447106. www.bbc.co.uk/history/ww2peopleswar/stories/06/a7447106.shtml.

Westcott, M. 2005. Memories of Kent. BBC WW2 People's War article A5235040. www.bbc.co.uk/history/ww2peopleswar/stories/40/a5235040.shtml. 


\section{Bibliography}

Whitehead, J. 2005. A change of heart. BBC WW2 People's War article A5782214. www.bbc.co.uk/history/ww2peopleswar/stories/14/a5782214.shtml.

Whitehouse, B. 2005. My recollections WW2. BBC WW2 People's War article A7877802. www.bbc.co.uk/history/ww2peopleswar/stories/02/a7877802.shtml.

Whitmore, E. 2004. My homemade 'siren suit'. BBC WW2 People's War article A2736669. www.bbc.co.uk/history/ww2peopleswar/stories/69/a2736669.shtml.

Willis, W. 2004. The Anderson shelter: London Blitz. BBC WW2 People's War article A2317439. www.bbc.co.uk/history/ww2peopleswar/stories/39/a2317439.shtml.

Wooderson, D. 2006. David Wooderson's War - Part 5: Back in Bexleyheath. BBC WW2 People's War article A8697757. www.bbc.co.uk/history/ww2peopleswar/stor ies/57/a8697757.shtml.

Woodward, J. 2003. War is not a game. BBC WW2 People's War article A4374344. www.bbc.co.uk/history/ww2peopleswar/stories/44/a4374344.shtml.

Woolard, D.J. 2004. Primary schooldays WW2. BBC WW2 People's War article A2864630. www.bbc.co.uk/history/ww2peopleswar/stories/30/a2864630.shtml.

Worrall, Y. 2005. The shelter - Mitcham. BBC WW2 People's War article A4440575. www.bbc.co.uk/history/ww2peopleswar/stories/75/a4440575.shtml.

Wright, J. 2003. A child's memories. BBC WW2 People's War article A2014598. www. bbc.co.uk/ww2peopleswar/stories/98/a2014598.shtml.

Young, J. 2005. Bombings in Liverpool. BBC WW2 People's War article A4813300. www.bbc.co.uk/ww2peopleswar/stories/00/a4813300.shtml. 


\section{Index}

Abercrombie, Patrick, 128

Aberdeen, 146

Abyssinia, 21, 26, 79

ack-ack see anti-aircraft guns

adults, 2, 21, 42-43, 49-52, 54, 63, 68, $76,84,92,94,101,108,111,114,116$, 119,144

adventure, 48, 89, 111, 115

adventure playgrounds, 19, 120-121;

bombsites as, 121

Aeromodeller (magazine), 137

aeromodelling, 2, 6, 19, 25, 43, 49, 130,

133, 135, 137, 140-141, 144-148, 152;

Airfix kits, 138, 140; clubs, 141;

FROG, 140, 144; 'Kiel Kraft' balsa

kits, 141; kits, 140, 144; Lines

Brothers, 140; modellers, 20, 144-146,

151; models as commodities, 139, 140,

141, 142; Penguin, 140; Skybird, 140;

Warcraft, 144; Woodason Aircraft

Models, 140; Worfolk's Toy Shop, 144

aesthetics, 22, 25, 29, 31, 45, 47, 50, 62, 65

age, 4, 42, 47, 51, 61, 62, 92, 147

Air Defence Cadet Corps, 138-140,

146-148; and see Air Training Corps

Air League, 138, 140

air raids, 1-3, 5-8, 12, 25-27, 29, 31-34,

$36,42,44,47-48,51-52,55-57$,

62-64, 67, 70, 75-95, 97-104,

$106-109,111,126,135,143$,

$154-155$

air raid drills, 1, 31, 76

Air Raid Precautions (ARP), 25, 26, 32 , 34, 44, 66, 71, 79, 80, 88, 95, 97; Air

Raid Precautions Act 1937, 79; Air Raid Precautions Department, 34, 38;

Air Raid Precautions subcommittee, 79

Air Raid Precautions wardens, 30, 33, 36, $38,42,44,52,66,71,88,94,104,111$ air raid shelters, 3, 4, 6, 12, 19, 29, 31, 44, 47, 55, 57, 64, 70, 75-109, 113, 120, 134, 143, 154-157; air filtration systems for, 79; Anderson shelters, 18, $61,62,75,80-84,89,91,94-98,100$, 103, 104, 106-108, 155; basement shelters, 3, 78, 82, 87, 90, 107; cellars, $78,82,107,121$; dampness of, 4, 6, 18, 19, 75-77, 81-82, 85, 92, 95-99, 109, 115; domestication of, 18 ; food in, 95 ; Morrison table shelters, 18, 86, 89, $101,107,143,154$; municipal or public shelters, 18, 76, 87; as play spaces, 92; sanitation, 87; smell and sense memories of, 97; soundscapes of, 100, 115; Tilbury Shelter, 96

air raid warnings, 76; all-clear, 4, 57, 93, 97, 100-102; rattles, 33; sirens, 8, 12, $45,47,49,51,75,76,83-87,93,96$, 97, 100-102, 106, 109, 135

Air Training Corps (ATC), 2, 9, 19, 20, $58,132,135,136,138-140,148$

aircraft, 2, 5, 20, 46, 48-49, 52-55, 57, $60,62,64-65,67,73,76,78,85,97$, 100-103, 109, 138, 140, 143-152; crashed, 20, 134

aircraft by type: Airspeed Oxfords, 148; Ansons, 148; Beaufighters, 147; Blenheims, 138; Bobcats, 149; Bostons, 149; C-47 Dakota, 149; Cessna Cranes, 149; Dorniers, 142; Fairey Battles, 132; Flying Fortress, 149; Hawker Hector, 148; Heinkel 111 bomber, 5; Heinkel 162 Volksjäger, 157; Heinkels, 142; Hotspur glider, 148; Hurricanes, 132, 133, 138, 141-142, 152; Lancaster bomber, 141, 149; Liberator, 149; Lightnings, 152; Lysander, 142; Messerschmitt, 133, 
138, 150; Mitchell, 146, 149;

Mosquito, 145, 149; Mustangs, 149;

Oxfords, 148; Spitfires, 1, 13, 20, 93,

$108,131,133$, 138, 141-142, 146-148,

150, 151, 152, 154; Stirlings, 149;

Sunderland, 141; Tempests, 154;

Thunderbolts, 149; Typhoons, 138;

Warwicks, 149; Wellingtons, 148

aircraft industry, 131

Aircraft of the Fighting Powers, 130, 137 aircraft recognition, 2, 19, 101, 130, 133,

135-140, 147, 148, 152; The Aeroplane

Spotter magazine, 135

books and magazines, 19, 133, 135, 137;

classes, 19; models, 137; National

Roof Spotters Association, 137;

National Association of Spotters'

Clubs, 135; National Certificates on

Aircraft Recognition, 137-138;

National Roof Spotters Association,

139; rooftop 'spotters' on workplaces,

135; Royal Observer Corps, 133;

spotters, 8, 133, 151; WEFT aircraft

recognition training system, 139;

young spotters, 136

airfields, 20, 132, 142, 148

Airmindedness, 19, 130-132

Aldwych, 98

American servicemen, 6, 58, 61-2

ammunition belt links, 67

Ancona Road School, 72

Anderson shelters see air raid shelters anthropology, 4, 8-12, 14-15, 17, 18, 24, $39,41,49,110$

anti-aircraft guns, 7, 47, 55, 143; see also shells, shrapnel

anxiety, 27, 68

archaeology, 10-14, 47, 110

ARP see Air Raid Precautions

artefacts see material culture

babies, 13, 21, 27, 42, 69, 86, 101, 102

Baldwin, Stanley, 25-26

Balham station bombing, 104

Banksy, 22-23

Barcelona, 26, 79, 128

barrage balloons, 152

Baudrillard, Jean, 49, 50

BBC (gas), 33

BBC People's War project, 1, 15-18, 33, $35,50,54,60,62,69-71,76,80,99$, $105,111,136,148-149$

Beano, 1, 2, 61

Beaton, Cecil, 158
Bedford, 139, 147

Bedlam Park, 98

Beirut, 111, 128

Benjamin, Walter, 50, 63

Berlin, 128

Blackburn, 26

blackout, 69, 70, 96, 98, 127

blindness, 25, 39, 45

Blitz see bombing

bomb squad, 57

bombed buildings, 4, 104, 110, 111, 115,118

bombers, 4, 25, 26, 47, 61, 73, 75, 78, 79, $97,100,101,103,144,148-151$

bombing, 4, 6, 7, 25, 26, 29, 47, 48, 51-56, 63-69, 71, 75, 76, 78-80, 83-90, 95, 97, 100-106, 109-114, 117, 121, 130, 132, 145, 149-151, 157, 158; blast damage, 76, 117, 122; crater, 6 , $10,110,126$

Bombing maps, 53

bombsites, 19, 60, 78, 109, 110, 111, 112, $113,116,120,122,124,125,129,154$, 156; as marginal, 'disordered spaces', 19, 111, 116; as places in transition, 117 ; as aesthetic spaces, 114; as play spaces, 122

Breithoff, Esther 12

Bristol, 127

Bruce Castle Museum, 73

bullets, 11, 25, 47-49, 52, 55, 57-59, 67, $68,87,88,125,149,150$; see also shrapnel

bunks, 82, 84, 87, 88, 95, 105

Burke, Peter, 9

butterfly bombs, 67, 68

cadets see Air Training Corps (ATC)

Calder, Angus, 6

casualties, 25, 54, 57, 90, 111; gas casualties, 21

cats, 127

Chemical Research Committee, 26

chemical weapons, 24, 25, 29, 35, 39, 44

child psychology, 129, 136, 156

children, 1, 4-6, 13, 15-18, 20-22, 25, 27 , 29-35, 37-44, 46-52, 54, 56, 57, 59-63, 65, 67-71, 73, 74, 76-78, 81, 83-97, 99-106, 108-114, 116, 118-119, 122, 144, 146-150, 152-158; agency of, 6; contributions to war effort, 8-9; discipline, 18, 128; health and welfare, 7; in wartime, 3, 4, 6, 17; protection of, 8; regarded as wild and 
unruly, 128; transformation of children's bodies, 20; troubled and disruptive children, 121; war traumatized, 19; 154-156

chloroacetophenone (CAP) gas, 33, 35, 38

children's literature, 16, 22

children's play see play

Chislehurst Caves, 107

chlorine, 24, 25, 33

Chronicles of Narnia, The, 22

Churchill, Winston, 86

cigarette cards, 32, 49, 50, 61, 133

Civil Defence, 1, 7, 8, 13, 19, 26, 30, 34, $43,65,67,79,104,111,138,139$; children's contributions, 8

Civil Defence Act, 79

Civilian Anti-Gas School, 34, 38

Classen, Constance, 50,

classrooms, 1, 30, 37, 85, 91

Cleethorpes, 78

clothing, 10, 28, 37, 85-87, 95

cluster bombs see butterfly bombs

Cold War, 21

collecting, 2, 4, 5, 8, 20, 32, 37, 46-74, 111, 129, 135, 137, 146, 149; exchange, 18; value, 17, 18, 154, 156; see also shrapnel collecting

colour, 27, 41, 54, 63, 64, 66, 67, 85, 95,132

comics, 2, 32, 61, 62, 73, 149

commemoration, 5, 12, 16

condensation, 28, 81, 97, 98

conkers, 41, 49, 54

conscientious objectors, 16, 99

containers, 25, 26, 27, 39, 41, 43; bags,

15; bottles, 15, 39; boxes, 1, 15, 40, 57,

60, 71, 95; cases, 24, 40; for gas masks see gas mask cases; shrouds, 15, 39

corrugated iron or steel, 80, 81, 97, 98, 103,108

Craik, Jennifer, 24, 42

Crime, 42, 70, 144, 150; arrest, 42, 150; arson, 111; fear of juvenile delinquency, 8, 20; looting, 111, 113, 150 ; petty theft, 155 ; stealing terrifying amounts of deadly weaponry, 149-150 crying, whimpering and howling, 154

Dad's Army, 106

Dandy, 61

Day-Lewis, Cecil, 123

death, 24, 26, 37, 75, 76, 99, 104, 109, $119,122,135,147,151$; by drowning, 24 ; on bombsites, 113, 117, 121 destruction, 17, 26, 69, 111, 114, 151;

bodily metaphors for, 117

Dinky toys, 121

discipline, 1, 17, 42, 43, 44, 101

Dix, Otto, 25

Doctor Who, 22

dolls, 50, 94, 124

Dulce et Decorum Est, 25

Dunkirk, 43

Dunstable, 137

dust filter mask, 22

ears, 28, 38, 100

Easingwold, Yorkshire, 34

East End of London, 87, 96

Eastwood Park, Falfield,

Gloucestershire, 34

ecology, 111, 120, 125

Edgerton, D, 13, 131

Edinburgh, 152

education, 20, 30, 32, 37, 43, 89

emergency services, 42, 111, 113; ambulance, 113, 155; fire brigade, 111, $113,114,127,154,155$; heavy and light rescue squads, 104, 113; police, $34,42,60,66,67,68,71,111,113$, 118,151 ; salvage teams, 113

emotion, 10, 28, 29, 51, 76, 96, 99, 106, 109; trauma and emotional numbness, 155

Empire Air Day, 132

evacuation and evacuees, $6,7,16,20,22$, 40, 43, 44, 47, 109, 114, 142, 155, 156; children's perspectives, 7; poor children from slum areas, 7

explosions, 51, 54, 63, 69, 78, 82, 97, 103, 104, 149, 150-151

Falfield, 34, 38

families, 1, 9, 16, 18, 27, 32, 39, 51, $54,55,75,76,80-89,95-97,99$, 101, 103-106, 108-110, 151, 153,156

farting noises, 31

fathers, 6, 7, 30, 32, 36, 41, 42, 44, 57, $61,66,73,81-84,89,101,104,105$, $107,132,145,146,147$; absent, 8

fear, 13, 19, 20, 26, 27, 43, 44, 51, 76, 78, $88,92,101,106,120,129,132$; of gas warfare, 21; sense of foreboding, 119

films, 16, 22, 32, 75, 96, 140;

Bed-knobs and Broomsticks, 22; Hope and Glory, 8; Memphis Belle, 142

fire, 46, 53, 64, 68, 69, 70, 78, 79, 97, $100,101,103,104,150,151$ 


\section{Index}

fire brigade see emergency services fire-watching, 39, 101

First World War, 2, 7, 11, 12, 18, 21, 24-26, 32, 35, 39, 44, 52, 53, 56, 79, $90,104,131$

flora and fauna; birds, 19; blackberries, 148; blackcurrant, gooseberry and raspberry bushes, 128; bombweed, 126 and see rosebay willowherb; brambles, 110, 126; budleia, 127; butterflies, 54, 116; coltsfoot, 126; dragonflies, 127; fennel, 126; fireweed, 126 and see rosebay willowherb; flowers, 54, 94; insects, 19; newts, 127; Oxford ragwort, 126; rosebay willowherb 19, 110, 112, 116, 117, 126, 129; sticklebacks, 127; stray animals, 19; trees, 30, 32, 54, 67, 126; water-boatmen, 127; water-spiders, 127; weeds, 19, 110, 111, 117; wild flowers, 19, 126

flying bombs, 52, 87, 100, 107, 109, 145,154

food, 1, 10, 20, 42, 76, 88, 94, 95, 148

football, 54

Formby, George, 41

fossils, 54

fragments, $2,10,18,20,46-49,52-54$, $57,59-61,63,64,66,69,71,72,74$, $110,129,145,149,151,157$; bomb fragments, 52, 113

France, 39, 79

Freud, Anna, 51, 156

Freud, Sigmund, 117, 121

Fulham, 80

fun, 74, 75, 91, 109

fundraising, 8, 58, 146, 150; 'Wings for Victory Week', 146, 147; National Savings Campaigns, 146; Spitfire Fund, 146, 150

fuse-rings, 57

games, 30, 43, 46, 57, 59, 89, 91-94, 96, $120,122,123,136,151,153,157$; see also play

gardens, 5, 30, 47, 53, 55, 56, 60, 61, $65,80,81,83,84,94,96,100,106$, 107,108

gas, 1, 6, 7, 8, 2, 21-39, 41-46, 48, 49, $57,64,70,76,79,90,91,95,104,109$, 111,143

gas leaks, 113-114

gas masks, $\mathrm{x}, 1-4,6,12,13,17,18$, $21-45,48,49,57,64,70,76,79,90$,
$91,95,105,109,120,143$; aesthetics of, 22; cases and containers for, 1-3, 6 , $15,17,20,22,30,35,37,39-42,46$, $48,57,58,66,67,70,71,84,90,95$, 105, 107, 149; children's, 10, 41; children's resistance to, 24; drills, 1 , 31, 157; infants', 13, 157; 'Mickey

Mouse' style, 6, 23, 27, 42-43;

P-helmet, 25; symbolism of, 18, 24; tests, 1, 35, 36

Gas Procession, 21

gas proofing, 26

gas protection, 13, 22, 24, 26, 27, 30, 42 gas threat, 25

gas training, 30, 35; anti-gas instructors, 34; gas chambers, 2, 18, 34-37; gas vans, 34,35

gender, 4, 7, 8, 13, 16, 50, 51, 59, 76, 84, 94, 109, 136; gendered perspectives, 156; gendered spaces, 7, 94, 109

General Civilian Respirator see gas mask Germans, 24, 25, 30, 67, 78, 97, 100-102, $107,111,137,138,145,146,149-151$

Germany, 20, 67, 131

Glasgow, 96

González-Ruibal, Alfredo, 10-12, 154

graffiti, 4, 22

gramophones, 101

Grayzel, Susan, 78, 79, 94

Ground Zero, 110

Guernica, 26

guns, $47,52,53,55,57,60,62,73,85$, $100-103,123,144,145,149,150,152$

Haapamaki, Michele, 78

Haber, Fritz, 24

Hague Convention, 24

Haldane, J.B.S., 26, 34, 158

Hamburg, 26

Hampstead, 3

health, 53, 76, 78, 96, 99, 106, 107;

coughing, 38, 102; malnourishment, 7; public health, 18,20

Hendon Air Pageant, 132

historical anthropology, 4, 9, 10-12, 15, $17,18,154,156-157$

Holman, Brett, 132

Home Front, 2, 6, 7, 9, 19, 30, 47, 70, 76,131

Home Guard, 36, 67, 151, 154

Home Office, 21, 26, 30, 34, 35, 36, 38, $42,44,81$

hooliganism, 29, 44

Hoskins, Janet, 14, 15, 17, 39-40 
hospital, 87, 93, 154, 155, 157

Hull, 67, 70

human body

broken, 12

human remains, 135, 156; 'row of blanket covered stretchers', 154; as objects of play, 119; in crashed aircraft, 151

identity, 4, 42, 45, 49, 92; formation of, 16,17 ; in conflict, 24

incendiary bombs, $6,25,32,46,49,52$, $55,57,65-67,70-72,79,115,122$, 125,146

india rubber, 26, 104

india rubber mouth guard, 104

injury, 26, 37, 67-70, 76, 90, 99, 109, $113,122,123,135,149$; children injured playing on bombsites, 121

Ipswich, 67

Israel, 44, 157

Italy, 15, 21, 26, 78, 79, 130, 137

Japan, 20, 79, 130

Jones, Helen, 8, 12, 13, 135-136

Kenton, Michael, 130

Kozlovsky, Roy, 121, 125

KSK (gas), 33

Law, John, 13

Left Book Club, 26

Lewisham, 88

Lewisite (gas), 33

Libya, 78

London, 4, 5, 25, 47, 48, 53, 64, 72, 73, 78, $81,84,87,90,95,96,99,104,105,112$, 114-116, 118, 126, 128; London Underground, 78, 104; Victoria Station, 5 Luftwaffe, 55, 67, 73, 76, 84, 112

Macaulay, Rose, 110, 117, 125

machine gun, $6,57,58,88,149,150$

Machine Gunners, The, 5, 6, 20, 47, 149

Madrid, 79

magazines, 130, 133-135, 137, 140; The Aero-Modeller, 146; Aeroplane, 137; Aeroplane Spotter, 135, 137; Aircraft Recognition, 135, 137; Flight, 137; The Skybird, 140

Magorian, Michelle, 110

Manchester, 1

marbles, 49, 73

marginal spaces, 18, 110, 119, 128;

bombsites as, 116
Mass Observation, 42, 44, 132

material culture, 3-6, 9-15, 20, 22, 23, $28,30,47,49-50,59,62,64,70,73$, $85,68,92,95,104,109,133,153,154$, 156, 157; of conflict, 11, 12, 13; of childhood, 17, 136; sensory impact of, $10,14,156$

McKinstry, Leo, 13

memorials, 75

memories, 4, 28-29, 31, 35, 43, 44, 46, $47,50-51,62,64,65,68,71,75,76$, 78, 80, 85-87, 89-90, 92, 94, 97-100, 104-106, 108, 109, 111, 114, 115, 148, 149, 152-155; 'material memories', 39; 'memory boom', 16; sense memories, $18-19$

metal, 6, 48, 52-56, 59, 60, 63, 65-69, 71, 74, 95, 98, 101, 102; aluminium, 5; metallic chaff, 67

Metropolitan Police, 34

mica, 25

middle-class attitudes towards poverty, 7

militaria, 5, 20, 135

milk bottle tops, 6,72

Ministry of Aircraft Production, 139, 145

model aircraft see aeromodelling

Moore, Henry, 110, 128

morale, $8,44,47,71,79,96,134,138$, 152,155

mothers, 7, 8, 44, 77, 85, 86, 96; at work, 8 ; evacuation of, 7 ; thankless proofreading of son's books...

Muensterberger, Werner, 51, 52

Munich Crisis (1938), 21, 42, 80, 98

museums, 11, 12, 15, 16, 49, 50, 107, 141; collections, 50; curators, 11

mustard gas, 29, 33, 39

narratives, 1, 8, 28, 31, 40, 44, 45, 48, 59, $61,62,65,68,73,76,78,94,97,111$, 123; autobiographical, 14, 17; dominant memory narratives, 17 ; historical narratives, 16 ; memory narratives, 7, 14, 19, 22, 24, 118; national narratives, 6

National Archives, 8

Nazis, 5, 88

neighbours, $27,70,76,83,84,85,86$, 104, 107

newspapers, 41, 55, 56

newsreels, 82

nightmares, 51, 115

Noakes, Lucy, 16-17 


\section{Index}

noise, 28, 31, 89, 97, 100-103, 119; thud, 105,151

Northern Ireland, 157

noses, 24, 25, 39, 46

nuclear threat, 21

nursery, 3

O'Brien, T.H., 26, 27, 36, 43, 78, 111

objects, 1, 24, 28-30, 35, 41, 45, 50-52, 54, $59,63,64,68,69,76,85,92,95,108$, 145, 150; mundane objects, 14 ; and memory, 15; see also material culture

Oradour-sur-Glane, 110

oral history, 13, 47, 48, 76; Forgotten Voices, 6

Otterbury Incident, The, 123

outbreak of war, $6,21,27,35,42$, $76,80,89,131,148$

Owen, Wilfred, 25

pacifism, 147

Palestine, 49, 157

Paneth, Marie, 121, 156

parents, $8,28,30,40,51,62,68,71,76$, $82,84,86,88,96,101,103,105,106$, 119,120

parks, 55, 65, 80, 87, 93, 107, 121,128

Paton Walsh, Jill, 110

Pearce, Susan, 49, 51

perspex, 20, 144, 145, 150

phosgene (gas), 24, 25, 26, 32,33

photographs, 2, 111, 137, 140,146

photophobia, 35

Picasso, 128

Piper, John, 110

planes see aircraft

plastic, 28, 42, 138, 144

play, $3,17,18,30-32,47,48,69,73$, 74, 76, 78, 87, 91-94, 97, 108, 109, 111, $115,119,121,153,156$; accidents and injury, 121; as therapy, 156; 'Cowboys and Indians', 124; creative play, 111; den-building, 19, 76, 92, 111, 120; destructive play, $3,107,111,125,129$, 153; gang fights, 111, 124; 'merry destruction', 19; playing 'house' or 'mothers and fathers', 124; throwing stones and bricks, 123, 124; war games, $19,111,123,124,125$

playgrounds, 19, 37, 49, 59, 61, 73, $110-111,114,118,120,121,123,126$,
129, 145, 154, 156; adventure

playgrounds, 111; bombsites as, 110, 120 and see bombsites

Plymouth, 21

police see emergency services

Poplar, 87, 90

posters, 19, 32, 57, 68, 133, 138, 146, 147,152

post-traumatic stress disorder (PTSD), 51, 115

Preston, Beth, 29-30

propaganda, 32, 57, 131, 146, 147

Proust, Marcel, 22

public-private narrative formation, 17

pulmonary edema, 24

Putney, 114

radar, 67,147

radio, $32,43,47,84,97,101,150$

RAF Hornchurch, 154

RAF Kidlington, 148

rationing, 6, 12, 47

Reading, 40

recycling, 6, 8, 71, 72; see also salvage

Red Cross, 34

reminiscences and reminiscence work, 15 , $17,47,80,81,84,98,132$

rescue squads see emergency services

respirators see gas masks

rhymes, 32

Royal Air Force (RAF), 131, 132, 138, 146, 147, 148, 149, 154

Royal Aircraft Establishment at Farnborough, 150

Royal Army Medical College, 25

rubber, 4, 26, 27, 28, 29, 31, 43, 104, 145, 146, 147; smell, 28

rubble, $6,82,104,105,110,113,117$, $120,124,125,126,129$

Rugby, 89

ruins, 4, 19, 104, 110-114, 116, 118, 121-126, 129; architectural ruins, 125; background noise of, 10, 153, 154,157

rules, 35,91

rural environments, $1,65,106$, 114,116

Rush Green Emergency Hospital, 154

Russia, 130

Russian aircraft, 135

safety pins, 27

salvage, 6, 72, 112

Salvation Army, 88 
sandbags, 82,84

sandwiches, 41, 85, 88

Saunders, Nicholas, xi, 11-14, 18, 53

Savoy Hotel, 93

scabies, 99

Schlanger, Nathan, 44, 45

school, 1, 2, 8, 27-34, 36-38, 40, 41, $43,44,46-48,55-57,59,61,63-65,67$, $68,71,75,76,78,84,89,91,98,99$, 102, 107-109, 116, 122, 149, 154;

closed during war, 8; playing fields, 4; venue for gas training, 30

scout troops, 57-58

screaming, 32, 105

scrumping, 30

searchlights, 7, 97, 100, 143, 152

Sebald, W.G., 128

Second World War, 1, 29, 30, 39, 42-44, 46-50, 53, 54, 70, 76, 78, 79, 82, 99, $107,110,148$

self-fashioning, 17,48

senses, 17, 18, 22, 25, 27-29, 31, 42, 45, $47,50,51,60,62-64,71,73,76,78$, $80,81,86,88,89,92,93,94,97$, 99-100, 103, 106, 108-110, 151-154; 'air that tasted of ashes', 114; sense memories, 10, 62, 76, 86, 92, 106, 109, 114-115; sensorium, 25, 45; sensory deprivation, 28; sensory experiences of bombsites, 2, 14, 18, 114, 119; taste, 114; see also smell, sound

sexual experimentation, 111

Shanghai, 79

Shapira, Michael, 7, 156

shells, 2, 10, 14, 24, 46-65, 67, 69-72, 78, 100, 110, 111; nose-cones, 10, 46, 55, 59, 61, 71; see also anti-aircraft guns, shrapnel

shelters see air raid shelters

shelter rash see scabies

shrapnel, 1, 2, 4, 6, 14, 18, 25, 30, 46-75,

$80,82,103,129,135,146,149,153-154$;

balls, 52; collecting, $\mathrm{x}, 4,48-50,55,59$, $60,62,69,71,73$; hot, 62,69

siren suits, $84,85,86,96$

skin, 25, 28, 31, 35, 39, 62, 63, 99

smell, 19, 27, 28, 29, 31, 32, 33, 39, 45,

$64,76,78,85-86,92,95,97-100,105$, 106, 108, 109, 114, 119, 148, 152;

aromatic fumes of 'proper' high octane aviation fuel, 148; bombed house, 115; brick dust, 115; burnt wet wood, 114; cabbagey smell of gas, 114; damp, 4; damp plaster, 115; explosives, 2; fire, 126; musty smell of shelters, 4, 19, 28, 32, 86, 97, 99, 109; rubber smell of gas masks, 22;

smell of warm aircraft, 148; urine, 92; see also senses

Smith, Ali, 33

Smith's crisps, 88

smoke, 25, 68, 89, 92, 100, 151

sodium phenate, 25

soldiers, 46, 53, 56, 57, 60, 61, 105, 149

sounds, 31, 47, 62, 66, 76, 78, 91, 92, 97, 99-103, 105, 106, 109, 154; of crying, 101, 102, 105, 154, 155; of Hoover, 115; soundscapes, 100; see also senses Southampton, 106

souvenirs, 5, 12, 18, 20, 42, 46, 49, 54, $56,57,59,65-68,71,88,142,149-151$

Soviet Union, 20

spaces, 1, 55, 75, 76, 78, 80, 82, 86-89, 92-97, 99-101, 106-111; disordered space, $51,110,116,123,128$; children as a potential source of disordered space, 8

Spanish Civil War, 26, 34, 79, 158

Speer, Albert, 128

Spitfire see aircraft by type

squander bug, 32

St John's Ambulance, 34

Stepney, 93, 96

Stepney Tenants' Defence League, 93

Stockport, 107

Stoke Newington, 105

street parties, 6

Subterranea Britannica, 108

Sunderland, 146

sweets, 59, 61, 83, 125

Syria, 129, 157

tail fins of bombs, 6, 46, 65, 66, 72, 150 taste, 36, 39, 45, 119; and see senses tea, $33,81,84,85,88,95$

teachers, $1,15,31,32,36,48,71,91$, 153,155 ; absence of male teachers, 8 tear gas, 2, $818,24,33,34,35,36,37$, $38,43,46$

Teignmouth, 76

television, 5, 16, 106

terror, 76, 78, 101, 103, 109

Times Education Supplement, 8

Tizer, 88

toilets, 19, 84, 88, 89, 92, 98, 102, 109

Tommy Cookers, 95

touch, sense of, $20,50,57,62,68,92,114$, $119,147,148,151-153$; in museums, 50; 


\section{Index}

heat and temperature, 2, 4, 28, 55, 61, $62,63,81,82,85,86,87,94,148,153$ toys, $1,2,20,30,41,47,54,57,61,96$, 108, 130, 138; aircraft-themed toys, 2 , 130; Dinky Toys, 142; dolls and dolls' prams, 124; football, 125; home-made fireworks, 125; musical instruments, 101, 124; wooden guns, 121,123

Tower of Babel, 110

trading cards, 50, 54, 60, 73

trauma, 10, 12, 17, 20, 30, 65, 76, $104,105,106,109,111,114$, 115,156

trench art, 12, 18, 142; aircraft models on plinths, 142; ashtrays, 12, 142

Tyneside, 5

uncanny, 11, 116-119; 'the architectural uncanny', 117; bombsite as an inherently uncanny space, 117

underground, $31,85,87,95,98,101$, 104, 107, 108

underground stations, 18, 95, 98, 101

unexploded ordnance (UXO), 53, 56, 57, 66,145

uniforms, 2, 24, 32, 42, 61, 86, 146,154

V1 see flying bombs

V2 ballistic missile, 88, 107

Valiant Clay, 21

vandalism, 18, 19, 29, 69, 70, 76

VE Day, 70

Vidler, Anthony, 117

Vietnam War, 51
Wales, 1

war effort, children's contributions to, 8 , $9,71,134$

wardens see Air Raid Precautions wardens

water, $25,38,42,80,95,96,98,99,104$, $105,107,108,111,145$

Watford, 36

weapons, 25, 26, 52, 73, 149,

150, 152, 157; abandoned, 5;

stolen, 5

welfare state, 131

wellbeing, 44, 48, 76

West, Fielding (MP), 147

West Ham, 53

Westall, Robert, x, 5, 6, 20, 47, 110,149

white star (gas), 25

whooping cough, 99, 154

Winnicott, D.W., 51

Withernsea, 149

women, 4, 13, 16, 25, 48, 53, 59, 69, 94, 96, 103; 'women and children', 7;

young women and promiscuity, 8, 156

Woolf, Virginia, 128

Woolwich Arsenal, 71

Woolworths, 40

wounded, 25, 39, 93, 104

wreckage, $6,5,110,113,118,121,135$, 149,151

Yorkshire, 144, 149

Ypres, 24

Yugoslavia, 157

zeppelins, 78 